\title{
Naturalis
}

\section{Palinología de la Formación Punta del Barco, Cretácico Inferior de Santa Cruz}

\section{Llorens, Magdalena}

Doctor en Ciencias Naturales

Dirección: Archangelsky, Sergio

Co-dirección: Morbelli, Marta Alicia

Facultad de Ciencias Naturales y Museo

2005

Acceso en:

http://naturalis.fcnym.unlp.edu.ar/id/20120126000075

\section{(c) (1) (2)(2) \\ BY NC SA}

Esta obra está bajo una Licencia Creative Commons

Atribución-NoComercial-Compartirlgual 4.0 Internacional

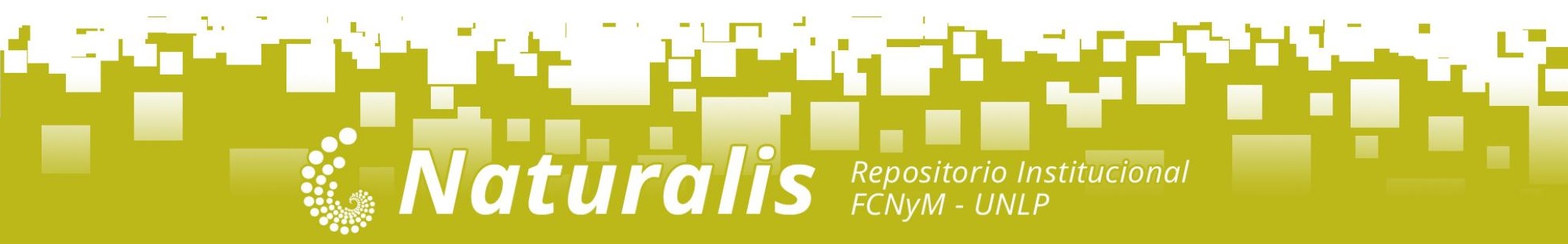




\section{Universidad Nacional de la Plata Facultad de Ciencias Naturales y Museo}

\section{Palinología de la Formación Punta del Barco, Cretácico Inferior de Santa Cruz}
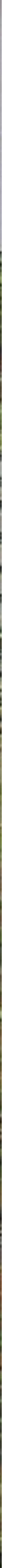
Universidad Nacional de la Plata

Facultad de Ciencias Naturales y Museo

\section{Palinología de la Formación Punta del Barco, Cretácico Inferior de Santa Cruz}

Autor: Magdalena Llorens

Director: Sergio Archangelsky

Codirector: Marta A. Morbelli

Tesis Doctoral

Mayo- 2005 


\section{ÍNDICE}

Resumen 1

INTRODUCCIÓN 3

I. MATERIALES Y METODOS 6

I.1. Obtención del material de estudio 6

$\begin{array}{ll}\text { I.2. Procesamiento de las muestras palinológicas } & 7\end{array}$

I.2.1. Procesamiento químico

I.2.2. Observación del material 8

I.2.3. Repositorio 8

$\begin{array}{lr}\text { I.3. Aproximación sistemática } & 8\end{array}$

I.4. Aproximación bioestratigráfica 9

I.5. Aproximación paleoecológica 9

II. MARCO GEOLÓGICO 11

II.1. Área de estudio 11

II.1.1. Vías de acceso 11

II.1.2. Población 11

II.1.3. Generalidades del área 11

II.2. Geología regional al sudoeste del Nesocratón del Deseado 12

II.2.1. Antecedentes 12

II.3. Geología y estratigrafía de la región de la Meseta Baqueró 13

II.3.1. Mesozoico 13

II.3.1.1. Formación Bajo Pobre 13

II.3.1.2. Grupo Bahía Laura 13

II.3.1.2.1. Formación Chon Aike 13

II.3.1.3. Formación Bajo Grande 14

II.3.1.4. Grupo Baqueró 14

II.3.1.4.1. Formación Anfiteatro de Ticó 14

II.3.1.4.2. Formación Bajo Tigre 15

II.3.1.4.3. Formación Punta del Barco 16

II.3.2. Cenozoico 16

II.3.2.1. Basaltos de Los Cerros Del Doce y Alma Gaucha 16

II.3.2.2. Formación Patagonia 16

II.3.2.3. Depósitos de agradación aterrazados 17

$\begin{array}{ll}\text { II.4. Rasgos estratigráficos del Grupo Baqueró } & 17\end{array}$ 
II.4.1. Extensión y Contacto Basal $\quad 17$

$\begin{array}{ll}\text { II.4.2. Divisiones y Espesores } & 17\end{array}$

II.5. Formación Punta del Barco 19

II.5.1. Litofacies 20

II.5.2. Contenido paleoflorístico 20

II.5.3. Interpretación paleoambiental 21

II.6. Descripción de los perfiles estudiados 22

II.6.1. Punta del Barco Norte (PBN) 22

II.6.2. Punta del Barco Sur (PBS) 23

II.6.3. Integración de los perfiles 24

III. SISTEMÁTICA PALINOLÓGICA 30

III.1. Consideraciones generales $\quad \mathbf{3 0}$

$\begin{array}{ll}\text { III.1.1. Lista taxonómica } & 30\end{array}$

III.1.2. Descripciones Sistemáticas 35

III.1.2.1. Esporas

III.1.2.2. Granos de polen $\quad 76$

$\begin{array}{lr}\text { III.1.2.1. Megasporas } & 97\end{array}$

III.1.2.1. Palinomorfos acuáticos 103

$\begin{array}{ll}\text { III.1.2.4.1. Algas } & 103\end{array}$

$\begin{array}{ll}\text { III.1.2.4.2. Incertae Sedis } & 107\end{array}$

IV. BIOESTRATIGRAFÍA 113

$\begin{array}{ll}\text { IV.1. Grupo Baqueró } & 113\end{array}$

IV.1.1. Distribución estratigráfica de los palinomorfos reconocidos en la Formación Punta del Barco 113

IV.1.2. Comparación con la palinoflora de la Formación Anfiteatro de Ticó $\quad 114$

IV.1.3. Caracterización de las asociaciones inferior y superior y propuesta de biozonas 115

IV.1.3.1. Biozona de Asociación A 116

IV.1.3.2. Biozona de Asociación B 116

IV.1.4. Comparación con las biozonas establecidas sobre la base de las megafloras 117

$\begin{array}{ll}\text { IV.2. Formación Kachaike } & 118\end{array}$

$\begin{array}{ll}\text { IV.2.1. Antecedentes } & 118\end{array}$

$\begin{array}{lr}\text { IV.2.2. Composición palinológica } & 120\end{array}$

IV.2.3. Rasgos característicos de la asociación de la Formación Kachaike 122

IV.2.4. Comparación con las asociaciones palinológicas del Grupo Baqueró 123

$\begin{array}{ll}\text { IV.2.5. Resultados } & 124\end{array}$ 
IV.3. Comparación con asociaciones eocretácicas de Argentina

IV.3.1. Cuenca Austral

IV.3.1.1. Afloramientos en el continente

IV.3.1.1.1. Formación Springhill

130

IV.3.1.1.2. Formación Río Mayer

130

IV.3.1.1.3. Formación Kachaike y Grupo Baqueró 130

$\begin{array}{lr}\text { IV.3.1.2. Plataforma Continental Argentina } & 130\end{array}$

IV.3.2. Cuenca del Golfo San Jorge 131

IV.3.3.Cuenca Neuquina $\quad 132$

IV.3.4. Cuenca de San Luis 133

$\begin{array}{ll}\text { IV.3.5. Resultados } & 133\end{array}$

IV.4. Comparación con asociaciones del ámbito gondwánico 134

$\begin{array}{ll}\text { IV.4.1. América del Sur } & 134\end{array}$

$\begin{array}{ll}\text { IV.4.2. Antártida } & 135\end{array}$

$\begin{array}{lr}\text { IV.4.3. Australia } & 136\end{array}$

$\begin{array}{lr}\text { IV.4.4. India } & 137\end{array}$

$\begin{array}{lr}\text { IV.4.5. Africa } & 137\end{array}$

$\begin{array}{ll}\text { IV.4.6. Resultados } & 138\end{array}$

V. MARCO PALEOFLORÍSTICO 144

$\begin{array}{ll}\text { V.1. Marco paleobiogeográfico } & 144\end{array}$

$\begin{array}{ll}\text { V.1.1. Paleogeografía } & 144\end{array}$

V.1.2. Paleofitogeografía 144

$\begin{array}{lr}\text { V.2. Marco paleoecológico } & 146\end{array}$

$\begin{array}{ll}\text { V.2.1. Estudios previos } & 146\end{array}$

$\begin{array}{lr}\text { V.2.2. Ambientes y vulcanismo } & 147\end{array}$

$\begin{array}{lr}\text { V.2.2.1. Marco general } & 147\end{array}$

$\begin{array}{ll}\text { V.2.2.2. Tipo de vulcanismo } & 147\end{array}$

$\begin{array}{ll}\text { V.2.2.3. Cuerpos de agua } & 148\end{array}$

$\begin{array}{lr}\text { V.2.2.4. } \text { Paleoincendios } & 149\end{array}$

V.2.2.5. Efectos del vulcanismo sobre la vegetación 150

V.2.3. Comunidades por niveles y preservación diferencial 151

V.2.3.1. Nivel 1

V.2.3.2. Nivel 2 151

V.2.3.3. Nivel 3

V.2.3.4. Nivel 4

V.2.3.5. Nivel 5 
V.2.3.6. Nivel $6 \quad 152$

V.2.3.7. Resultados 152

V.2.4. Efectos producidos por el estrés $\quad 153$

$\begin{array}{ll}\text { V.2.5. Factores ecológicos relacionados con las angiospermas primitivas } & 154\end{array}$

$\begin{array}{ll}\text { V.2.6. Consideraciones finales } & 155\end{array}$

V.3. Paleoflora de la Formación Punta del Barco 157

$\begin{array}{ll}\text { V.3.1. Evidencias macroscópicas } & 157\end{array}$

$\begin{array}{ll}\text { V.3.1.1. Tipo de fosilización } & 157\end{array}$

V.3.1.1.1. Improntas $\quad 157$

V.3.1.1.2. Momificaciones 157

V.3.1.1.3. Fusinita 158

V.3.1.1.1. Moldes 159

V.3.1.2. Diversidad taxonómica 159

V.3.1.3. Abundancia relativa 160

$\begin{array}{ll}\text { V.3.2. Evidencias microscópicas } & 160\end{array}$

V.3.2.1. Tipo de fosilización 160

V.3.2.2. Diversidad taxonómica 161

V.3.2.3. Abundancia relativa 161

V.3.3. Conjunto paleoflorístico 162

V.3.3.1. Consideraciones finales 164

V.3.3.2. Reconstrucción del paleoambiente 165

CONCLUSIONES 169

1. Palinoflora de Formación Punta del Barco 169

2. Extinción / evolución 170

3. Angiospermas 171

4. Aportes paleoecológicos 172

$\begin{array}{ll}\text { 4.1. Algas } & 172\end{array}$

4.2. Plantas con flor $\quad 172$

4.3. Vulcanismo 172

4.4. Familia Cheirolepidiaceae 172

5. Perspectivas de nuevos estudios 173

$\begin{array}{lr}\text { AGRADECIMIENTOS } & 174\end{array}$

$\begin{array}{ll}\text { REFERENCIAS BIBLIOGRÁFICAS } & 175\end{array}$ 


\section{Resumen}

\section{“PALINOLOGÍA DE LA FORMACIÓN PUNTA DEL BARCO, CRETÁCICO INFERIOR DE SANTA CRUZ"}

El presente trabajo de tesis doctoral está dedicado a la palinología de la Formación Punta del Barco (unidad cuspidal del Grupo Baqueró), de edad aptiana, que aflora en el centro de la provincia de Santa Cruz. El objetivo es, mediante el estudio sistemático de los palinomorfos, caracterizar la paleovegetación y establecer comparaciones con la unidad inferior (Formación Anfiteatro de Ticó) dentro del Grupo, y con otras asociaciones polínicas australes y gondwánicas en general. Por último, se han realizado consideraciones paleoecológicas y paleambientales.

En primer término se realiza la descripción del marco geológico y se incluyen ilustraciones de los principales sitios en los que se han coleccionado muestras palinológicas y otras piezas fósiles.

El capítulo central es el que corresponde al estudio sistemático de los taxones hasta ahora estudiados. Las formas dominantes en esta microflora son las esporas de briofitas y las de helechos afines a la Familia Gleicheniaceae, de las que se describen seis nuevas formas. Por otra parte, se destaca también el hallazgo de varias esporas perisporadas y granos de afinidad angiospérmica que no fueron descriptos previamente. Dentro de los granos de polen, el grupo mejor representado es la Familia Araucariaceae. Otra característica relevante de este conjunto polínico reside en la alta diversidad y abundancia de palinomorfos acuáticos continentales.

La ilustración de ese material se efectuó al microscopio óptico y se presenta en láminas en color y en muchos casos con fotografías tomadas con el Microscopio Electrónico de Barrido (MEB). En tal sentido, Densoisporites corrugatus Arch. \& Gam. -una especie de importancia bioestratigráfica- se presenta por primera vez ilustrado con ese tipo de microscopía.

En base a la información palinológica obtenida, se analizan aspectos bioestratigráficos dentro de esta unidad formacional, habiéndose observado un paulatino empobrecimiento de la flora hacia los niveles más modernos. Seguidamente, se realiza una comparación integrando los datos palinológicos del Grupo Baqueró, de donde resulta una propuesta de biozonación, sustentada por un marcado cambio entre los elementos polínicos de la unidad inferior y la superior. Este hecho cobra interés teniendo en cuenta el corto lapso, acotado por métodos radimétricos, transcurrido entre ambas. En un ámbito regional, y para observar la evolución florística, se realiza la comparación con la Fm. Kachaike (Albiano) de la Cuenca Austral. Además, se incorporan correlaciones con paleofloras de áreas vecinas y gondwánicas.

En tal sentido, resultan de especialinterés los granos de polen con afinidad angiospérmica, constituyendo una herramienta valiosa para ese tipo de análisis como así también para un estudio paleoecológico. Este trabajo enfatiza la rápida diversificación de ese grupo vegetal, en un marco de fuerte estrés ambiental. Las evidencias litológicas y paleoecológicas demuestran que los fuertes disturbios 
ambientales del eoaptiano fueron provocados por un evento volcánico de gran magnitud. El comportamiento de las angiospermas basales y algunos helechos oportunistas y briofitos, contrasta con la marcada retracción de otros grupos vegetales. Es notorio sobre todo la ausencia de algunas coníferas que, junto a otros grupos gimnospérmicos, habrían resultado perjudicados por esas condiciones ambientales. 


\section{INTRODUCCIÓN}

En el inicio del Período Jurásico la flora patagónica se caracterizó por una asociación florística dominada por Bennettitales y helechos. Al promediar ese período, la flora se enriqueció con una marcada diversificación de coníferas y otras gimnospermas. Al mismo tiempo, se intensificaba la actividad volcánica en el margen del Protopacífico, originando un basamento porfírico que se extendió por Patagonia y parte de Antártida. Sobre esa platea se desarrollaron secuencias sedimentarias en el Jurásico medio y tardío, y luego en el Cretácico. Patagonia se convirtió entonces en un gran yacimiento de fósiles vegetales que hace posible tener una visión sobre la evolución florística durante ese lapso temporal. La vegetación a nivel global tuvo, durante el Cretácico temprano, cambios significativos con extinción de importantes grupos acompañada de la aparición de otros, que se manifestaron definitivamente hacia fines de esa época. La biota marina, por su parte, también registró alteraciones, generadas por complejas variaciones climáticas, y de circulación y química oceánicas. Todas ellas fueron atribuidas a la intensa actividad volcánica del momento.

En esa época se desarrollaron las secuencias litológicas del Grupo Baqueró dentro del Macizo del Deseado, donde quedó bien registrado un fuerte vulcanismo para Patagonia, que habría sido el detonante de los cambios bióticos que aquí se produjeron.

Los sedimentos baqueroenses constituyen entonces, la manifestación de ese episodio tectonovolcánico desarrollado en un ambiente estrictamente continental. Estos depósitos se sitúan, por otra parte, en un sitio poco explorado como es la Patagonia, que para el Aptiano, ciertamente no tiene aún vinculaciones paleogeográficas y paleobiológicas muy precisas con otras regiones.

Por lo tanto, el Grupo Baqueró constituye un importante punto de referencia, ya que ha brindado abundante información acerca de su tafoflora, y es reconocida internacionalmente por el tipo de preservación de los restos vegetales tanto palinológicos como megascópicos, diversidad de la flora y grado de detalle alcanzado en su estudio.

A esto se suma el logro que denota la obtención de una datación fiable, la cual ubicó al Grupo Baqueró en los 118/119 Ma, constituyendo así una referencia para la correlación con eventos geológicos a escala más regional, y aún global.

Durante las últimas décadas esa unidad fue intensamente estudiada, no obstante lo cual, la gran mayoría de los materiales hallados fueron referidos a la porción basal de ese paquete sedimentario -la Fm. Anfiteatro de Ticó. No fue sino hasta fines de la década pasada que se obtuvo material polínico de la porción superior; esto permitió completar la visión de la flora baqueroense, y realizar una confrontación de esos datos con los ya conocidos de la megaflora.

Hoy en día crece el interés en la influencia que tienen las erupciones volcánicas en los ecosistemas. Los depósitos baqueroenses constituyen una muy buena fuente de información al respecto, máxime si se tiene en cuenta que el episodio allí documentado, fue de una magnitud sin precedentes en tiempos históricos, dando así indicios del alcance que pueden tener. 
Es posible entonces, realizar acercamientos teóricos con respecto a la dinámica de la comunidad vegetal del Aptiano y sus respuestas a los sucesos extrínsecos que la afectaron.

Por lo expuesto, el estudio palinológico detallado de los depósitos de la Formación Punta del Barco reviste interés por múltiples motivos:

- Por corresponder a un momento crucial en la historia de los vegetales a nivel global, en el que pueden documentarse los cambios en las tasas de evolución/extinción de los diversos grupos involucrados.

- Por constituir el primer aporte al conocimiento de la palinoflora de una nueva Formación geológica.

- Por contar con una datación confiable que la establece como un punto de referencia cronológica.

- Por ser un paquete sedimentario desarrollado íntegramente en un ámbito continental, que lo diferencia de otras unidades coetáneas donde la influencia marina minimizó el registro de episodios volcánicos, erigiéndose por ello en un referente en lo que atañe a los efectos que éstos tuvieron sobre la vegetación.

- Por contribuir al conocimiento de la diversificación temprana de las angiospermas.

- Por echar luz sobre los aspectos paleoecológicos que operaron en la evolución basal de ese grupo.

- Por ampliar el conocimiento previo sobre la flora de esa etapa geológica mediante la confrontación con el registro megascópico conocido previamente.

- Por establecer relaciones con el continente antártico, aportando así pautas sobre las conductas migratorias de las plantas con flor basales. 


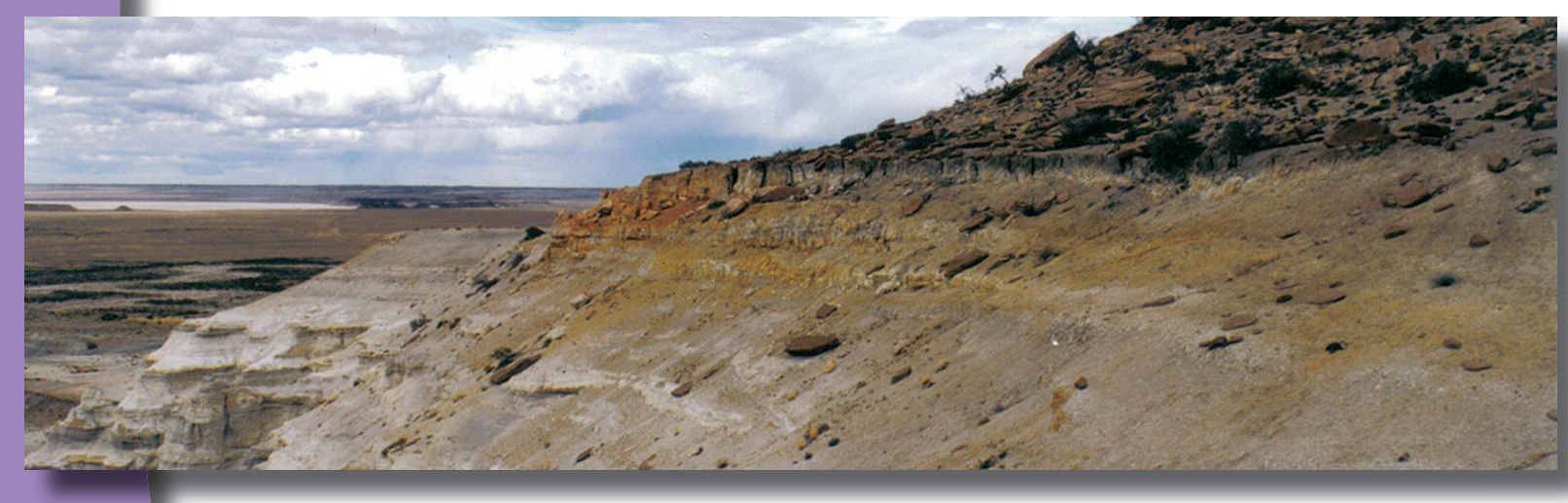

\section{CAPITULO I}

Materiales y Métodos 


\section{MATERIALES Y METODOS}

La metodología de trabajo seguida es la tradicional en la palinoestratigrafía. Las distintas etapas cumplidas en el desarrollo del proyecto se resumen de la siguiente manera:

- 1. Obtención del material de estudio

- 2. Procesamiento de las muestras palinológicas

- 3. Aproximación sistemática

- 4. Aproximación bioestratigráfica

- 5. Aproximación paleoecológica

\section{I.1. Obtención del material de estudio}

El muestreo palinológico se realizó en varias campañas a la zona de la Meseta Baqueró, durante las décadas del 80 y 90, dentro del estudio integral de la -en ese momento- Formación Baqueró. Luego de varios intentos infructuosos, en el año 1999 se llevó a cabo un muestreo lateral a lo largo de 200 metros del contacto entre un paleosuelo y la toba suprayacente de la Barda Norte de la Meseta, en cercanías de la Ea. El Verano. En ese viaje de campo participaron los Dres. Sergio Archangelsky y Renato Andreis junto al Lic. Gerardo Cladera. En la misma campaña se coleccionaron las tobas que fueron utilizadas para la datación de este cuerpo de roca (Corbella, 2001). Aquellas muestras brindaron un contenido polínico abundante con la mayor parte de los taxones representados en esta microflora, y lo llamaremos en este trabajo, Nivel 1. Inicialmente esas muestras provenientes del perfil de Ea. El Verano fueron las que se destinaron a la autora para llevar a cabo este trabajo de tesis.

Ante la inminente propuesta estratigráfica que elevaría a la unidad toda al rango de Grupo, y a este paquete sedimentario en particular, al de Formación, se realizó una nueva campaña en diciembre de 2001, en la que participaron Los Lic. Gerardo Cladera y Manuel Paez, junto con la autora. En esa oportunidad se efectuó un muestreo sistemático de la unidad cuspidal en tres localidades de la Meseta Baqueró: la ya mencionada Estancia El Verano en la barda Norte (PBN), Punta del Barco sensu stricto (localidad tipo en el extremo oriental) y en la barda Sur, Punta del Barco Sur (PBS). Para ello se localizó primeramente la discordancia erosiva con la Formación subyacente y a partir de ésta, se muestrearon todos los niveles pelíticos hasta el techo de la actualmente denominada Formación Punta del Barco. PBN, referida recientemente como localidad paratípica (Cladera et al. 2002) y PBS brindaron material polínico, en tanto no lo hizo Punta del Barco en su localidad tipo. A la vista del hallazgo de nuevos niveles polínicos y una localidad fosilífera, un año más tarde se realizó el último viaje de campo a esta formación, hasta el momento. De él participaron los Lic. Gerardo Cladera y Mauro Passalia. En la ocasión, se volvieron a extraer muestras de los distintos niveles, pudiendo incorporar al aquí llamado Nivel 5 de PBS, que no había sido registrado hasta ese momento. El actual estudio entonces, es de dos localidades de la Meseta Baqueró: PBN y PBS, con 6 niveles resultantes de la integración de ambos perfiles. 


\section{I.2. Procesamiento de las muestras palinológicas}

El procesamiento de las primeras muestras fue llevado a cabo por el señor Luis Lezama y la autora en el laboratorio de Paleobotánica del Museo Argentino de Ciencias Naturales "Bernardino Rivadavia". En tanto, el del material obtenido en la última campaña, lo realizó la Sta. Soledad Tancoff en el laboratorio de procesamiento con ácidos del Museo Paleontologico "Egidio Feruglio".

Las técnicas de procesamiento de muestras sedimentarias, corresponden esencialmente a la técnica tradicional (ClH-FH-ClH) sintetizada por Volkheimer \& Melendi (1976).

\section{I.2.1. Procesamiento químico}

En primer lugar, se disgregó por medios físicos una porción de muestra de aproximadamente 150 gramos. El material fue colocado en frascos resistentes a la digestión ácida, y se le agregó una gota de $\mathrm{HCl}$ para probar la presencia de carbonatos. Ninguna de las muestras reaccionó a esta prueba, por lo tanto se omitió el pre tratamiento con $\mathrm{HCl}$ tendiente a desechar el material carbonático.

Se colocó en cada frasco $500 \mathrm{~cm}^{3}$ de $\mathrm{HF}$ al 70\%, responsable de la digestión de la sílice. Durante 3 días aproximadamente, las muestras se dejaron en agitadora, revisando periódicamente su estado de disgregación y en los casos en que fuera necesario, se agregó más ácido.

Una vez disueltos por completo los silicatos, se realizó el lavado que consistió en la neutralización del ácido y luego que el material decantase en forma natural, el sobrenadante fue filtrado por malla de $200 \mu \mathrm{m}$ y descartado. Esta operación se repitió 3 veces aproximadamente dependiendo del grado de acidez del sobrenadante.

Cuando la muestra alcanzó un PH neutro, se trató con $\mathrm{HCl}$ al 50\% para eliminar los fluorosilicatos, carbonatos y calcio que pudieran permanecer en ella. Este ácido fue agregado al material ya decantado, en una cantidad igual a la que había de éste; luego se calentó a baño María a $50^{\circ} \mathrm{C}-70^{\circ} \mathrm{C}$ durante 20 minutos, agitando constantemente.

Nuevamente se lavó la muestra, diluyendo el ácido una vez con agua tibia y dos veces más con agua fría. En todos los casos en que fue necesario realizar decantados, se hicieron sin utilizar centrífugas para reducir al máximo el riesgo de la pérdida de material por rotura, evitando así la destrucción de posibles estructuras preservadas en la muestra (cutículas, megasporas, etc.)

En los casos en los que se observó una gran cantidad de materia orgánica fina que no aportaba datos y entorpecía la observación del material, se lo trató con reactivo Schulze, que es una mezcla de ácido nítrico y clorato de Potasio $\left(\mathrm{KClO}_{3}\right)$, durante 30 segundos o un minuto según la cantidad de material indeseado. Se agregaron dos medidas de esta mezcla por cada medida de muestra. El Schulze tiene un átomo de oxígeno libre del ácido y otro del $\mathrm{KClO}_{3}$, que lo convierte en un muy buen oxidante para los carbohidratos, volviéndolos inestables y propensos a ser arrastrados por una base, en este caso, carbonato de sodio.

Es importante resaltar que en todas las situaciones de manipulación del material, se trabajó con un neutralizador (carbonato de sodio) e indumentaria adecuada (máscara, guantes, etc.) para disminuir al máximo los riesgos. 


\section{I.2.2. Observación del material}

Una vez obtenido el residuo palinológico, fue filtrado por malla de $100 \mu \mathrm{m}, 25 \mu \mathrm{m}$ y $17 \mu \mathrm{m}$. En el caso del Nivel 4 (PBS) donde se hallaron numerosos granos de polen de angiospermas con tamaños muy pequeños, se realizó el filtrado por malla de $25 \mu \mathrm{m}$ y $10 \mu \mathrm{m}$ para facilitar la localización de esos granos.

Finalmente, se realizó un montaje simple de las diferentes fracciones del material en glicerinagelatina, con la adición de formol según la propuesta de Gamerro \& Cárdenas (1980). Esa práctica favorece la conservación de los preparados microscópicos permanentes, al tiempo que mantiene inalteradas las propiedades ópticas para ser observado al microscopio óptico.

El microscopio utilizado para tal fin fue el Leitz Dialux No 881392 ubicado -provisoriamente- en el Museo Paleontológico "Egidio Feruglio".

Las fotomicrografías se tomaron en un microscopio Zeiss Axioskop 2, ubicado en ese mismo museo, y fueron tomadas con una cámara digital Sony Cyber Shot.

La recuperación de las megasporas se llevó a cabo por medio de un "picking" en la fracción $+100 \mu \mathrm{m}$, y luego montadas sobre planchuelas metálicas para ser incorporadas al taco del Microscopio Electrónico de Barrido (MEB).

La observación de palinomorfos con ese tipo de microscopía fue realizada mayormente en el Instituto de Botánica "Darwinion” con un equipo ZEISS 940 A, y también en un microscopio PHILIPS XL serie 30 ubicado en el Museo Argentino de Ciencias Naturales "Bernardino Rivadavia".

\subsubsection{Repositorio}

Parte del material estudiado se halla depositado en la Colección Palinológica de la División Paleobotánica del Museo Argentino de Ciencias Naturales "Bernardino Rivadavia” (BA Pb Pal). El material que fue observado con microscopía electrónica ha sido depositado en esa colección bajo la sigla $\mathrm{BA} \mathrm{Pb} \mathrm{MEB}$. De igual manera, el resto del material estudiado se encuentra en la Colección Palinológica del Museo Paleontológico "Egidio Feruglio", bajo las siglas MPEF Palin y MPEF Palin MEB.

\subsection{Aproximación sistemática}

El análisis polínico se realizó mediante la metodología clásica, según conceptos tomados en parte de los trabajos clásicos en el tema (Erdtman, 1952, Faegri \& Iversen, 1975). La clasificación del polen y microsporas dispersos desarrollada en el capítulo dedicado a la sistemática, se llevó a cabo según el concepto morfológico propuesto por Potonié \& Kremp (1954), y luego ampliado por Potonié $(1956,1958,1960)$. En algunos casos se tuvo en cuenta también la revisión de Dettmann (1963). La clasificación de los palinomorfos en "Turmas", facilita el ordenamiento de los taxa. Sin embargo en el caso de las megasporas, si bien la organización se ha hecho con ese esquema de clasificación morfológica, se las trata en un subcapítulo aparte. 
Por último, para determinar los restos algales, se tomó en cuenta la afinidad taxonómica con grupos actuales y fueron separados en familias, tomando como referencia principal el trabajo sistemático y ecológico de Zippi (1998).

\section{I.4. Aproximación bioestratigráfica}

El desarrollo de este tópico ha seguido la modalidad estándar. Como primer paso, se procuró contar con un marco litoestratigráfico consistente, que se logró mediante numerosos aportes bibliográficos referidos al actual Grupo Baqueró y a la geología de la región adyacente. El criterio cronoestratigráfico que se adoptó es el presentado por Gradstein et al. (1999) para el Cretácico, estableciendo el límite Barremiano-Aptiano en los $121 \pm$ 1,4 Ma, según el cual la asociación en estudio se ubica en la base del Aptiano.

Una de las secciones litoestratigráficas que se utilizaron estaba disponible en la bibliografía publicada, mientras la de la barda Sur (PBS) fue levantada en la última campaña al área de estudio. Ambas resultaron indispensables tanto para referir los muestreos, como para la elaboración de cuadros de distribución de los taxa.

En una segunda instancia, esas herramientas se utilizaron para la comparación con otras unidades formacionales próximas en el tiempo, dentro del ámbito regional. De este análisis surgió la propuesta de dos biozonas (palinozonas). Dicha propuesta se ha realizado siguiendo las normas establecidas por el Comité Argentino de Estratigrafía (1992). Sobre esa base, se hizo una comparación intra e intercuenca para finalmente hacer comparaciones con otras unidades gondwánicas.

\section{I.5. Aproximación paleoecológica}

Para este fin, primero se situó la asociación en estudio dentro de un marco paleobiogeográfico. Luego se caracterizó la flora de la época en base a los conceptos de diversidad taxonómica y de abundancia relativa. Para tal fin, se integraron los datos aportados por los restos mega y microscópicos. Estos últimos, fueron sujetos a un recuento de alrededor de 300 individuos en dos muestras representativas que exhibían buen estado de preservación.

Por último, cabe señalar que en el texto de los dos últimos ítems, se combinan una taxonomía formal y una informal. 


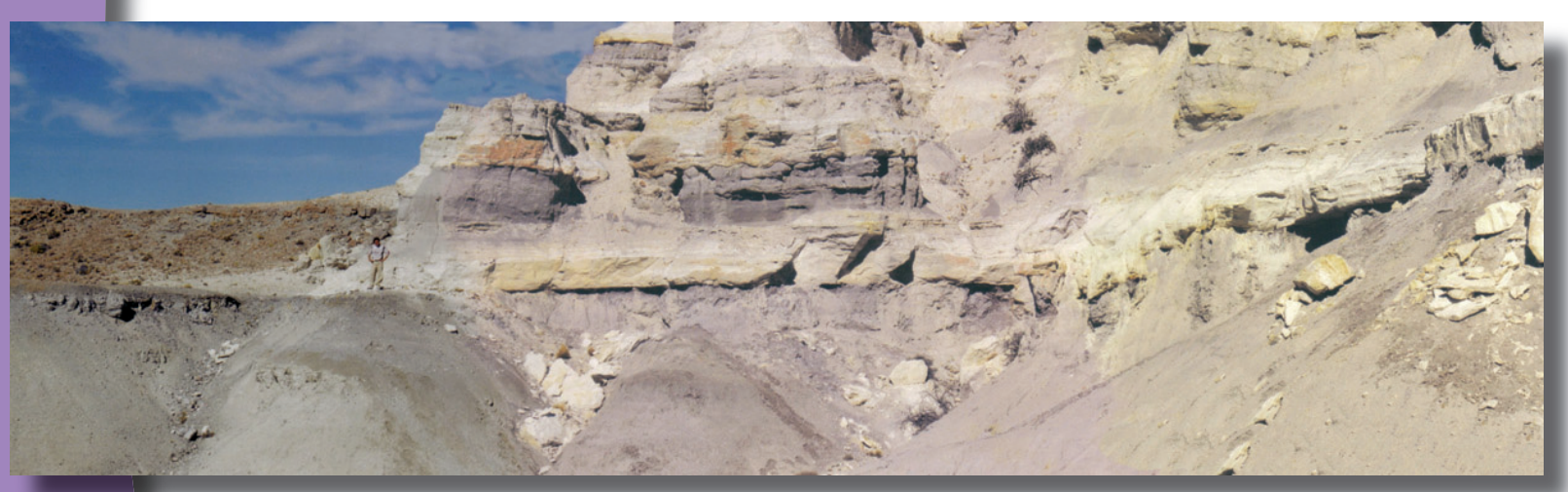

CAPITULO II

Marco Geológico 


\section{MARCO GEOLÓGICO}

\section{II.1. Área de estudio}

La Formación Punta del Barco es la unidad cuspidal del Grupo Baqueró y aflora casi exclusivamente en la zona de la Meseta Baqueró (Cladera et al. 2002).

La Meseta Baqueró y áreas vecinas se encuentran ubicadas en el sector sudoeste del Nesocratón del Deseado, en el Departamento de Magallanes, Provincia de Santa Cruz (fig. 1a), dentro de la Hoja Geológica 55 d “Gobernador Gregores”, delimitada por las coordenadas de $48^{\circ} 35^{\prime}$ - $48^{\circ} 45^{\prime}$ de latitud Sur y 69¹0’ - 69²0’ de longitud Oeste de Greenwich.

\section{II.1.1. Vías de acceso}

El acceso a la zona se realiza por la ruta Provincial $N^{\circ} 251$, que une las localidades de Puerto San Julián y Gobernador Gregores.

A $130 \mathrm{~km}$ al oeste del primero, (o $90 \mathrm{~km}$ al este desde Gobernador Gregores) por esta ruta provincial, se llega al cruce que conduce al campamento de la Compañía Minera Piedra Grande, localizada aproximadamente $30 \mathrm{~km}$ al norte de ese cruce (fig. 1a).

A los afloramientos puede accederse mediante varias huellas que son poco transitables en períodos invernales o de fuertes precipitaciones.

\section{II.1.2. Población}

Los escasos habitantes se distribuyen en estancias o puestos, siendo el núcleo poblacional más numeroso el campamento minero de Piedra Grande, donde trabajaban alrededor de 20 personas. Fuera del área de trabajo se ubican dos núcleos urbanos, Gobernador Gregores y Puerto San Julián. Este último, de mayor importancia, posee 4500 habitantes y es cabecera del Departamento de Magallanes.

\section{II.1.3. Generalidades del área}

La región estudiada se destaca por mostrar un relieve bajo e irregular de mesetas y lomadas. Son comunes los bajos endorreicos donde se forman lagunas temporarias, siendo la principal el Guadal de Baqueró de 4,5 km. de longitud y $7 \mathrm{~km}$. de ancho. Arroyos de carácter efímero y generalmente de diseño centrípeto alrededor de los bajos, o bien siguiendo líneas de fallas, drenan a los bajos endorreicos. Allí se almacena agua en forma esporádica ya que en el verano se resume por evaporación. Normalmente estos sistemas fluviales obedecen a las estaciones de lluvias o épocas de deshielo. Las mesetas se encuentran coronadas por bancos de litología resistente a la erosión como coquinas y basaltos (Cladera, 1998).

La altura de los puntos más elevados en el área de trabajo corresponden a la Meseta Baqueró (312 mh.s.n.m.) y al Cerro Cuadrado ( 285 mh.s.n.m) (fig.1c). 
Los agentes modeladores del paisaje son los procesos de remoción en masa (deslizamiento de segmentos de las mesetas), la acción eólica y la erosión hídrica. Los asentamientos de bloques generan la erosión retrocesiva de las escarpas, conformando como consecuencia, bordes festoneados con estrechas y profundas cárcavas separadas por amplios valles de fondo plano (Cladera, 1998).

El clima es de tipo continental seco a muy seco; frío en invierno, con nevadas, y fresco a templado en el verano. La temperatura estival promedio es de $14^{\circ}$ a $20^{\circ} \mathrm{C}$, y de $10^{\circ}$ a $15^{\circ} \mathrm{C}$ bajo cero en el invierno (De Giusto et al. 1980; Caranza, 1988). Las precipitaciones no superan los $130 \mathrm{~mm}$ anuales, mientras el viento predominante es del oeste, que en primavera y verano alcanza ráfagas que superan los $100 \mathrm{~km}$. por hora (Panza, 1987; Caranza, 1988). Menos frecuentes son los vientos del SE que aportan a la región lluvias y humedad.

La comunidad vegetal de la región es la estepa arbustiva, caracterizada por arbustos achaparrados xerófilos y pastos duros como el neneo y el coirón (Aleman \& Lopez Raffo, 1972; Caranza, 1988). Los mallines son escasos en el área pero aumentan en épocas de lluvias y los suelos son pedregosos, ricos en arena y canto rodado, con horizonte húmico casi ausente (Panza, 1987).

La napa freática de donde se obtiene el agua potable, se encuentra a $50 \mathrm{~m}$ de profundidad, pero en épocas de lluvias puede ascender y mantener con agua somera al Guadal Baqueró por períodos prolongados.

\section{II.2. Geología regional al sudoeste del Nesocratón del Deseado}

\section{II.2.1. Antecedentes}

El Nesocratón del Deseado se encuentra ubicado en la Provincia de Santa Cruz, entre los Ríos Deseado y Chico y desde la Costa Atlántica hasta la dorsal del Río Mayo (De Giusto et al., 1980).

Los primeros trabajos en la región fueron realizados por Hatcher $(1897,1900,1903)$, y posteriormente Windhausen $(1919,1931)$ le asignó el nombre “Escudo del Deseado” a la región.

El estudio geológico del área fue desarrollado por los geólogos de Yacimientos Petrolíferos Fiscales (YPF). Entre ellos cabe resaltar a Feruglio (1949-1950), quien aportó los primeros conocimientos estratigráficos y sustituyó el nombre de Escudo del Deseado por el de "Macizo del Deseado". Le sucedieron a esos trabajos los realizados por De Giusto (1954, 1955, 1956, 1957, 1958, 1959), Di Persia $(1954,1955,1956,1957,1958,1959)$ y De Giusto et al. (1980), quienes mapearon la región a escala de 1:100.000, y la definieron como subpositiva y tectónicamente estable, al tiempo que convalidaron la denominación de Nesocratón de Deseado de Harrington (1962). Sobre la base de los trabajos realizados por estos autores, fueron caracterizadas diversas unidades formacionales (Stipanicic \& Reig, 1955 y 1956; Archangelsky, 1967; Bracaccini, 1968; Turic, 1969). Las sedimentitas eocretácicas fueron referidas a la Formación Baqueró, la cual se subdividió en dos miembros, uno inferior y otro superior (Archangelsky, 1967).

En las últimas décadas, los geólogos del Servicio Geológico Nacional continuaron los trabajos de características regionales, y realizaron numerosas hojas geológicas (Marin, 1982, 1984 -Hoja 55c Gobernador Gregores; Panza, 1982, 1986 y 1988, para las Hojas 53e Gobernador Moyano, 
54e Cerro Vanguardia, 54d La Manchuria, 55e Cerro Rubio) y por último la hoja geológica de Gobernador Gregores, a una escala 1: 250.000 (Panza \& Marín, 1998). Estos autores ratifican o rectifican la sucesión estratigráfica existente. Cabe mencionar que en la mayoría de los trabajos se hizo referencia a la Meseta Baqueró. Otros estudios de detalle fueron realizado por Caranza (1988) en el Anfiteatro de Ticó, y por A. Archangelsky et al. (1995) en la Meseta Baqueró.

Finalmente, la sedimentología de esta región fue abordada por Cladera (1998) quien junto a otros autores (Cladera et al. 1999, 2002), propusieron una reestructuración de la estratigrafía, y elevaron a la categoría de Grupo la unidad denominada con anterioridad Formación Baqueró. Este Grupo esta integrado, de base a techo, por las formaciones Anfiteatro de Tico, Bajo Tigre y Punta del Barco.

\section{II.3. Geología y estratigrafía de la región de la Meseta Baqueró}

Las unidades litoestratigráficas presentes en el área de estudio que se caracterizan, de base a techo son las siguientes:

\section{II.3.1. Mesozoico}

\section{II.3.1.1. Formación Bajo Pobre (Lesta \& Ferello, 1972)}

Aunque esta unidad tiene una gran distribución en zonas aledañas al área de estudio, en la zona de trabajo sólo está representada por afloramientos aislados en forma de lomadas bajas (Panza, 1987). De este modo se manifiesta, en las cercanías del Lote 18, como un pequeño cerro de 8 a $10 \mathrm{~m}$ de altura, ocupando una superficie aproximada de $500 \mathrm{~m}^{2}$ (fig. 1b). Dichos afloramientos no presentan contacto con las unidades infra y suprayacentes (Panza \& Marín, 1998). Esta formación es, en general, basáltica, de coloración oscura, matriz maciza y fenocristales de grano fino.

\section{II.3.1.2. Grupo Bahía Laura (Lesta \& Ferello, 1972)}

Esta unidad está compuesta por rocas vinculadas a procesos alternados de vulcanismo efusivo (lavas de composición riolítica a riodacítica) y explosivo (tobas e ignimbritas), que comprenden a la Formación Chon Aike, e incluyen también, depósitos epiclásticos relacionados con la erosión de las rocas mencionadas. Estos últimos dan origen a la Formación La Matilde. Cabe mencionar que en la región de estudio solamente aflora la Formación Chon Aike, de edad jurásica.

\section{II.3.1.2.1. Formación Chon Aike (Stipanicic, 1957; Archangelsky, 1967)}

La distribución de esta unidad es muy amplia en toda la región. En el área de trabajo se distribuye en el sector austral, en especial en el Cañadón Agustín. Se trata de afloramientos bien preservados de riolitas y, en forma subordinada, presentan aglomerados volcánicos gruesos, tobas y tufitas (Panza, 1987; Panza \& Marín, 1998). En esa área, se observan depósitos de abanicos aluviales en facies proximales, de hasta $20 \mathrm{~m}$ de espesor. Son de coloración rojiza y están constituidos por bloques angulosos de riolitas, con matriz de arena gruesa a sabulítica. Esta sucesión se muestra 
marcadamente granodecreciente. Estos depósitos estarían indicando áreas positivas cercanas y probablemente, un fallamiento post-riolitas y pre-tobas.

El espesor de la Formación Chon Aike en el área de estudio es difícil de establecer, pero no superaría los $300 \mathrm{~m}$ (Panza, 1986). Este espesor varía a nivel regional, ya que se estima un espesor de 600 a 700 m en el ámbito del Macizo Norpatagonico (De Barrio et al. 1986).

La relación de contacto con los basaltos de la Formación Bajo Pobre es desconocida en el área de este trabajo.

\section{II.3.1.3. Formación Bajo Grande (Di Persia, 1957)}

En el área de trabajo, los afloramientos de la Formación Bajo Grande se encuentran ubicados en las cercanías de Meseta Baqueró, en el borde Sur de la misma, y al Norte, en el Anfiteatro de Tícó. Los mismos son de colores claros (gris a amarillo pálido). Se trata de depósitos continentales de origen fluvial, de granulometría psefítica, con clastos de guijas y guijarros de hasta $5 \mathrm{~cm}$, provenientes de las vulcanitas de la Formación Chon Aike. Pueden exhibir estructura cruzada en artesa. Estas psefitas gradan a psamitas líticas de tamaño medio con pumicitas de hasta $5 \mathrm{~mm}$ o a pirosamitas con estructura laminada, o bien pueden presentarse macizas. Estos ciclos granodecrecientes alcanzan hasta $2 \mathrm{~m}$ de potencia. En el tope de algunos de los mismos puede observarse bioturbación del tipo endichnia o paleosuelos de escaso desarrollo.

Como ya fue mencionado, debido a la falta de restos fósiles la edad de esta formación fue adjudicada en forma indirecta al lapso Kimmeridgiano superior - Hauteriviano (Panza \& Marín, 1998).

\section{II.3.1.4. Grupo Baqueró (Cladera et al. 2002)}

En fecha reciente se otorgó un rango mayor - de Grupo- al paquete sedimentario denominado Formación Baqueró (Archangelsky, 1967), y se definieron tres formaciones en base a la litoestratigrafia (Cladera, 1998; Cladera et al. 1999; 2002).

Este Grupo está integrado, de base a techo, por las formaciones:

\section{II.3.1.4.1. Formación Anfiteatro de Ticó}

Los afloramientos de esta unidad se apoyan mayormente sobre la Formación La Matilde, y en menor medida sobre la Formación Bajo Grande, en tanto en el área de estudio, lo hace sobre la Fm. Chon Aike (Cladera et al. 2002). Se extienden desde el Cerro Terciario (Ea. Aguada del Cuero) por el norte, hasta la Ea. La Generosa por el sur. Abarcan una franja paralela a la Ruta Nacional No 3, por el este, hasta discretos afloramientos sobre la ruta 502, por el oeste (Fig. 1b). La formación se compone de litofacies silicoclásticas y volcaniclásticas. Entre las primeras, se incluyen conglomerados clasto soportados, macizos o con estructuras cruzadas en artesa, areniscas gruesas hasta sabulíticas con estructuras cruzadas en artesa , además de escasas areniscas finas con óndulas asimétricas de corriente. Aparecen también arcilitas y limolitas gris oscuro, con estructuras macizas o con discretas estructuras 
lentiformes arenosas y laminación. Esa litología se correspondería con canales fluviales sinuosos asociados a extensos cuerpos lacustres someros, donde la sedimentación ocurría bajo condiciones euxínicas moderadas (tonos grises de las pelitas). Su composición es caolinítica.

La mayor parte de los niveles fosilíferos citados en la literatura para este Grupo, provienen de esta formación. Las litofacies arenosas, pelíticas y tobáceas contienen una rica paleoflora integrada por fragmentos vegetales que se presentan como briznas milimétricas carbonizadas o como pínnulas y hojas casi enteras, dispuestas en los planos de laminación. Es común que en estas facies los fósiles se conserven como momificaciones, con su cutícula epidérmica, como así también otras membranas, y los contenidos de los órganos fértiles (óvulos, polen y esporas).

En cambio en las facies pelíticas, sólo en ciertos casos se han preservado las membranas, siendo las improntas el tipo de fosilización más frecuente. En estas facies también fueron hallados bivalvos de agua dulce y gasterópodos.

\section{II.3.1.4.2. Formación Bajo Tigre}

Esta unidad es la de distribución más amplia dentro del Grupo, pues sus afloramientos han sido reconocidos en las estancias Bajo Tigre y Anfiteatro de Ticó, también se extiende a otros sitios localizados hacia el norte de la provincia de Santa Cruz (Bajos Grande y Belgrano, Cerro Botellón, Cerro Madre e Hija y el Bosque Petrificado de Jaramillo, Fig. 1b). Dentro del área de estudio del presente trabajo, únicamente aflora en la barda norte de la Meseta Baqueró, donde alcanza a medir sólo unos $10 \mathrm{~m}$. No aparece en la barda sur, en Cerro Cuadrado y el yacimiento El Puma, quizás eliminada por los procesos erosivos asociados a la sedimentación de la Formación Punta del Barco (Cladera et al. 2002).

El contacto basal se da con la Formación Anfiteatro de Ticó, y solo en la región comprendida entre el Cerro Madre e Hija y el Bosque Petrificado de Jaramillo, está en contacto con las sucesiones de la Formación La Matilde.

La unidad está compuesta por depósitos volcaniclásticos, que incluyen tufopsefitas y tufopsamitas, y menores proporciones de piroarenitas (tobas blancas macizas). Entre las tufopsefitas predominan las brechas clasto-soporte y las brechas matriz-soporte, con matrices desde limosas hasta heterogéneas. Estas psefitas incluyen guijas a guijones de tobas gris castaño pálidas y ocasionales clastos redondeados derivados del sustrato jurásico (Formación Chon-Aike). Por su parte las tufopsamitas, con tonalidades semejantes, macizas o con débil laminación, presentan modificaciones por bioturbación moderada hasta total. Esta es del tipo endichnia, a modo de tubos cilíndricos verticales o casi verticales. En las paleosuperficies de estas rocas se han encontrado escasas raíces. La ciclicidad está representada por ciclos de espesor métrico, compuestos de brechas clasto soporte o matriz soporte, seguidos de las areniscas bioturbadas. La alta frecuencia de esos ciclos sugiere la existencia de flujos traccionales o suspensivos asociados a corrientes encauzadas en valles amplios y someros, generadas por lluvias torrenciales de variable intensidad. 
Esta unidad contiene escasos restos fósiles de vegetales en casi todos sus afloramientos, y no se ha reportado hasta el momento el rescate de palinomorfos.

\section{II.3.1.4.3. Formación Punta del Barco}

Esta unidad cuspidal es el objeto de estudio de este trabajo y será descripta en detalle más adelante.

\section{II.3.2. Cenozoico}

\section{II.3.2.1. Basaltos de Los Cerros Del Doce y Alma Gaucha (Panza, 1982, 1984)}

Se incluye bajo esta denominación a un conjunto de afloramientos de vulcanitas básicas, las cuales se distribuyen estratigráficamente, en forma poco clara, dentro del área de estudio, pero son fácilmente detectables en fotos aéreas. Los espesores de los basaltos son variables pero pueden alcanzar hasta $10 \mathrm{~m}$, acuñándose lateralmente. Ocupan los valles o depresiones de un relieve preexistente labrados en los depósitos del Grupo Baqueró. En el área de estudio, el contacto con la Formación Patagonia y su relación estratigráfica no pudieron ser determinados (Cladera, 1998).

Una muestra de estos basaltos fue analizada en el INGEIS, y dio una edad de $44 \mathrm{Ma} . \pm 5 \mathrm{Ma}$, la cual coincide con los datos obtenidos por Panza (1982), quién le asignó una edad paleógena (Eoceno- Oligoceno).

\section{II.3.2.2. Formación Patagonia (Zambrano \& Urien, 1970)}

En la región estudiada esta formación se dispone en contacto paraconcordante con la Fm. Punta del Barco, en las localidades de Meseta Baqueró y Cerro Cuadrado (fig. 1c). El espesor de esta formación en el área de trabajo no supera los $60 \mathrm{~m}$ y está compuesta por arcilitas macizas de color verde claro, con trazas del tipo endichnia y abundantes concreciones ferruginosas. Hacia el tope de la sucesión pelítica aparecen bancos de coquinas de color castaño claro, que en general no superan 1,70 m de espesor. La geometría de estos cuerpos es marcadamente tabular, presentando internamente estructuras cruzadas en artesas o planares, las cuales indican paleocorriente bipolar en general Este-Oeste. En las coquinas se pueden observar restos fósiles de equinodermos y bivalvos junto a clastos de la Formación Chon Aike de hasta $5 \mathrm{~mm}$ de diámetro. Cabe señalar que también en el Anfiteatro de Ticó estas coquinas se disponen directamente sobre las sedimentitas del Grupo Baqueró.

Los depósitos de pelitas en la base de la Formación Patagonia, en el área de Meseta Baqueró, estarían indicando una rápida transgresión marina. La ausencias de las mismas en el área de Anfiteatro de Ticó podría deberse a una fuerte variación lateral de estas facies pelíticas, generada, tal vez, por un paleorrelieve significativo en el momento de la depositación de la Formación Patagonia (Cladera, 1998).

Los depósitos que afloran en la Meseta Baqueró son de difícil correlación, pero corresponderían al miembro Monte León (Panza \& Marín, 1998). 


\section{II.3.2.3. Depósitos de agradación aterrazados}

Estos son depósitos cuaternarios poco consolidados de hasta $2 \mathrm{~m}$ de espesor, que poseen una granulometría psefítica mediana a gruesa, con clastos de composición volcánica, redondeados a subangulosos, de hasta $8 \mathrm{~cm}$. La matriz es arenosa (media a gruesa) de color gris claro.

Los depósitos son tabulares y su mejor desarrollo se encuentra entre el Guadal Baqueró y el Campamento 1.

\section{II.4. Rasgos estratigráficos del Grupo Baqueró}

\subsubsection{Extensión y Contacto Basal}

Los afloramientos del Grupo Baqueró se encuentran ubicados entre los paralelos de $47^{\circ}$ y $49^{\circ}$ de latitud Sur y los meridianos de $68^{\circ}$ y $69^{\circ} 30^{\prime}$ de longitud Oeste, al sur del río Deseado. En general estos afloramientos coinciden a grandes rasgos con los afloramientos de la Formación Bajo Grande, e incluso la traslapan hacia el E y NE (Turic, 1969).

En Meseta Baqueró y vecindades, este Grupo se apoya en forma discordante sobre rocas volcaniclásticas de la Formación Chon Aike y la Formación Bajo Grande. El techo de esta unidad está cubierto por la Formación Patagonia, por coladas basálticas o por rodados Tehuelches.

\section{II.4.2. Divisiones y Espesores}

Archangelsky (1967) realizó observaciones lito y bioestratigráficas detalladas en las localidades de Bajo Tigre, Bajo Grande y en Anfiteatro de Ticó, las cuales le permitieron dividir a la secuencia en dos Miembros (Inferior y Superior). El Miembro Inferior se compone de rocas epiclásticas (arcilitas y limolitas), con una geometría tabular bien definida. Por su parte el Miembro Superior está compuesto por rocas epiclásticas y piroclásticas (tobas, tufitas y brechas finas a gruesas con clastos de tobas); en el tope de la secuencia se ubican depósitos conglomerádicos (clasto-soportados), escasamente representados en la localidad de Bajo Tigre, aunque de espesores considerables en la zona de Ticó (Caranza, 1988). Con respecto a los afloramientos de Meseta Baqueró, específicamente en Punta del Barco, Archangelsky (1967) manifiesta la existencia de diferencias litológicas notables en relación a las localidades anteriores, indicando además dudas con respecto a su ubicación estratigráfica.

La existencia de los dos Miembros, para la Formación Baqueró fue adoptada por Turic (1969), De Giusto et al. (1980) y Panza (1982, 1987; Panza \& Marín, 1998); sin embargo Hechem y Hamovc (1987), basándose en la propuesta de Casas (1963), propusieron al Miembro Superior como perteneciente a la Formación Laguna Palacios que integra el Grupo Chubut en la Provincia homónima, y restringieron la Formación Baqueró solo al Miembro Inferior original. Los criterios seguidos por estos autores se basan en estudios realizados al norte de esta región, en la cercanías de Punta España (Ea. La Sierras), donde observaron que los depósitos de la Formación Laguna 
Palacios cubren progresivamente el paleorelieve hacia el sur; además dichos autores, hacen mención de semejanzas paleoambientales y litológicas entre ambas unidades, asociando las sedimentitas de la Formación Baqueró a depósitos fluviales y palustres, mientras que la Formación Laguna Palacios está formada por sedimentitas piroclásticas exclusivamente y con una gran distribución areal. Otro argumento de estos autores es la datación de una toba realizada por el INGEIS (muestra tomada en la base de la Formación Laguna Palacios, en la localidad de Cerro Bayo, Ea. Bajo Grande), que arrojó una edad de 90 Ma. Por otra parte, el hallazgo, en la misma localidad de polen de angiospermas (Psilatricolpites psilascabratus) ubicado en la sección basal de la Formación Laguna Palacios, motivó una asignación al intervalo Cretácico Superior-Terciario Inferior, con lo cual se argumentó la separación cronológica entre ambas unidades.

Cuadro 1. Equivalencias de las propuestas estratigráficas generales de la unidad de estudio. Modificado de Cladera et al. (2002)

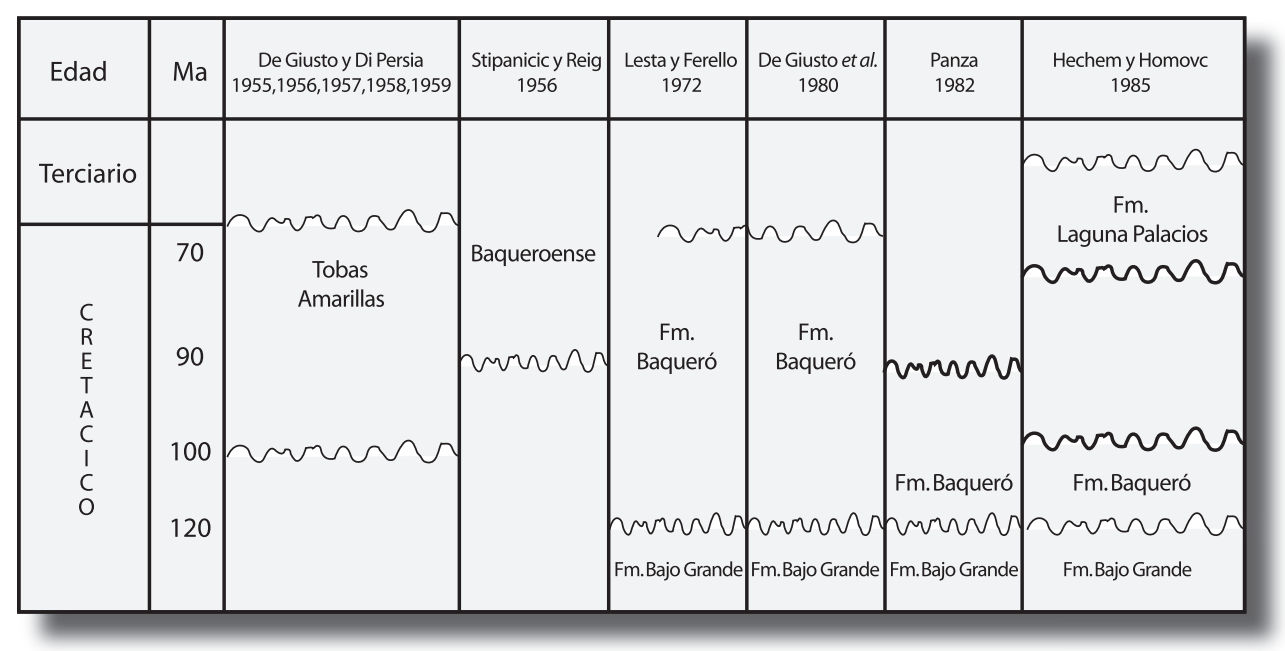

Según referencias de Archangelsky (1967) y de Cladera (1998), en el área de Meseta Baqueró, Bajo Tigre y Anfiteatro de Ticó, aflorarían los dos miembros propuestos por Archangelsky (1967).

Posteriormente Cladera (1998) sobre la base de diferencias litológicas, composicionales, paleoambientales y una discordancia manifestada en la secuencia del Miembro Superior de la Formación Baqueró (observada en la barda noreste de la Meseta Baqueró), propuso dividir informalmente a la Formación Baqueró en dos Formaciones A y B. La Formación A se la dividió en dos Miembros I y II. El Miembro I, equivalente al Miembro Inferior propuesto por Archangelsky (1967), y el Miembro II a la base del Miembro Superior propuesto por el mismo autor. La Formación B se encuentra en discordancia erosiva con la Formación A y se compone de facies epiclásticas (conglomerados, areniscas líticas etc.) y piroclásticas (tufopsamitas y piropsamitas) de colores gris claro. La Formación B incluye la mayoría de los afloramientos de la Meseta Baqueró. En Bajo Tigre solo aparece saltuariamente en el tope de las mesetas, y en la localidad de Anfiteatro de Ticó aflora en el sector occidental de la meseta. Finalmente, Cladera et al. (2002), en una revisión completa que 
abarca un área amplia de afloramientos que pertenecen a este Grupo, efectuaron una propuesta que formaliza la denominación de cada unidad. El Grupo Baqueró queda entonces integrado, de base a techo, por las formaciones Anfiteatro de Ticó, Bajo Tigre y Punta del Barco.

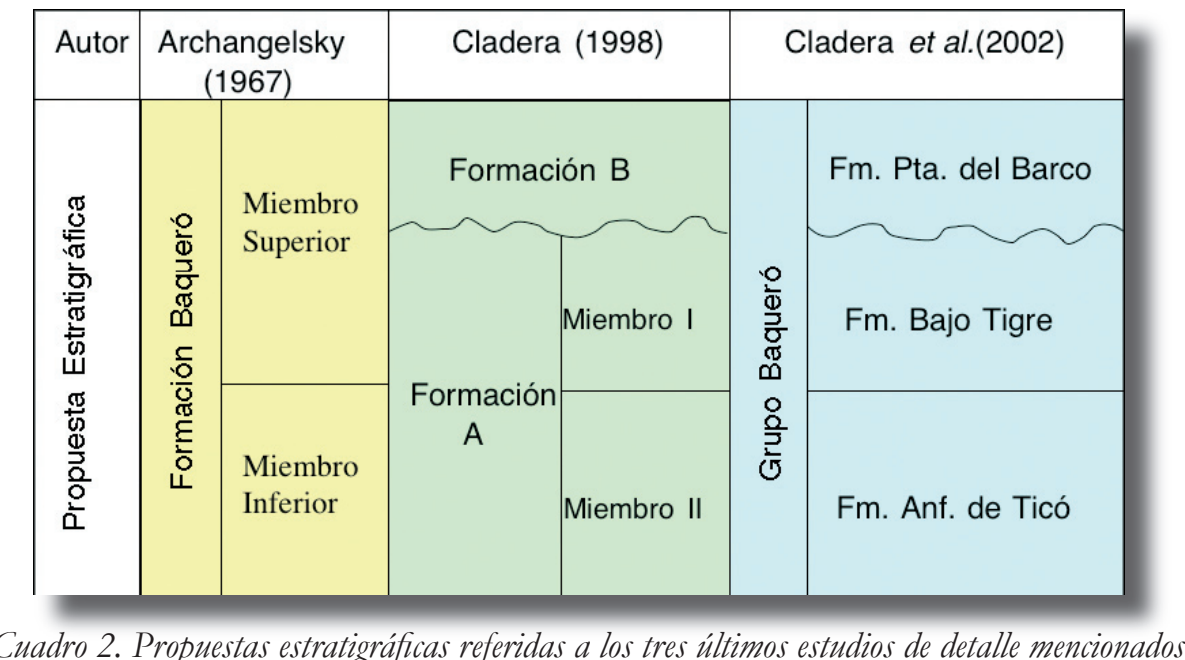

En el cuadro 2 se presenta en la tercer columna la propuesta estratigráfica más moderna hasta el momento (Cladera et al. 2002), que es la adoptada en el presente trabajo.

Conforme con ese criterio, las formaciones más antiguas dentro del Grupo Baqueró -Anfiteatro de Ticó y Bajo Tigre- han sido descriptas previamente, en tanto se caracterizará a continuación la unidad superior, Formación Punta del Barco, que es motivo de este trabajo.

\section{II.5. Formación Punta del Barco}

Los afloramientos de esta unidad no tienen un buen desarrollo areal, y se hallan restringidos a la Meseta Baqueró en ambas bardas, el Cerro Cuadrado y el Yacimiento El Puma, y pierde espesor hacia el norte, en dirección al Anfiteatro de Ticó (sector occidental) y en la vertiente oeste de la depresión donde se localiza la Ea. Bajo Tigre (Fig. 1b). El contacto con las formaciones infrayacentes -Anfiteatro de Ticó y Bajo Tigre- está representado por una superficie erosiva que quizás refleja una discordancia angular de bajo grado, que aparece en la barda norte de la meseta, vinculada a la Fase Mirano (Cladera et al. 2002, A. Archangelsky et al. 1995).

El holoestratotipo de la unidad se localiza en la clásica localidad de Punta del Barco (Fig. 2), en el

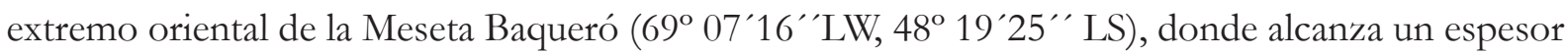
de $110 \mathrm{~m}$. El paraestratotipo se ubica también en la barda norte de la Meseta Baqueró (Fig. 3) en las cercanías de la Ea. El Verano (Cladera et al. 2002), donde fue realizado un perfil estratigráfico detallado (A. Archangelsky et al. 1995). 


\section{II.5.1.Litofacies}

La unidad está constituida por depósitos volcaniclásticos, en particular epiclásticos y piroclásticos. Los primeros se acumulan en su parte basal y media y se componen de conglomerados finos a medianos, clasto soporte, macizos o con débil imbricación de los clastos redondeados y estructuras cruzadas en artesa. Su composición es lítica, con materiales derivados de la erosión de lavas e ignimbritas de la Formación Chon-Aike y tobas de la Formación Bajo Grande. En la zona del Campamento 1 pueden incluir también guijas hasta bloques angulosos (máximo $20 \mathrm{~cm}$ ) de las arcilitas caoliníticas infrayacentes, depositadas en las depresiones y derivadas del lavado pluvial de las ignimbritas y lavas caolinizadas de la Formación Chon-Aike. Los conglomerados forman ciclos granodecrecientes con las areniscas líticas (con estructuras cruzadas en artesa) y, rara vez, los conglomerados culminan con pelitas laminadas (facies de abandono). Las sucesiones conglomerádicas pueden alcanzar los $40 \mathrm{~m}$ de ancho y $10 \mathrm{~m}$ de espesor, y su aspecto cordoniforme indica el evidente relleno de depresiones alineadas, posiblemente generadas por su enorme poder erosivo. A veces aparecen areniscas finas con óndulas linguoides o laminación. Las rocas pelíticas, representadas por arcilitas y limolitas gris oscuro, aparecen macizas o a veces laminadas y de composición caolinítica. Suelen exhibir raíces axiales ramificadas con una longitud de hasta $15 \mathrm{~cm}$ y un diámetro de pocos milímetros. Los canales tienen su eje orientado en dirección NNE-SSO (A. Archangelsky et al.1995; Cladera et al. 2002), lo cual sugiere que las corrientes que generaron y depositaron los sedimentos fluyeron en un amplio arco, desde el NO al NNE, es decir con una paleopendiente inclinada hacia el Norte en sentido amplio. Es allí donde fueron depositados los sedimentos epiclásticos.

Por otra parte, las litofacies piroclásticas dominan en la mitad superior de la unidad, e incluyen tobas primarias reelaboradas de color blanquecino, con laminación, estructuras cruzadas en artesa o macizas. Hay niveles con lapilli acrecionales (chalazolitas) dispuestos en láminas junto con las tobas laminadas o dispersas en las tobas macizas; en ellas aparecen también ocasionales bioturbaciones de tipo endichnia a modo de tubos verticales de hasta $10 \mathrm{~cm}$ de altura y con diámetros entre pocos $\mathrm{mm}$ hasta $1 \mathrm{~cm}$. En algunas tobas macizas fueron hallados niveles de raíces axiales muy ramificadas, hasta $15 \mathrm{~cm}$ de largo y un diámetro máximo de $3 \mathrm{~cm}$. Las tobas finas (pelíticas) son poco frecuentes y aparecen macizas o laminadas.

\section{II.5.2. Contenido paleoflorístico}

Las facies volcaniclásticas, psefíticas o arenosas, incluyen frecuentes troncos silicificados, de tamaños variados, que pueden alcanzar hasta $2 \mathrm{~m}$ de longitud y $0,20 \mathrm{~m}$ de diámetro, y no presentan raigones. Aparecen en la base de la unidad en ambas localidades estudiadas: Ea. El Verano (A. Archangelsky et al., 1995) y en la Barda Sur, además del sector occidental en el Anfiteatro de Ticó. Con duda, se han citado improntas en la Ea. Bajo Tigre y afloramientos aislados en las Estancias Las Mercedes y Manantiales (Archangelsky, 2001). En las tobas arenosas primarias y reelaboradas aparecen muchos restos de plantas en excelente estado de preservación, algunos en posición de crecimiento (A. Archangelsky et al. 1995), y briznas carbonizadas (Feruglio, 1949; Stipanicic \& Reig, 
1956; Archangelsky, 1963 a y b, 1967). Los fósiles macroscópicos se disponen en hasta 5 niveles sucesivos, aunque son más abundantes en los dos horizontes inferiores (Archangelsky, 2003). Los morfogéneros más frecuentes son Gleichenites, Hausmannia, Pagiophyllum, Pseudoctenis, Araucaria, Brachyphyllum, Nilssonia y Sphenopteris (ver cap. V.3.1.2). En las pelitas se preservan restos de plantas flotadas y con escaso transporte.

En una campaña reciente se ha registrado un cuerpo lentiforme de cerca de $3 \mathrm{~m}$ de largo y 0,80-1m de espesor que representa un meandro abandonado en donde se preservaron restos flotados de ramas y hojas en forma de momificaciones junto con leños asbestizados y charcolificados (Llorens et al. 2003) (Lám. XIII).

El presente estudio es el primer reporte de palinomorfos para esta unidad cuspidal.

\section{II.5.3. Interpretación paleoambiental}

Los depósitos volcaniclásticos conglomerádicos y arenosos fueron depositados por flujos traccionales en ríos y arroyos, cuyo relleno tiene diseño entrelazado, y aparecen encajados por erosión en el sustrato. Existe una clara ciclicidad, ya que se advierten ciclos conglomerados clasto soporte macizos-con estructuras cruzadas en artesa o conglomerados clasto soporte con estructuras cruzadas en artesa- areniscas gruesas hasta sabulíticas con estructuras cruzadas en artesa, que sugiren la formación de barras longitudinales seguidas de barras linguoides con crestas curvas y discontinuas. La aparición de escasas tobas con óndulas asimétricas en el tope de las barras longitudinales, o de tobas laminadas y pelitas, se asocia a períodos de bajante en los canales activos (Cladera et al. 2002). El progresivo aumento de la actividad volcánica explosiva hacia el W-NW, incrementó el volumen de cenizas depositadas en la mitad superior de la unidad. Estas, cubrieron el sistema de ríos y arroyos, ahogándolos debido al aumento de la carga provocando su lenta reducción hacia el tope de la unidad. La disminución de las pendientes transformó este sistema inicial en meandriforme, de baja sinuosidad y notable ciclicidad, cuyos canales surcaban un paisaje suavemente ondulado. La presencia de tobas modificadas por incipiente pedogénesis y la existencia de plantas, indica periódicas detenciones en la lluvia de cenizas. El hallazgo de lapilli acrecionales (chalazolitas) dispersos en las tobas macizas, sugiere que éstas estuvieron asociadas a grandes nubes de cenizas transportadas por vientos, que se depositaron de forma progresiva sobre el terreno. Ya las tobas lapillíticas laminadas parecen sugerir que ellas fueron erosionadas por aguas pluviales y las chalazolitas se depositaron en discretos cuerpos lacustres, o bien en los canales fluviales. Es probable que en la llanura ondulada se produjeran oscilaciones del nivel freático con formación simultánea de cuerpos de agua someros, en los cuales se depositaron cenizas laminadas o con óndulas. La persistencia en la posición del nivel freático fue el factor que favoreció el crecimiento de una vegetación baja en sus sectores marginales (Archangelsky, 2003). 


\section{II.6. Descripción de los perfiles estudiados}

\section{II.6.1. Punta del Barco Norte (PBN) (Fig. 3)}

La Formación Punta del Barco presenta un espesor en esta localidad de $38.5 \mathrm{~m}$; se apoya en discordancia erosiva sobre la Formación Bajo Tigre, compuesta por arcilitas y brechas intraformacionales de un ambiente de llanura.

En este perfil se destacan dos tipos de facies principales: en la mitad inferior dominan las facies de canales fluviales epiclásticos, mientras hacia el tope comienza el dominio de flujo de detritos y arroyos efímeros asociados a facies de llanura.

La Formación en estudio entonces, presenta en su base conglomerados que corresponden a facies de canales fluviales con estratificación cruzada en artesa, de color amarillo rojizo e inclusión de molde de troncos y troncos asbestizados de hasta $2 \mathrm{~m}$ de largo. Su textura es clasto-sostén con matriz arenosa hasta sabulítica, constituída principalmente, por clastos de tobas y vulcanitas provenientes de la erosión de la Formación Chon Aike. Los clastos son en general de tamaño gránulo hasta guija subredondeados de forma oblada y prolada, dispuestos con débil imbricación; otros, son angulosos e intraformacionales pelíticos. Estos conglomerados forman ciclos granodecrecientes terminando en pelitas laminadas o arenas. Las pelitas alcanzan $1 \mathrm{~m}$ de espesor y son de color gris oscuro con laminación marcada, su base es neta y el techo erosivo. Por su parte, las areniscas se caracterizan por su color anaranjado. Ellas pueden ser granodecrecientes, desde gruesas con estratificación cruzada en artesa a medianas con laminación paralela, la base es plana y el techo puede ser plano o erosivo.

Estas series granodecrecientes de facies de canal tienen $6 \mathrm{~m}$ de espesor y pasan, mediante contacto ondulado, a tobas de llanura $(0.6 \mathrm{~m})$, de color blanquecino y con laminación. Por encima se depositan $3.6 \mathrm{~m}$ de conglomerados matriz soportados correspondientes a facies de flujo de detritos de color amarillo claro. Están compuestos de una matriz tufopelitíca o tufosamítica, con clastos intraformacionales aislados, y su estructura interna es mayoritariamente maciza, aunque pueden presentar laminación paralela poco definida. Estos flujos de detritos se intercalan hasta 6 veces en el perfil, siendo más importantes en los sectores medio y superior.

Hacia arriba continúan $0.7 \mathrm{~m}$ de tufopsefitas con matriz tufopsamítica o tufopelítica de color marrón claro, y clastos intraformacionales angulosos de pelitas y arcillitas más oscuros. Éstos son macizos y corresponden a facies de arroyos efímeros similares a los anteriores, pero con rasgos de bioturbación. Luego siguen $1.4 \mathrm{~m}$ de tobas macizas con inclusiones de chalazolitas, presencia de raíces y rasgos pedogénicos que sugieren que se trata de un paleosuelo. El perfil continúa con intercalaciones de las litologías ya descriptas hasta rematar en el techo de la sección inferior en tufopelitas de $0.6 \mathrm{~m}$ de espesor de color gris muy claro y estructura interna maciza. Se han encontrado aquí nuevamente raíces y razgos pedológicos atribuíbles al desarrollo de un paleosuelo; a este nivel se lo ha denominado nivel 1 en el muestreo palinológico, y ha brindado las muestras más ricas en palinomorfos de la Formación.

El sector medio de la columna estratigráfica de este perfil, se caracteriza por depósitos de tufopsamitas, 
$2.4 \mathrm{~m}$ de colores gris claro, los contactos son ondulados, y presentan estratificación entrecruzada en artesa, restos de vegetales, y cuerpos esféricos o chalazolitas. Luego pasan a conglomerados y arenas gruesas $(2.7 \mathrm{~m})$ con estructura cruzada en artesa e inclusiones de troncos. Por encima, se depositan $4 \mathrm{~m}$ de conglomerado soportado por una matriz tufosamítica de color amarillo con contactos planos. Sobre ese cuerpo de roca se apoyan $2.5 \mathrm{~m}$ de intercalaciones de tobas y tufopelitas de color gris muy claro, con contactos planos y estructura laminada en las tufopelitas y, en menor medida, en las tobas. Este nivel es portador de plantas fósiles y bioturbaciones, al tiempo que dos de esos paquetes pelíticos corresponden a los niveles polínicos 3 y 4 según nuestra denominación. La serie tobácea es interrumpida por la depositación de $2.5 \mathrm{~m}$ de conglomerados clasto-sostén como los descriptos previamente, de estructura interna maciza. Por encima continúa un paquete arenoso maciso granodecreciente de $2.3 \mathrm{~m}$ de espesor, al que suprayacen tobas de facie de llanura, con un espesor de $1.1 \mathrm{~m}$ gris muy claro correspondientes a un paleosuelo (nivel polínico 6), con estructura maciza que hacia el techo presenta raíces y rasgos pedogéneticos. Inmediatamente después, se deposita una toba laminada de $2.5 \mathrm{~m}$ de espesor y coloración blanquecina, para terminar en el techo en $0.7 \mathrm{~m}$ de conglomerado matriz soporte en facie de flujo de detritos ya descripto.

El contacto en el techo con la Formación Patagonia, es neto.

\section{II.6.2. Punta del Barco Sur (PBS) (Fig. 4)}

En este perfil la Formación Punta del Barco se apoya en discordancia erosiva sobre la Formación Anfiteatro de Ticó, representada aquí por pelitas gris oscuro laminadas de origen lacustre.

La Formación Punta del Barco está constituida en su base, al igual que en el perfil antes descripto, por facies de canales fluviales que comienzan con conglomerados clasto-soportados de color amarillo rojizo, con estructuras cruzadas en artesa e inclusión de troncos fósiles. Los clastos son subredondeados, tamaño guija hasta gránulo, que pueden presentar débil imbricación; la matriz es arenosa hasta sabulítica, constituída por clastos de tobas y vulcanitas provenientes de la erosión de la Formación Chon Aike. El espesor de estos conglomerados es de $3.8 \mathrm{~m}$ y pasan, mediante contacto erosivo, a conglomerados finos de $2.4 \mathrm{~m}$, y luego a arena gruesa hasta sabúlitica, de color anaranjado y con estructuras cruzadas en artesa (1.6 $\mathrm{m}$ de espesor). Este tipo de arreglos granodecrecientes, continúan por encima con un espesor de $7.8 \mathrm{~m}$, e intercalaciones conglomeradoarena, de estructura predominantemente maciza y contactos erosivos. Hacia arriba aflora un nivel pelítico gris oscuro, con restos de raíces y rasgos pedogenéticos, que denotan que se trata de un paleosuelo, al que suprayacen tufosamitas de color gris muy claro a blanco, portadoras de improntas vegetales asignables a ramas de araucariáceas.

Luego de un contacto de tipo erosivo, sigue un conglomerado fino con matriz arenosa de $3 \mathrm{~m}$ de espesor con estructura maciza y de origen fluvial. Continúan $0.5 \mathrm{~m}$ de arenisca fina con restos radiculares, interpretado como un paleosuelo. Este nivel ha brindado material polínico y ha sido referido al Nivel 2. Mediante contacto neto, está asociado a un nivel de pelitas macizas de color 
gris oscuro, con desarrollo pedogénico y raíces. El siguiente cuerpo rocoso corresponde a $1.1 \mathrm{~m}$ de tufosamitas blanquecinas de estructura maciza que, contacto neto mediante, continúa con arenas finas. Luego aparece un cuerpo de arquitectura lenticular compuesto por lutitas de color marrón oscuro y macizas, de $1.1 \mathrm{~m}$ de espesor. Esta lente es portadora de diferentes órganos vegetales con distintos tipos de fosilización y una rica asociación polínica (Nivel 4). Esos restos vegetales presentan signos de transporte (Llorens et al. 2003), por lo que se ha interpretado a este nivel como un meandro abandonado .

Por encima se deposita una tufosamita de $0.9 \mathrm{~m}$ de espesor, seguida de $1 \mathrm{~m}$ de lutitas color marrón (nivel polínico 5). A continuación se encuentran $0.7 \mathrm{~m}$ de conglomerado matriz-soportado marrón claro y macizo, por encima del cual apoya una tufolimolita gris blanquecina de $0.9 \mathrm{~m}$ de espesor, con restos de raíces. Siguen $0.5 \mathrm{~m}$ de arenas finas que mediante contacto erosivo pasan a $1.3 \mathrm{~m}$ de tufosamitas gris claro en contacto neto con $2 \mathrm{~m}$ de arena mediana correspondiente a una facie fluvial que grada a un cuerpo de $2 \mathrm{~m}$ de arena fina, para terminar en el techo con $3.5 \mathrm{~m}$ de espesor correspondientes a una tufopelita grisácea.

Por encima aflora, mediante contacto neto, el Patagoniano que está representado aquí por facies pelíticas.

\section{II.6.3. Integración de los perfiles}

La integración o correlación de los perfiles de las bardas Norte y Sur de la Meseta Baqueró (PBN y PBS), se realizó mediante los arreglos de facies y los contactos entre las diferentes formaciones, tanto en su relación de techo como de base. Así mismo, otra herramienta de correlación utilizada, fueron los diferentes niveles fosilíferos comunes a ambos perfiles.

El punto de partida para esta integración fue el evidente contacto erosivo de la formación Punta del Barco con las infrayacentes Bajo Tigre y Anfiteatro de Ticó, respectivamente. Una vez integradas sus bases, el siguiente punto de correlación es una toba de casi $1 \mathrm{~m}$ de potencia, portadora de plantas fósiles de taxones presentes en las dos columnas en cuestión (Cladera, com.pers.).

Además, también existió una muy buena correlación de los 6 niveles pelíticos que fueron muestreados para obtener material polínico en ambos perfiles. Finalmente, se utilizó la transgresión marina de pelitas verdes portadoras de invertebrados fósiles de la Formación Monte León (Mioceno). 

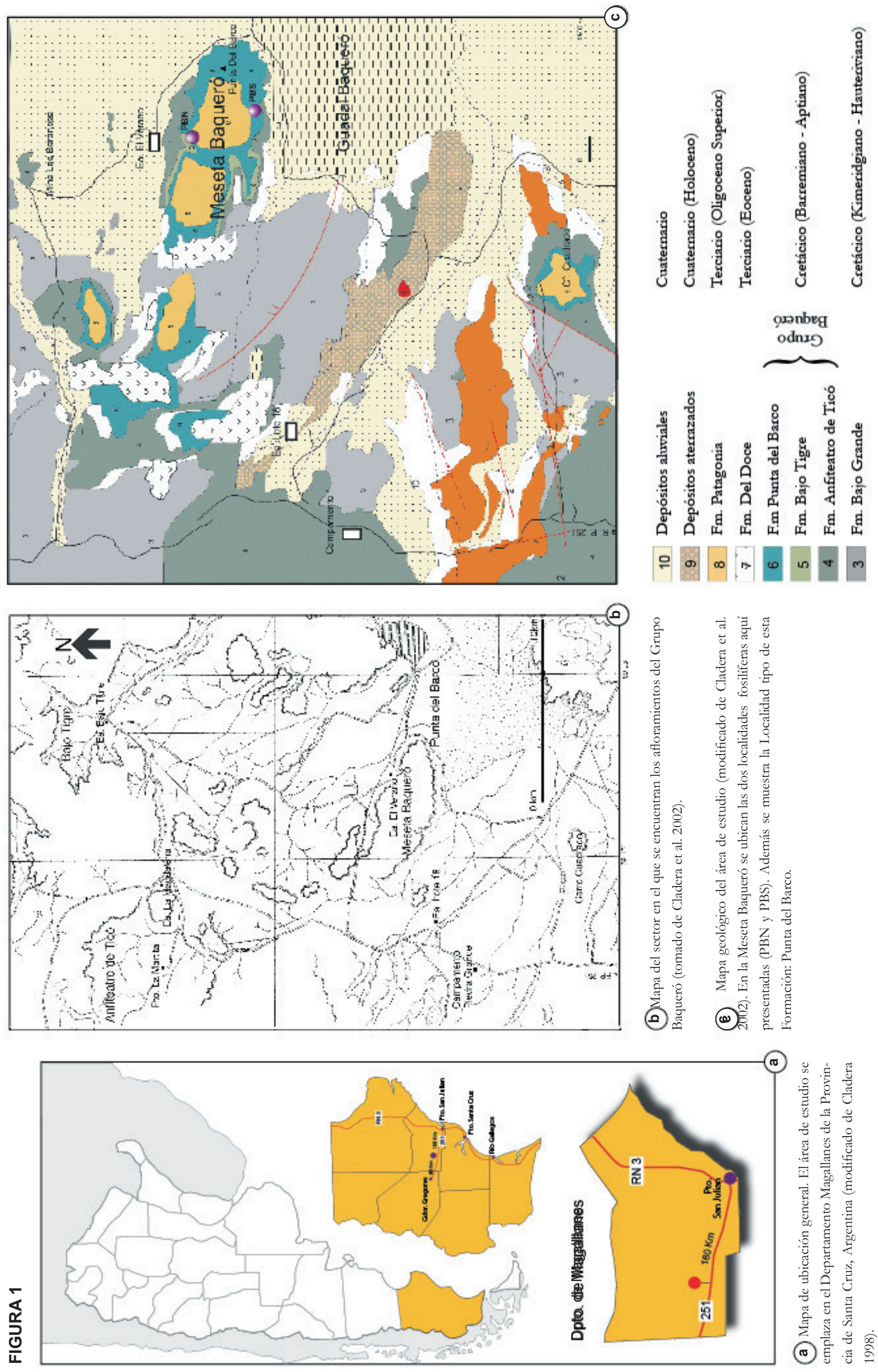


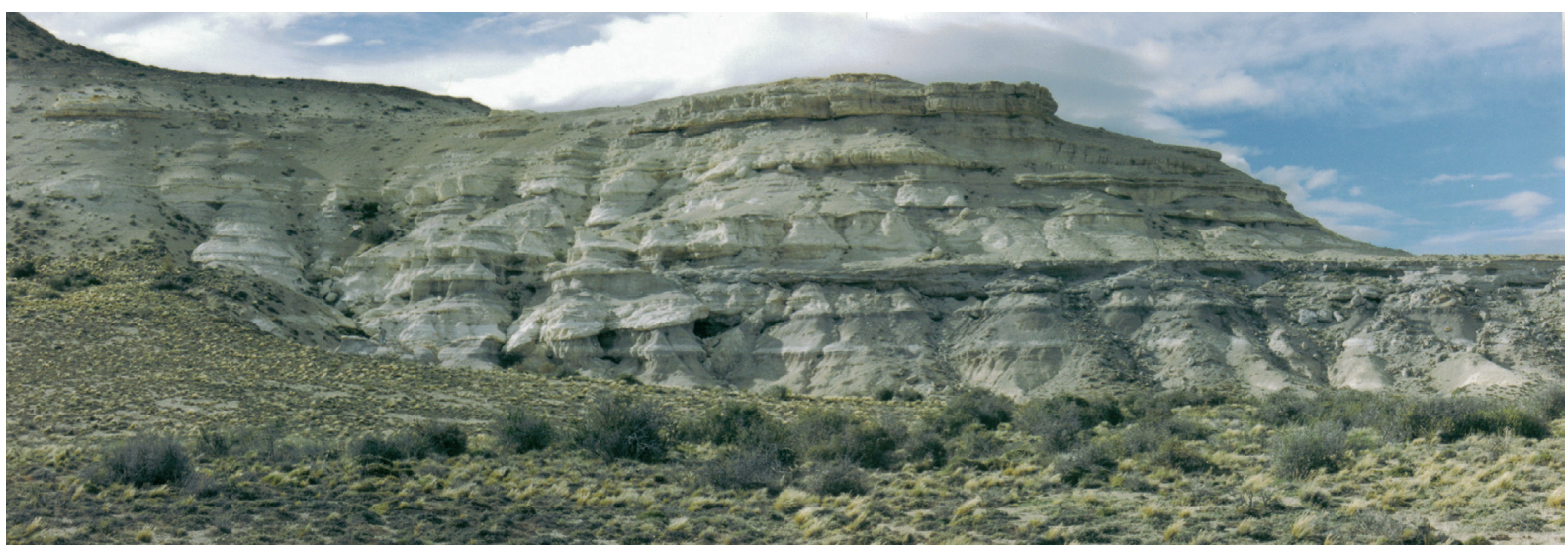

\section{FIGURA 2}

Foto de la localidad tipo de Fm. Punta del Barco y perfil tipo (tomado de Cladera et al. 2002).

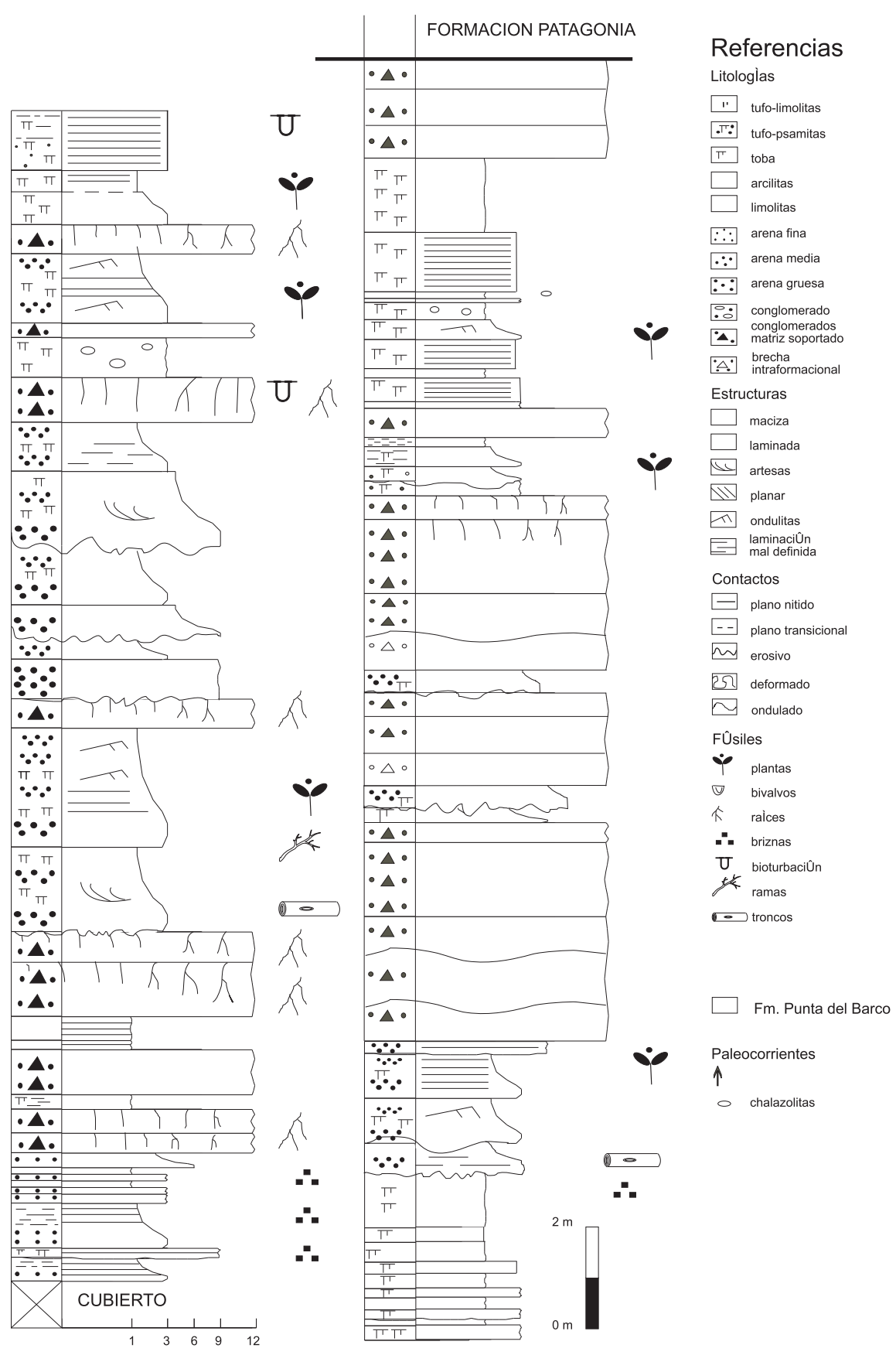




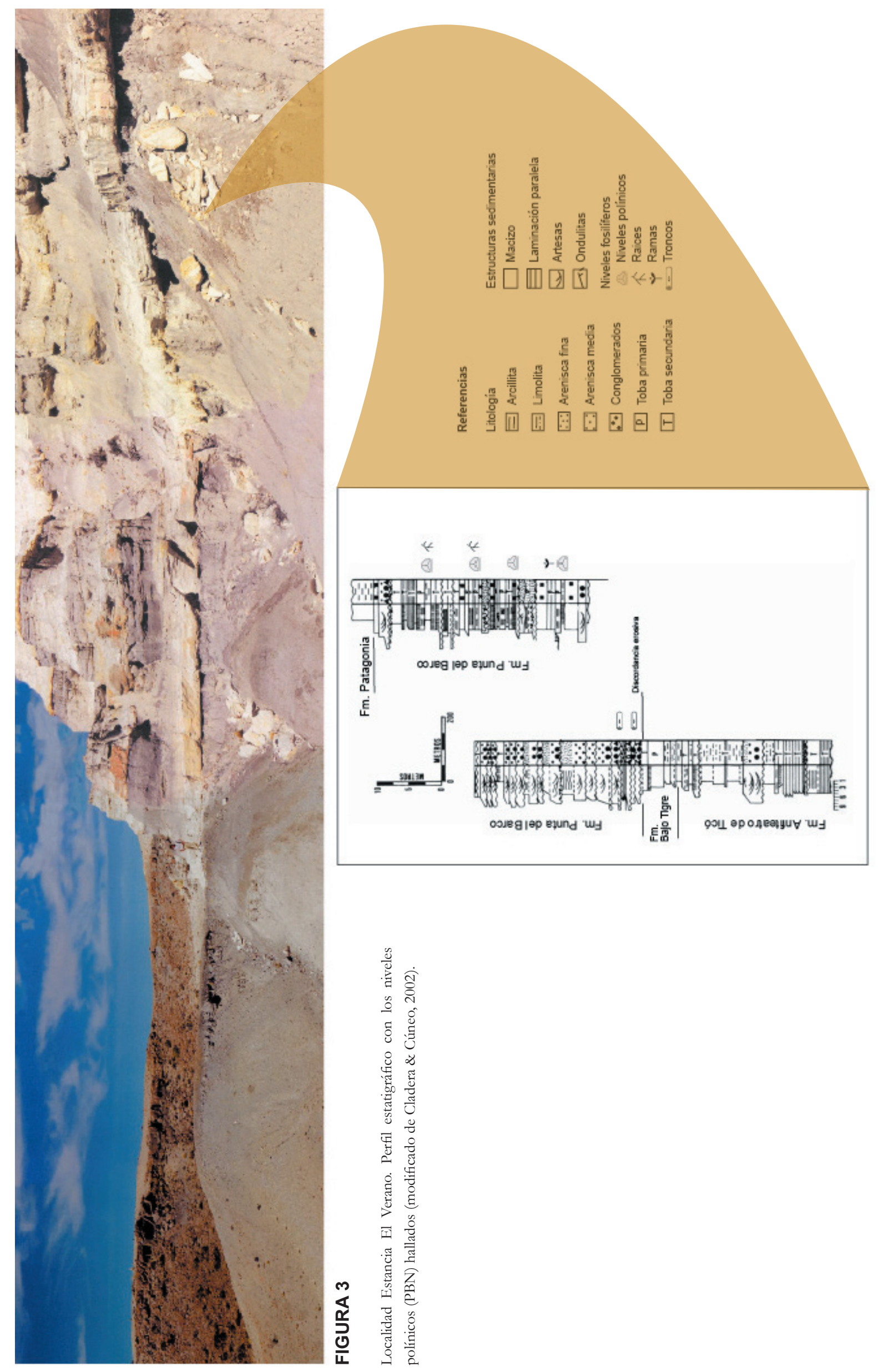




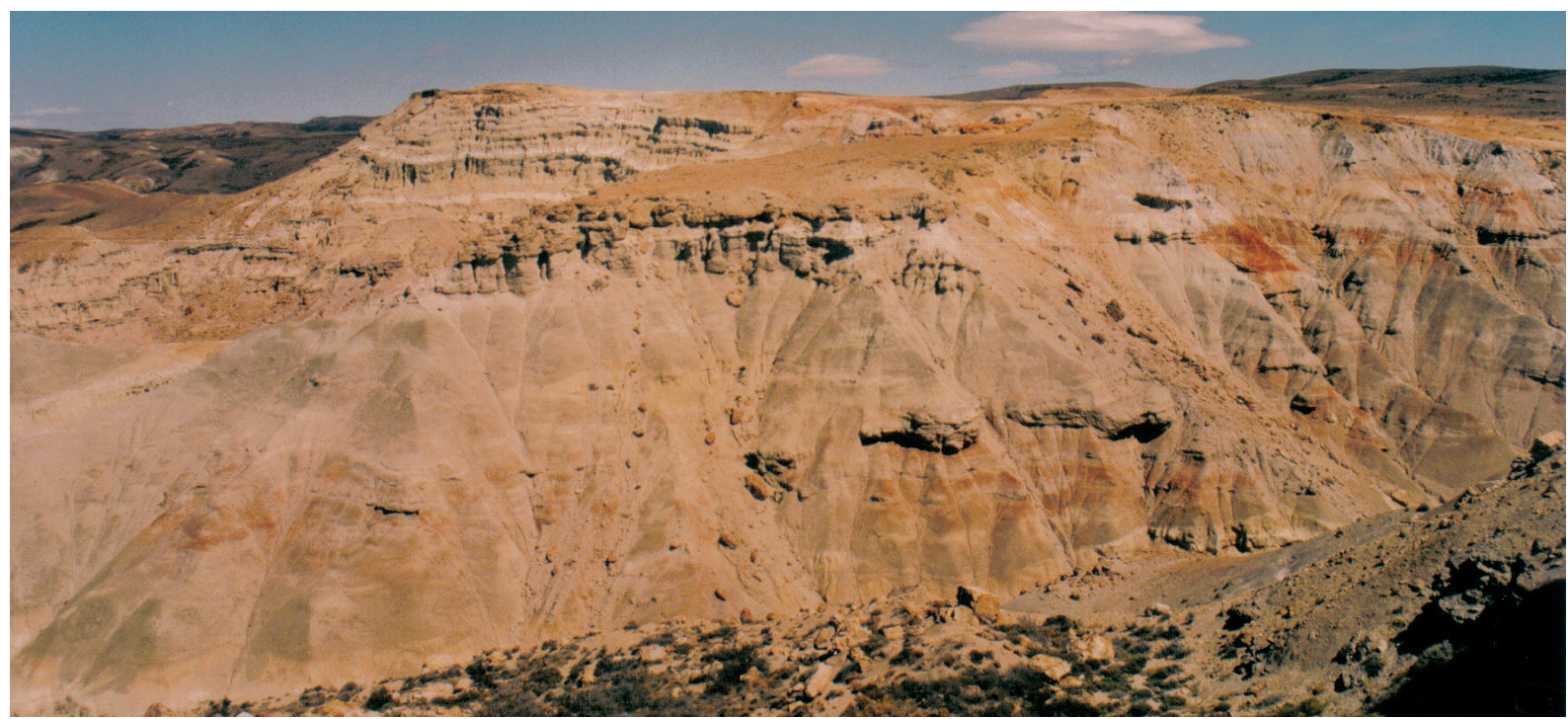

FIGURA 4 Foto de la localidad Barda Sur (PBS) y perfil con los niveles polínicos hallados (modificado de Llorens et al. 2003).
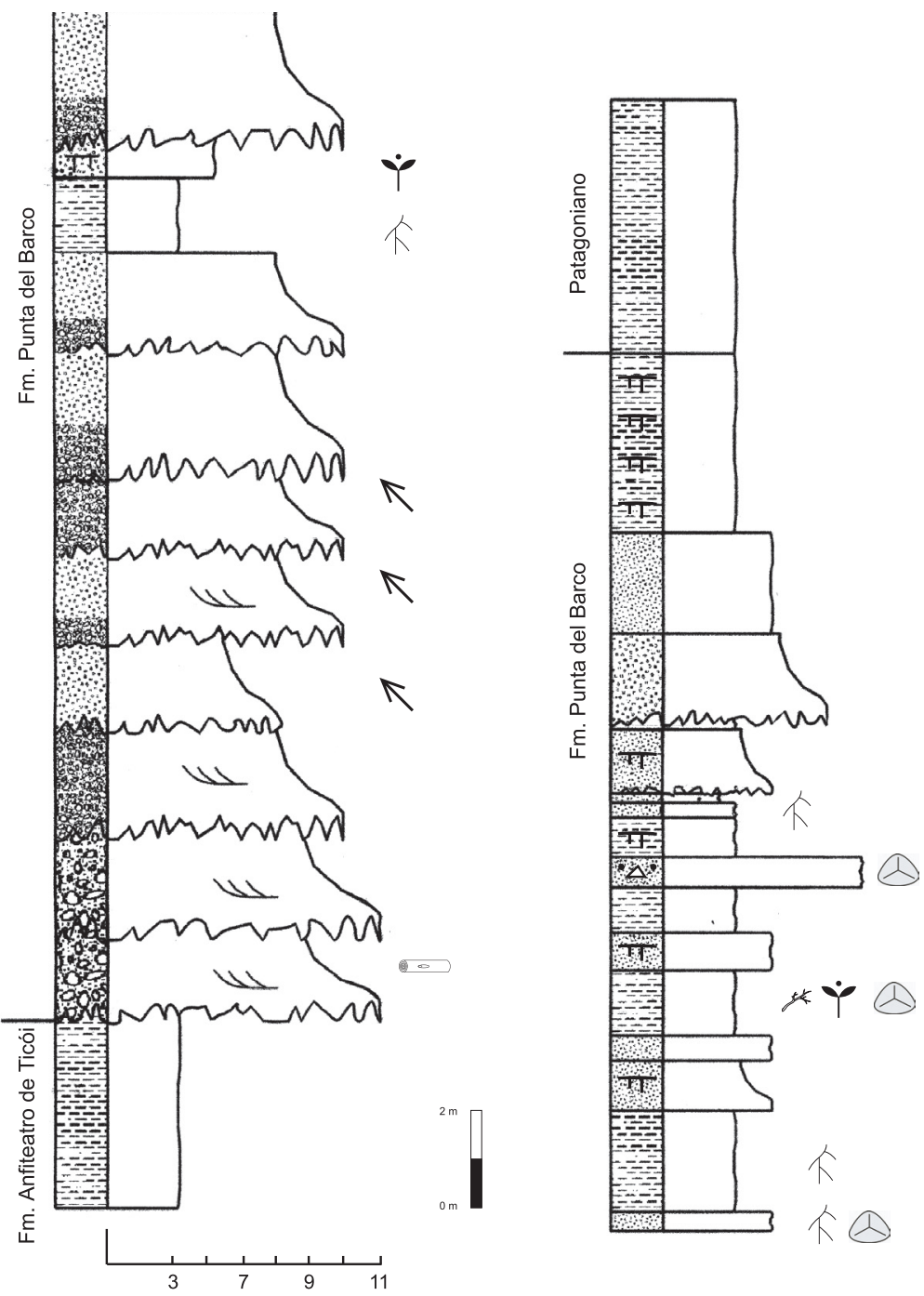

\section{Referencias}

Litologías

\begin{tabular}{|c|c|}
\hline 7 & tufo-limolitas \\
\hline गा: & tufo-psamitas \\
\hline & arcilitas \\
\hline $\bar{E}$ & limolitas \\
\hline$\therefore$ & arenisca fina \\
\hline$\therefore$ & arenisca media \\
\hline & arenisca gruesa \\
\hline .0 & conglomerado \\
\hline & brecha intraforma \\
\hline
\end{tabular}

Estructuras

$\square$ maciza

4 artesas

Contactos

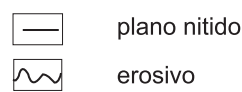

Niveles fosilíferos

A niveles polínicos

plantas

$\uparrow$ raices

敌 ramas

$\varpi$ troncos

N Paleocorrientes 


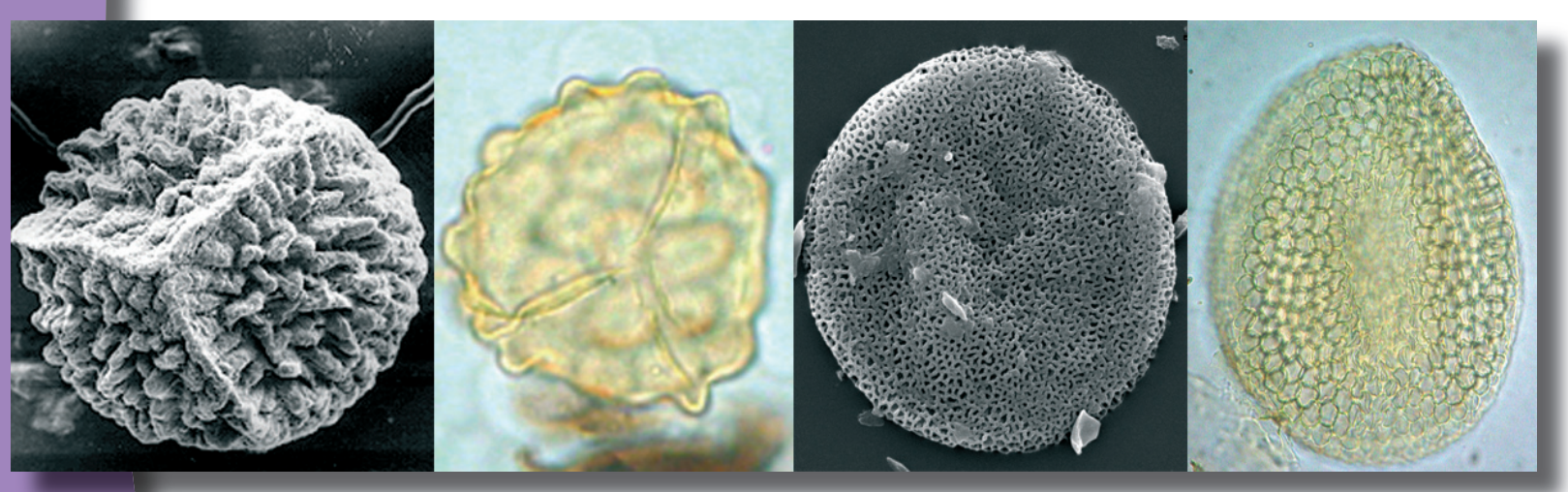

CAPITULO III

Sistemática Palinológica 


\section{SISTEMÁTICA PALINOLÓGICA}

\section{III.1. Consideraciones generales}

En este capítulo se realiza el análisis taxonómico del material palinológico recuperado de las muestras extraídas en los afloramientos de la Formación Punta del Barco. Se describen 76 especies referidas a 47 morfogéneros, de los cuales 3 tienen determinación incierta. A ellos se suman 3 formas incertae sedis sin asignación genérica o específica.

Como ya fuera adelantado en el capítulo I, la clasificación del polen y microsporas dispersos se llevó a cabo según el concepto morfológico propuesto por Potonié \& Kremp (1954), y luego ampliado por Potonié $(1956,1958,1960)$. En algunos casos -como el de la Infraturma Tricrassati- se tuvo en cuenta también la revisión efectuada por Dettmann (1963). Sin embargo no se han seguido en este trabajo algunas de sus ideas, ignorando el rango de Suprasubturma por ella propuesto. En ese sentido, las esporas perisporadas se mantienen en el rango de Subturma según la propuesta original.

La clasificación de los palinomorfos en "Turmas", facilita el ordenamiento de los taxa. No obstante en el caso de las megasporas, si bien la organización se ha hecho con ese esquema de clasificación morfológica, se las trata en un subcapítulo aparte.

Por otra parte, para determinar los restos algales se tomó en cuenta la afinidad taxonómica con grupos actuales y fueron separados en familias, tomando como referencia principal el trabajo sistemático y ecológico de Zippi (1998).

En los casos en que las especies determinadas tienen un amplio registro y numerosas menciones anteriores, se procede a dar una lista de sinonimias que contiene sólo las citas que se han considerado más relevantes, obviando aquellas que no brindan mayor información. De igual manera, las especies con numerosas descripciones previas, no son descriptas en este trabajo a menos que el material presente características especiales que lo justifiquen.

En el caso en que se conoce alguna afinidad botánica para el morfogénero, es presentada luego del encabezado genérico, y si se ha registrado dicha afinidad para una de las especies descriptas, esto se hace dentro del cuerpo en que se describe tal especie.

Para terminar, los géneros y especies aquí descriptos se agrupan bajo los encabezados: Esporas, Granos de polen, Megasporas y Palinomorfos acuáticos.

A continuación se listan los taxones analizados, agrupados según el ordenamiento seguido en el trabajo:

\section{III.1.1. Lista taxonómica}

Anteturma SPORITES H. Potonié 1893

Turma TRILETES Reinsch emend.Dettmann 1963

Subturma AZONOTRILETES Luber emend. Dettmann 1963

Infraturma LAEVIGATI ( Bennie \& Kidston) Potonié 1956

Biretisporites cf. B. potoniaei Delcourt \& Sprumont 1955 
Biretisporites sp.A

Biretisporites sp.B

Biretisporites sp.C

Deltoidospora sp. A

Deltoidospora sp. B

Todisporites sp.A

Todisporites sp.B

Cyathidites patagonicus Archangelsky1972

Cyathidites sp. cf C. minor Couper 1953

Infraturma APICULATI Bennie \& Kidston emend.Potonié 1956

Ceratosporites sp.A

Ceratosporites sp. B

Concavissimisporites penolaensis Dettmann 1963

Concavissimisporites sp. A

Staplinisporites caminus (Balme) Pocock 1962

Retitriletes sp. A

Retitriletes douglasii Dettmann 1986

Espora apiculada gen. et sp. indeterminado

Subturma PERINOTRILITES Erdtman 1947

Lygodiidites sp. 1

Lygodiidites sp. 2

Auroraspora sp.

Espora perisporada gen. et sp. indeterminado

Turma ZONALES (Bennie \& Kidston 1886) Potonié 1956

Subturma ZONOTRILETES Waltz 1935

Infraturma CINGULATI Potonié \& Klaus 1954

Densoisporites velatus (Weyland \& Krieger) emend. Krasnova (ex. Dettmann, 1963)

Densoisporites corrugatus Archangelsky \& Gamerro, 1965

Foraminisporis dailyi (Cookson \& Dettmann) Dettmann 1963

Foraminisporis sp.

Contignisporites glebulentus (Dettmann) emend. Filatoff \& Price 1988

Contignisporites burgueri Filatoff \& Price 1988

Contignisporites cooksoniae (Balme) Dettmann 1963 
Infraturma TRICRASSATI Dettmann 1963

Gleichenïdites senonicus Ross 1949

Gleichenïdites sp.1

Gleicheniidites sp.2

Gleicheniidites sp.3

Gleicheniidites sp.4

Ornamentifera sp. 1

Ornamentifera sp. 2

Clavifera cf. C. triplex (Bolkh.) Bolkhovitina 1966

Turma MONOLETES Ibrahim 1933

Subturma AZONOMONOLETES Luber 1935

Infraturma LAEVIGATOMONOLETI Dybová \& Jachowicz 1957

Laevigatosporites ovatus Wilson \& Webster 1946

Laevigatosporites sp.

Infraturma SCULPTATOMONOLETI Dybová \& Jachowicz 1957

Reticuloidosporites sp. 1

Reticuloidosporites sp. 2

Reticuloidosporites sp. 3

Anteturma POLLENITES Potonié 1931

Turma ALETES Ibrahim 1933

Subturma AZONALETES Luber emend. Potonié \& Kremp 1954

Inaperturopollenites $\mathrm{sp}$.

Araucariacites australis Cookson ex Couper, 1953

Cyclusphaera psilata Volkheimer \& Sepúlveda, 1976

Cyclusphaera sp. A

Subturma MONOPORINES Naumova 1939

Balmeiopsis limbatus (Balme) Archangelsky 1977

Classopollis sp.

Turma SACCITES Erdtman 1947

Subturma DISACCITES Cookson 1947

Podocarpidites ellipticus Cookson, 1947

Podocarpidites marwickii Couper, 1953 
Microcachryidites antarcticus Cookson ex Couper, 1953

Microcachryidites sp. A

Trisaccites microsaccatus (Couper) Couper, 1960

Dacrydiumites sp.

Turma PLICATES Naumova 1939

Subturma MONOCOLPATES Iversen \& Troels-Smith 1950 Infraturma QUASILAEVIGATI Potonié 1970

Cycadopites nitidus (Balme) de Jersey 1964

Cycadopites sp. A

Clavatipollenites sp. A

Clavatipollenites sp. B

Monocolpopollenites sp.

Retimonocolpites sp. A

Retimonocolpites sp. B

Retiacolpites sp.

Asteropollis sp.

\section{MEGASPORAS}

Género Hughesisporites Potonié 1956

Hughesisporites cf. H. patagonicus Archangelsky 1965

Género Bacutriletes (Van der Hammen) Potonié 1956

Bacutriletes sp. 1

Género Horstisporites Potonié 1956

Horstisporites sp. 1

Género Erlansonisporites Potonié 1956

Erlansonisporites sp.

Género Apiculatisporites Ibrahim 1933

Apiculatisporites sp. 


\section{PALINOMORFOS ACUÁTICOS}

División Chlorophyta Pascher 1914

Clase Chlorophyceae Kützing 1843

Orden Chlorococcales Marchand orth. mut. Pascher 1915

Familia Botryococcaceae Wille 1909

Género Botryococcus Kützing 1849

Botryococcus sp.

Orden Zygnematales Borge \& Pascher 1931

Familia Zygnemataceae (Meneghini) Kützing 1898

Género Lecaniella Cookson \& Eisenack 1962

Lecaniella foveata Singh 1971

Género Schizosporis (Cookson \& Dettmann) Pierce 1976

Schizosporis reticulatus Cookson \& Dettmann 1959

Género Ovoidites (Cookson \& Dettmann) Nakoman 1966

Ovoidites parvus (Cookson \& Dettmann) Zippi 1998

Género Tetraporina Naumova emend. Lindgren 1980

Tetraporina sp. 1

Tetraporina sp. 2

Género Chomotriletes Naumova 1939 ex 1953

Chomotriletes minor (Kedves) Pocock 1970

Incertae Sedis

Género Retirotundia (Krutzsch) Zippi 1998

Retirotundia pseudoreticulata (Krutzsch) Zippi 1998

Formas inaperturadas gen. et sp. indeterminado

Inaperturado sp. 1

Inaperturado sp. 2

Inaperturado sp. 3 


\section{III.1.2. Descripciones Sistemáticas}

\section{III.1.2.1. Esporas}

Anteturma SPORITES Potonié 1893

Turma TRILETES Reinsch emend.Dettmann 1963

Subturma AZONOTRILETES Luber emend.Dettmann 1963

Infraturma LAEVIGATI ( Bennie \& Kidston) Potonié 1956

\section{Género Biretisporites (Delcourt \&Sprumont) \\ Delcourt, Dettman \& Hughes, 1963}

Especie tipo: B. potoniaei, Delcourt \& Sprumont 1955, pl. 42, figs. 12-14; pl. 44, fig. 11.

\section{Biretisporites cf. B. potoniaei Delcourt \& Sprumont 1955}

Lám. Ia

Descripción. Esporas triletes de contorno ecuatorial subtriangular con ángulos ampliamente redondeados o bien subcircular con la cara distal globosa. La lesura es recta acompañada por labios de un espesor variable, y un largo de 4/5 del radio. Las ramas de la lesura pueden verse con alguna sinuosidad, pero nunca en las tres de un mismo ejemplar. En los casos en que la exina está plegada, se observa que la lesura llega hasta el borde del contorno. Exina psilada, o bien ligeramente granular en la cara distal, debido a una corrosión incipiente.

Dimensiones. (13 ejemplares) Diámetro ecuatorial: 15,5 (18,5) 21,7 $\mu \mathrm{m}$; espesor de la exina: 0,40,9 $\mu \mathrm{m}$; ancho del labio: $0,7-1,2 \mu \mathrm{m}$; alto del labio: 0,9 $-2 \mu \mathrm{m}$.

Discusión y comparaciones. Posiblemente la forma aquí descripta sea una de las esporas con exina lisa más frecuentes de la Formación Punta del Barco. Es comparable a la especie tipo del género, pero no puede ser asignada a ella definitivamente por poseer un tamaño sensiblemente menor

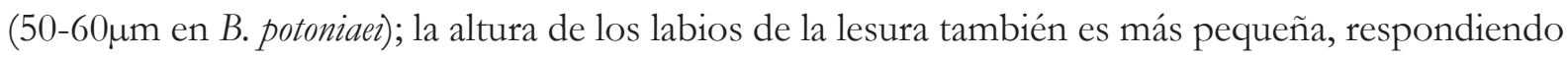
al tamaño y la relación diámetro ecuatorial/ altura del labio. Morfológicamente es muy similar a Biretisporites sp. de la Formación Springhill de Patagonia Austral (Baldoni \& Archangelsky, 1983),

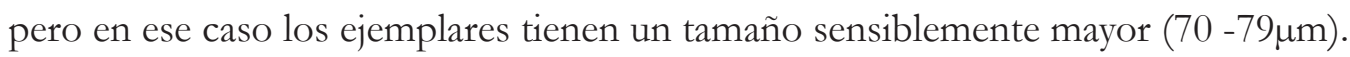

Material estudiado. PBN N1: Ba Pb Pal 5552, 5569, 5570, 5574 y 5575.

\section{Biretisporites sp.A}

Lám. Ib 
Descripción. Espora trilete lisa, de contorno ecuatorial subtriangular con los ángulos ampliamente redondeados. La cara distal es claramente convexa, mientras que la proximal se presenta en forma piramidal, con los rayos de la marca $\mathrm{Y}$ alcanzando el ecuador, acompañados por labios tenues, angostos y rectos.

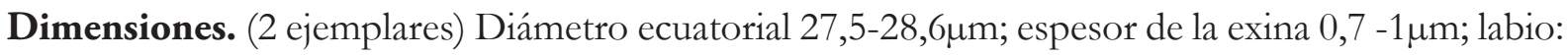
ancho $0,7 \mu \mathrm{m}$, alto $0,8 \mu \mathrm{m}$.

Discusión y comparaciones. Se incluye esta forma en el género Biretisporites por sus características generales, pero es imposible darle una asignación específica por diferir de las especies conocidas en sus dimensiones y por no contar con suficiente material (dos ejemplares) para una descripción completa.

Material estudiado. PBN N1: $\mathrm{Ba} \mathrm{Pb} \mathrm{Pal} 5552$.

\section{Biretisporites sp.B}

Lám. Ic

Descripción. Espora pequeña, biconvexa de contorno subtriangular a subcircular, de aspecto globoso. La lesura es levemente sinuosa, se extiende hasta el ecuador flanqueada por labios más o menos angostos y altos, razón por la cual se observan ondulaciones debidas a compresión.

Exina totalmente lisa en la mayoría de los casos, o bien con irregularidades por diferencia de espesor, probablemente producto de corrosión.

Dimensiones. Diámetro ecuatorial (10 ejemplares): 11,8 (18) 19,8 $\mu \mathrm{m}$; espesor de la exina (6

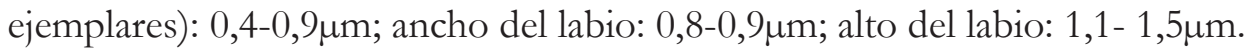

Discusión y comparaciones. Se incluye esta forma en el género por coincidir en los caracteres dados en la diagnosis enmendada por Delcourt et al.(1963). Existen similitudes con Biretisporites cf. B. potoniaei en Prámparo (1988), pero difiere en las dimensiones, que en ésta son mayores, y por poseer la lesura sinuosa llegando a los ángulos. Este último carácter se presenta en B. crassilabratus Archangelsky (1972) pero en ese caso, la lesura es recta. Por otro lado, B. potoniaei del Albiano de Oklahoma (Wingate, 1980), tiene un gran parecido y un tamaño también menor al de la especie tipo (34-50 $\mu \mathrm{m})$, pero no alcanza a ser tan reducido como en nuestro material.

Material estudiado. PBN N1: Ba Pb Pal 5566, 5552, 5577 y 5568. 


\section{Biretisporites sp. C}

Lám. Id

Descripción. Espora trilete biconvexa y globosa, de contorno ecuatorial circular. Lesura recta a levemente sinuosa, encerrada entre labios delgados y bajos, llegando hasta el ecuador. La exina es levigada en la mayoría de los casos, pero también puede aparecer scabrada; es muy delicada, por lo que se encuentra frecuentemente plegada.

Dimensiones. (20 ejemplares) diámetro ecuatorial: 15,4(20,5)27,5 $\mu \mathrm{m}$; espesor de la exina: 0,4-

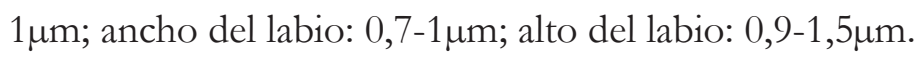

Comentarios. La morfología general de estas esporas es comparable con el género Todisporites, pero la presencia de un labio como carácter continuo para el conjunto, permite ubicarla dentro de Biretisporites. Si bien el número de ejemplares de este tipo es suficiente para proponer un nuevo taxón, se ha decidido no proponer una asignación específica por encontrar una marcada semejanza con el cuerpo central de una espora perisporada muy abundante en este nivel polínico, y que será descripta en una futura contribución. Aunque existe la posibilidad de que se trate de ejemplares incompletos, se considera conveniente describirlos y ubicarlos en un morfogénero que los caracterice.

Material estudiado. PBN N1: Ba Pb Pal 5551, 5552, 5566 y 5577.

Género Deltoidospora Miner 1935

Especie tipo: D. hallii, Miner 1935, p. 618, t. 24, fig.7.

Afinidad botánica. El hallazgo de estas formas estaría asociado con el de algunos helechos mesozoicos afines a las Familias Gleicheniaceae y Cyatheaceae (Balme, 1995; Jansonius \& Hills, 1976: 748).

\section{Deltoidospora sp.A}

Lám. Ie

Descripción. Espora trilete subtriangular de lados rectos y ángulos redondeados. Exina lisa; lesura simple de ramas rectas a levemente sinuosas que se extienden hasta el ecuador.

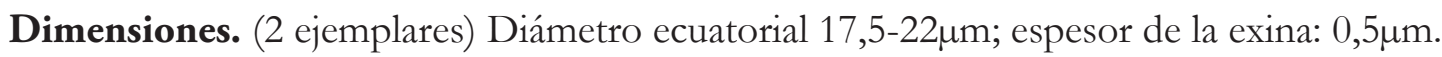


Discusión y comparaciones. Esta forma tiene una gran similitud con el género Leiotriletes, según la enmienda realizada por Potonié \& Kremp (1954) donde se dió como carácter diagnóstico para ese género una configuración piramidal de las facetas (Jansonius \&Hills, 1976: 1472). Sin embargo en los ejemplares aquí estudiados, esa configuración es deltoide, razón por la cual se asigna a Deltoidospora, sin poder darles un nombre específico por la escasés de material.

Material estudiado. PBN N1: $\mathrm{Ba} \mathrm{Pb} \mathrm{Pal} 5552$.

\section{Deltoidospora sp. B}

Lám. If

Descripción. Espora trilete de contorno subtriangular con lados convexos. Exina lisa en su superficie externa y rugosa en la interior. Lesura recta que se extiende casi hasta el ecuador.

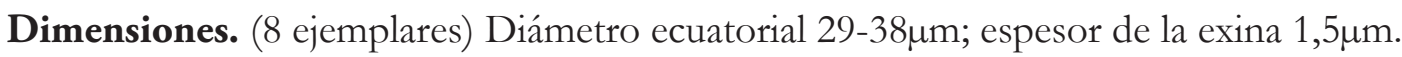

Material estudiado. PBN N3: MPEF Palin 61.

\section{Género Todisporites Couper 1958}

Especie tipo: Todisporites major Couper (1958)

Afinidad botánica. Fam. Osmundaceae (Balme, 1995).

\section{Todisporites sp.A \\ Lám. Ig}

Descripción. Espora biconvexa de cuerpo globoso y contorno ecuatorial circular. La marca trilete es recta y está acompañada de labios apenas insinuados, llegando cerca del ecuador. Exina lisa, delgada y muy delicada, que tiende a plegarse.

Dimensiones. (2 ejemplares) Diámetro ecuatorial: $22 \mu-24,2 \mu$; espesor de la exina: $0,5 \mu$.

Discusión y comparaciones. Si bien por la forma circular y naturaleza de la exina estas formas son atribuibles a este género, la presencia de labios incipientes es un carácter transicional con el género Biretisporites. No se cuenta con material suficiente para una asignación específica. 
Material estudiado. PBN N1: $\mathrm{Ba}$ Pb Pal 5551.

\section{Todisporites sp.B}

Lám. Ih

Descripción. Espora trilete marcadamente globosa, biconvexa y con contorno ecuatorial siempre circular. Exina psilada, hialina y bastante rígida. La lesura es poco conspicua, de ramas rectas que llegan hasta el ecuador y puede pasar al hemisferio distal, aparentando estar bifurcada en el extremo.

Dimensiones. (4 ejemplares) Diámetro ecuatorial: 16- 36 $\mu \mathrm{m}$; espesor de la exina: 0,7 -1 $1 \mu \mathrm{m}$.

Discusión y comparaciones. En rigor, no se ha encontrado en la bibliografía alguna forma comparable a esta. Sin embargo el escaso material, hace imposible proponer una diagnosis.

Material estudiado. PBN N1: Ba Pb Pal 5566 y 5552; PBS N4: MPEF Palin 56.

\section{Género Cyathidites Couper 1953}

Especie tipo: Cyathidites australis Couper 1953, p. 27, pl. 2, figs. 11 y 12.

Afinidad botánica. Se vincula este tipo de esporas con las Familias Gleicheniaceae, Dipteridaceae y Cyatheaceae (Balme, 1995).

\section{Cyathidites patagonicus Archangelsky1972}

\section{Lám. Ii}

1969. Cyathidites sp., Fasola: 14, lám. 3, fig.1.

1972. Cyathidites patagonicus, Archangelsky: 68, lám.1, fig. 4.

1988. Deltoidospora sp. A, Prámparo: 51, lám.1, figs. 1,4 y 6.

Descripción. Espora de contorno ecuatorial triangular, con lados levemente cóncavos y ángulos muy redondeados. La lesura es simple y bien delimitada, con ramas rectas que llegan hasta $2 / 3$ del radio. La exina es robusta, lisa a scabrada y está compuesta por dos capas.

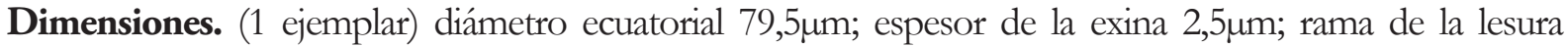
$28 \mu \mathrm{m}$. 
Discusión y comparaciones. Esta forma es igual a la descripta por Archangelsky (1972) para el Eoceno de la Formación Río Turbio de la provincia de Santa Cruz. Sin embargo, el hallazgo de un único ejemplar y el mal estado de su exina dan la pauta de que podría tratarse de material alterado, con modificaciones de su anatomía original, por lo que no se da una determinación cierta. La morfología coincide con el material asignado como Deltoidospora sp. A del Titoniano de la Cuenca Neuquina (Volkheimer \& Quattrocchio, 1975), aunque en ese caso las dimensiones son mucho mayores $(90-113 \mu \mathrm{m})$.

Distribución estratigráfica. Argentina: Eoceno de la Formación Río Turbio de la provincia de Santa Cruz (Archangelsky, 1972). Formación La Cantera -Aptiano de San Luis- asignado como Deltoidospora sp. A. (Prámparo, 1988). En el Albiano de la Cuenca Austral -Formación Kachaike- (A. Archangelsky \& Llorens, 2003).

Chile: Formación Lotena (Terciario Medio) asignado a Cyathidites sp. (Fasola, 1969).

Material estudiado. PBN N1: $\mathrm{Ba}$ Pb Pal 5555.

\section{Cyathidites sp. cf C. minor Couper 1953}

Lám. Ij

Descripción. Espora trilete de contorno ecuatorial triangular, de lados cóncavos y ángulos ampliamente redondeados. La lesura es simple y bien delimitada ,con ramas rectas que llegan hasta $2 / 3$ del radio. Exina gruesa, lisa a scabrada.

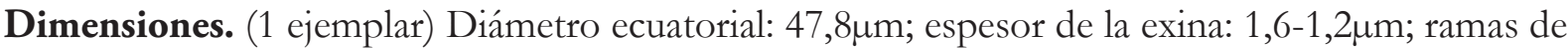
la lesura: $16,6-9 \mu \mathrm{m}$.

Discusión y comparaciones. Esta espora es muy semejante a las descriptas por Archangelsky (1972) para el Eoceno de Río Turbio en Santa Cruz como C.patagonicus, diferenciándose por el diámetro ecuatorial, ya que para esa forma oscila entre $70 \mu \mathrm{m}-90 \mu \mathrm{m}$,y nuestro ejemplar es considerablemente menor. Por otro lado, es muy semejante también a la especie tipo, con la que coincide en dimensiones, pero no así en el largo de la lesura, que en este caso es de $2 / 3$ del radio. La mayor afinidad se ha encontrado con C.minor Couper (1953),pero su diámetro es menor al mínimo citado para esa especie, y además tiene una exina más delgada $(1,2 \mu \mathrm{m})$ que la citada en ese caso, donde es de $1,5 \mu \mathrm{m}$. No es posible dar mayores aproximaciones dado que no se cuenta con un número suficiente de ejemplares.

Material estudiado. PBN N1: Ba Pb Pal 5571 y 5574. 
Infraturma APICULATI Bennie \& Kidston emend.Potonié 1956

Género Ceratosporites Cookson \& Dettmann 1958

Especie tipo: Ceratosporites equalis Cookson \& Dettmann 1958

\section{Ceratosporites sp.A}

Lám.IIa

Descripción. Espora trilete de contorno ecuatorial subtriangular, con lados convexos y ángulos ampliamente redondeados. La cara proximal es plana a subpiramidal y la distal marcadamente convexa. Lesura simple, de ramas rectas que se extienden hasta el borde ecuatorial. La exina es delgada -nunca sobrepasa los $0,8 \mu \mathrm{m}$ - y delicada. La ornamentación es lisa a suavemente scabrada en la cara proximal, en tanto la distal presenta espinas anchas en la base $(1-2,4 \mu \mathrm{m})$, que se angostan hacia el extremo, que se encuentra ocasionalmente curvado. Se disponen a una distancia entre sí de $3 \mu \mathrm{m}$ a $6 \mu \mathrm{m}$; están unidas en su base por muros bajos que forman un retículo discontinuo, que puede ser parcial o bien abarcar casi la totalidad de las espinas.

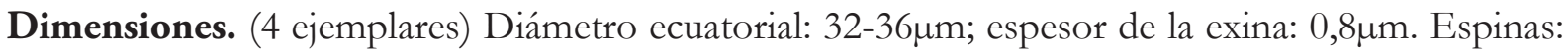

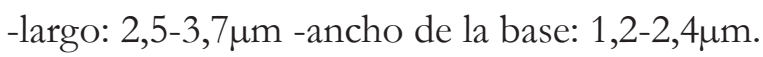

Discusión y comparaciones. Estas formas se incluyen en el género Ceratosporites, por responder al tipo de ornamentación con procesos conspicuos en la cara distal, y la cara proximal lisa. Existe una gran similitud con la especie tipo descripta en el trabajo citado anteriormente y con el material descripto para la Formación Baqueró (actual Anfiteatro de Ticó) por Archangelsky \& Villar de Seoane (1994), pero no pueden ser incluidos en ella por tener procesos más cortos y unidos, eventualmente en la base por muros bajos. Difieren también en que los ejemplares en estudio sólo presentan procesos equinados, sin báculas ni clavas; no poseen tampoco labios membranosos acompañando a la lesura. Por otra parte, en los ejemplares de la Formación Baqueró se describe la presencia de un muro que une las espinas por su base formando una corona en el ecuador, mientras que en este caso, si existe unión entre las espinas ecuatoriales, es una unión discontinua y poco conspicua.

Material estudiado. PBN N1: Ba Pb Pal 5552, 5556, 5558 y 5570.

\section{Ceratosporites sp. B}

Lám. IIb 
Descripción. Espora trilete muy pequeña, de contorno ecuatorial circular a subtriangular. Cara proximal lisa y plana con una exina muy delgada en ocasiones apenas perceptible, mientras que la distal es convexa y ornamentada con espinas y conos uniformemente dispuestos, pequeños, con una relación alto/ancho de la base cercana a 1. Lesura de ramas rectas que se extienden hasta el borde ecuatorial acompañadas por un labio tenue que en ningún caso supera $1 \mu \mathrm{m}$ de alto.

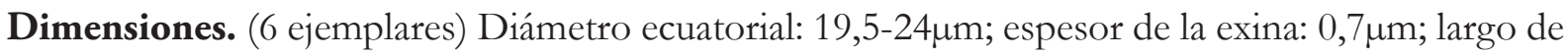
las espinas: $0,8-1,5 \mu \mathrm{m}$ y ancho: $0,6-1 \mu \mathrm{m}$.

Comparaciones. Esta forma se diferencia de Ceratosporites sp.A por su tamaño sensiblemente menor y por poseer elementos de la escultura aislados, sin muros que los conecten.

Material estudiado. PBN N1: $\mathrm{Ba} \mathrm{Pb} \mathrm{Pal} 5566,5570$ y 5574.

Género Concavissimisporites Delcourt \& Sprumont 1955

emend. Pocock 1965

Especie tipo: Concavissimisporites verrucosus Delcourt \& Sprumont 1955

\section{Concavissimisporites penolaensis Dettmann 1963}

Lám. IIc

1963. Concavissimisporites penolaensis Dettmann: 31, lám. III, fig. 13-16; fig. 4c.

1965. C. longiverrucosus Döring: pl. XI.

Descripción. Microspora trilete de contorno ecuatorial subtriangular con ángulos ampliamente redondeados y lados cóncavos. La lesura tiene ramas rectas que se extienden hasta $3 / 4$ del radio. Exina gruesa dividida en dos capas, la interna lisa y levemente engrosada en los ángulos $(0,8$ $1,1 \mu \mathrm{m})$, mientras que la externa es robusta, con un espesor uniforme o apenas aumentado en los ángulos. Esta capa se encuentra esculturada, con rúgulas que no sobrepasan los $0,8 \mu \mathrm{m}$ de alto, y su base oscila entre $1,5 \mu \mathrm{m}$ y $1,9 \mu \mathrm{m}$; su forma es irregular pero generalmente bastante isodiamétrica. Están dispuestas muy juntas y dejan muy poco espacio entre sí, simulando un retículo negativo.

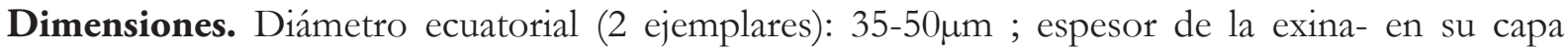

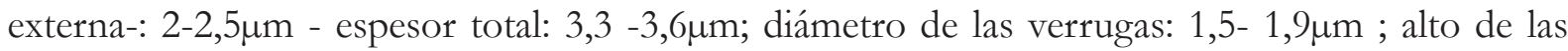
verrugas: $0,6-0,8 \mu \mathrm{m}$. 
Discusión y comparaciones. Se toma en consideración la enmienda que hace Pocock (Jansonius \& Hill, 1976: 550), donde amplía la diagnosis genérica a esporas con una ornamentación uniforme que varía desde subgranulosa a verrucosa. Aunque se cuenta sólo con dos ejemplares, la calidad de preservación ha permitido distinguir claramente todos los caracteres diagnósticos, pudiendo así incluir esta forma en C. penolaensis. Dettmann (1963), hace un completo análisis de sinonimias de este género, además de una comparación gráfica entre esta especie, C. verrucosus y C.crassatus. Hemos seguido este criterio para clasificar nuestro material. Cabe destacar la similitud en forma, tipo de lesura y ornamentación con la especie australiana, no así con respecto a las medidas, ya que la especie tipo tiene diámetro ecuatorial de $52-81 \mu \mathrm{m}$, mientras que nuestros ejemplares miden 35-50 $\mu \mathrm{m}$; también existen diferencias en el tamaño de las rúgulas, pero se mantiene la proporción ancho/alto, en relación al diámetro ecuatorial; esto puede deberse al proceso de preparación del material.

Afinidad botánica. Hay un cierto parecido con esporas de los géneros actuales Adiantum Linn. (Fam. Pteridaceae), Lygodium Sw. (Fam. Schizaceae) y la especie Dennstaedtia wercklei Ch. Try. (Fam. Dennstaedtiaceae).

Distribución estratigráfica. Cretácico Inferior de Australia.

Observaciones. Es la primera cita para Argentina.

Material estudiado. PBN N1: Ba Pb Pal 5568; PBS N2: MPEF Palin 64.

\section{Concavissimisporites sp. A}

Lám. IId

Descripción. Espora trilete de contorno ecuatorial triangular, con lados generalmente cóncavos, en ocasiones pueden ser rectos pero nunca los tres lados de un mismo ejemplar; los ángulos son redondeados. Lesura delimitada por un margo, con ramas rectas que llegan casi al borde ecuatorial. La exina está compuesta por dos capas, levemente engrosada en los ángulos; la ornamentación es finamente rugulada, siendo las rúgulas alargadas y anastomosadas entre si. Forman un retículo irregular fino dispuesto de manera uniforme en todo el cuerpo de la espora, con aréolas menores a $1 \mu \mathrm{m}$.

Dimensiones. (2 ejemplares) Diámetro ecuatorial:30,8 8 m - $40 \mu \mathrm{m}$; espesor de la exina en los lados: $1.4-1.6 \mu \mathrm{m}$ y en los ángulos: $2.2-2.4 \mu \mathrm{m}$. Ancho del margo: $1.1-2.6 \mu \mathrm{m}$. 
Comparaciones. Es semejante a C. Irroratus Pad. Phil. \& Fel., pero esa especie tiene elementos que no se fusionan (Paden Phillips \& Felix, 1971).

Material estudiado. PBN N1: $\mathrm{Ba} \mathrm{Pb}$ Pal 5503.

Género Staplinisporites Pocock 1962

Especie tipo: Cingulatisporites caminus Balme, 1957. Staplinisporites caminus (Balme) Pocock, 1962.

Staplinisporites caminus (Balme) Pocock 1962

Lám. IIg.

Dimensiones. (3 ejemplares). Diámetro ecuatorial: $34-38 \mu \mathrm{m}$; espesor de la exina: 0,8 $-1 \mu \mathrm{m}$; diámetro del engrosamiento en el polo distal: 8-8,5 $\mu \mathrm{m}$.

Discusión y comparaciones. El presente material muestra similitud con los ejemplares descriptos para el Jurásico de Cuenca Neuquina (González Amicón \& Volkheimer, 1982), para la Formación Springhill (Cretácico Inferior) en Baldoni \& Archangelsky (1983), y con un ejemplar citado para la subyacente Formación Anfiteatro de Ticó (Archangelsky \& Villar de Seoane, 1996).

Afinidad botánica. Guarda afinidad con las esporas de la briofita actual Encayipta ciliata Herd. (Dettmann, 1963).

Material estudiado. PBN N1: Ba Pb Pal 5569 y 5574.

\section{Género Retitriletes Pierce 1961}

Especie tipo. Retitriletes globosus Pierce 1961

\section{Retitriletes sp. A}

Lám. IIe

Descripción. Espora trilete de contorno ecuatorial subtriangular de ángulos ampliamente redondeados y lados convexos. Las ramas de la lesura son rectas y alcanzan hasta casi el margen ecuatorial. Cara proximal plana y levigada, mientras que la distal es cóncava y está ornamentada 
por muros robustos e irregulares que se anastomosan formando un retículo denso con lúminas poligonales a subcirculres; en las intersecciones los muros están más elevados.

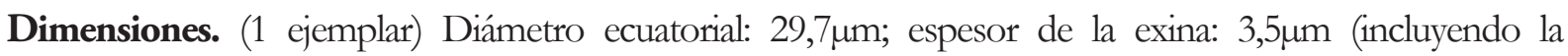

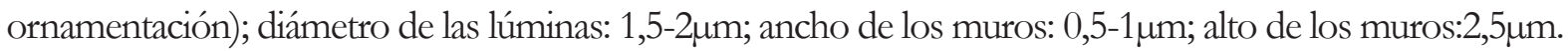

Material estudiado. PBN N1: $\mathrm{Ba} \mathrm{Pb}$ Pal 5564.

\section{Retitriletes douglasii Dettmann 1986}

Lám. IIf

1963. Lycopodiumsporites reticulumsporites (auct. non Rouse) Dettmann: 45, pl. 7, fig. 4. 1975. Lycopodiumsporites reticulumsporites Filatoff: 53, pl. 7, figs. 9-11 y pl. 8, fig. 3 ayb. 1986. Retitriletes douglasii Dettmann: 96, fig. 6 ay b.

Descripción. Espora trilete de contorno ecuatorial subtriangular, con ángulos ampliamente redondeados y los lados convexos. Cara distal convexa y proximal plano-convexa. La primera está totalmente ornamentada por muros que forman un retículo bien definido, con celdas pentahexagonales de diámetros bastante uniformes, mientras que sobre la segunda se extienden los muros desde el ecuador en forma radial hacia el polo. En este caso, hay diferencias en cuanto a la extensión de los mismos, ya que pueden prolongarse cortamente dejando casi la totalidad de la cara proximal sin ornamentación o bien extenderse hasta cerca del polo; en ningún caso alcanza a la lesura. En este último caso los muros radiales pueden anastomosarse formando algún lúmen de forma indefinida y diámetro mayor al de los distales, extenderse libremente hasta la zona polar psilada o bien converger en otro muro que demarca esa zona polar. La lesura es simple o muy raramente con un labio tenue y se extiende hasta 3/4 del radio. Los muros son anchos en su base y angostos en el extremo.

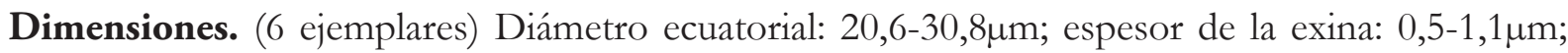

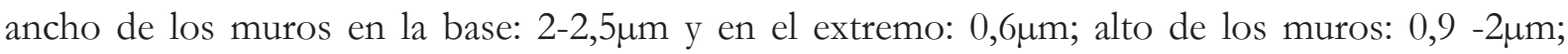

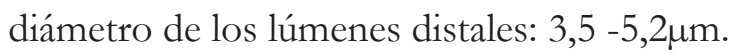

Discusión y comparaciones. Se asemeja al subgen. Clavatisporis Krutzsch 1963, pero no es tan reticulado en la cara proximal y los muros son más bajos (Jansonius \& Hills, 1976: 2405).

Distribución estratigráfica. ?Barremiano-Aptiano de Australia (Dettmann, 1986b). Es la primera mención para Argentina.

Material estudiado. PBN N1: Ba Pb Pal 5552, 5566, 5570, 5569 y 5572; PBS N2: MPEF Palin 66. 


\section{Espora apiculada gen. et sp. indeterminado}

Lám. IIh-i

Descripción. Espora trilete de contorno ecuatorial circular-subcircular. Lesura de ramas rectas con labios llegando al ecuador. La esculturación de la exina está bien diferenciada en ambas caras; la cara proximal es micropunteada con una puntuación densa y regular en toda la superficie, mientras que la cara distal se encuentra cubierta por papilas de base ancha (alrededor de 5,5 $\mu \mathrm{m}$ ) y $3.2 \mu \mathrm{m}$ de alto. Estas consisten de domos formados por la exina, que tiene un grosor uniforme $(0,8 \mu \mathrm{m})$ en toda la superficie, dando a este tipo de esculturación un aspecto de "ampollas" que forman un anillo en el ecuador y otro concéntrico a éste.

Dimensiones. (1 ejemplar). Diámetro ecuatorial: 31,2 $\mu \mathrm{m}$. Ramas de la lesura: 13,8 $\mu \mathrm{m}$; espesor de la exina: $0,8 \mu \mathrm{m}$. Ancho de la base de las papilas: 5,6 $\mu \mathrm{m}$; alto de las papilas: 3,2 $\mu \mathrm{m}$.

Observaciones. No ha podido ser asignado a un morfogénero descripto dado que no ha podido definirse su tipo de esculturación. Estas estructuras presentan la particularidad de no ser verrugas en el sentido estricto del término, ya que no se presentan como engrosamientos de la exina.

Material estudiado. PBN N1: $\mathrm{Ba} \mathrm{Pb} \mathrm{Pal} 5557$.

Subturma PERINOTRILITES Erdtman 1947

Género Lygodiidites Pocock 1965

Especie tipo. Lygodiidites laevigatus Pocock 1965

Afinidad botánica. El género es usado para incluir esporas de Lygodium flexuosus y esporas dispersas similares (Jansonius \& Hills, 1976: 1552).

\section{Lygodiidites sp. 1}

Lám. IIIa-b

Descripción. Espora perisporada trilete. Cuerpo subtriangular de lados ligeramente convexos a rectos y ángulos redondeados. La exina es lisa y la lesura muy poco visible, simple y de ramas rectas que se extienden hasta la mitad del radio. La perina es laxa, finamente granular, desprendida 
totalmente del cuerpo interno excepto en la lesura., y con pliegues en el borde que le dan un aspecto crenulado.

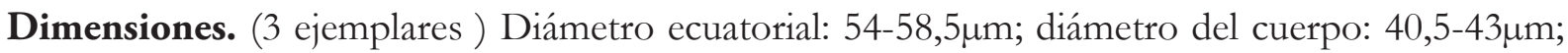

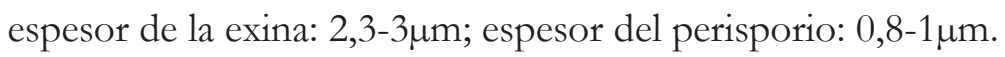

Material estudiado. PBN N1: BA Pb Pal 5558.

\section{Lygodiidites sp. 2}

Lám. IIIc

Descripción. Espora trilete con perina, de contorno ecuatorial subtriangular, lados convexos y ángulos ampliamente redondeados; cara proximal piramidal y distal hemisférica. Exina bastante gruesa y levigada de espesor irregular. La lesura se extiende hasta el borde ecuatorial encerrada entre labios fuertes y sinuosos. La perina consiste en un velo que no guarda relación alguna con la forma del cuerpo y se despliega totalmente desprendida de éste.

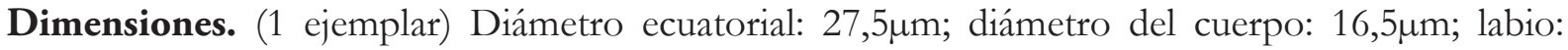
$1,5 \mu \mathrm{m}$.

Material estudiado. PBN N1: BA Pb Pal 5577.

Género Auroraspora Hoffmeister, Staplin \& Malloy 1955

Especie tipo. Auroraspora solisortus H. S. \& M. Ibid. Pl. 37, fig. 3.

\section{Auroraspora sp.}

Lám. IIId

Descripción. Espora trilete de contorno triangular, con lados rectos a levemente cóncavos y ángulos fuertemente redondeados. Exina lisa de espesor uniforme excepto en el polo proximal donde aparecen 3 engrosamientos circulares a modo de papila. Lesura simple muy tenue, que se extiende con ramas rectas hasta $1 / 2$ del radio. Perina lisa, muy delgada y hialina que se encuentra unida al cuerpo central sólo en la lesura; presenta pliegues muy finos y delicados que se ubican radialmente en la cara proximal y se vuelven más abundantes en el borde, dándole un aspecto crenulado. 
Dimensiones. (1 ejemplar) Diámetro total: $51 \mu \mathrm{m}$; diámetro del cuerpo: $33 \mu \mathrm{m}$; espesor de la exina: $0,8 \mu \mathrm{m}$.

Discusión y comparaciones. Esta forma se incluye en el género Auroraspora por presentar la perina unida al cuerpo central en la región proximal, a partir de la cual se ubican los pliegues radiales, a diferencia de Lygodiidites donde esa disposición cercana de ambas capas resulta en un plegamiento corrugado. Esta espora es semejante en algunos caracteres -como las papilas apicales- a Densoisporites velatus, pero la sexina no presenta la estructura esponjosa que lo caracteriza.

Material estudiado. PBN N1: BA Pb Pal 5500.

\section{Espora perisporada gen. et sp. indeterminados}

Lám. IIIe-h

Descripción. Espora trilete de contorno circular y en menor medida subtriangular de ángulos ampliamente redondeados, exina lisa y lesura acompañada de un labio no siempre visible, de ramas rectas que se extienden hasta el ecuador. Perina globosa totalmente desprendida del cuerpo que puede encontrarse secundariamente plegada. Su ornamentación es muy variable y está conformada por placas de forma y espesor irregulares. En algunos casos estas placas son grandes y prominentes y se observa en ellas una mayor o menor concentración de perforaciones menores a $1 \mu \mathrm{m}$ que no siguen un patrón definido en su disposición. En otros casos, las placas se tornan difusas o quedan reducidas a muros que se fusionan formando un retículo discontínuo e irregular. En la unión entre ellos, hay conos, báculos y crestas. También aparecen ejemplares con una ausencia total de las placas, sumado a un espesor menor de esta capa, con una estructura compuesta por pequeños conos aislados de base irregular.

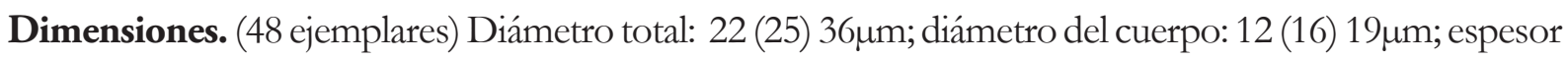

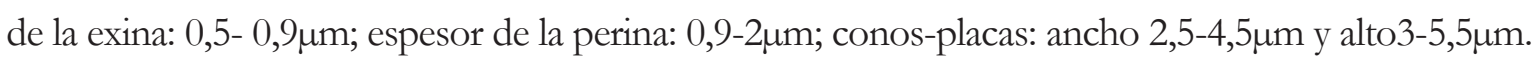

Observaciones. Todos los ejemplares fueron rescatados de dos muestras próximas tomadas en el muestreo lateral de un mismo nivel polínico. Esto, sumado a la forma del cuerpo central, y a la rigidez de la perina, son los criterios que se tuvieron en cuenta para considerarlos como un único grupo con variaciones morfológicas. Estas variaciones parecen responder a un proceso de maduración de la espora, y consiste en la desaparición gradual de las placas que cubren a la perina, pasando por etapas intermedias hasta la desaparición total de ellas, quedando en superficie su estructura interna. Las placas parecen ser más grandes y de mayor grosor en un estadío temprano del desarrollo de 
la espora. En ese momento del desarrollo es cuando se observan las perforaciones sobre ellas, luego éstas quedarían reducidas a muros con conos, báculos y crestas entre su fusión, formando retículos discontinuos e irregulares. El último estadío estaría representado por una perina delgada ornamentada con pequeños conos de bases irregulares que pueden estar conectadas formando un retículo tenue. Acompañando estos caracteres, se observa una correlación entre el espesor de la exina y la separación entre el cuerpo central y la perina: la primera disminuye mientras la segunda aumenta con la maduración.

Comparaciones. El género más afín a este tipo perisporado, es Retispora Staplin, por la consistencia y ornamentación externa de la perina, aunque no incluye conos o "placas" como aparecen en este caso, y el cuerpo central no tiene labios. Otra forma con la perina ornamentada es Calyptosporites Richardson, con conos y espinas bifurcadas en su extremo, además de pliegues que acompañan a las ramas de la lesura, caracteres éstos ausentes en nuestros ejemplares. El resto de las formas perisporadas presentan una perina lisa a escabrada.

Material estudiado. PBN N1: BA Pb Pal 5500, 5552, 5569, 5574 у 5577.

Turma ZONALES (Bennie y Kidston 1886) Potonié 1956

Subturma ZONOTRILETES Waltz 1935

Infraturma CINGULATI Potonié y Klaus 1954

Género Densoisporites (Weyland \& Krieger, 1953)

emend. Dettmann, 1963.

Especie tipo. Densoisporites velatus. Weyland \& Krieger, 1953.

Afinidad botánica. Clase Lycopsida (Balme, 1995).

Densoisporites velatus (Weyland \& Krieger) emend. Krasnova

(ex. Dettmann, 1963)

Lám. IVa

1953- Densoisporites velatus, Weyland \& Krieger: 12, lám.IV, figs. 12-14.

1958- D.perinatus, Couper: 145, lám.XXIII, figs.6-9.

1963- D. microrugulatus, Brenner: 61,lám. XV, fig. 6- lám. XVI, fig. 1. 
1965- D. velatus (Weyland \& Krieger) emend. Krasnova, Archangelsky \& Gamerro: 162, lám. 1-4. 1967- D. velatus (Weyland \& Krieger) emend. Krasnova, Archangelsky \& Gamerro: 212, lám. I, fig. C. 2003- D. velatus (Weyland \& Krieger) emend. Krasnova, A. Archangelsky \& Llorens: 76, fig. 2J

Descripción. Espora trilete de contorno subtriangular a circular y lados convexos; cara distal convexa y proximal subcónica. La lesura varía en extensión y nitidez, pudiendo ser poco visible o, en los casos donde es más evidente, presentar un engrosamiento. Las ramas son levemente sinuosas y se extienden hasta el borde interno del cíngulo. Exina compuesta por dos capas con una separación variable entre ellas, excepto en la cara proximal. La interna es de un espesor homogéneo en toda su superficie, o bien puede presentar tres engrosamientos circulares o elípticos cerca del polo proximal; la capa externa tiene una textura microalveolar, y se encuentra engrosada a nivel del ecuador. Los alvéolos son más amplios en la cara distal que en la proximal, y son elongados y de mayor tamaño aún en el cíngulo, dándole a éste un aspecto estriado-esponjoso. Frecuentemente el cíngulo se encuentra engrosado en los ángulos.

Dimensiones. Diámetro ecuatorial: (77 ejemplares) 26,7 (30) 75 $\mu \mathrm{m}$; diámetro del cuerpo

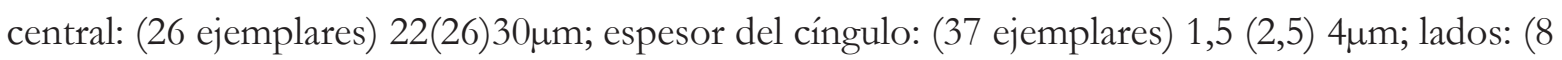
ejemplares) 2 (2,6) $4 \mu \mathrm{m}$, ángulos $3(4,5) 5,3 \mu \mathrm{m}$.

Observaciones. Cabe destacar el amplio rango de tamaños observados en este material. No obstante, a partir de los $48 \mu \mathrm{m}$, solo se registran unos pocos ejemplares de las medidas mayores, concentrándose la moda dentro de un rango reducido $(30-34 \mu \mathrm{m})$.

Discusión y comparaciones. El género Densoisporites fue enmendado por Dettmann (1963), quien agregó como carácter diagnóstico la presencia de tres engrosamientos (papilas) en la capa interna de la exina, cerca del polo proximal; a tal respecto, Archangelsky \& Gamerro (1965) aclaran para su material de la Formación Baqueró, que estas papilas no siempre son visibles, situación que se repite en este trabajo. En comparación con los ejemplares estudiados por estos autores para la unidad basal de este Grupo, las medidas del presente material son considerablemente menores. Es así que el diámetro ecuatorial varía de $40-80,5 \mu \mathrm{m}$ a $26,7-75 \mu \mathrm{m}$ en los especímenes de la unidad basal y la

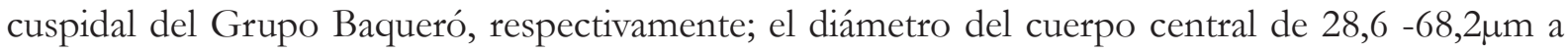

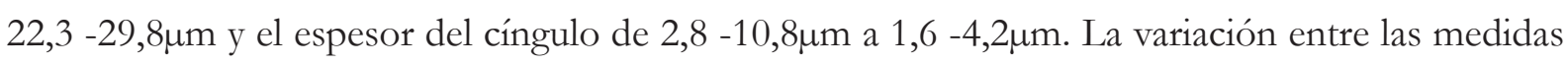
puede deberse a las técnicas de preparación utilizadas en cada caso, y también a la naturaleza esponjosa de la exina.

Material estudiado. PBN N1: BA Pb Pal 5500, 5501, 5503, 5550, 5551, 5552, 5557, 5555, 5558, 5567, 5568, 5569, 5572 y 5574; N3: MPEF Palin 60 y 61. 


\section{Densoisporites corrugatus Archangelsky \& Gamerro, 1965}

Lám. IVb-c, e

1965- D. corrugatus Archangelsky \& Gamerro: 163, lám. II, figs. 1-11

2003- D. corrugatus Archangelsky \& Gamerro, A. Archangelsky \& Llorens: 76, fig. 2K

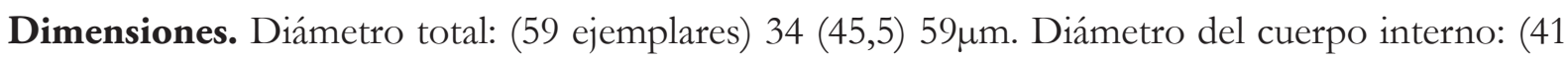

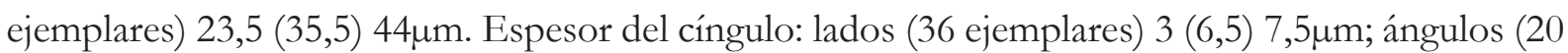
ejemplares) 3 (5,5) $7 \mu \mathrm{m}$. Diámetro polar: (1 ejemplar) $34 \mu \mathrm{m}$.

Discusión. Si bien esta forma coincide con la descripta por Archangelsky \& Gamerro (1965) para la Formación Baqueró , cabe mencionar algunos aspectos diferentes que presenta este material.

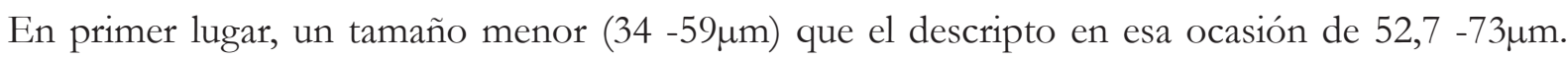
También en este caso, la variación en el diámetro puede deberse en parte a las técnicas originales de preparación, más oxidantes que las actuales. Por otra parte, se menciona un ensanchamiento del cíngulo en los ángulos; en este aspecto, el material es muy variable, pudiendo presentarse sin ensanchamientos o bien con los lados más anchos.

Observaciones. En la diagnosis original se da como carácter diagnóstico la presencia de tres engrosamientos circulares o elípticos (papilas) de la capa interna de la exina en el polo proximal; este carácter está presente en nuestro material sólo en un 50\% de los casos.

Distribución estratigráfica. Para la Cuenca Austral, esta forma se encuentra citada para las formaciones Anfiteatro de Ticó (Aptiano) y Kachaike (Albiano); en tanto, para la Formación La Cantera sólo figura en una nómina (Prámparo, 1988).

Material estudiado. PBN N1: BA Pb Pal 5500, 5501, 5503, 5550, 5557, 5564, 5567, 5568, 5569, 5572 y 5574; N3: MPEF Palin 60 y 61; N4: MPEF Palin 62.

Género Foraminisporis Krutzsch 1959 (sensu Dettman 1963)

Especie tipo. Foraminisporis foraminis Krutzsch 1959

Foraminisporis dailyi (Cookson \& Dettmann) Dettmann 1963 Lám. IVf

1966- Foraminisporis dailyi (Cookson \& Dettmann) Dettmann; Archangelsky \& Gamerro: 204, lám. II, fig.1-3. 
1974- F. dailyi (Cookson \& Dettmann) Dettmann; Burger, lám. 14, fig. 10.

2003- F. dailyi (Cookson \& Dettmann) Dettmann, A. Archangelsky \& Llorens: 76, fig. 2I

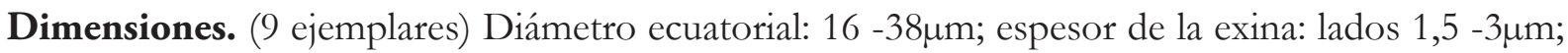
espesor capa interna de la exina: $0,5-1 \mu \mathrm{m}$.

Material estudiado. PBN N1: BA Pb Pal 5566 y 5577; N3: MPEF Palin 60; PBS N4: MPEF Palin 57 y 58.

\section{Foraminisporis sp.}

Lám. IVd

Descripción. Espora trilete cingulada de contorno ecuatorial subcircular. La lesura es simple, porta algunos gránulos pequeños sólo observables cuando está cerrada; se extiende hasta el ecuador, abarcando también el cíngulo. Este último es angosto y presenta unas pocas fósulas dispuestas ampliamente y de manera irregular.

Exina con dos capas, la interna de un espesor uniforme; la externa bastante lisa, sólo con algunos gránulos dispersos y desordenados de no más de $0,6 \mu$ de base.

Dimensiones. (2 ejemplares): diámetro ecuatorial 22,5 -27,5 $\mu \mathrm{m}$; espesor de la capa interna de la

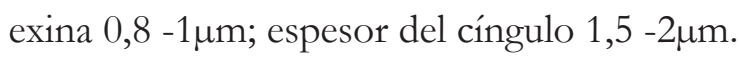

Discusión y comparaciones. Dettman (1963) considera que el engrosamiento de la exina en el ecuador es, a diferencia de la diagnosis original, un carácter distintivo; aunque no es fácilmente distinguible de no ser en ejemplares que se encuentren en una vista netamente polar. También destaca que los ejemplares australianos sólo adquieren esa posición en preparados microscópicos montados en un $50 \%$ de glicerina.

Por tanto considero que esta forma, al presentar esa característica debe ser incluída en este género, sin poder llegar a una asignación específica a causa del escaso número de ejemplares recuperados. La similitud más cercana se encontró con F. dailyi (Cookson \& Dettmann) Dettmann, 1963 con la que se diferencia por carecer de labios y gránulos tanto en la cara distal, como en la proximal.

Material estudiado. PBN N1: BA Pb Pal 5552 y 5566. 


\section{Género Contignisporites Dettman 1963 emend. Filatoff \& Price 1988}

\section{Especie tipo. Contignisporites glebulentus Dettmann 1963}

Observaciones. Para las tres especies del género Contignisporites citadas, existe una diferencia en las dimensiones con respecto a las diagnosis originales, siempre son medidas menores, pero no han sido consideradas como un carácter distintivo por ser una situación que se repite en varios taxones. Sin embargo cabe destacar que también existen diferencias en la medida $\Delta$-ratio, a pesar de que, como ha sido indicado por J. L. McKellar (referencia tomada de Filatoff \& Price,1988), tiende a compensar la variabilidad intrapoblacional y los cambios influenciados por las condiciones postdepositacionales. Este valor representa el cociente entre diámetro ecuatorial y la suma de 4 muros más sus respectivas zonas de separación.

Afinidad botánica. Dentro de las formas actuales se encuentra una afinidad con las esporas del género Pityrogramma Link (Fam. Pteridaceae) (Tryon \& Lugardon, 1990: 129 fig 34)

\section{Contignisporites glebulentus (Dettmann) emend. Filatoff \& Price 1988 Lám. IVi}

1963- Contignisporites glebulentus Dettmann; Dettmann: 74, pl. XV, fig. 1-10; Fig. 5.

1988- C. glebulentus Dettmann; Filatoff \& Price: fig. 7 E-P. (Ver en este trabajo la sinonimia completa)

2003- C. glebulentus (Dettmann) emend. Filatoff \& Price, A. Archangelsky \& Llorens: 76, fig. 3 A

Descripción. Espora trilete de contorno ecuatorial triangular-subcircular. La simetría en la cara proximal es radial, mientras que distalmente es bilateral. Cara proximal plana a levemente convexa, con una ornamentación que consta de engrosamientos tangenciales elongados a lo largo del borde interno del cíngulo en cada una de las áreas de contacto, extiéndose desde una lesura a la otra; el resto de las facetas presenta verrugas raramente aisladas y en la mayoría de los casos fusionadas en pulvínulos que acompañan la lesura cerca del polo. El ecuador está surcado por un cíngulo liso de un ancho uniforme o ligeramente ensanchado en los ángulos, que se presentan más elevados. La cara distal fuertemente convexa, presenta una serie de 9 a 11 muros que nacen en el borde del cíngulo y se extienden en forma paralela o subparalela a ésta, pudiendo ocasionalmente bifucarse, y a menudo se anastomosan antes de fusionarse nuevamente con el cíngulo en el ángulo opuesto.

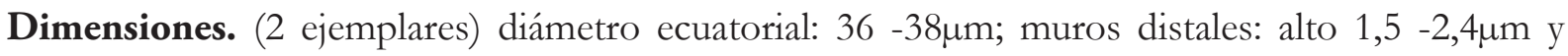

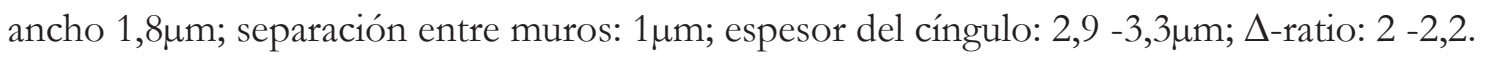


Distribución estratigráfica. Ampliamente distribuída entre el Jurásico Medio y el Cretácico Superior de Gondwana (Sajjadi \& Playford, 2002a).

Material estudiado. PBN N1: BA Pb Pal 5577.

\section{Contignisporites burgueri Filatoff \& Price 1988}

$$
\text { Lám. IVg-h }
$$

1966- C. cooksonii (Balme) Dettmann; Archangelsky \&Gamerro: 205, lam.II figs. 9-12

1975- C. cooksonii (Balme) Dettmann; Volkheimer \& Quattrocchio: 218, lam. III, fig 7-8

1983- C. cooksonii (Balme) Dettmann, Baldoni \& Archangelsky: 65, lám. 4, figs. 5y6

1988- Contignisporites burgueri Filatoff \& Price: Fig. 8 A-H

2003- C. burgueri Filatoff \& Price, A. Archangelsky \& Llorens: 76, fig. 3 B

Descripción. Espora trilete de contorno ecuatorial triangular-subcircular-oval. La simetría en la cara distal es bilateral y definida por un plano de simetría que incluye al eje polar y es paralelo o subparalelo a una de las ramas de la lesura. Cara proximal plana a levemente convexa, con una ornamentación que consta de engrosamientos tangenciales elongados a lo largo del borde interno del cíngulo en cada una de las áreas de contacto, extiéndose desde una lesura a la otra; el resto de las facetas presenta verrugas raramente aisladas y en la mayoría de los casos fusionadas en pulvínulos que acompañan la lesura cerca del polo. Cíngulo liso y con un ancho uniforme o ligermente ensanchado en los ángulos, que se presentan más elevados. La cara distal fuertemente convexa, presenta una serie de 6 a 9 muros paralelos que nacen en el borde del cíngulo en el lado opuesto a la rama de la lesura que coincide con el plano de simetría, se extienden en forma paralela o subparalela a ésta, pudiendo ocasionalmente bifucarse, y a menudo se anastomosan antes de fusionarse nuevamente con el cíngulo en el ángulo opuesto.

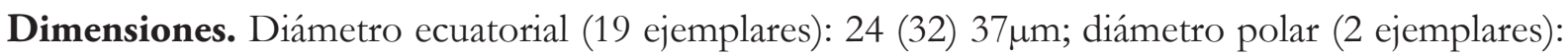

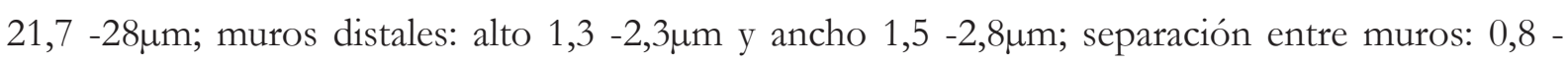
3,2 $\mu \mathrm{m}$; espesor del cíngulo: $2(2,7) 4 \mu \mathrm{m} ; \Delta$-ratio: 1,8-3,6.

Discusión y comparaciones. Como ya se ha señalado en las observaciones para el morfogénero, los ejemplares de esta especie presentan tamaños y medidas menores a los descriptos anteriormente. Esa situación es particularmente notoria en esta especie, dado que se han encontrado más individuos que en las otras y todo el conjunto es muy homogéneo en sus dimensiones.

En cuanto a la ocurrencia, ha sido reportada como C. cooksonii por Baldoni \& Archangelsky (1988) para la Fm. Springhill, quienes presentaron una ilustración en la que se observan claramente los 
elementos esculturales de las facetas proximales. A. Archangelsky \& Llorens (2005) lo reportan formalmente por primera vez para el país. Sajjadi \& Playford (2002a) describen un rango que va del Jurásico Medio al Cretácico Superior de Australia.

Material estudiado. PBN N1: BA Pb Pal 5569, 5572, 5574, 5575 y 5577.

\section{Contignisporites cooksoniae (Balme) Dettmann 1963}

Lám. IVj

1963- Contignisporites cooksonii Balme; Dettmann: 75, pl. XV, fig. 11-16.

1983- C. cooksonii (Balme) Dettmann: 64, lam.IV, figs. 4-6

1988- C. cooksoniae (Balme) Dettmann; Filatoff \& Price: fig. 7 E-P.(Ver en este trabajo la sinonimia completa)

2003- C. cooksoniae (Balme) Dettmann, A. Archangelsky \& Llorens: 78, fig. 3C

Descripción. Espora trilete de contorno ecuatorial subcircular - oval. La simetría en la cara proximal es radial a bilateral, mientras que distalmente es bilateral. Cara proximal plana a levemente cóncava, con engrosamientos tangenciales a lo largo del borde interno del cíngulo y sin ornamentación en las áreas de contacto. El ecuador está surcado por un cíngulo liso de un ancho uniforme o ligeramente ensanchado en los ángulos, que ocasionalmente se presentan más elevados. La cara distal fuertemente convexa, presenta una serie de 6 a 9 muros que nacen en el borde del cíngulo y se extienden en forma paralela o subparalela a ésta, pudiendo ocasionalmente bifucarse, y a menudo se anastomosan antes de fusionarse nuevamente con el cíngulo en el ángulo opuesto.

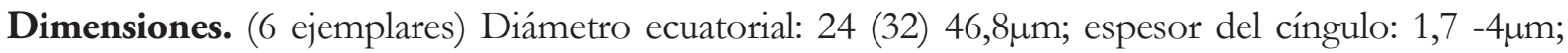

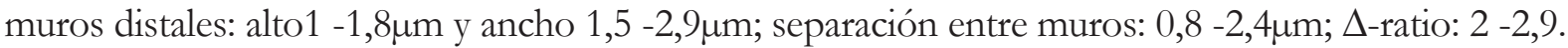

Distribución. En Argentina esta especie fue descripta previamente por Volkheimer \& Quattrocchio (1975) para el Jurásico de la cuenca Neuquina y por Archangelsky \& Gamerro (1966a) para el Grupo Baqueró del Cretácico Inferior de Santa Cruz. Presente en el Cretácico de Australia (Filatoff \& Price, 1988).

Material estudiado. PBN N1: BA Pb Pal 5568, 5572, 5574 y 5577. 
Observaciones. Este es un grupo con características morfológicas de difícil interpretación. Se han hallado en la literatura visiones taxonómicas dispares para el grupo, pero en este trabajo se ha decidido continuar con la clasificación realizada por Bolkhovitina (1967), que es lo suficientemente amplia para incluir a todas las formas presentes. Si bien esa autora encuentra que los pliegues distales son caracteres presentes en las esporas fósiles y actuales de la Familia Gleicheniaceae, he considerado -habiendo observado abundante material- que en ocasiones responden también a factores de la depositación y compresión de los individuos, por lo que no ha sido considerado en la segregación de especies.

Género Gleicheniidites Ross ex Delcourt \& Sprumont 1955

Especie tipo: Gleicheniidites senonicus Ross 1949.

Afinidad botánica. Pteridophyta, Familia Gleicheniaceae (Bolkhovitina,1967).

Gleicheniidites senonicus Ross 1949

Lám. Va-d

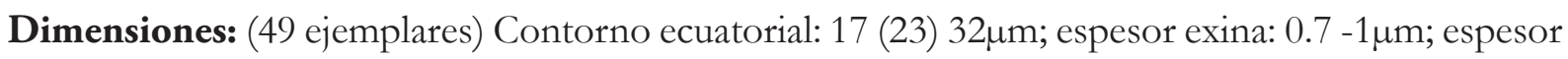
engrosamientos interradiales: $1,5-3 \mu \mathrm{m}$.

Comentarios: Se incluyen aquí ejemplares con los márgenes lobados en distinta medida, aunque sin alcanzar a ser serrados, por lo que se diferencian de G. serratus Archangelsky \& Llorens, descripta para la Fm. Kachaike (Archangelsky \& Llorens, 2005). Esta especie es cosmopolita y en Argentina está ampliamente distribuida en el Cretácico y Paleógeno.

Afinidad botánica: Familia Gleicheniaceae.

Material estudiado: PBN N1: BA Pb Pal 5500, 5501, 5551, 5552, 5565, 5566, 5569, 5570, 5574, 5575; PBN N3: MPEF Palin 60, N4: MPEF Palin 62 y PBS N5: MPEF Palin 63 y 65.

\section{Gleicheniidites sp.1}

Lám. Vb-c, e 
Descripción. Espora pequeña de contorno triangular y exina lisa. Cara proximal con lados levemente cóncavos a rectos y ángulos agudos; mientras la distal tiene lados cóncavos y ángulos que rematan en una línea recta que une los extremos de los espesamientos de la exina. Lesura recta con labios altos y robustos que alcanzan el ecuador. Engrosamientos interradiales prominentes, que en ocasiones presentan su margen externo ondulado.

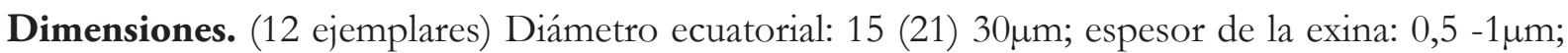

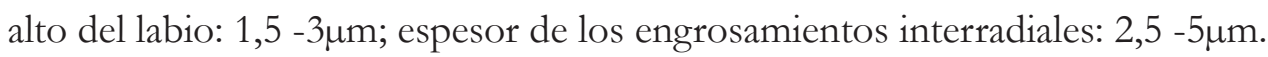

Comparaciones. El carácter más distintivo de esta especie es la forma de su cara distal, que la separa del resto de las especies.

Material estudiado. PBN N1: BA Pb Pal 5500, 5501, 5552, 5566, 5570 y 5574.

\section{Gleicheniidites sp.2}

Lám. Vf

Descripción. Espora de contorno triangular, con ángulos redondeados y lados ligeramente convexos. Exina rígida y lisa. La cara proximal es levemente piramidal y la distal globosa. Lesura recta que alcanza el ecuador, con labios bajos y delicados. Los engrosamientos interradiales tienen el margen externo recto, en tanto el interno es cóncavo; su porción mas ancha es breve y luego rematan gradualmente hacia los ángulos.

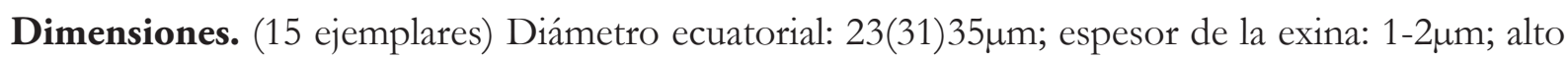

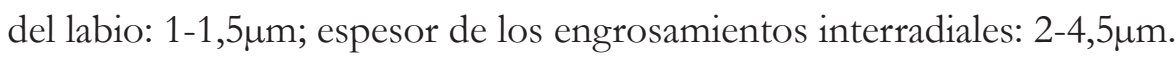

Comentarios. Se separa esta forma de G. senonicus por la rigidez de su exina que hace que no se formen pliegues distales.

Material estudiado. PBN N1: BA Pb Pal 5500, 5501, 5553, 5569, 5570,55725574 y 5577.

\section{Gleicheniidites sp.3}

Lám. Vg 
Descripción. Espora pequeña de contorno triangular, con ángulos ampliamente redondeados y lados convexos. Lesura recta surcada por labios anchos que alcanzan el ecuador o bien se extienden hasta la cara distal, donde en ocasiones se bifurca. Exina lisa. Los engrosamientos interradiales presentan ambos márgenes enteros y rectos, tienen un amplio desarrollo y se extienden desde la cara proximal a la distal, y sólo se interrumpen brevemente en los ángulos, determinando una faja ecuatorial engrosada que le confiere rigidez a la espora.

Dimensiones. (5 ejemplares) Diámetro ecuatorial: $13-22 \mu \mathrm{m}$; ancho del labio: 2 -2,5 $\mu$ m; engrosamientos interradiales: $2-3,4 \mu \mathrm{m}$.

Comentarios. No se han encontrado en la bibliografía consultada ejemplares semejantes a los aquí descriptos. Los caracteres que distinguen a estos últimos son su pequeño tamaño y el mayor desarrollo del labio y engrosamientos interradiales.

Material estudiado. PBN N1: BA Pb Pal 5552, 5553 y 5566.

\section{Gleicheniidites sp.4}

Lám. Vh

Descripción. Espora trilete con la cara proximal triangular de lados cóncavos, y distal circular a subtriangular. Exina lisa y delgada que presenta un engrosamiento en los interradios a la altura del ecuador. La lesura es recta y alcanza el ecuador, surcada por labios membranosos.

Dimensiones. (3 ejemplares) Diámetro ecuatorial: $16-23 \mu \mathrm{m}$; espesor de la exina: 0,5 -1 $1 \mu \mathrm{m}$; engrosamientos interradiales: 1,5-2,5 $\mu \mathrm{m}$; alto del labio: $1,5 \mu \mathrm{m}$.

Comentarios. Este tipo podría incluirse en el género Dictyophyllidites según la enmienda hecha por Dettmann (1963), en la que incluye ejemplares con labios; los pliegues que acompañan a la lesura también pueden tomarse como espesamientos proximales de la exina (torus o kirtomas) que los relaciona con el género Concavisporites. Sin embargo he considerado pertinente referirlo a Gleicheniidites por atender al hecho de que ambas caras de la espora son diferentes y en ese contexto, los engrosamientos serían ecuatoriales y no proximales. La comparación más cercana es con Gleicheniidites sp. A ilustrado por Dettmann \& Thomson (1987) para el Cretácico Medio de Antártida, aunque en esa ocasión no hicieron una descripción del material.

Material estudiado. PBN N1: BA Pb Pal 5552. 
Género Ornamentifera Bolkhovitina 1966

Especie tipo: Ornamentifera echinata (Bolkh.) Bolkhovitina 1966.

Afinidad botánica. Pteridophyta, Familia Gleicheniaceae.

Observaciones. La diagnosis genérica hace referencia a la ornamentación de la espora como cualidad distintiva. Los ejemplares aquí estudiados presentan esculturación sólo en el hemisferio distal, sin embargo se incluyen en este morfogénero por presentar los espesamientos interradiales de la exina y los pliegues distales que caracterizan a las esporas de la Familia Gleicheniaceae (Bolkhovitina, 1967).

\section{Ornamentifera sp. 1}

Lám. Vi

Descripción. Espora de contorno triangular con ángulos redondeados. Cara proximal pequeña con lados marcadamente cóncavos y cara distal con lados levemente convexos a rectos. Lesura recta que alcanza el ecuador flanqueada por labios delgados y elevados. Exina dividida en dos capas, una interna lisa y la externa ornamentada. La cara proximal es mayormente lisa con pocas fósulas en la cercanía del ecuador, mientras la cara distal está finamente ornamentada por gránulos, pequeños conos y rúgulas (los de mayor tamaño de $1 \mu \mathrm{m}$ ) fusionados entre si determinando un patrón rugulado-fosulado. Engrosamientos interradiales poco desarrollados.

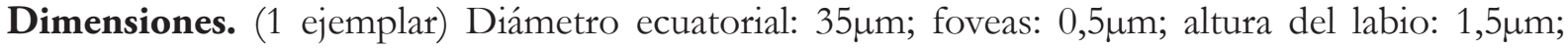
engrosamientos interradiales: $2,5 \mu \mathrm{m}$.

Discusión y comparaciones. Bolkhovitina (1968) incluye dentro de la especie tipo ejemplares con una ornamentación muy variable tanto en tamaño como en la forma de las espinas, pero - a diferencia de este caso- dispuestas de manera dispersa. El material descripto por Dettmann \& Thomson (1987) como Ornamentifera sp. A, y aquél que posteriormente fuera ilustrado y referido a esa especie por Barreda y otros autores (1999) -ambas para Antártida-, son bastante similares al material aquí presentado. Sin embargo en ningún caso mencionan la diferencia de la ornamentación proximal y distal.

Material estudiado. PBN N1: BA Pb Pal 5500. 


\title{
Ornamentifera sp. 2
}

\author{
Lám. Vj-k
}

Descripción. Espora de contorno triangular con ángulos redondeados. Cara proximal pequeña, con lados marcadamente cóncavos y exina lisa a escabrada. La cara distal tiene lados rectos a levemente cóncavos. Lesura recta que alcanza el ecuador, flanqueada por labios robustos. Exina dividida en dos capas, una interna lisa y la externa fuertemente ornamentada por conos, verrugas y rúgulas (los de menor tamaño de $1 \mu \mathrm{m}$ ) fusionados en la base en mayor o menor medida. Esta fusión es más densa hacia el ecuador, y se vuelve casi completa sobre los espesamientos de la exina en los interradios, donde los elementos se tornan indistinguibles y la superficie se vuelve fosulada. La exina es gruesa en la cara distal, ligeramente más delgada en los ángulos y con engrosamientos interradiales en el ecuador.

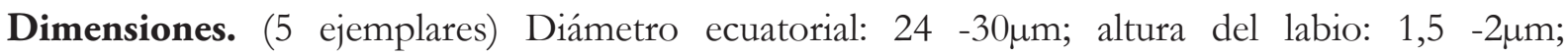

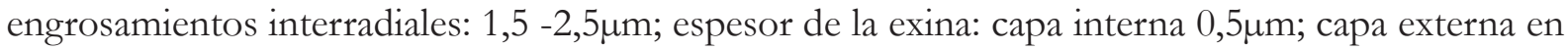

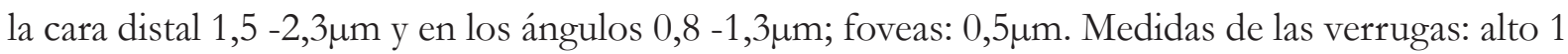
$-1,5 \mu \mathrm{m}$; base: $1-1,5 \mu \mathrm{m}$; foveas: $0,5 \mu \mathrm{m}$.

Discusión y comparaciones. Esta especie es separada de la anterior por tener elementos esculturales más robustos y poco fusionados. En la Formación Kachaike se reportó un ejemplar asignado a Ornamentifera cf. O. echinata (A. Archangelsky \& Llorens, 2005); ésta es la primer mención de una esculturación diferente entre las caras proximal y distal. Sin embargo en ese caso los elementos son espinas. Archangelsky \& Villar de Seoane (1992) describen para la Formación Anfiteatro de Ticó O. tuberculata y Ornamentifera sp. A, ambas con gránulos y ornamentación en ambas caras.

Material estudiado. PBN N1: BA Pb Pal 5570; PBS N2: MPEF Palin 64 y N5: MPEF Palin 65.

Género Clavifera Bolkhovitina 1966

Especie tipo: Clavifera triplex (Bolkh.) Bolkhovitina 1966

Clavifera cf. C. triplex (Bolkh.) Bolkhovitina 1966

Lám. Vl

Descripción: Esporas muy pequeñas, de forma subtriangular con lados rectos a convexos. Cara proximal ligeramente piramidal y distal globosa. Las proyecciones en los ángulos se encuentran surcadas por los extremos de la lesura, que está acompañada de labios prominentes. Los 
engrosamientos interradiales son groseros y tienen el margen externo suavemente ondulado, mientras el interno es recto. En vista polar se observan sobre la cara distal tres "engrosamientos" paralelos a los lados que corresponderían a plegamientos debidos a la compresión.

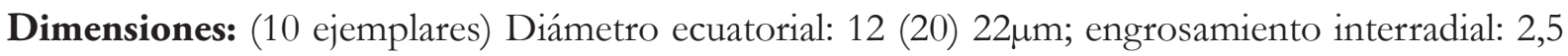
$-3,5 \mu \mathrm{m}$; altura del labio: $2-2,5 \mu \mathrm{m}$.

Comentarios. La especie tipo se describió para el Aptiano de Rusia (Bolkhovitina, 1966) y presenta proyecciones apicales más prominentes que en estos ejemplares. En Argentina ha sido citada para el Maastrichtiano de Mendoza (Papú, 2002); al tiempo que se registró también en el ConiacianoSantoniano de Antártida (Barreda et al. 1999).

Afinidad botánica: Pteridophyta, Familia Gleicheniaceae.

Material estudiado: PBN N1: BA Pb Pal 5552, 5565, 5566, 5570 y 5575.

Turma MONOLETES Ibrahim 1933

Subturma AZONOMONOLETES Luber 1935

Infraturma LAEVIGATOMONOLETI Dybová \& Jachowicz1957

Género Laevigatosporites Ibrahim 1933

Especie tipo. Laevigatosporites vulgaris (Ibrahim) Ibrahim, 1933

Laevigatosporites ovatus Wilson \& Webster 1946

Lám. VIa

Descripción. Espora monolete de exina gruesa y lisa, de espesor uniforme. Contorno oval en vista polar y cóncavo-convexo en vista ecuatorial. Lesura recta llegando casi al ecuador, encerrada en un

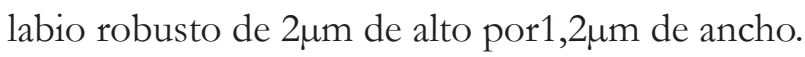

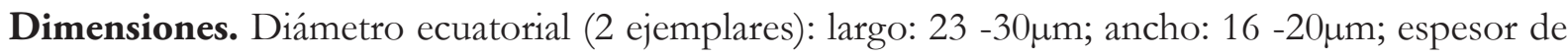
la exina: $1-1,5 \mu \mathrm{m}$.

Material estudiado. PBN N1: BA Pb Pal. 5570; PBN N3: MPEF Palin 61. 


\section{Laevigatosporites sp.}

Lám. VIb

Descripción. Espora monolete de grandes dimensiones, con contorno ovalado en vista polar y plano-convexo a biconvexo en vista ecuatorial . La lesura es simple y recta, con una apariencia de corte, que no llega a abarcar la mitad de la longitud máxima de la espora. La exina es lisa y rígida, de un espesor de 1,5 -3,2um, con pliegues secundarios. A menudo se observa un pliegue de la exina paralelo al ecuador que puede confundirse con una capa interna.

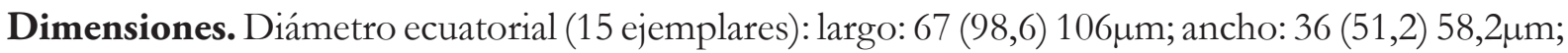

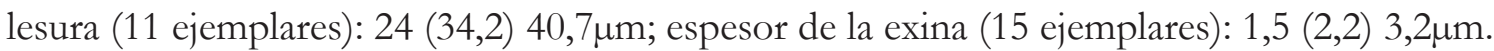

Discusión y comparaciones. Los ejemplares estudiados son muy semejantes a L. belfordii descripto por Burger (1984) para el Neocomiano-Aptiano de Australia y citado por Archangelsky et.al. (1983) para el Cretácico de Argentina Austral, pero presenta una diferencia, ya que en el material aquí estudiado, la lesura es simple, y no tiene labio, por lo que no puede incluirse en ese taxón. El resto de las especies afines, tienen un rango de tamaños mucho menor y además siempre muestran una forma arriñonada en vista lateral.

Los ejemplares que Pflug (en Thompson \& Pflug, 1953) describe como L. discordatus no muestran ese carácter como tampoco un labio, pero su rango de diámetro ecuatorial es menor (50 - $90 \mu \mathrm{m})$ que el de los nuestros.

Material estudiado. PBN N1: BA Pb Pal 5500, 5503, 5550, 5569 y 5572.

Infraturma SCULPTATOMONOLETI Dybová \& Jachowicz 1957

Género Reticuloidosporites Pflug 1953

Especie tipo. Reticuloidosporites dentatus (Pflug) Pflug, 1953.

Afinidad botánica. Fam. Polypodiaceae.

\section{Reticuloidosporites sp. 1}

Lám. VIc-d

Descripción. Espora monolete de forma arriñonada en vista ecuatorial. Exina delgada, ornamentada 
con muros bajos $-0,7 \mu \mathrm{m}$ de alto- $\mathrm{y}$ delgados $-0,5 \mu \mathrm{m}$ de ancho- que forman un retículo de lúminas penta o hexagonales.

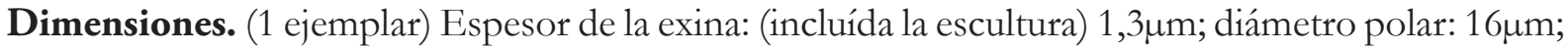
diámetro ecuatorial: $22 \mu \mathrm{m}$.

Material estudiado. PBN N1: BA Pb Pal 5552.

\section{Reticuloidosporites sp. 2}

Lám. VIe-f

Descripción. Espora monolete de forma arriñonada en vista ecuatorial. Exina gruesa, esculturada con muros elevados $(2 \mu \mathrm{m})$ de un ancho irregular $(0,7-1,5 \mu \mathrm{m})$ que forman un retículo de pequeños alvéolos penta-hexagonales.

Dimensiones. (1 ejemplar) Diámetro ecuatorial: $33 \mu \mathrm{m}$; diámetro polar: $23 \mu \mathrm{m}$; espesor de la exina:

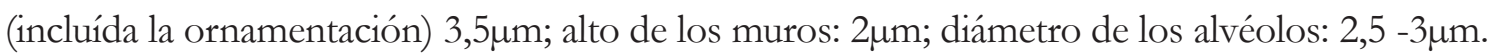

Material estudiado. PBN N1: BA Pb Pal 5567.

\section{Reticuloidosporites sp. 3}

Lám. VIg-h

Descripción. Espora monolete de forma arriñonada en vista ecuatorial. Exina gruesa ornamentada por muros muy delgados $(0,5 \mu \mathrm{m})$ y elevados $(3 \mu \mathrm{m})$ que forman un retículo amplio con lúminas de forma penta o hexagonales.

Dimensiones. (1 ejemplar) Diámetro ecuatorial: $22 \mu \mathrm{m}$; diámetro polar: $16 \mu \mathrm{m}$; espesor de la exina:

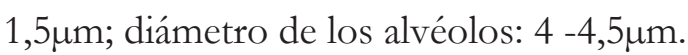

Material estudiado. PBN N1: BA Pb Pal 5569. 


\section{LÁMINA I}

\section{Esporas Levigadas}

a: Biretisporites cf. B. potoniaei.

b: Biretisporites sp. A

c: Biretisporites sp.B

d: Biretisporites sp. C

e: Deltoidospora sp.A

f: Deltoidospora sp. B

g: Todisporites sp.A

h: Todisporites sp.B

i: Cyathidites patagonicus

j: Cyathidites sp. of C. minor

Todas las escalas: $10 \mu \mathrm{m}$ 

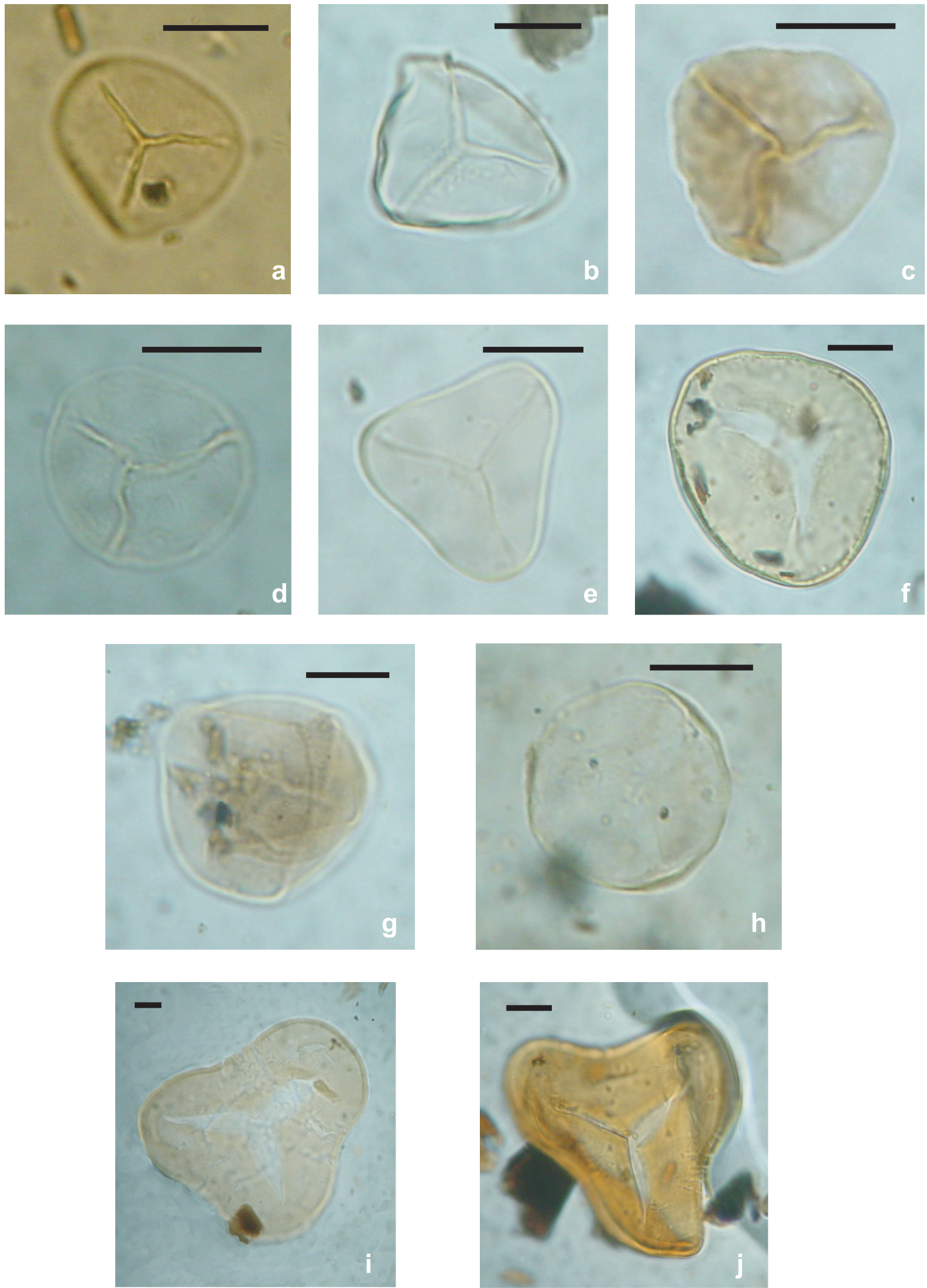


\section{LÁMINA II}

\section{Esporas Apiculadas}

a: Ceratosporites sp.A

b: Ceratosporites sp. B

c: Concavissimisporites penolaensis

d: Concavissimisporites sp. A

e: Retitriletes sp. A

f: Retitriletes douglasii

g: Staplinisporites caminus

h: Espora apiculada gén. et sp. indeterminado (vista proximal)

i: Espora apiculada gén. et sp. indeterminado (vista distal)

Todas las escalas: $10 \mu \mathrm{m}$ 

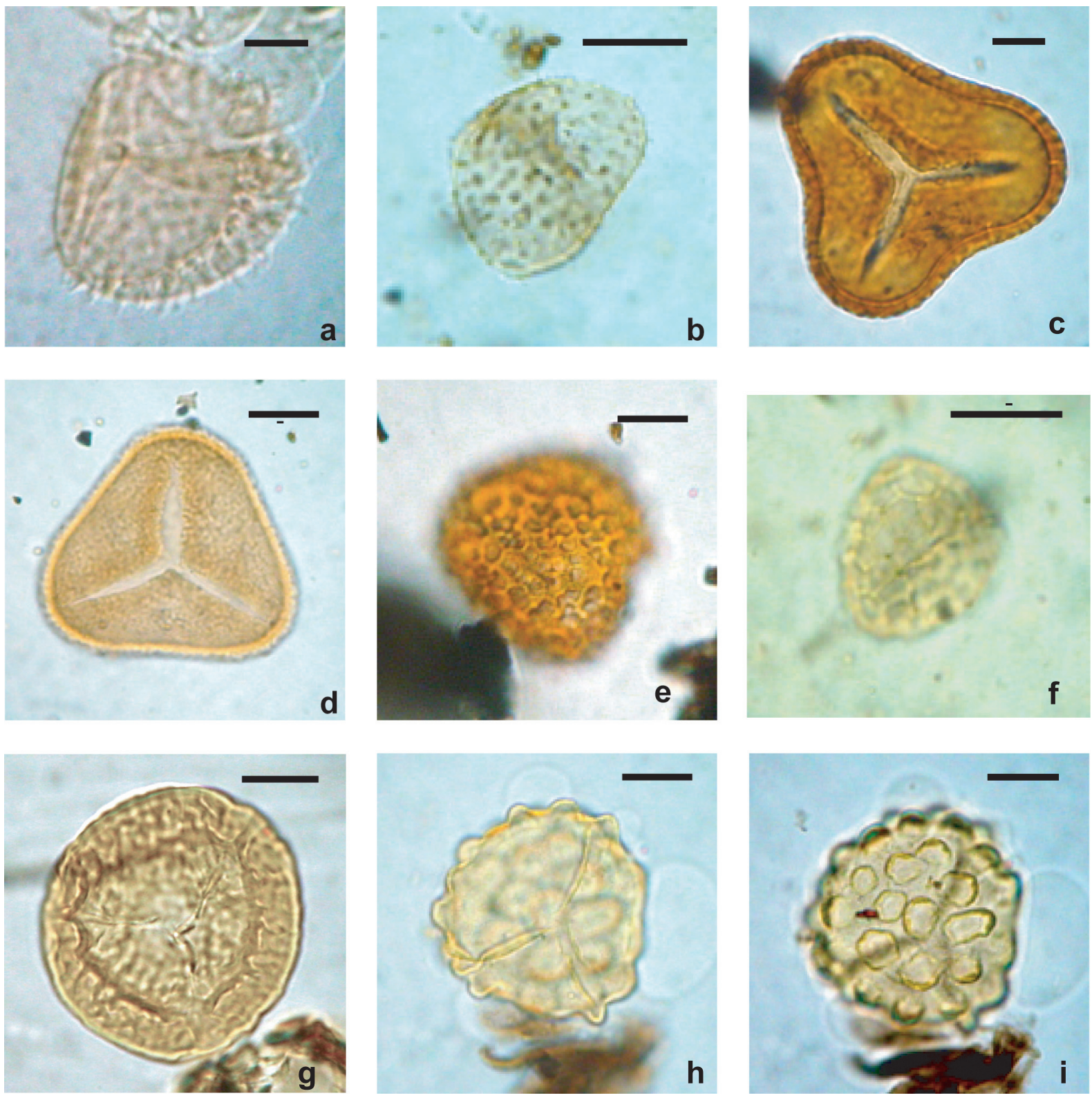


\section{LÁMINA III}

\section{Esporas Perisporadas}

a-b: Lygodiidites sp. 1. a-Tres ejemplares posiblemente pertenecientes a una misma tétrade; $\mathbf{b}$ - detalle de un ejemplar.

c: Lygodiidites sp. 2

d: Auroraspora sp.

e-h: Espora perisporada género et sp. indet. e- Corte óptico mostrando un perisporio grueso compuesto por "placas"; f- corte óptico en que se observa una separación pequeña entre el cuerpo de la espora y el perisporio; g- ejemplar con perisporio en partes grueso y en otras, los conos empiezan a ser visibles; $\mathbf{h}$ - la separación entre el cuerpo y el perisporio es mayor, ese último se ve delgado y con conos.

Todas las escalas: $10 \mu \mathrm{m}$ 

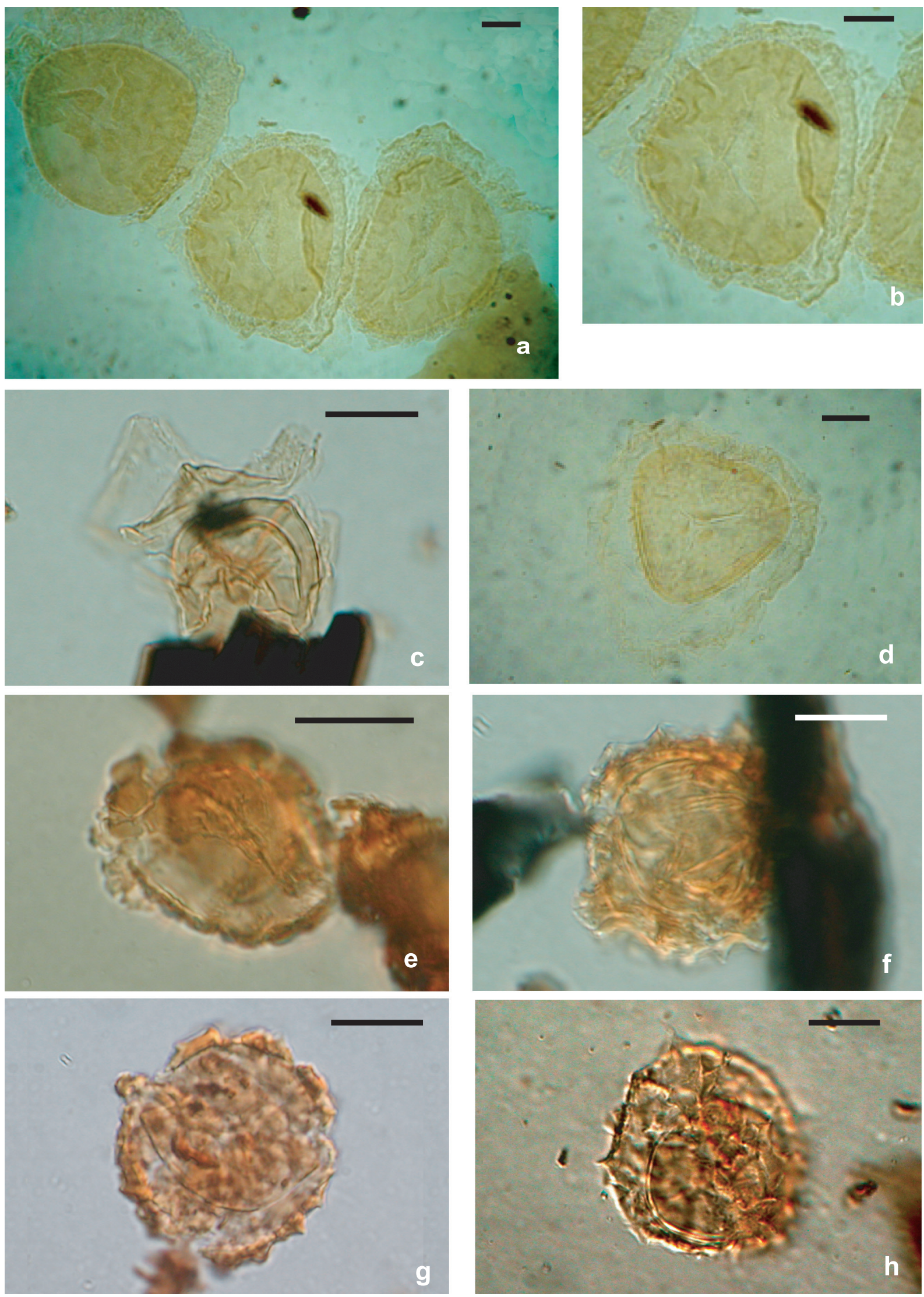


\section{LÁMINA IV}

\section{Esporas Cinguladas}

a: Densoisporites velatus

b-c, e: Densoisporites corrugatus. b- vista distal; c- vista proximal; efotografía tomada con MEB.

d: Foraminisporis sp. (vista proximal + distal)

f: Foraminisporis dailyi

g-h: Contignisporites burgueri. g- cara proximal donde se observan los pulvínulos; $\mathbf{h}$ - cara distal.

i: Contignisporites glebulentus

j: Contignisporites cooksoniae (vista proximal en que se observan las facetas lisas)

Todas las escalas: $10 \mu \mathrm{m}$ 

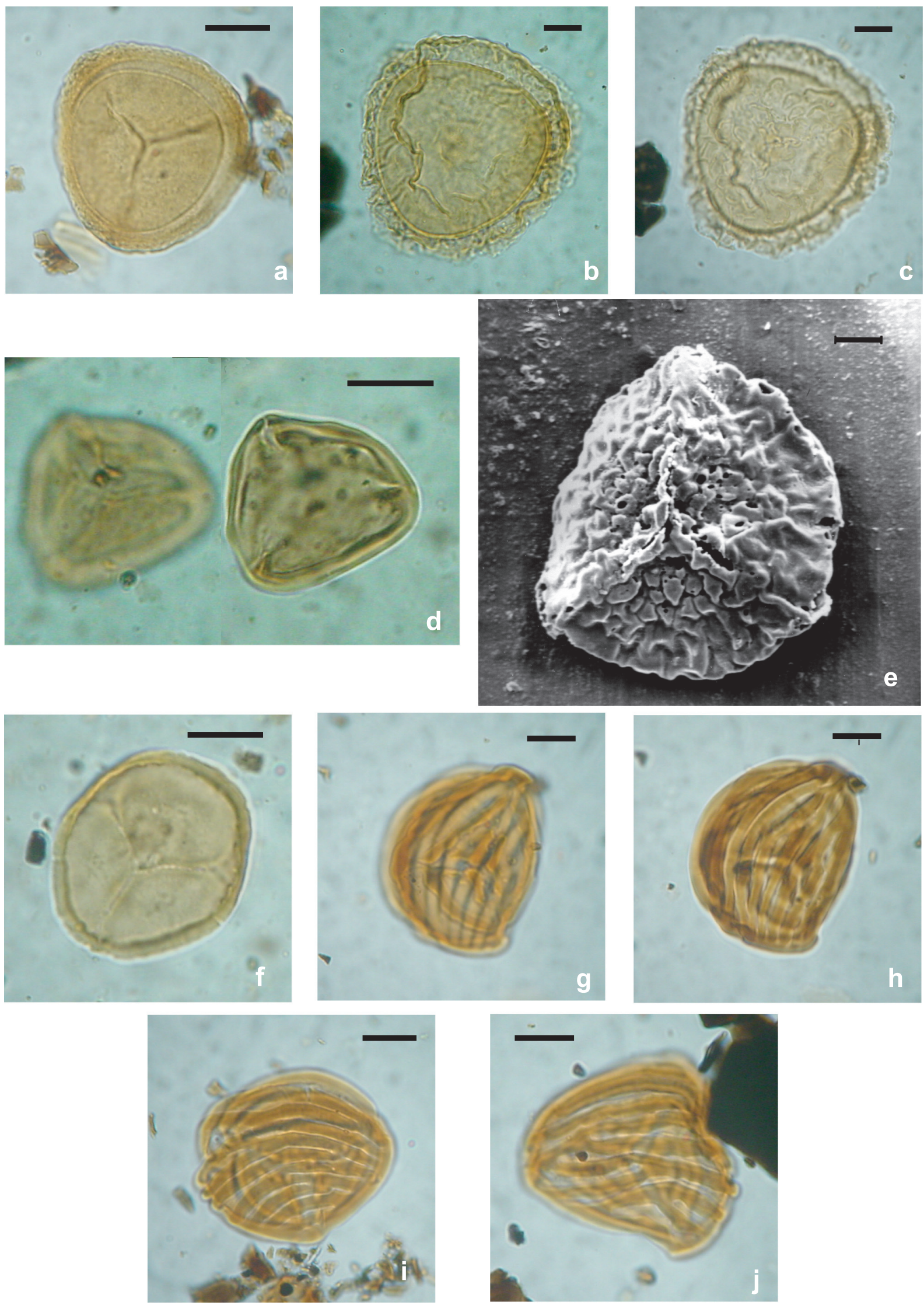


\section{LÁMINA V}

\section{Esporas Tricrasadas}

a-d: Gleichenïdites senonicus. a- foto al microscopio óptico; $\mathbf{d}$ - foto al MEB.

b-c, e: Gleichenüdites sp.1. b- vista proximal; c- vista distal; efotografía tomada con MEB.

f: Gleicheniidites sp. 2

g: Gleicheniidites sp.3

h: Gleicheniidites sp.4

i: Ornamentifera sp. 1

j-k: Ornamentifera sp. 2. j- vista proximal; k- vista subecuatorial.

I: Clavifera cf. C. triplex

Todas las escalas: $10 \mu \mathrm{m}$ 

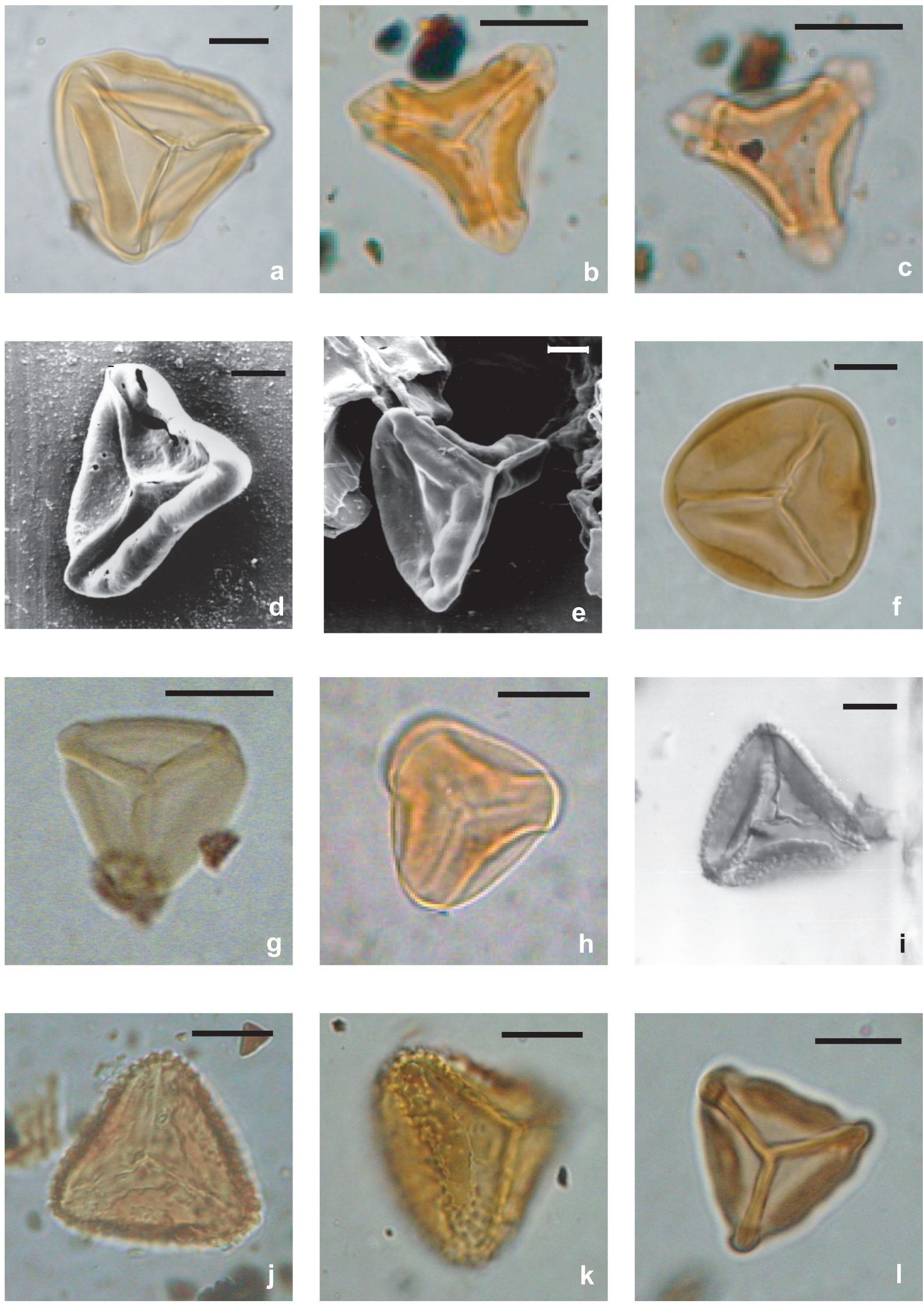


\section{LÁMINA VI}

\section{Esporas Monoletes}

a: Laevigatosporites ovatus.

b: Laevigatosporites sp.

c-d: Reticuloidosporites sp. 1

e-f: Reticuloidosporites sp. 2

g-h: Reticuloidosporites sp. 3

Todas las escalas: $10 \mu \mathrm{m}$ 

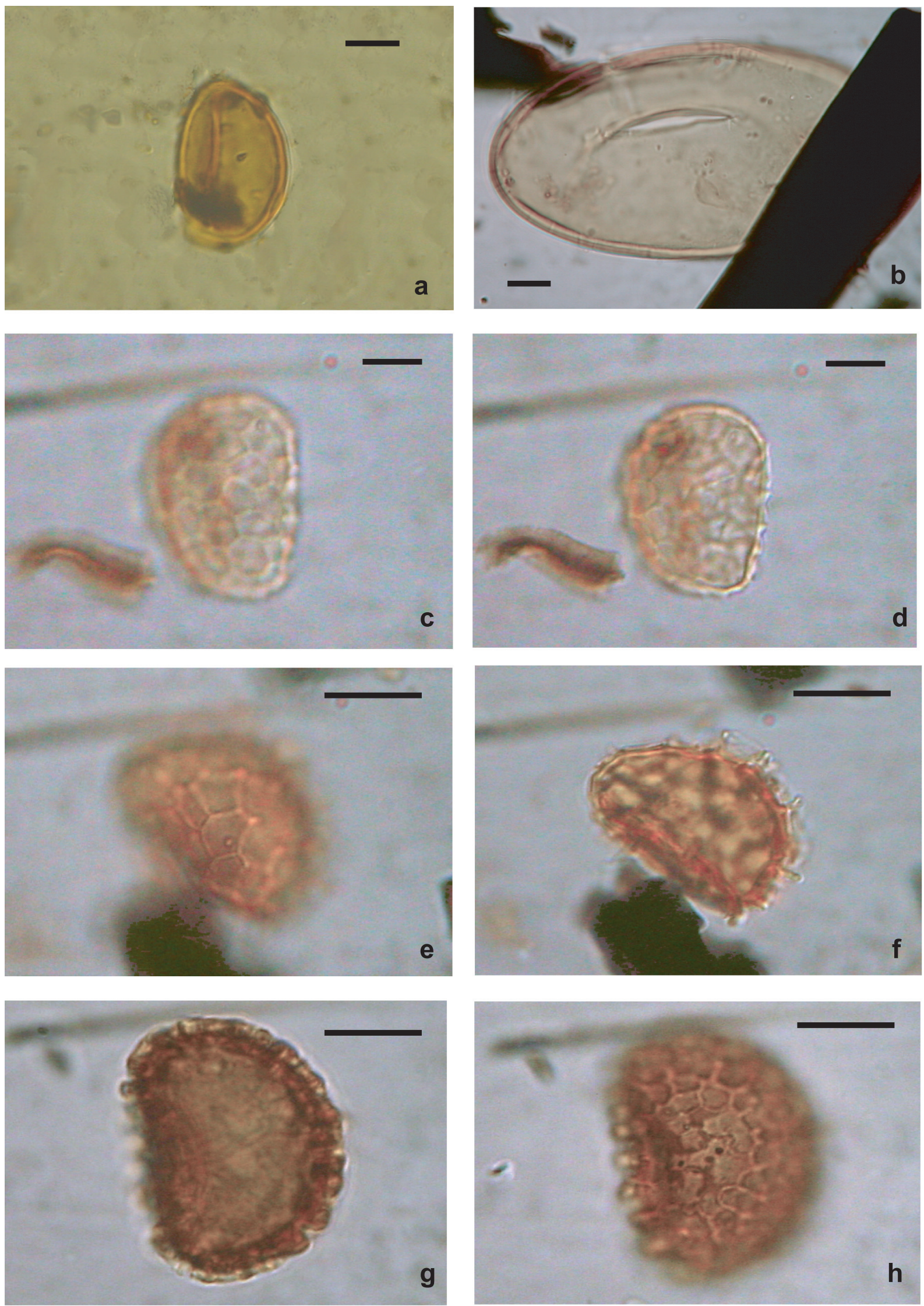


\section{III.1.2.2. Granos de Polen}

Anteturma POLLENITES Potonié 1931

Turma ALETES Ibrahim 1933

Subturma AZONALETES Luber emend. Potonié \& Kremp 1954

Género Inaperturopollenites Pflug \& Thompson 1953, sensu Nilsson 1958

Especie tipo. Inaperturopollenites dubius (Pot. \& Ven.) ex Th. \& Pfl. Ibid. Pollenites magnus f. dubius Potonié \& Venitz 1934.

\section{Inaperturopollenites sp.}

Lám. VIIa

Descripción. Grano de polen inaperturado con contorno ecuatorial oval-subcircular. La exina es compacta, levigada y relativamente gruesa en relación a su pequeño diámetro ecuatorial (20 $25 \mu \mathrm{m})$, con un espesor uniforme, que al comprimirse presenta con frecuencia un pliegue paralelo al contorno que le otorga un aspecto de doble exina.

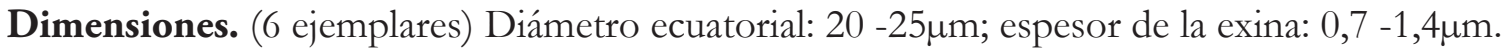

Discusión y comparaciones. Esta forma se incluye en el género Inaperturopollenites en el sentido de Nilsson (Jansonius \& Hill, 1976: 1308 y 1982: 3985), quien consideró sólo formas inaperturadas azonadas, con una exina firme y lisa para las que sugirió una afinidad botánica con las gimnospermas. Existe similitud con Inaperturopollenites sp. C descripto para el Jurásico Superior de Neuquén (Volkheimer \& Quattocchio, 1975) que tiene sin embargo, un rango de diámetro ecuatorial mayor

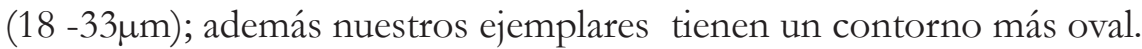

Afinidad botánica. Desconocida, aunque muchas de las formas inaperturadas suelen vincularse con la Familia Araucariaceae.

Material estudiado. PBN N1: BA Pb Pal 5552, 5566, 5575 y 5574.

Género Araucariacites Cookson ex Couper, 1953

Araucariacites australis Cookson ex Couper, 1953

Lám. VIIb-c

Especie tipo. Araucariacites australis Cookson, 1947 ex Couper

1967- Araucariacites australis Cookson, Archangelsky \& Gamerro: 214, lám. II, fig.1.

1968- A. australis Cookson, Volkheimer: 356, lám. VII, figs. 3 y 4.

1972- A. australis Cookson, Volkheimer: 135, lám.XI, figs. 98 y 99. 
1975- A. australis Cookson, Volkheimer \& Quattrocchio: 229, lám.IX, figs. 9 y 10.

1980- A. australis Cookson, Archangelsky \& Seiler: 223, fig. 10.

1980- A. australis Cookson, Quattrocchio: 15, lám. D, fig.27.

1995- A. australis Cookson, Vallati: 286, lám. 4, fig. 8.

Dimensiones. (10 ejemplares) Diámetro ecuatorial: 40 (50) 73,5 $\mu \mathrm{m}$.

Distribución estratigráfica. Esta especie está ampliamente presente en sedimentos mesozoicos y terciarios del mundo. Sajjadi \& Playford (2002) describen su distribución.

Afinidad botánica. Familia Araucariaceae.

Material estudiado. PBN N1: BA Pb Pal 5568, 5569 y 5574.

Turma POROSES Naumova emend. Potonié 1960

Subturma DIPORINES (Naumova 1939) Potonié 1960

Género Cyclusphaera Elsik 1966

Especie tipo. Cyclusphaera euribei Elsik, 1966.

Cyclusphaera psilata Volkheimer \& Sepúlveda, 1976

Lám. VIId-e

Basónimo: Cyclusphaera psilata Volkheimer \& Sepúlveda, 1976.: 101, lám.2, figs.1-7.

1980- C. psilata Volkheimer \& Sepúlveda, Quattrocchio: 210, lám. 1, fig. 11.

1981- C. psilata Volkheimer \& Sepúlveda,Volkheimer \& Quattrocchio, lám.VIII, fig.10.

1983- C. psilata Volkheimer \& Sepúlveda, Archangelsky et. al.

1994- C. psilata Volkheimer \& Sepúlveda, Archangelsky et. al:: 136, fig.7 (a)

1995- C. psilata Volkheimer \& Sepúlveda, Vallati: 286, lám.4, fig.1.

1999- C. psilata Volkheimer \& Sepúlveda, Prámparo \& Volkheimer: 225, fig. 4(E)

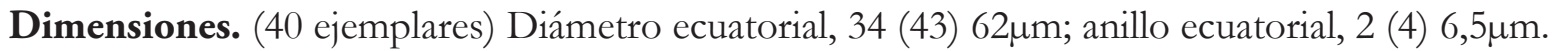

Discusión y comparaciones. Esta forma es posiblemente una de las más abundantes y frecuentes en todas las muestras estudiadas. El rango del diámetro ecuatorial establecido para la especie es de $43-82 \mu \mathrm{m}$, y nuestro material se ajusta mayormente a estas medidas; sin embargo es preciso mencionar que existen ejemplares de tamaño menor en un rango de 34-62 $\mu \mathrm{m}$. Esta misma situación se presenta también en el trabajo de Archangelsky y otros autores (1983), donde se describe para la Argentina austral, un rango de $35-70 \mu \mathrm{m}$.

Otra diferencia está dada por el espesor del engrosamiento ecuatorial, que es de 1,9-6,5 $\mu \mathrm{m}$ en el material en estudio, considerablemente menor al establecido de $3-10 \mu \mathrm{m}$.

Afinidad botánica. En una reciente revisión del material tipo de Brachyphyllum mirandai, se encontró un cono masculino en conección con estas ramas. Ese cono masculino afín a la Familia Araucariaceae, 
portaba polen del tipo Cyclusphaera psilata (del Fueyo \& Archangelsky, 2004).

Material estudiado. PBN N1: BA Pb Pal 5500, 5503, 5550, 5557, 5564, 5567, 5568, 5574 у 5572.

\section{Cyclusphaera sp. A}

Lám. VIIf

Descripción. Grano biaperturado. Contorno ecuatorial circular-subcircular. Aberturas grandes irregulares, a menudo con bordes rectilíneos . Exina lisa ecuatorialmente engrosada.

Dimensiones. (6 ejemplares) Contorno ecuatorial: 38 -46 $\mu \mathrm{m}$; engrosamiento ecuatorial: 1,5 $2,5 \mu \mathrm{m}$.

Discusión y comparaciones. Esta forma es muy similar a Cyclusphaera psilata, aunque el engrosamiento ecuatorial es menor en relación con su diámetro ecuatorial. Esa característica está presente en Balmeiopsis limbatus pero ese taxón sólo posee una apertura. Cyclusphaera Morfotipo 2 (Vallati, 1993) es la forma más parecida a la aquí descripta y sólo difiere de ésta por poseer tamaños mayores $(66,5-82,5 \mu \mathrm{m})$.

Afinidad botánica. Familia Araucariaceae.

Material estudiado: PBN N3: MPEF Palin 61.

Subturma MONOPORINES Naumova 1939

Género Balmeiopsis Archangelsky 1977

Especie tipo. Balmeiopsis limbatus (Balme) Archangelsky 1977

Balmeiopsis limbatus (Balme) Archangelsky 1977

Lám. VIIg-h

1957- Inaperturopollenites limbatus, Balme: 31, lám.7, figs.83-84

1964- I. limbatus, Balme: 74, lám.VII, fig.7

1967- I. limbatus Balme type, Archangelsky \& Gamerro: 180, lám. I, figs. J-G

1967- I. limbatus Balme, Archangelsky \& Gamerro, lám. II, fig. E

1971- I. limbatus Balme, Playford. Lám.107, fig. 8

1977- Balmeiopsis limbatus (Balme) Archangelsky, lám. 1, figs. 1-5

1980- B. limbatus, Archangelsky \& Seiler, lám. 1 fig. 8

1995- B. limbatus (Balme) Archangelsky, Vallati: 286, lám.4, fig.4

Dimensiones. (18 ejemplares) Diámetro ecuatorial: 39,7 (48) 66,3 $\mu \mathrm{m}$, engrosamiento ecuatorial: $1,6(1,9) 3,8 \mu \mathrm{m}$. 
Discusión y comparaciones. En la descripción original (Balme, 1957) se establece un rango de tamaño de $67 \mu \mathrm{m}$ a $96 \mu \mathrm{m}$, mientras que en los ejemplares citados para el Grupo Baqueró (Archangelsky \& Gamerro, 1967a), los tamaños oscilan entre $55 \mu \mathrm{m}$ y $92 \mu \mathrm{m}$. En ambos casos las dimensiones son bastante mayores que las descriptas en el presente trabajo.

Distribución estratigráfica. En el país, está citado ampliamente para el Jurásico y Cretácico Inferior. Fue encontrado además en el Cretácico Inferior de Australia (Sajjadi \& Playford, 2002).

Afinidad botánica. Fam. Araucariaceae.

Material estudiado. PBN N1: BA Pb Pal 5567, 5568, 5571, 5572, 5552, 5550 y 5501.

\section{Género Classopollis Pflug 1953}

2002- Corollina Maljawkina emend. Cornet \& Traverse, Sajjadi \& Playford,p.134.

En este trabajo se ofrece una amplia lista sinonímica y discusión de la situación nomenclatural de esta forma polínica.

Especie tipo. Classopollis classoide, Pflug 1953.

\section{Classopollis sp.}

Lám. VIIi

Descripción. En el material estudiado, no se observa con claridad el pseudoporo distal ni tampoco la marca trilete en la cara proximal. La asignación genérica se basa entonces, en la estructura de la pared, y en algunos casos la presencia de la rímula. Así, no es posible asignar estos ejemplares a ninguna especie en particular. En las preparaciones en las que aparecen estos granos, el resto del material está muy bien preservado, con lo que se deduce que estos granos serían redepositados, o bien retransportados, dado que en ocasiones presentan alteración térmica de su exina, en contraste con los demás esporomorfos que no la presentan.

Material estudiado. PBN N1: BA Pb Pal 5566 y 5575; PBS N4: MPEF Palin 51 y 52.

Afinidad botánica. Coniferophyta, Fam. Cheirolepidiaceae.

Turma SACCITES Erdtman 1947

Subturma DISACCITES Cookson 1947

Género Podocarpidites Cookson 1947

Especie tipo. Podocarpidites ellipticus Cookson, 1947

Comentario. Siguiendo la diagnosis realizada por Potonié (1958), se incluyen dentro de este 
género a todas las formas bisacadas con cuerpo oval a poligonal, cresta marginal, área germinal sin engrosamientos y sacos distales finamente reticulados, sin discriminar por el tipo de ornamentación que presentan. Para una discusión acabada de las taxonomía del grupo, ver el trabajo de Archangelsky \& Villar de Seoane (2005).

Es importante señalar que este morfogénero es muy abundante y diverso en la formación basal del Grupo; por otra parte, las plantas productoras tienen por su tipo de polinización, una alta tasa de polinación. Es por tanto, altamente probable que los escasos ejemplares aquí encontrados hayan sido retrabajados desde aquellos sedimentos.

Afinidad botánica. Coniferophyta, Familia Podocarpaceae.

Podocarpidites ellipticus Cookson, 1947

Lám. VIIIa

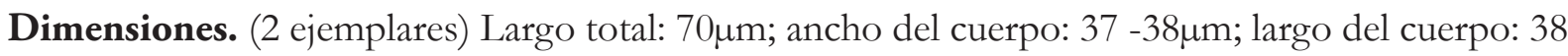

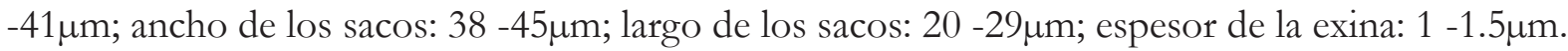

Distribución estratigráfica. Esta es una especie ampliamente representada en el mundo en sedimentos del Jurásico temprano-Terciario temprano (ver referencias completas en: Sajjadi \& Playford, 2002b). En Argentina, desde el Jurásico medio al Terciario, y en la Fm. Anfiteatro de Ticó (ver distribución y comentarios en Archangelsky \& Villar de Seoane, 2005).

Material estudiado. PBN N1: BA Pb Pal 5573; PBS N4: MPEF Palin 59.

Podocarpidites marwickii Couper, 1953

Lám. VIIIb

Dimensiones. ( 2 ejemplares) Largo total: $32 \mu \mathrm{m}$; ancho del cuerpo: $23-27 \mu \mathrm{m}$; largo del cuerpo: $24 \mu \mathrm{m}$; ancho de los sacos: $22 \mu \mathrm{m}$; largo de los sacos: $13-14 \mu \mathrm{m}$; espesor de la exina: $1.5-2 \mu \mathrm{m}$.

Distribución estratigráfica. Esta es una especie ampliamente representada en sedimentos terciarios de Argentina, aunque ya ha sido citada también para el Cretácico Superior (ver distribución y comentarios en Archangelsky \& Villar de Seoane, 2005). Este es el segundo reporte de la especie para el Cretácico Inferior, mientras que el de la Fm. Anfiteatro de Ticó, constituye el más antiguo para Sudamérica (Archangesky \& Villar de Seoane, 2005).

Material estudiado. PBN N1: BA Pb Pal 5574, 5577.

Afinidad botánica. Se hallaron en la formación basal del Grupo, conos fértiles asignados como Squamastrobus, que poseen granos de polen del tipo Podocarpidites marwickii (Archangelsky \& Del Fueyo, 1989). 
Subturma POLISACCITES Cookson 1947

Género Microcachryidites Cookson ex Couper, 1953

Especie tipo. Microcachryidites antarcticus Cookson, 1947.

Afinidad botánica. Las formas polínicas multisacadas sólo se encuentran en la Fam. Podocarpaceae.

Microcachryidites antarcticus Cookson ex Couper, 1953

Lám. VIIIc-d

1967- M. antarcticus Cookson, Archangelsky \& Gamerro: 217, pl. II, fig. G.

1975- M. antarcticus Cookson, Volkheimer \& Quattrocchio: 226, lám.VIII, fig. 8-9

1977- M. antarcticus Cookson, Volkheimer et. al:: 62, lám. II, fig.1 ayb

1996- M. antarcticus Cookson, Prámparo et al:: 399, lám.I, fig.8

Dimensiones. Diámetro del cuerpo: ecuatorial (16 ejemplares) $26(30,2) 33 \mu \mathrm{m}$, polar (3 ejemplares)

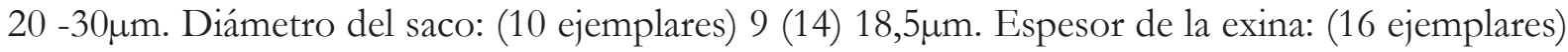
$0,8(1,5) 1,8 \mu \mathrm{m}$.

Comentario. Estas formas trisacadas se incluyen en la especie tipo de este género descripto por Cookson (1947) por ajustarse a todos sus caracteres diagnósticos.

Distribución. La especie ha sido reportada ampliamente en el país para el Mesozoico. Lo mismo ocurre a nivel mundial, y Sajjadi \& Playford (2002b) ofrecen una lista completa de la presencia de la especie.

Material estudiado. PBN N1: BA Pb Pal 5500, 5501, 5550, 5552, 5566, 5569, 5574, 5577; PBS N4: MPEF Palin 51 y N2: MPEF Palin 64.

\section{Microcachryidites sp. A}

Lám. VIIIe-f

Descripción. Grano de polen trisacado, con el contorno ecuatorial del cuerpo circular en vista polar, y oval en vista lateral. Los sacos sobresalen poco del contorno, insertos en su totalidad sobre la cara distal, que se presenta escabrada. En tanto, la proximal muestra una exina gruesa, con verrugas dispuestas apretadamente. El tamaño de las mismas es menor en el polo y aumenta hacia el ecuador, donde estos elementos alcanzan su mayor magnitud y una forma alargada. La base de los sacos tiene un diámetro igual o menor que el ancho máximo de los mismos. La superficie externa de los sacos es lisa, mientras el intra-retículo es muy conspicuo.

Dimensiones. (16 ejemplares) Diámetro ecuatorial: 21 (27) 31 $\mu \mathrm{m}$; diámetro mayor del saco: 9 (13)

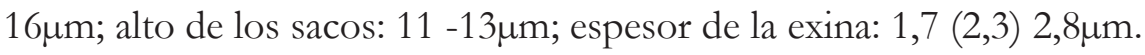

Discusión y comparaciones. El hecho de que este grano posea tres sacos bien desarrollados y una 
forma circular, ha permitido incluirlo en el género Microcachryidites, pero no se encontró afinidad de este material con ninguna especie conocida. Menéndez (1968) describe para el Jurásico Medio de Neuquén a $M$. castellanosii, que comparte muchos caracteres con nuestro material, pero no coincide en el tamaño que es considerablemente menor en este caso, y en el desarrollo de los sacos, ya que en el taxón jurásico, pueden estar unidos por expansiones de las bases, situación que está ausente en nuestros ejemplares.

Material estudiado. PBN NF1: BA Pb Pal 5500, 5501, 5550, 5552, 5566, 5569, 5574, 5577; PBS N4: MPEF Palin 51 y N2: MPEF Palin 64.

\section{Género Trisaccites Cookson \& Pike 1954}

Especie tipo: Trisaccites micropterus, Cookson \& Pike (1954)

Trisaccites microsaccatus (Couper) Couper, 1960

$$
\text { Lám. VIIIg }
$$

1953. Dacrydium microsaccatum Couper: 35, lám.4, fig.38.

1960. Trisaccites microsaccatus Couper: 46, lám.4, fig.12.

1975. T. microsaccatus Couper, Volkheimer \& Quatrocchio: 226, lám. IX, figs. 1-3.

1977. T. microsaccatus Couper, Volkheimer et al:: 63, lám. II, figs. 3 y 4.

1986. Trichotomosulcites subgranulatus Couper; Dettmann: 102, figs. $8 \mathrm{H}-\mathrm{J}$.

Dimensiones. (17 ejemplares) Diámetro ecuatorial: 13,8 (25) 29,3 $\mu \mathrm{m}$, espesor de la exina: 0,6 -

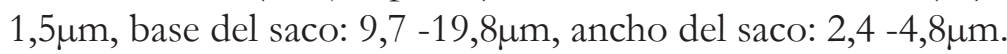

Discusión y comparaciones. Dettmann (1986) invalida el género Trisaccites Cookson \& Pike 1954 por hallar que se trata de un sinónimo junior de Trichotomosulcites Couper 1953. Si bien el procedimiento se ajusta a las reglas del CINIB (Código Internacional de Nomenclatura Botánica -Kiesling, 2002-) considero conveniente no tener en cuenta esa enmienda y conservar a Trisaccites como nombre genérico por ser el más difundido y descriptivo, cualidad esta última de suma utilidad al momento de trabajar con morfogéneros. Por otra parte, la apertura "tricotomosulcada" está presente en diversos grupos de angiospermas -Palmae, Liliaceae, Myrthaceae- (Jansonius \& Hill, 1976: 1739; 2964).

Para el Jurásico medio de Neuquén, Menéndez (1968) cita T.micropterus, muy semejante al presente material. Esta forma encontrada como polen disperso, puede referirse a la conífera Trisacocladus tigrensis, un complejo en conexión orgánica de ramas foliosas y conos femenino y masculino, descripto para la Fm. Anfiteatro de Ticó (ex-Fm. Baqueró). El polen obtenido de estos conos fue estudiado por Gamerro (1965), quien menciona una evidente semejanza con T. microsaccatus y muestra una importante variedad morfológica intraespecífica para este taxón. Estas diferencias también se encuentran en el material disperso encontrado en la Formación Punta del Barco, donde aparecen ejemplares con 2 sacos y sólo el esbozo de uno tercero.

La distribución estratigráfica para el resto del mundo ha sido reportada por Sajjadi \& Playford (2002b).

Afinidad botánica. Gamerro (1965) hace una detallada discusión sobre la asignación botánica de esta 
forma polínica, y concluye que si bien no existe en la actualidad ningún grano semejante a Trisaccites, es evidente su vinculación con las Podocarpáceas, única familia de coníferas que presenta formas polínicas multisacadas. Como ya se ha expuesto en la discusión, polen de este tipo morfológico fué hallado dentro de un complejo de ramas foliosas y conos femenino y masculino, en conexión orgánica, descripto para la Fm. Anfiteatro de Ticó como Trisacoladus tigrensis (Archangelsky, 1966c).

Material estudiado. PBN N1: BA Pb Pal 5570, 5574, 5575, 5551, 5552 y 5577.

Afinidad botánica. Fam. Podocarpaceae.

Género Dacrydiumites Cookson ex Harris 1965

Especie tipo. Dacrydiumites florinii Cookson \& Pike ex Harris 1965

\section{Dacrydiumites sp.}

Lám. VIIIh

Descripción. Grano de polen esférico con exina gruesa $(2-3,5 \mu \mathrm{m})$ y sagrinada. Sacos en número de 2 a 3 con límites poco definidos, que en ocasiones son imperceptibles, tomando un aspecto de saco único. Estos desprendimientos de la ectexina pueden ser apenas insinuados hasta bien desarrollados y se encuentran dispuestos alrededor de la apertura de forma casi circular.

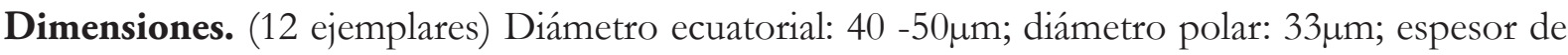
la exina: $2-3,5 \mu \mathrm{m}$.

Material estudiado. PBS N4: MPEF Palin 56, 57 y 58.

Afinidad botánica. Fam Podocarpaceae.

Turma PLICATES Naumova 1939

Subturma MONOCOLPATES Iversen \& Troels-Smith 1950

Infraturma QUASILAEVIGATI Potonié 1970

Género Cycadopites Wodehause 1933

Especie tipo. Cycadopites follicularis Wilson \& Webster 1946.

Afinidad botánica. Este tipo polínico representa tanto a las Cycadales como a las Bennetitales; también las Ginkgoales presentan granos de este tipo, sólo diferenciables en un estudio de ultraestructura de la exina. 
Cycadopites nitidus (Balme) de Jersey 1964

Lám. VIIj

Descripción. Grano de polen monosulcado; contorno ecuatorial fusiforme. El sulco distal es simple, sin engrosamientos y atraviesa el largo total del grano. Exina levigada y delgada.

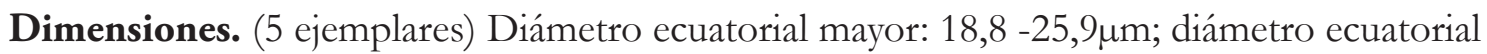

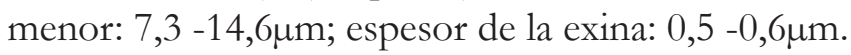

Discusión y comparaciones. Volkheimer \& Quattrocchio (1975) citan esta especie para el Titoniano de Neuquén, aunque es notable la diferencia de tamaño, presentando un diámetro mayor de $25-49 \mu \mathrm{m}$. Archangelsky \& Gamerro (1967) por su parte, citan para la Formación Baqueró (actual Anfiteatro de Ticó) ejemplares del morfogénero Ginkgocycadophytus muy semejantes a los aquí presentados, pero existen diferencias en los extremos del sulco, que en nuestro caso siempre son más agudos, y los bordes nunca se solapan. Baldoni \& Archangelsky (1983) describen esta especie para la Formación Springhill y dan una completa lista de sinonimias y la distribución estratigráfica de este taxón. El tamaño del material de esa formación es mayor al de los ejemplares aquí descriptos.

Material estudiado. PBN N1: BA Pb Pal 5551, 5552 y 5556.

\section{Cycadopites sp. A \\ Lám. VIIk}

Descripción. Grano de polen monosulcado, de contorno ecuatorial oval con ángulos ampliamente redondeados. El sulco se extiende a lo largo de casi toda la superficie distal, aunque no alcanza el ecuador; los bordes son paralelos o bien se invaginan en el centro. Exina gruesa, lisa y rígida.

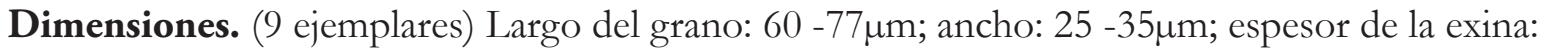
$1,5-2.5 \mu \mathrm{m}$.

Discusión y comparaciones. La forma del grano y rigidez de la exina podrían recordar al género Ephedripites, del que ha sido excluído por no presentar engrosamientos paralelos al sulco. La especie C. linae descripta por Herbst (1965) para el Triásico de Argentina, presenta dimensiones semejantes a esta, pero en aquel caso la exina es mucho más delgada y los ángulos más agudos debido a que el sulco se extiende hasta el ecuador. Esta última característica también está presente en C. grandis, del Jurásico de Australia (Sajjadi \& Playford, 2002b); con dimensiones similares y exina robusta, aunque menos rígida y de contorno diferente.

Material estudiado. PBN N3: MPEF Palin 61. 
Infraturma SCULPTATI Potonié 1970

Género Clavatipollenites Couper 1958

Especie tipo: Clavatipollenites hughesii Couper 1958 (pl. 31, figs. 19-22).

Observaciones. Ambas formas incluidas en este morfogénero son casi indistinguibles en una observación con microscopio óptico, aunque claramente diferentes al microscopio electrónico. Se ha preferido mantenerlos dentro del género por ser el más difundido y encontrar muy dificultosa la comparación con otras formas semejantes que no tienen una descripción basada en caracteres observados en el microscopio electrónico de barrido. Las descripciones hechas de este material se basan en ese tipo de caracteres.

\section{Clavatipollenites sp. A}

Lám. IXa-d

Descripción. Grano de polen con contorno ecuatorial subcircular-oval. Exina delgada y rígida que le confiere una forma subesférica. Está compuesta por una capa basal que porta numerosas columelas cortas no siempre visibles dispuestas de manera apretada. Por encima se presentan cubiertas por un tectum que es mayormente discontinuo, formando un semitectum finamente reticulado, en el que los muros son más anchos que los lúmenes. En menor medida, el tectum es continuo. Estos dos tipos de organización de la exina pueden estar presentes en un mismo ejemplar. El colpo es breve e irregular en extensión y forma, con bordes poco definidos.

Comentarios. La composición de la exina refleja una densidad electrónica alta que le confiere al grano un color claro y brillante.

Dimensiones. (148 ejemplares). Diámetro ecuatorial, 17 (20) $22 \mu \mathrm{m}$; espesor de la exina: 0,8 (1) $1,2 \mu \mathrm{m}$; espesor de la nexina: $0,3-0,5 \mu \mathrm{m}$.

Material estudiado. PBS N4: MPEF Palin 51-55.

\section{Clavatipollenites sp. B \\ Lám. IXe-g}

Descripción. Grano de polen monocolpado con contorno ecuatorial circular-subcircular. La exina es laxa y el grano aparece colapsado, con una apariencia discoide. Está compuesta por una capa basal en la que se insertan columelas largas dispuestas de manera espaciada. Esas columelas están unidas en su extremo por muros que forman un retículo de lúmenes amplios, con un tamaño de malla constante en toda la superficie. El colpo es breve e irregular en extensión y forma, con bordes poco definidos.

Comentarios. A diferencia de la especie A, la composición de la exina en este caso refleja una densidad electrónica baja, y el grano tiene un color más oscuro y opaco. 
Dimensiones. (126 ejemplares). Diámetro ecuatorial, 20 (24) 26 $\mu \mathrm{m}$; espesor de la exina: 1 $1,5 \mu \mathrm{m}$; espesor de la nexina: $0,3-0,5 \mu \mathrm{m}$.

Material estudiado. PBS N4: MPEF Palin 51-55.

Género Monocolpopollenites Pflug \& Thompson

en Thompson \& Pflug 1953

Especie tipo: Monocolpopollenites tranquillus (Potonié) Thompson \& Pflug 1953.

Comentarios. Esta forma se asigna al género Monocolpopollenites en el sentido dado por Krutzsch (Jansonius \& Hills, 1976: 1691), quien incluye a todas las formas monocolpadas con una esculturación fina (punteado, granulado y con verrugas planas).

\section{Monocolpopollenites sp.}

Lám. Xa-b

Descripción. Grano de polen monocolpado, de contorno subcircular a oval, colpo no siempre visible de extensión variable. Exina compuesta por dos capas, claramente estratificada. Nexina de espesor uniforme, mas delgada que la sexina. Capa columelar compuesta por columelas simples, dispuestas en forma densa. Tectum robusto $(0,5 \mu \mathrm{m})$ regularmente perforado.

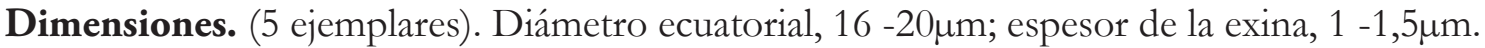

Discusión y comparaciones. Este tipo polínico presenta similitud con los granos hallados asociados a un estambre en la flora Barremiana-Aptiana? Vale de Agua de Portugal (Friis et al. 1999). En esa ocasión, los granos fueron observados con microscopía electrónica de barrido, pudiendo así determinar que las foveas en el tectum estaban dispuestas en una ancha faja ecuatorial. Este carácter es muy difícil de distinguir con una observación en microscopio óptico, sin embargo en el material en estudio esos elementos ornamentales aparentan estar uniformemente dispuestos en toda la superficie del grano.

Material estudiado. PBS N4: MPEF Palin 51,52 y 54.

Género Retimonocolpites Pierce 1961

Especie tipo: Retimonocolpites dividuus Pierce, 1961.

\section{Retimonocolpites sp. A}

Lám. Xc 
Descripción. Grano de polen monocolpado, semitectado, fusiforme con extremos agudos. Colpo bien definido que se extiende hasta los polos. Exina muy delgada, columelas muy reducidas que sólo en ocasiones están unidas por su extremo, formando un retículo delicado, de malla muy fina.

Dimensiones. (1 ejemplar) Diámetro ecuatorial $31 \mu \mathrm{m}$; espesor de la exina menor a $0,5 \mu \mathrm{m}$.

Material estudiado. PBS N4: MPEF Palin 51.

\section{Retimonocolpites sp. B}

Lám. Xe-f

Descripción. Grano de polen monocolpado, de contorno circular a subcircular, semitectada. Colpo bien definido, llegando al borde del grano. Exina gruesa claramente estratificada $(1,5 \mu \mathrm{m})$ más delgada cerca de la apertura $(0,7 \mu \mathrm{m})$. Retículo de lúmenes variables (heterobrocado), de malla más amplia en las proximidades del colpo.

Dimensiones. (1 ejemplar). Diámetro ecuatorial: $22 \mu \mathrm{m}$; espesor de la exina menor a 1,5 $\mu \mathrm{m}$; diámetro de los lúmenes: $0,5-1 \mu \mathrm{m}$.

Material estudiado. PBS N4: MPEF Palin 51.

Género Retiacolpites Schrank 2002

Especie tipo: Retiacolpites collumelatus Schrank 2002.

\section{Retiacolpites sp.}

Lám. Xd

Descripción. Grano de polen inaperturado, subesferoidal, circular. Exina delgada con una capa basal donde se insertan las columelas. Sexina reticulada, retículo homobrocado de lúmenes pequeños.

Dimensiones. ( 1 ejemplar) Diámetro ecuatorial: 23,5 $\mu \mathrm{m}$; espesor de la exina: $1 \mu \mathrm{m}$; diámetro de los lúmenes del retículo: $0,5-1 \mu \mathrm{m}$.

Discusión y comparaciones. La diferencia de este ejemplar con respecto a la especie tipo, radica en que presenta un diámetro menor ( $28-42 \mu \mathrm{m}$ ) y un menor tamaño en los lúmenes del retículo.(1 $-2 \mu \mathrm{m}$ vs. $0,5-1 \mu \mathrm{m})$.

Material estudiado. PBS N4: MPEF Palin 52. 
Género Asteropollis Hedlund \& Norris 1968

Especie tipo: Asteropollis asteroides Hedlund \& Norris, 1968.

\section{Asteropollis sp.}

Lám. Xg-h

Descripción. Granos de polen de contorno circular-subcircular. Exina relativamente gruesa y hialina, semitectada con un retículo irregular. Las aperturas son poco distinguibles (leptomas) y consisten en zonas de adelgazamiento de la exina sin forma ni delimitación definidas; aparecen en número variable sobre uno de las polos o bien pueden alcanzar el ecuador.

Dimensiones. (15 ejemplares). Diámetro ecuatorial: 22 (24) 30 $\mu \mathrm{m}$; espesor de la exina: 1 -2 $\mu \mathrm{m}$.

Comentarios. Este género ya había sido registrado en la Formación Punta del Barco en la localidad de Ea. El Verano (Llorens, 2000). En esa oportunidad el material fue asignado a la especie Asteropollis asteroides, aunque una revisión más detallada de los ejemplares, permitió visualizar una diferencia en el aparato apertural que los separa de la especie tipo. En aquel caso se trataba de una única apertura con tres a seis proyecciones, mientras en el material estudiado aquí, se encuentran zonas de debilidad de la exina que no siguen un patrón morfológico definido y tienen límites difusos.

Material estudiado. PBS N4: MPEF Palin 52; PBN N1: BA Pb Pal 5551, 5552, 5554, 5555, 5566 y 5575 . 


\section{LÁMINA VII}

\section{Granos de Polen}

a: Inaperturopollenites sp.

b-c: Arancariacites australis. c- fotografía tomada en el MEB.

d-e: Cyclusphaera psilata. d- fotografía tomada en el MEB; emicrofotografía donde se observan dos aperturas.

f: Cyclusphaera sp. Obsérvese el engrosamiento ecuatorial de poco espesor y los márgenes angulosos de la abertura.

g-h: Balmeiopsis limbatus. $\mathbf{g}$ - foto al MEB de un ejemplar en el que no se observan aberturas; $\mathbf{h}$ - ejemplar con un solo leptoma.

i: Classopollis sp.

j: Cycadopites nitidus

k: Cycadopites sp. A

Todas las escalas: $10 \mu \mathrm{m}$ 

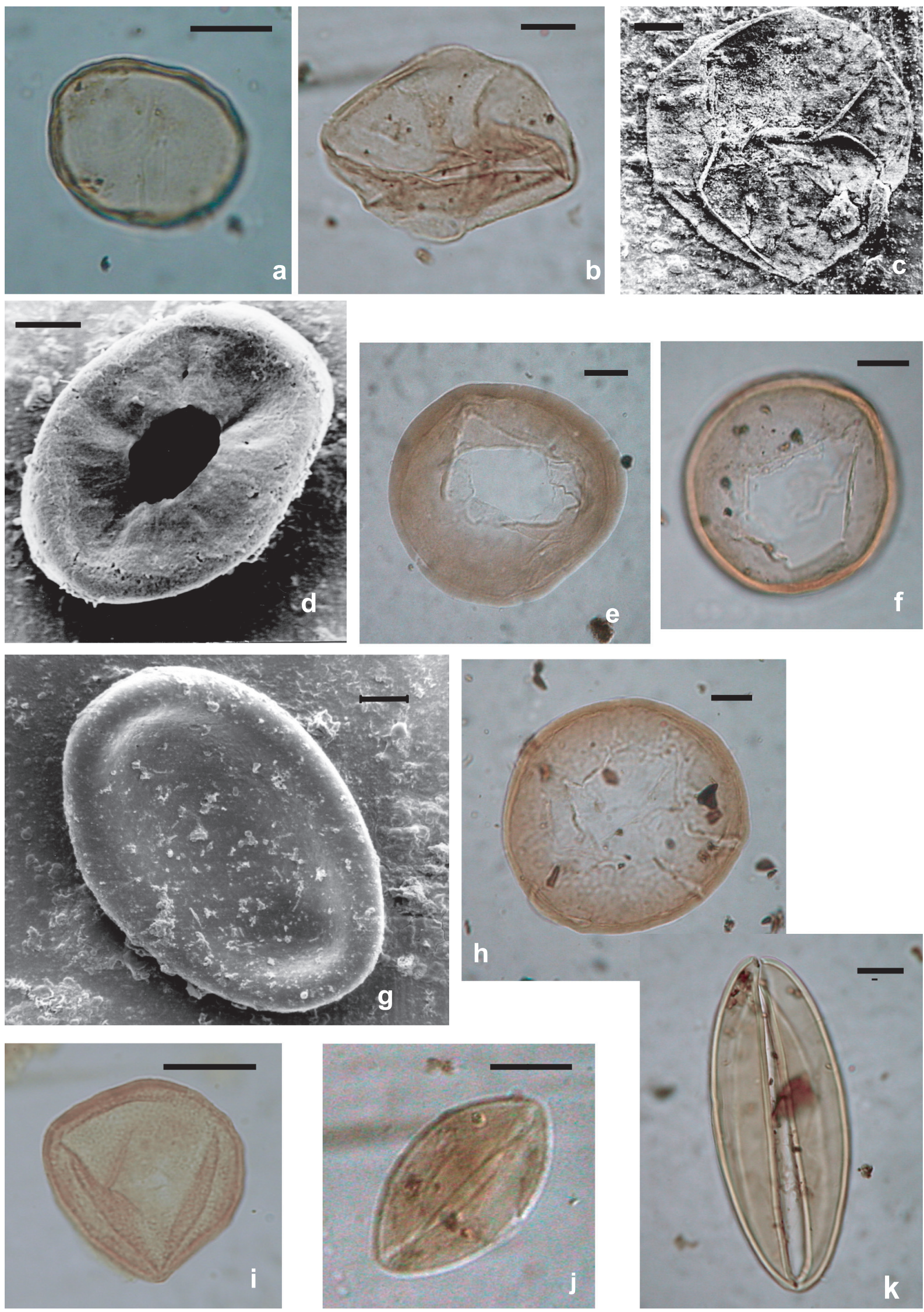


\section{LÁMINA VIII}

\section{Granos de Polen sacados}

a: Podocarpidites ellipticus

b: Podocarpidites marwickii

c-d: Microcachryidites antarcticus. d- fotografía tomada en el MEB.

e-f: Microcachryidites sp. A. e- fotografía tomada en el MEB.

g: Trisaccites microsaccatus

h: Dacrydiumites sp.

Todas las escalas: $10 \mu \mathrm{m}$ 

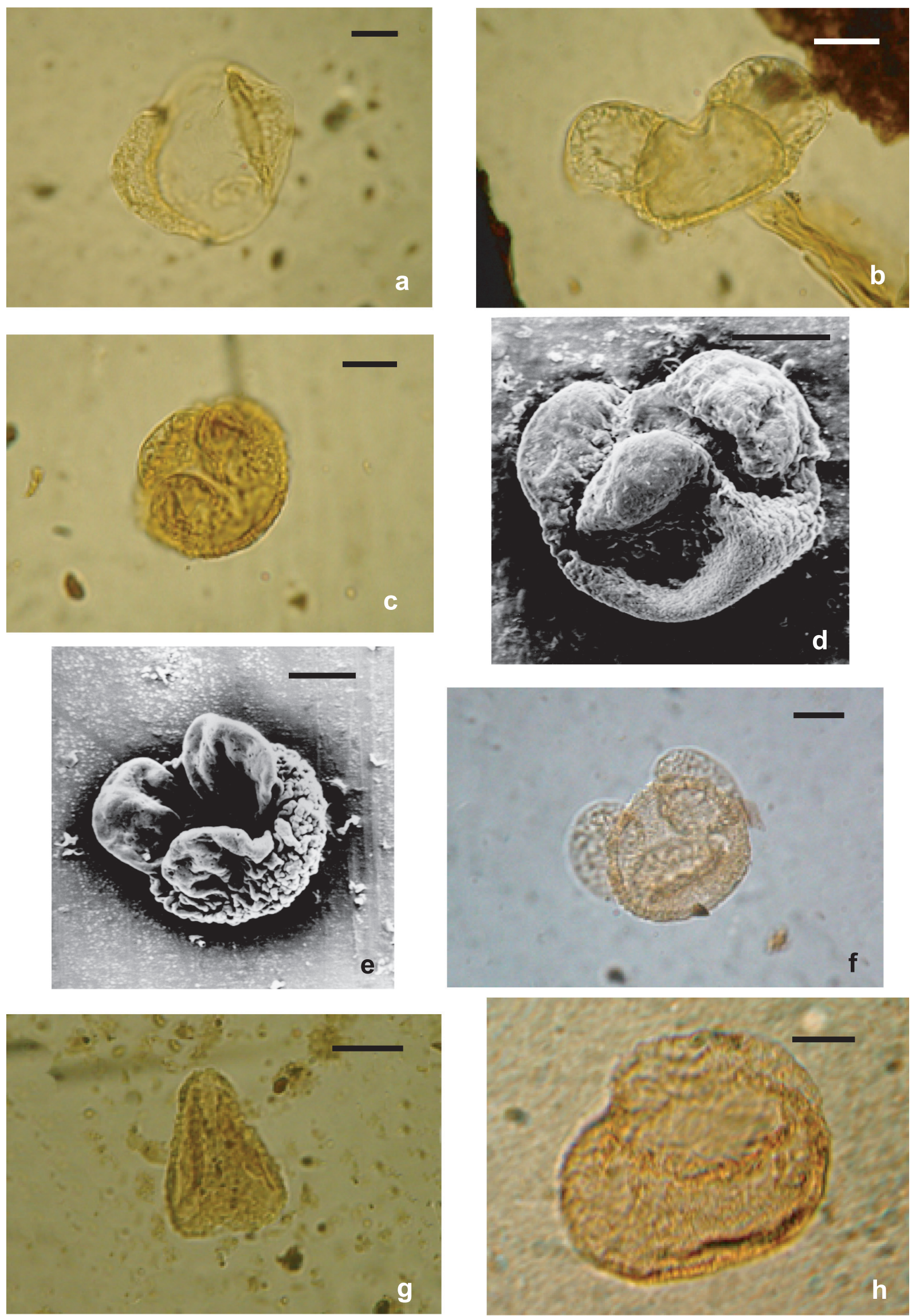


\section{LÁMINA IX}

\section{Género Clavatipollenites}

a-d: Clavatipollenites sp. A. a- abertura; b- corte óptico; c- vista ecuatorial con microscopía electrónica de barrido; $\mathbf{d}$ - detalle de la arquitectura de la pared, en la que se observa en semi tectum formando un retículo muy fino, y algunas columelas intectadas.

e-h: Clavatipollenites sp. B. e- borde del colpo; f- corte óptico de la pared; $\mathbf{g}$ - vista proximal mostrando un contorno circular; $\mathbf{h}$ - detalle de la arquitectura de la pared, en la que se observan las columelas altas unidas por un semi tectum.

Figuras a-b y e-f, las escalas equivalen a $10 \mu \mathrm{m}$.

Figuras $\mathbf{C}$ y $\mathbf{g}$, la escala representa $5 \mu \mathrm{m}$, en tanto en $\mathbf{d} \mathrm{y} \mathbf{h}, 1 \mu \mathrm{m}$. 

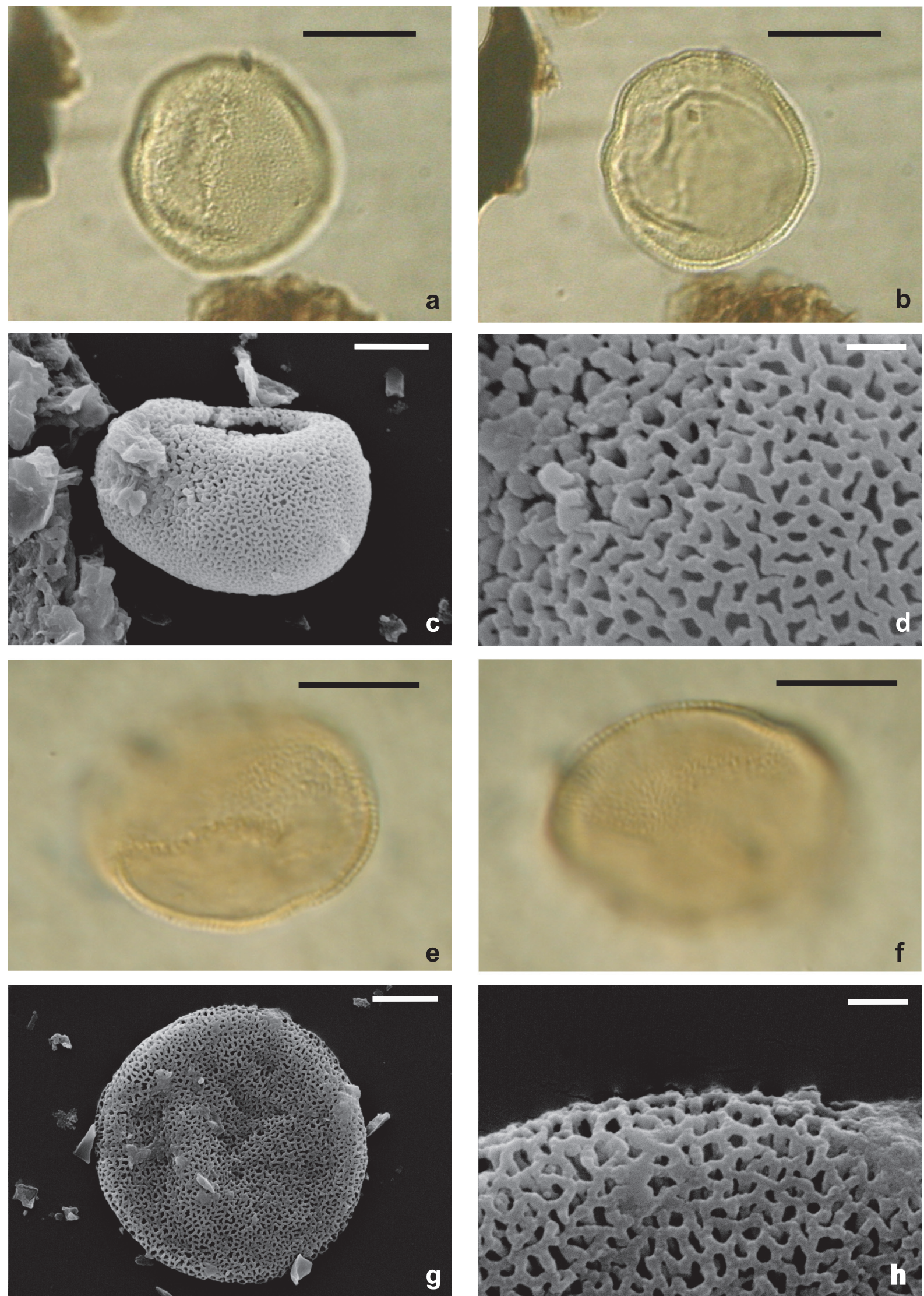

g

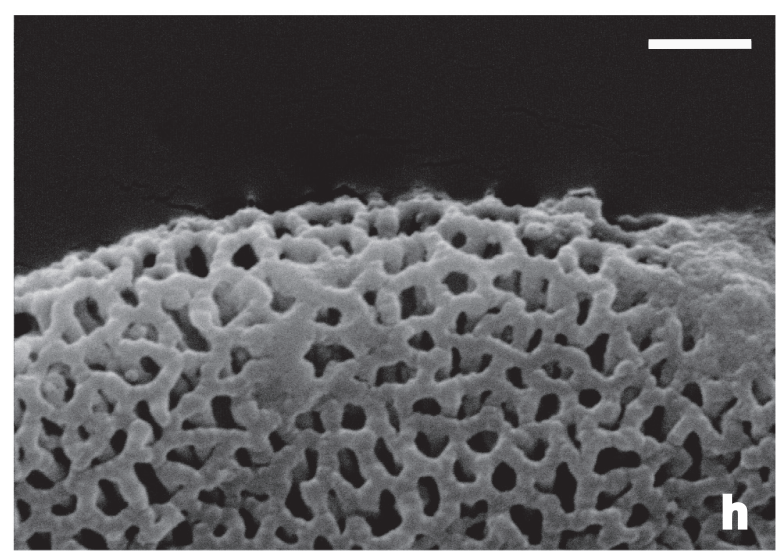




\section{LÁMINA X}

\section{Granos de Polen de Angiospermas}

a-b: Monocolpopollenites sp. a- corte óptico; b- vista ecuatorial donde se observa el extremo del colpo.

c: Retimonocolpites sp. A

d: Retiacolpites sp.

e-f: Retimonocolpites sp. B. e- vista distal donde se observan diámetros de malla mayores en las proximidades del colpo; f- corte óptico en el que se distingue un adelgazamiento de la pared cerca de la abertura.

g-h: Asteropollis sp. g- vista distal con las zonas de debilidad de la exina; $\mathbf{h}$ - vista proximal en la que se observa un retículo muy apretado.

Todas las escalas: $10 \mu \mathrm{m}$ 

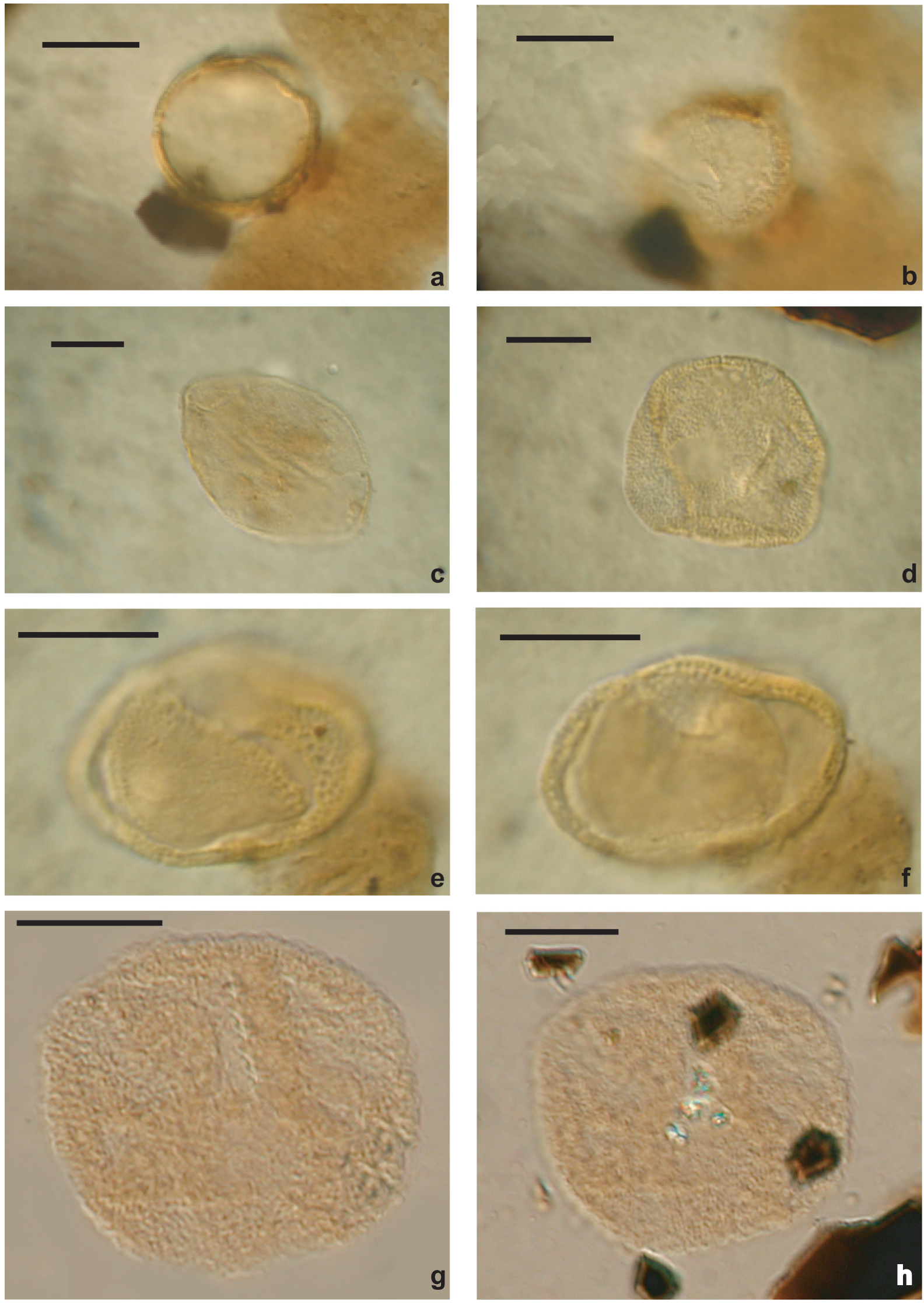


\section{III.1.2.3. Megasporas}

Género Hughesisporites Potonié 1956

Especie tipo. Trilites ( al. Triletes) galericulatus (Dijkstra) Potonié 1956

Hughesisporites cf. H. patagonicus Archangelsky 1965

Lám. XIa

Descripción. Megaspora trilete de forma aproximadamente subesférica, contorno ecuatorial circular y deprimida en sentido polar. Superficies de contacto con escultura verrucosa irregular; verrugas comúnmente alargadas, que se disponen en forma radial y tienden a converger hacia el polo proximal. Curvaturas ausentes, un fino surco marca el límite entre las caras proximal y distal; ésta última se presenta lisa.

Dimensiones. (1 ejemplar) Diámetro ecuatorial: $292 \mu \mathrm{m}$; ancho rayo del trilete: $11,5 \mu \mathrm{m}$; ancho de verrugas: $15,2-19 \mu \mathrm{m}$.

Discusión y comparaciones. El material tipo de esta especie fue descripto por Archangelsky (1965) para la actual Fm. Anfiteatro de Ticó. Aunque los caracteres generales de nuestro ejemplar coinciden bastante con los mencionados en esa ocasión, no se hace una asignación definitiva por contar con un único ejemplar que tiene algo degradada su porción polar. Por otra parte, su diámetro ecuatorial es bastante menor $(292 \mu \mathrm{m})$ que en el material original (529 $-644 \mu \mathrm{m})$.

Afinidad botánica. Familia Selaginellaceae. Gamerro (1975) sugirió la afinidad botánica con el género actual Selaginella Beauv.

Distribución estratigráfica. Esta especie ha sido citada para la Fm Anfiteatro de Ticó (Archangelsky, 1965; Archangelsky \& Villar de Seoane, 1990).

Género Bacutriletes (Van der Hammen) Potonié 1956

Especie tipo. Bacutriletes (Selaginellites) arnoldii (Miner 1932) Potonié 1956.

\section{Bacutriletes sp. 1}

Lám. XIb 
Descripción. Megaspora trilete de forma subesférica y contorno ecuatorial circular. Superficies de contacto ornamentadas con escultura fuertemente baculada e irregular; báculas comúnmente alargadas en la base, que se disponen de manera apretada sin un patrón definido. Los rayos de la lesura son rectos y alcanzan el ecuador surcados por un labio alto que está acompañado a su vez por un margo. Este, está compuesto de muros paralelos dispuestos en forma perpendicular al labio. No presenta curvatura, una leve diferencia de tamaños en los elementos esculturales marca el límite entre las caras proximal y distal.

Dimensiones. (1 ejemplar) Diámetro ecuatorial: $223 \mu \mathrm{m}$; ancho rayo del trilete (labio más margo): $50 \mu \mathrm{m}$; alto del labio: $20 \mu \mathrm{m}$; bases de las báculas: ancho $10 \mu \mathrm{m}$ y largo $15-20 \mu \mathrm{m}$; alto de las báculas: $20-27 \mu \mathrm{m}$.

Comparaciones. No se han encontrado en la literatura consultada ejemplares semejantes.

Afinidad botánica. Familia Selaginellaceae.

Género Horstisporites Potonié 1956

Especie tipo. Horstisporites ( al. Triletes) reticuliferus (Dijkstra) Potonié

\section{Horstisporites sp. 1}

Lám. XIc-d

Descripción. Megaspora trilete de forma tetraedral a biconvexa, subesférica con contorno circular en vista polar y elíptico en vista ecuatorial. Lesura recta con un labio protuberante y rígido que alcanza el ecuador. Curvatura ausente, el límite entre las caras proximal y distal está marcado por una leve diferencia del tamaño en la esculturación, siendo ésta menos visible en la cara proximal. Toda la superficie del cuerpo de la espora presenta un reticulado suave. Este retículo está formado por muros bajos de base ancha y agudos en el tope, que le confieren un patrón de lúmenes cóncavos con diámetros variables.

Dimensiones. (2 ejemplares) Diámetro ecuatorial: 650 -750 $\mu \mathrm{m}$; diámetro polar: $805 \mu \mathrm{m}$; ancho rayo del trilete: $50 \mu \mathrm{m}$; alto del labio: $76 \mu \mathrm{m}$; diámetro de los lúmenes: 25 -40 $4 \mathrm{~m}$.

Comparaciones. La mayor similitud encontrada es con la especie Horstisporites microlumenus Dett. descripta para el Mesozoico de Tasmania y Australia (Dettmann, 1961), aunque esos ejemplares 
no poseen labios prominentes y su retículo es más fino. También existen semejanzas con el ejemplar jurásico ilustrado por Morbelli (1990) y asignado como Hughesisporites sp. Sin embargo, en esa oportunidad la esculturación es más pronunciada en el hemisferio proximal que en el distal, situación inversa a la aquí presentada. Además nuestros ejemplares tienen un tamaño mucho mayor $(650-750 \mu \mathrm{m})$ a los del Jurásico $(400 \mu \mathrm{m})$.

Afinidad botánica. Familia Selaginellaceae.

Género Erlansonisporites Potonié 1956

Especie tipo. Erlansonisporites erlansonii (Miner) Potonié 1956

\section{Erlansonisporites sp.}

Lám. XIe-f

Descripción. Megaspora trilete de forma subesférica, con contorno subtriangular en vista polar. Lesura trilete. Superficie distal densamente reticulada. Ese retículo está formado por muros elevados que se fusionan en el extremo formando una superficie reticulada-foveolada, con lúmenes circulares de diámetros variables.

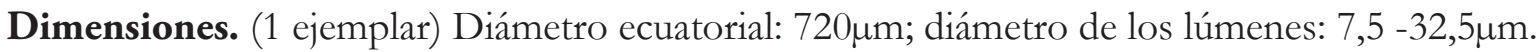

Comentarios. El único ejemplar encontrado se pudo observar sólo distalmente y su ornamentación se encuentra algo degradada. Sin embargo, pudo ser asignado a este morfogénero por tres caracteres contemplados en la diagnosis original: el trilete no siempre es visible, la ornamentación está compuesta por muros elevados y su frecuente hallazgo como fragmentos. Es evidente que los muros de nuestro ejemplar son delicados y vulnerables a la degradación, sin embargo perduran algunas porciones poco alteradas. Por otro lado, su apertura trilete se infiere por el contorno subtriangular del cuerpo.

Afinidad botánica. Familia Selaginellaceae.

Género Apiculatisporites Ibrahim 1933

Especie tipo. Triletes VI Bennie \& Kidston 1886 


\section{Apiculatisporites sp.}

Lám. XIg-h

Descripción. Espora trilete de forma esférica, con contorno circular en vista polar. Lesura trilete corta y simple. Ornamentación compuesta por espinas y espínulas; las primeras, en ocasiones tienen una relación base/alto cercana a 1 y podrían considerarse como conos. Los elementos se disponen densamente en toda la superficie excepto cerca del área de contacto donde tienen un tamaño menor y están más esparcidos. La exina está compuesta por dos capas, una interna lisa y la externa más gruesa y ornamentada. Ambas con estructura esponjosa.

Dimensiones. (1 ejemplar) Diámetro ecuatorial: $365 \mu \mathrm{m}$; espinas: alto: $4-6 \mu \mathrm{m}$ y base: $2-6 \mu \mathrm{m}$; espesor de la exina (sin escultura): $8 \mu \mathrm{m}-5 \mu \mathrm{m}$ la capa externa y $3 \mu \mathrm{m}$ la interna-.

Discusión. Este morfogénero ha sido largamente discutido (Jansonius \& Hills, 1976: 134). En esta oportunidad la asignación se hace siguiendo la diagnosis original, puesto que posteriormente las megasporas de este grupo morfológico fueran transferidas al género Tuberculatisporites Ibr. (Jansonius \& Hills, 1976: 3099-3101), pero ese otro grupo comprende una esculturación muy dispersa y con elementos redondeados. Nuestro ejemplar escapa a esa descripción.

Comentarios. Se ha considerado a la abertura observada como la lesura trilete luego de la germinación. Los caracteres tenidos en cuenta para hacer esa inferencia son la forma trirradiada de esa abertura y la presencia de elementos esculturales de menor tamaño y más dispersos en una de las áreas de contacto. Este último carácter ha sido identificado en algunas especies del género. Se ha considerado también que los elementos romos son el resultado del quiebre apical de las espinas más largas.

Afinidad botánica. Familia Selaginellaceae. 


\section{LÁMINA XI}

\section{Megasporas}

a: Hughesisporites cf. H. patagonicus

b: Bacutriletes sp. 1

c-d: Horstisporites sp. 1. c- vista proximal; d- vista ecuatorial.

e-f: Erlansonisporites sp. e- vista distal; f- detalle de la ornamentación.

g-h: Apiculatisporites sp. g- vista proximal de un ejemplar con la lesura abierta; $\mathbf{h}$ - detalle de la pared mostrando una estructura interna esponjosa.

Figuras a-e, las escalas equivalen a $100 \mu \mathrm{m}$.

Figuras f-g, la escala corresponde a $50 \mu \mathrm{m}$, y fig. $\mathbf{h}$, a $10 \mu \mathrm{m}$. 

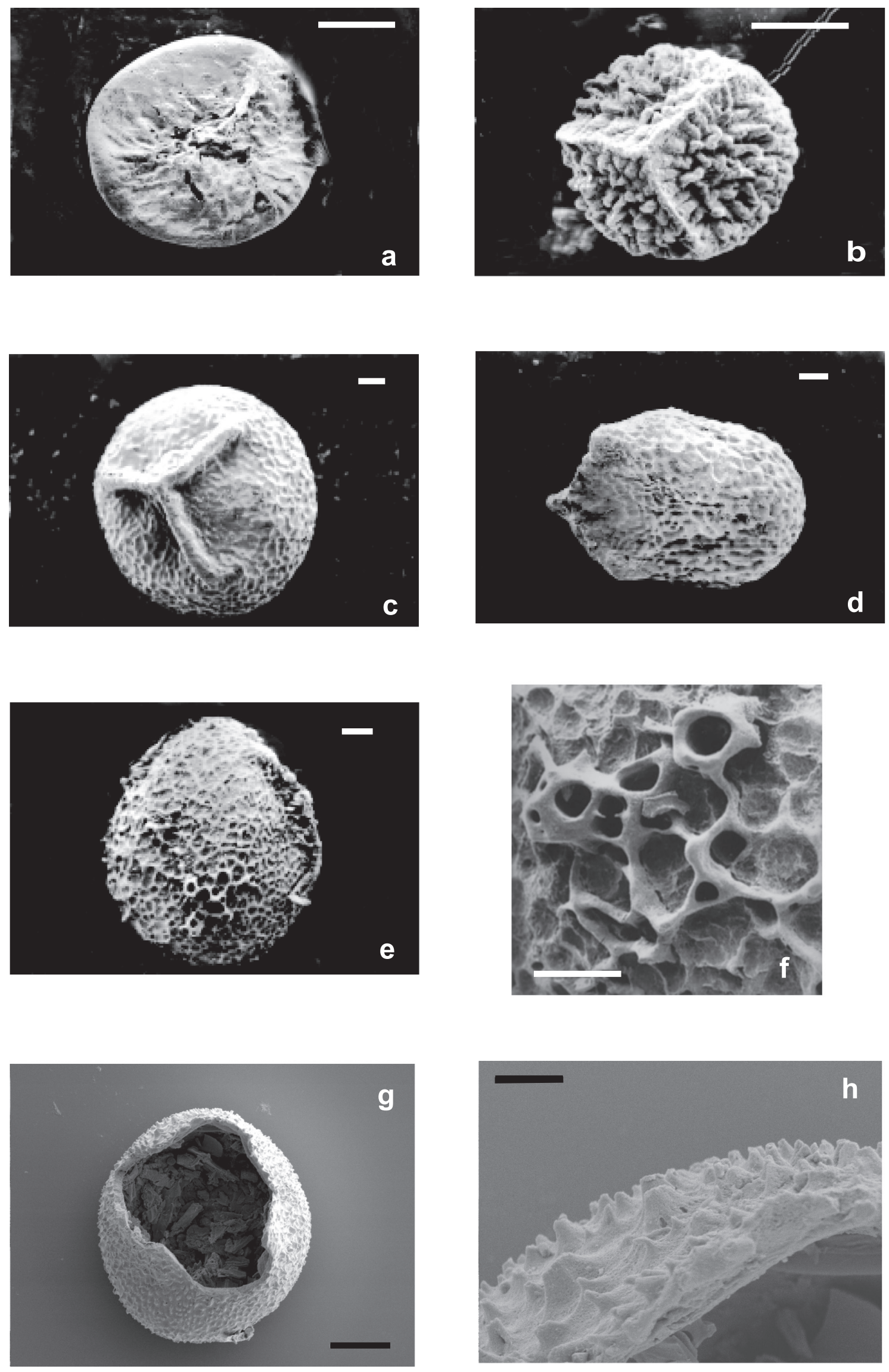


\section{III.1.2.4. Palinomorfos acuáticos}

\section{III.1.2.4.1. Algas}

División Chlorophyta Pascher 1914

Clase Chlorophyceae Kützing 1843

Orden Chlorococcales Marchand 1895 orth. mut. Pascher 1915

Familia Botryococcaceae Wille 1909

Género Botryococcus Kützing 1849

Especie tipo. Botryococcus braunii Kützing 1849

\section{Botryococcus sp.}

Lám. XIIa

Descripción. Colonia multicelular con cúpulas organizadas más o menos radialmente. Estas cúpulas son los vestigios de las células vivas que se desprenden dejando esos restos en la matriz de la colonia. Las formas y tamaños son variados.

Material estudiado. PBS N4; PBN N1.

Orden Zygnematales Borge and Pascher 1931

Familia Zygnemataceae (Meneghini) Kützing 1898

Género Lecaniella Cookson \& Eisenack 1962

Especie tipo. Lecaniella margostriata Cookson \& Eisenack 1962

Lecaniella foveata Singh 1971

Lám. XIIb-c

Descripción. Zigospora típicamente separada en dos mitades a lo largo de una sutura ecuatorial de dehiscencia. Contorno ecuatorial circular, cada mitad conserva esa forma. Pared con dos capas, una interna lisa y la externa ornamentada con muros bajos que se anastomosan formando un retículo. A lo largo de la sutura, se observa una zona marginal lisa.

Dimensiones. (3 ejemplares) Diámetro ecuatorial: 53 - $61 \mu \mathrm{m}$; espesor de la capa interna: 0,8 -

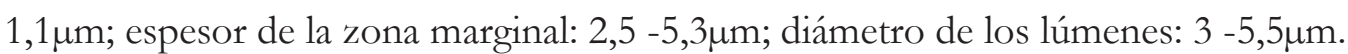


Afinidad botánica. Este tipo de esporas se encuentran en los representantes actuales de la Familia Zygnemataceae, en especial en la especie Zygogonium tunetanum, cuyas esporas presentan una ornamentación foveo-reticulada (Zippi 1998). La presencia de esporas con esta afinidad, tiene interesantes implicancias ecológicas (ver cap. V.2.2.3).

Distribución estratigráfica. Albiano de Canadá (Zippi 1998). Ver distribución completa en Singh (1971).

Material estudiado. PBN N1: BA Pb Pal 5500 y 5503.

Género Schizosporis (Cookson \& Dettmann) Pierce 1976

Especie tipo: Schizosporis reticulatus Cookson \& Dettmann 1959.

Schizosporis reticulatus Cookson \& Dettmann 1959

Lám. XIId

Descripción. Especímenes típicamente esféricos a levemente elipsoidales con su eje menor perpendicular al plano ecuatorial. La sutura de dehiscencia se extiende a lo largo del ecuador. A menudo se encuentran las mitades de los ejemplares dispersas. Pared externa compuesta por celdas más o menos isodiamétricas y con una forma redondeada, limitada por 5 a 7 celdas con las que comparte una pared en común. La pared externa de las celdas está ausente.

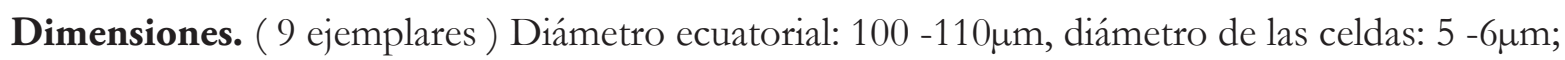
espesor de la capa basal: $2 \mu \mathrm{m}$.

Material estudiado. PBS N4: MPEF Palin 56, 64 y 66.

Distribución estratigráfica. Ver lista sinonímica y distribución en Zippi (1998)

Argentina: Fm. Anfiteatro de Ticó, Jurásico de Cuenca Neuquina (Vallati, 2001).

Afinidad botánica. La sutura ecuatorial longitudinal es un carácter diagnóstico de las Zygnemataceae (Zippi 1998).

Material estudiado. PBS N4: MPEF Palin 56; N2: 66 y 64. 
Género Ovoidites (Cookson \& Dettmann) Nakoman 1966

Especie tipo. Ovoidites ligneolus Potonié ex Krutzsch 1959

Ovoidites parvus (Cookson \& Dettmann) Zippi 1998

Lám. XIIe

Descripción. Zigospora con forma elipsoidal y una sutura a lo largo de la cual se divide en dos partes iguales. La exina es lisa, con una coloración amarilla.

Dimensiones. (20 ejemplares) Largo: 52 (87) $115 \mu \mathrm{m}$; ancho: 21 (32) $45 \mu \mathrm{m}$.

Comentarios. Este taxón ha sido ampliamente citado en todo el mundo y también hay varias citas para el país con el nombre de Schizosporis parvus. Zippi (1998) realiza un exhaustivo análisis de la situación nomenclatorial de la especie y considera que pertenece al género Ovoidites, en tanto brinda una completa lista sinonímica y de distribución.

Distribución estratigráfica. Ver distribución mundial en Zippi (1998).

Argentina: ampliamente distribuído en el país.

Afinidad botánica. $O$. parvus tiene una similitud directa a las zigosporas de varias especies de los géneros actuales Spirogyra y Zygogonium (Zippi 1998).

Material estudiado. PBS N4: MPEF Palin 51, 52, 54, 56, 57 y 59; N2: 66.

Género Tetraporina Naumova emend. Lindgren 1980

Especie tipo. Tetraporina antiqua Naumova 1950

Distribución estratigráfica. El género tiene un rango del Carbonifero a la actualidad: ver distribución completa en (Jarzen 1979).

Afinidad botánica. El género incluye formas con caracteres en común con varios géneros modernos de las Zygnemataceae (Jarzen 1979). 


\section{Tetraporina sp. 1}

Lám. XIIf

Descripción. Zygospora cuadrangular con lados levemente cóncavos y ángulos redondeados amplios. Exina rígida psilada. Sutura de dehiscencia ecuatorial.

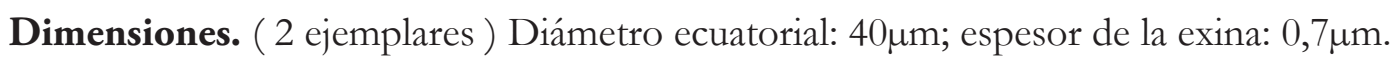

Material estudiado. PBS N3: MPEF Palin 70.

\section{Tetraporina sp. 2}

Lám. XIIg

Descripción. Zygospora cuadrada con lados rectos a levemente convexos y ángulos agudos. Exina lisa, hialina, delgada y con pliegues secundarios. Sutura de dehiscencia ecuatorial.

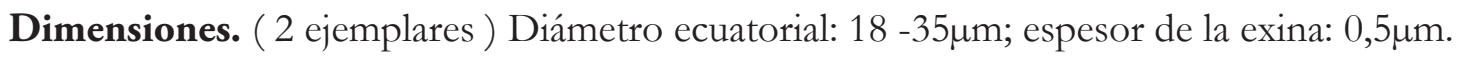

Material estudiado. PBS N4: MPEF Palin 55.

Género Chomotriletes Naumova 1939 ex 1953

Especie tipo. Chomotriletes vedugensis Naumova 1953.

Chomotriletes minor (Kedves) Pocock 1970

Lám. XIIh

Descripción. Espora alete de contorno ecuatorial circular a subcircular. Ambas caras ornamentadas por muros bajos (menores a $1 \mu \mathrm{m}$ ) y delgados, que forman anillos concéntricos que se repiten desde el ecuador hasta el polo, donde en ocasiones suelen presentarse interrumpidos. El canal que separa dos anillos contiguos es levemente más ancho que los muros $(0,9 \mu \mathrm{m}-1,1 \mu \mathrm{m})$.

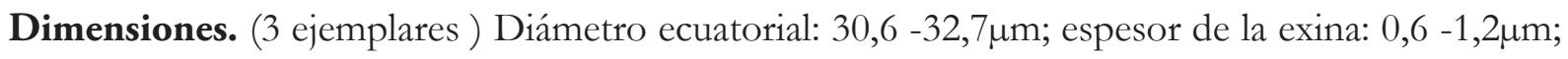

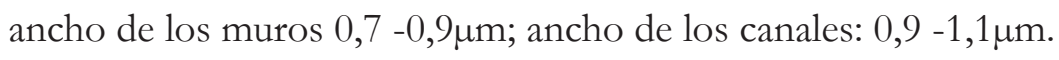


Distribución estratigráfica. En el país este taxón está descripto para la Fm. Anfiteatro de Ticó (Archangelsky \& Villar de Seoane, 1996), y en esa ocasión las medidas coinciden con las nuestras. Vallati (2001) ha reportado ejemplares de Chomotriletes sp. para las Formaciones Huincul y Cerro Lisandro (Albiano?-Cenomaniano) de la Cuenca Neuquina.

Mundialmente están registrados entre el Jurásico Superior y el Albiano (ver Zippi, 1998).

Afinidad botánica. Se han especulado diversas afinidades para este palinomorfo (ver Vallati, 2001) aunque en los últimos años se ha coincidido en darle una afinidad incierta (Batten, 1996), y Zippi (1998) advierte similitudes en su ornamentación con algunas oosporas de las Oedogoniaceae.

Material estudiado: PBN N1: BA Pb Pal 5577 y 5574.

III.1.2.4.2. Incertae Sedis

Género Retirotundia (Krutzsch) Zippi 1998

Especie tipo. Retirotundia pseudoreticulata Krustzsch 1970

Retirotundia pseudoreticulata (Krutzsch) Zippi 1998

Lám. XIIi

Descripción. Cuerpo esférico pequeño con una pared gruesa dividida en secciones poligonales, produciendo un retículo negativo en la superficie. Las bases de las columnas poligonales están conectadas formando la capa interna de la pared. Los lados de las secciones poligonales están estriados verticalmente, mientras que la superficie superior es granular.

Dimensiones. (2 ejemplares) Diámetro ecuatorial: $24 \mu \mathrm{m}$; espesor de la pared: $2,5 \mu \mathrm{m}$; diámetro de las columnas poligonales: $6 \mu \mathrm{m}$.

Distribución estratigráfica. Sólo existen registros previos para el Plioceno a Pleistoceno temprano de Europa Central (Krutzsch 1970 y Krutzsch \& Pacltova 1990, según Zippi 1998) y para el Albiano de Canadá.

Afinidad botánica. El tamaño pequeño y la falta de una marca de dehiscencia, favorece una afinidad con los hongos, en tanto la carencia de poros, hace pensar que puede tratarse de un quiste de algas clorofíceas.No obstante, diversos autores coinciden en que se trata de un elemento planctónico de agua 
dulce (Zippi 1998). Este autor confirmó esa postura al haber hallado en un lago actual especímenes de este tipo.

Material estudiado. PBN N1; PBS N4: MPEF Palin 54.

\section{Formas inaperturadas gen. et sp. indeterminados}

Comentarios. Las formas aquí presentadas son palinomorfos inaperturados que presentan pocos caracteres diagnósticos, y los que tiene, son comunes a varios géneros. Es así que teniendo en cuenta sólo aspectos morfológicos, los ejemplares descriptos como Inaperturado sp. 1, podrían incluirse en el género Laricoidites, con el que difiere sólo por poseer tamaños menores. Los otros podrían asignarse también al género Inaperturopollenites en el sentido de Nilsson (Jansonius \& Hill, 1976: 1308), quien consideró sólo formas inaperturadas azonadas, con una exina firme y lisa. En ambos casos se trata de granos de polen y se sugirió una afinidad botánica con las gimnospermas. Por otro lado, géneros como Leiosphaera y Membranosphaera son también afines al material aquí descripto, pero no es conveniente referirlo a ellos, siendo que en ambos casos fueron hallados en sedimentos de origen marino.

Considero que la afinidad más probable sería con las algas, dado que hay una gran abundancia y diversidad de esporas de resistencia por la recurrencia de facies correspondientes a planicies de inundación (ver cap. V.2.2.3).

\section{Inaperturado sp. 1}

Lám. XIIj

Descripción: Vesículas esféricas de contorno circular a oval y tamaño pequeño. Pared delgada y rígida de color amarillo claro, con pliegues ocasionales.

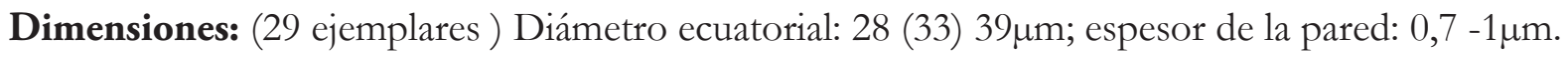

Material estudiado: PBS N4: MPEF Palin 57, 54 y 52; N2: MPEF Palin 64; PBN N4: MPEF Palin 62.

\section{Inaperturado sp. 2}

Lám. XIIk 
Descripción: Vesículas de contorno primario circular. Pared delgada altamente flexible y de color amarillo claro, que aparece con numerosos pliegues que hacen difusa su forma inicial.

Dimensiones: (10 ejemplares ) Diámetro ecuatorial: 27 (40) 50 $\mu \mathrm{m}$; espesor de la pared: menor a $0,5 \mu \mathrm{m}$.

Material estudiado: PBS N4: MPEF Palin 51, 52, 56 y 62; N2: MPEF Palin 67.

\section{Inaperturado sp. 3}

Lám. XIIl

Descripción: Vesículas de contorno más o menos circular, pared gruesa muy rígida y de color amarillo.

Dimensiones: (4 ejemplares ) Diámetro ecuatorial: $45-62 \mu \mathrm{m}$; espesor de la pared: $2-2,5 \mu \mathrm{m}$.

Material estudiado: PBN N3: MPEF Palin 61; N6: MPEF Palin 71. 


\section{LÁMINA XII}

\section{Palinomorfos Acuáticos}

a: Botryococcus sp.

b-c: Lecaniella foveata. $\mathbf{b}$ - foto al microscopio óptico; c- fotografía tomada con MEB.

d: Schizosporis reticulatus

e: Ovoidites parvus

f: Tetraporina sp. 1

g: Tetraporina sp. 2

h: Chomotriletes minor

i: Retirotundia pseudoreticulata fotografía de MEB.

j: Inaperturado sp. 1

k: Inaperturado sp. 2

I: Inaperturado sp. 3

Todas las escalas: $10 \mu \mathrm{m}$ 

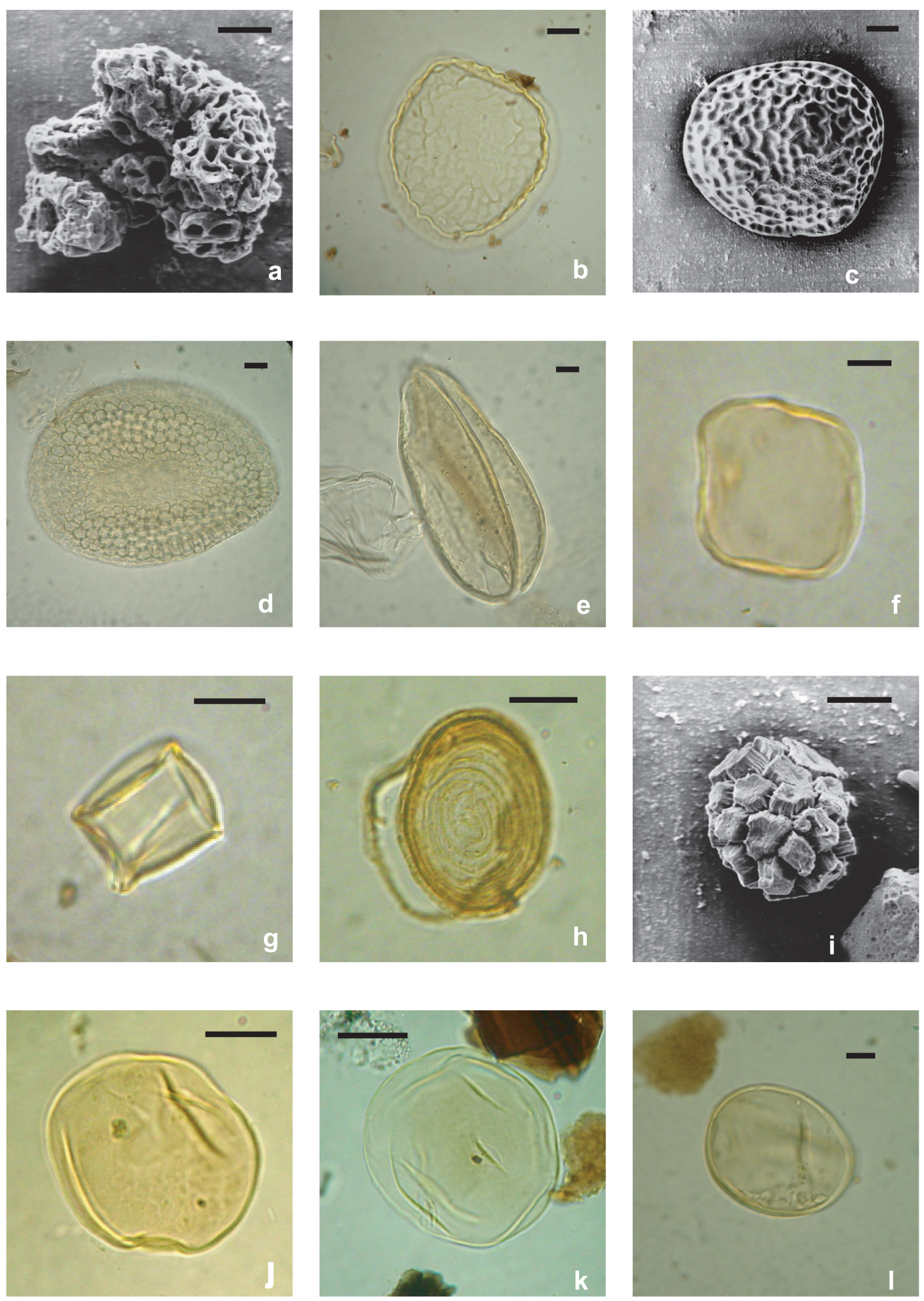


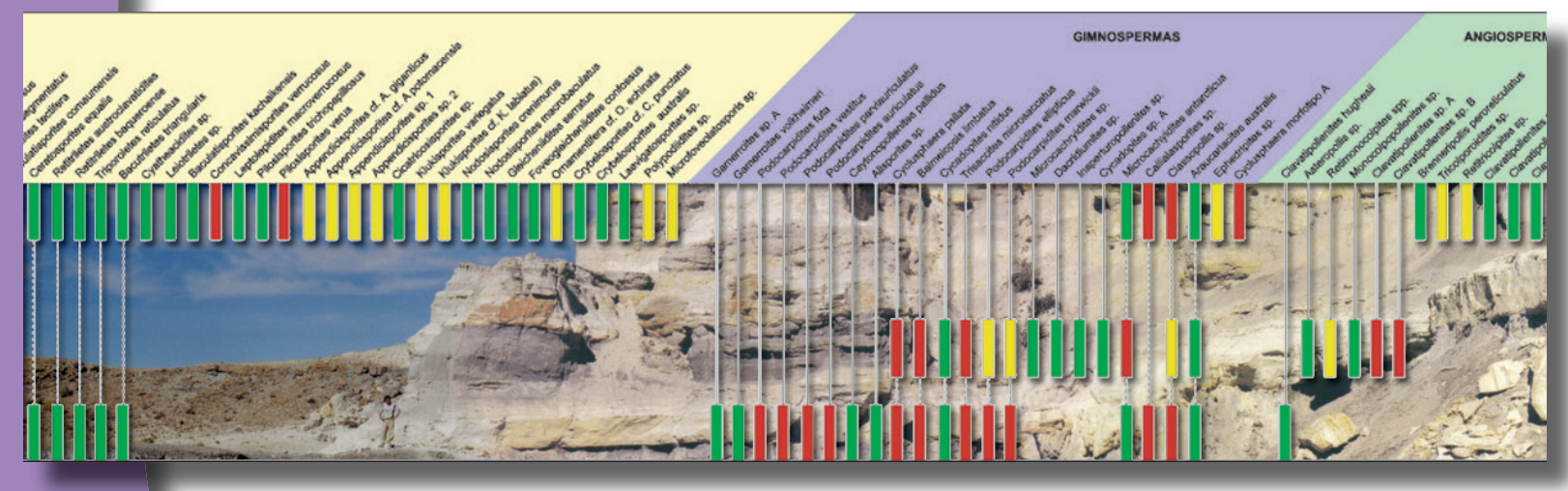

CAPITULO IV

Bioestratigrafía 


\section{BIOESTRATIGRAFÍA}

\section{Introducción}

Las unidades bioestratigráficas fueron definidas por Hedberg (1972) como "un cuerpo de estratos de roca, el cual está unificado por su contenido fosilífero o carácter paleontológico y así diferenciado de estratos adyacentes".

El estudio sistemático de la microflora de la Fm. Punta del Barco ha revelado una importante diferencia en su composición con respecto a la microflora conocida de la Formación inferior del Grupo Baqueró: Anfiteatro de Ticó.

Cuando la categoría de los taxones involucrados en este tipo de cambios es alta (géneros, familias u órdenes), su desaparición de los registros es un importante indicio que puede significar un cambio en las condiciones de vida de la biota continental. Si son varios los taxones que simultáneamente desaparecen de la columna estratigráfica, es muy probable que estemos en presencia de una extinción biótica de cierta magnitud. Este parecería ser el caso del cambio producido en la biota baqueroense. Esas diferencias, sumadas a las que se observan en la megaflora, justifican un análisis bioestratigráfico de detalle.

Para tal fin, se incluyen en este análisis a las restates unidades formacionales de Grupo Baqueró y a la Fm. Kachaike, dado ellas contienen las tafofloras conocidas de mayor cercanía témporo-espacial (más antiguas y más moderna, respectivamente). El objetivo del estudio es identificar los grupos polínicos que intervienen en el cambio florístico mencionado y cotejar los resultados arrojados por la palinoestratigrafía con aquellos que fueran observados en la megaflora, a fin de evaluar la validez de las biozonas propuestas para el Grupo y observar la evolución florística de Patagonia Austral durante el lapso Aptiano-Albiano.

\section{IV.1. Grupo Baqueró}

\section{IV.1.1. Distribución estratigráfica de los palinomorfos reconocidos en la Formación Punta del Barco}

Se estudiaron palinomorfos en 6 niveles que forman una secuencia, siendo el nivel 1 el más antiguo y el nivel 6 el más moderno. Esta secuencia resultó de la integración de los datos obtenidos en los distintos niveles fértiles de ambas localidades estudiadas: Punta del Barco Norte (PBN) y Punta del Barco Sur (PBS) (ver cap. II.6.3). Los niveles fértiles 1, 3 y 6 provienen de PBN, en cambio, los niveles 2 y 5, de PBS. El nivel 4 es el único representado en ambos perfiles, aunque la mayor parte de la información procede de la muestra tomada en PBS.

En el cuadro 3 (pág. 139) se presenta la distribución de todos los taxones en los niveles estudiados. Allí puede observarse una disminución de taxones representados a lo largo de la columna estratigráfica. El nivel 1 es, entonces, el que mayor diversidad y cantidad de palinomorfos presenta. Aquí las esporas de gleicheniáceas son el grupo mejor documentado, con casi un 30\% del total de la asociación, también son importantes las araucariáceas -representadas por Cyclusphaera-Balmeiopsis- 
Arancariacites- (19\%) y las podocarpáceas -Microcachryidites-Trisaccites- $(7 \%)$.

Son elementos comunes y exclusivos de este nivel: las esporas perisporadas - Auroraspora, Lygodiidites, etc.-, los géneros Contignisporites, Ceratosporites, Cyathidites, Concavissimisporites, Todisporites, Biretisporites, Staplinisporites, Trisaccites, Clavifera, Reticuloidosporites, Inaperturopollenites, Balmeiopsis y Araucariacites. También hay especies exclusivas: Gleicheniidites sp. 1, 2, 3 y 4, Deltoidospora sp. A, Laevigatosporites sp., Foraminisporis sp.y Cycadopites nitidus. Además, cuatro de las cinco de las megasporas de esta asociación han sido rescatadas en este horizonte.

El segundo nivel es muy pobre y sólo se han registrado unas pocas esporas de Retitriletes y granos esporádicos de Podocarpidites.

El horizonte 3 es un poco más rico en palinomorfos, y tiene a Cycadopites sp. A, Cyclusphaera sp. y Deltoidospora sp. B como taxones exclusivos.

La mayor cantidad de información del cuarto nivel fue aportada por una lente con características especiales (ver cap. V.2.3.4) que propició la preservación de granos con afinidad angiospérmica. Ellos refieren más del 40\% de la asociación, y aportan a este nivel taxones exclusivos como: Clavatipollenites, Retimonocolpites, Monocolpopollenites y Retiacolpites. Además de los géneros Apiculatisporites y Dacrydiumites. Este nivel también ha aportado una gran cantidad de palinomorfos acuáticos exclusivos.

El nivel 5 es muy pobre en palinomorfos y no tiene taxones característicos.

Finalmente, el sexto nivel presenta sólo restos de hongos y algas. Estas últimas son el único grupo representado en todos los horizontes fértiles del perfil.

El taxón más longevo es Gleicheniidites senonicus, presente desde el nivel 1 al 5. Otros taxa que persisten a lo largo de la columna son Ornamentifera sp. 2, Foraminisporis dailyi, Densoisporites velatus y D. corrugatus; también los granos de Podocarpidites y Classopollis, aunque muy probablemente en ambos casos se trate de material redepositado (ver cap. V.3.2.3). Por último, Asteropollis sp. persiste desde el nivel 1 al 4, siendo la forma angiospérmica más difundida en el perfil y la de más temprana aparición.

\section{IV.1.2. Comparación con la palinoflora de la Formación Anfiteatro de Ticó}

La ubicación estratigráfica de la Fm. Anfiteatro de Ticó en el Grupo Baqueró, por debajo de la Fm. Punta del Barco, invita a una comparación con la asociación que hemos estudiado.

La palinoflora de la Fm. Anfiteatro de Ticó comprende 108 taxones que fueron estudiados en sucesivas contribuciones por varios autores: Archangelsky (1965; 1966 a y b), Gamerro (1965 a y b); Archangelsky \& Gamerro (1965; 1966 a, b y c; 1967 a y b); Gamerro (1975); Archangelsky (1977); Baldoni \& Taylor (1982); Taylor et al. (1987); Archangelsky (1988); Taylor \& Taylor (1988); Archangelsky \& Villar de Seoane (1989, 1990, 1991, 1992, 1994, 1996, 1998 y 2005); Archangelsky \& Taylor, 1993; Archangelsky (1994).

En el cuadro 4 (pág. 140) se incluye la lista de especies de la formación Anfiteatro de Ticó y se establecen las coincidencias con la Fm. Punta del Barco. En tanto, se ilustra el mismo tipo de 
comparación en base a la lista genérica, en el cuadro 5 (pág. 140).

La comparación general entre las microfloras muestra una marcada disparidad entre la muy rica asociación de la Fm. Anfiteatro de Ticó y otra más pobre para la palinoflora en estudio. Sólo un $15,74 \%$ de las especies presentes en la asociación basal están presentes también en la cuspidal. Existen 17 coincidencias entre ambas asociaciones, de las cuales 2 (Podocarpidites ellipticus y $P$. marwikii) muy probablemente sean producto de la redepositación.

Otras concordancias involucran a 3 araucariáceas (Cyclusphaera psilata, Balmeiopsis limbatus y Araucariacites australis) y 2 podocarpáceas (Microcachryidites antarcticus y Trisaccites microsaccatus).

Cinco de las especies compartidas están ligadas a facies de cuerpos de agua dulce (Foraminisporis dailyi, Staplinisporites caminus, Chomotriletes minor, Densoisporites velatus y D. corrugatus) y no revisten interés bioestratigráfico.

Un aspecto interesante es la diferencia que marcan ciertos grupos vegetales. Tal es el caso de las licopsidas representadas por megasporas: son muy diversas y mucho más abundantes en la Fm. Anfiteatro de Ticó que en la Fm. Punta del Barco. Sin embargo es de destacar que las aquí estudiadas no se corresponden con las primeras, excepto por la especie Hughesisporites patagonicus, manifestando un cambio composicional en estas pteridofitas.

Otro grupo que marca diferencias es el de las angiospermas, con un único referente en la formación inferior (Clavatipollenites hughesii) y una mayor diversidad en la superior, donde aquél único taxón no está presente.

La comparación a nivel genérico pone en evidencia una mayor coincidencia, que alcanza un 41,2\%. En gran medida esto sucede porque hay géneros como Gleichenïdites, por ejemplo, que si bien está ampliamente representado en ambas microfloras, comparte sólo una especie (Gleicheniidites senonicus).

El género Cicatricosisporites, que representa a la Familia Schizaeaceae, es distintivo en la palinoflora más antigua, mientras está ausente en la más moderna. Un caso similar se da con las esporas de los géneros Cyatheacidites, Polypodiaceisporites y Muricingulisporis, que son abundantes en los depósitos de la Formación Anfiteatro de Ticó, y no se han registrado en la Fm. Punta del Barco. Esto marca una retracción de las familias Lophosoriaceae y Pteridaceae.

Por otro lado, el género Classopollis presenta una situación semejante, aunque si bien está presente en ambas microfloras, en la asociación en estudio su presencia muy probablemente, sea producto de la redepositación, situación ésta similar a la de Podocarpidites (ver cap. V.3.2.3).

Los géneros Alisporites, Vitreisporites y Caytonipollenites son representantes de las pteridospermas, y de igual manera faltan en la asociación superior.

Es así que puede inferirse una palinoflora inicial rica, con muchos grupos vegetales representados, que más tarde se empobrece con la desaparición casi completa de algunos de esos grupos y la disminución numérica de otros. 


\section{IV.1.3. Caracterización de las asociaciones inferior y superior y propuesta de biozonas}

En este trabajo se proponen dos Biozonas (o Zonas Bioestratigráficas), para el Aptiano Temprano de Patagonia Austral, representadas ambas en el Grupo Baqueró emplazado en el Cratón del Deseado. Esta zonación se basa en la distribución estratigráfica de los palinomorfos que se listan en los cuadros 6 y 7 (pág. 141 y 142), donde se integraron los datos de las megasporas. La definición se ha hecho según los lineamientos del Código Argentino de Estratigrafía (Art. 41 al 45). Por sus características, se las clasifica como Biozonas de Asociación, según el artículo 38 de dicho código. Se describen a continuación en edad decreciente:

\section{IV.1.3.1. Biozona de Asociación A}

Esta unidad se halla registrada en las áreas Anfiteatro de Ticó, Bajo Grande y Bajo Tigre (Archangelsky, 2003). Los principales taxones que caracterizan esta asociación son los géneros Podocarpidites Cicatricosisporites - Classopollis, por ser los elementos con mayor diveridad y abundancia. Los dos primeros tienen una representatividad variable según los diferentes niveles, en tanto Classopollis es muy abundante en toda la columna estratigráfica. El límite inferior de esta biozona corresponde al primer registro de polen del complejo Clavatipollenites, que cuenta en esta biozona con un único representante.

La unidad presenta un número elevado de taxones exclusivos. Esto sucede a nivel específico: Podocarpidites futa, P. vestitus, P. auriculatus, P. parviauricularus, Ceratosporites cetosus, Cicatricosisporites ticoensis, C. baqueroensis, etc., y a nivel genérico: Auriculozonospora, Muricingulisporis, Trilobosporites, Reticulatisporites, Gamerroites, Caytonipollenites, etc. (ver listas completas en los cuadros 4 y 5).

Estratigráficamente coincide con la Formación Anfiteatro de Ticó.

Estratotipo: La sección tipo de esta biozona corresponde a la parte inferior del perfil de la localidad Anfiteatro de Ticó, que es a su vez, el perfil tipo de la formación homónima (ver figura 3 en Cladera et al. 2002).

\section{IV.1.3.2. Biozona de Asociación B}

Esta biozona se encuentra representada en el área de Meseta Baqueró, con dos localidades: Punta del Barco Norte y Punta del Barco Sur.

Se caracteriza por la abundancia y diversidad de esporas emparentadas con la Familia Gleicheniaceae (Gleicheniidites, Clavifera y Ornamentifera). La particularidad de esta unidad radica en la baja participación o ausencia de polen de los tipos Classopollis, Callialasporites y esporas cicatricosas (Cicatricosisporites y Appendicisporites), abundantes en las unidades adyacentes.

Además esta biozona se caracteriza por una mayor diversidad de polen de afinidad angiospérmica con respecto a la Biozona A. Su límite inferior corresponde al primer registro de polen del complejo Asteropollis.

Esta asociación se encuentra caracterizada principalmente por taxones ausentes, aunque tanto Asteropollis como Dacrydiumites son exclusivos.

Estratotipo: La sección tipo de esta biozona corresponde al perfil del flanco norte de la Meseta 
Baqueró (PBN), cerca de la Estancia El Verano (fig. 3). El nivel 1 de esa secuencia presenta la asociación más completa estudiada hasta el momento.

\section{IV.1.4. Comparación con las biozonas establecidas sobre la base de las megafloras}

En el estudio de la megaflora baqueroense, la distribución de los fósiles vegetales megascópicos ha permitido reconocer dos biozonas: Ptilophyllum la inferior, y Gleichenites la superior (Archangelsky 1999 y 2001a). Las características esenciales de las dos biozonas propuestas fueron resumidas en los siguientes aspectos (Archangelsky, 2003):

1)Desaparición de las Bennettitales y Ginkgoales en la biozona Gleichenites.

2) Géneros exclusivos de la biozona Ptilophyllum : Baqueroites, Apterocladus, Araucarites, Morenoa, Notopehuen, Squamastrobus, Tarphyderma, Trisacocladus, Almargemia, Sueria, Ticoa, y todos aquellos asignados a los órdenes Bennettitales y Ginkgoales.

3) Especies exclusivas de la biozona Ptilophyllum: Cladophlebis antarctica, C. cyathifolia, C.tripinnata, Ktalenia circularis, Pachypteris elegans, Ruflorinia pilifera, R.papillosa, Mesosingeria herbstii, M. mucronata, M.parva, M.striata, Pseudoctenis crassa, P.dentata y P.giganteus.

4) Especies exclusivas de la biozona Gleichenites: Cladophlebis browniana, C. patagonica, Gleichenites argentinica, G.feruglioi, G. san martinii, Hausmannia patagonica, Araucaria grandifolia, Sphenopteris patagonica, Mesosingeria obtusa y Pseudoctenis ornata. Estratigráficamente la biozona Ptilophyllum corresponde a la Formación Anfiteatro de Ticó y la Gleichenites a las formaciones Bajo Tigre y Punta del Barco. En la Fm. Bajo Tigre no se recuperaron aún palinomorfos, aunque se hallaron escasos restos vegetales. Éstos se restringen a frondes gleicheniáceas y cladofleboides, además de Hausmannia papilio. Entre las gimnospermas, hay reportes de Mesosingeria? obtusa y Brachyphyllum (Archangelsky, 2001a), además de Elatocladus y Pseudoctenis (Archangelsky, 2003). El conjunto florístico mencionado coincide plenamente con la caracterización de la biozona Gleichenites. Por otra parte, las litofacies que componen esta Formación, evidencian un recrudecimiento en la actividad volcánica, al tiempo que sugieren la existencia de flujos traccionales o suspensivos, asociados a corrientes encauzadas en valles amplios y someros, generadas por lluvias torrenciales de variable intensidad (Archangelsky, 2003). Este ambiente de depositación, en el que el agente de transporte tuvo una alta energía, habría determinado la escasez y naturaleza fragmentaria de los restos vegetales megascópicos (Gastaldo, 1992). Por otra parte, una columna de agua de esa naturaleza, no habría favorecido la preservación de los palinomorfos por tratarse de ambientes altamente oxigenados. Los niveles bajos de ese paquete sedimentario no han brindado fósiles, los que aquí se comentan provienen de los niveles altos, en donde la lluvia de cenizas habría sido menor o bien habría cesado por momentos (Archangelsky, 2003). Por lo expuesto, es probable que los elementos polínicos que caracterizan la asociación hallada en la Fm. Punta del Barco también estuviesen presentes durante el tiempo en el que se depositó la Fm. Bajo Tigre. Por ello se puede sugerir -aunque sin confirmar por ahora- que al menos la biozona $\mathrm{B}$ abarca parte de esta última formación. 
Originalmente se había señalado la ausencia de angiospermas en la unidad cuspidal del Grupo (Archangelsky, 2001a). Sin embargo, luego se registró allí una impronta foliar con esa afinidad (Passalia \& Cladera, 2003). Más aun, el material polínico estudiado demuestra que este grupo vegetal estaba presente en esta unidad en mayor medida que en la anterior (Llorens, 2003).

Por otro lado, el presente estudio confirma variaciones importantes para las coníferas. Una está dada por el tipo polínico Classopollis, que representa a la Familia Cheirolepidaceae. Este es un elemento importante en la biozona Ptilophyllum, mientras que está prácticamente ausente en la zona Gleichenites, donde se han registrado escasos ejemplares de este tipo, con la exina alterada muy posiblemente por una redepositación. Otra divergencia en este sentido es la de las podocarpáceas con polen bisacado. Ellas tienen por lo menos 9 tipos en la biozona inferior, mientras sólo hay 2 tipos pobremente representados y posiblemente redepositados, en la superior.

Existe coincidencia también en cuanto a la cantidad y exclusividad de algunas gleicheniáceas, que en nuestro caso quedó documentada por 7 especies que no fueron citadas para la asociación inferior. Empero, la palinología no aporta información selectiva en el caso de los grupos que producen polen monosulcado y liso del tipo Cycadopites (Bennetitales, Cicadales y Ginkgoales), ya que está presente en ambas asociaciones. Ese tipo polínico puede corresponder también a algunas pteridospermas, aunque son muy comunes dentro de ellas los morfogéneros Vitreisporites, Alisporites y Caytonipollenites, todos ellos ausentes en la biozona Gleichenites.

Puede establecerse entonces que, las Biozonas A y B propuestas en este trabajo, serían equivalentes a las Zonas Ptilophyllum y Gleichenites, respectivamente.

En síntesis, dentro del paquete sedimentario correspondiente al Grupo Baqueró, entonces, se proponen dos biozonas en secuencia, definidas por megafósiles (Archangelsky, 2001a) y microfósiles (este trabajo). En una consideración general e integrada del grupo, es conveniente establecer el límite entre las biozonas inferior y superior en la base de la Fm. Bajo Tigre, que es donde se producen los grandes cambios de litología (ver cap. II.3.1.4.2). Estos cambios litológicos marcan a su vez, cambios en las condiciones ecológicas que habrían sido la causa de la alteración de la flora.

\section{IV.2. Formación Kachaike}

En el área de estudio, el Grupo Baqueró presenta en su techo un hiato significativo puesto que está cubierto por depósitos terciarios referidos al "Patagoniano" (ver cap. II.3.2.2).

Los depósitos más modernos y próximos en edad con una palinoflora conocida, se presentan a nivel regional, y corresponden a la Fm. Kachaike, de la Cuenca Austral; esta unidad ha sido datada como Albiano-Cenomaniano temprano (ver ítem siguiente).

\section{IV.2.1. Antecedentes}

Esta formación fue definida formalmente por Riccardi (1971) en la Bahía de La Lancha, al este del 
lago San Martín. Aflora en las inmediaciones de los lagos Tar, San Martín y Cardiel, en el borde noroccidental de la Cuenca Austral, provincia de Santa Cruz.

Litológicamente está compuesta por una sucesión de psamitasy pelitasque comenzaron a depositarse en un ambiente deltaico que se continentalizó definitivamente hacia el techo (Nullo et al. 1999).

El primer estudio de la flora de esta unidad lo realizó Halle (1913) quien describió ejemplares de Athrotaxis ungeri (Halle) Florin -Fam. Taxodiaceae-; muy recientemente ese taxón fue hallado en la localidad de Arroyo Caballo Muerto junto con un ejemplar afín a las cheirolepidiáceas (Llorens \& Del Fueyo, 2003). De esa misma localidad proceden las improntas de hojas relacionadas a las angiospermas, que describieran Cúneo \&

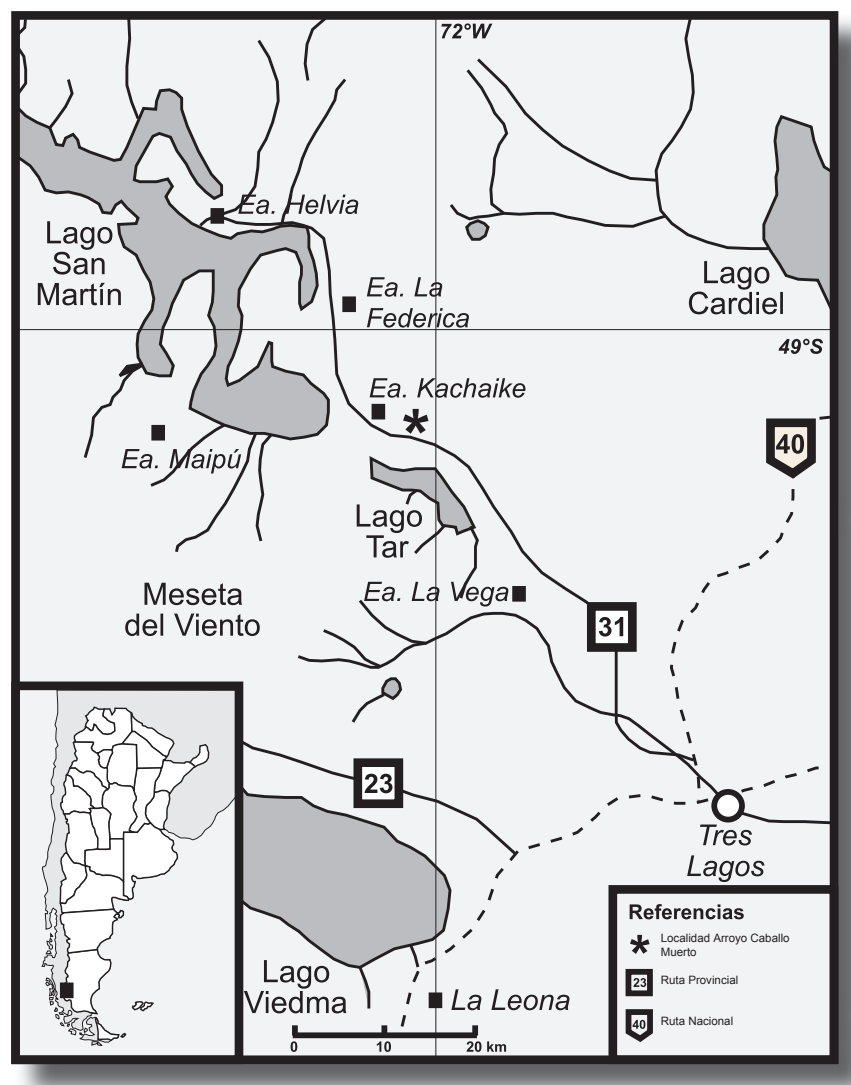

Modificado de A. Archangelsky \& Llorens, 2003 Gandolfo (2003 y 2005) (ver mapa).

Las asociaciones florísticas más frecuentemente halladas en la Formación Kachaike en las localidades fosilíferas La Potranquita, Cerro Mirador y La Florida, todas de la provincia de Santa Cruz, están conformadas por pteridophytas, bennettitales y cycadales (Baldoni \& Ramos, 1981; Longobucco et al. 1985). En cambio, para la localidad Estancia Kachaike (o Arroyo Caballo Muerto), Rebasa (1982) sólo menciona la presencia de pteridophytas, angiospermas y coniferales representadas éstas últimas por podocarpáceas, araucariáceas y un cono microsporangiado sin afinidad taxonómica conocida.

La microflora de la Formación cuenta con varios estudios de megasporas (Baldoni, 1888; Baldoni \& Taylor, 1988; Baldoni \& Batten, 1991) y el resto del contenido polínico fue citado en dos listas taxonómicas (Gamerro, 1982 y Baldoni et al. 2001).

El estudio sistemático integral de la microflora de la Formación Kachaike ha sido abordado recientemente (Archangelsky \& Llorens, 2003; 2005) y ha arrojado datos de interés sistemático y bioestratigráfico.

Existen diferentes criterios en cuanto a la edad de la Formación Kachaike. En base a la palinología, se propuso una edad Aptiano Tardío- Albiano Temprano (Gamerro, 1982; Baldoni et al. 2001). En tanto la fauna marina y los dinoflagelados, indicarían una edad Albiano -Cenomaniano Temprano (Aguirre Urreta, 2002; Guler \& Archanglesky, 2002; Pirrie et al. 2004). 


\section{IV.2.2. Composición palinológica}

Hasta el presente se han reconocido 54 taxones en la Fm. Kachaike, todos ellos procedentes del perfil levantado en el Arroyo Caballo Muerto, dentro de la Estancia homónima en el valle del Río Chalía. En esta oportunidad se ha decidido hacer referencia a aquellos taxa que han sido descriptos y/o ilustrados, sin tener en cuenta las nóminas presentadas (Gamerro, 1982 y Baldoni et al. 2001). La lista completa de las esporas está tomada de (A. Archangelsky \& Llorens, 2003 y 2005), en tanto los tipos angiospérmicos fueron referidos por Archangelsky y colaboradores (2004).

Crybelosporites cf. C. punctatus Dettmann 1963

Crybelosporites australis A. Archangelsky \& Llorens 2005

Cyathidites patagonicus Archangelsky 1972

Cyathidites minor Couper 1953

Cyathidites cf C. punctatus (Delcuort \& Sprumont) Delcourt, Dettmann \& Hughes, 1963

Cyathidites sp. A. Archangelsky \& Llorens 2003

Deltoidospora australis(Couper) Pocock1970

Deltoidospora inconspicua Martin 1973

Concavisporites ef C. semiangulatus Menéndez 1963

Dictyophyllidites sp. A. Archangelsky \& Llorens 2003

Todisporites minor Couper 1958

Leiotriletes of L. regularis (Pflug) Krutsch 1959

Baculatisporites comaumensis (Cookson) Potonié 1956

Baculatisporites kachaikensis Llorens \& A. Archangelsky 2005

Ceratosporites equalis Cookson \& Dettmann 1958

Concavissimisporites verrucosus Delcourt \& Sprumont 1955

Leptolepidites macroverrucosus Schulz 1967

Osmundacidites cf. O. wellmanii Couper 1953

Pilosisporites trichopapillosus (Thierg.) Delcourt \& Sprumont 1955

Pilosisporites verus (Delcourt \& Sprumont) Llorens \& A. Archangelsky 2005

Appendicisporites cf. A. giganticus Groot \& Groot 1962

Appendicisporites cf. A potomacensis Brenner 1963

Appendicisporites sp. 1 A. Archangelsky \& Llorens 2005

Appendicisporites sp. 2 A. Archangelsky \& Llorens 2005

Cicatricosisporites australiensis (Cookson) Potonié 1956

Cicatricosisporites hughesi Dettmann 1963

Cicatricosisporites sp. A. Archangelsky \& Llorens 2005

Klukisporites variegatus Couper 1958

Klukisporites cf.K. labiatus (Volkheimer) Baldoni \& Archangelsky 1983

Nodosisporites crenimurus (Srivastava) Davies 1985 
Nodosisporites macrobaculatus A. Archangelsky \& Llorens 2005

Retitriletes austroclavatidites (Cookson)Döring, Mai, Krutzsch \& Schulz 1963

Retitriletes baqueroense Archangelsky \& Seoane, 1998

Staplinisporites caminus (Balme) Pocock 1962

Foraminisporis dailyi (Cookson \& Dettmann) Dettmann 1963

Foraminisporis asymmetricus (Cookson y Dettmann) Dettmann 1963

Densoisporites velatus Weiland \& Krieger 1953

D. corrugatus Archangelsky \& Gamerro 1965

Contignisporites glebulentus (Dettmann) Filatoff \& Price 1988

C. burgerii Filatoff \& Price 1988

C. cooksoniae (Balme) Detmann 1963

Taurocusporites segmentatus Stover 1962

Cyatheacidites tectifera Archangelsky \& Gamerro 1965

Cyatheacidites sp. A. Archangelsky \& Llorens 2003

Aequitriradites spinulosus (Cookson \& Dettmann) Cookson \& Dettmann 1963

A. baculatus Döring 1964

Gleicheniidites serratus A. Archangelsky \& Llorens 2005

Gleichenïdites senonicus Ross 1949

Foveogleicheniidites confossus (Hedlund) Burger 1975

Ornamentifera cf.O. echinata (Bolkh.) Bolkhovitina 1966

Triporoletes reticulatus (Pocock) Playford 1971

Laevigatosporites sp. A. Archangelsky \& Llorens 2005

Polypodiidites sp. A. Archangelsky \& Llorens 2005

Microfoveolatosporis sp. A. Archangelsky \& Llorens 2005

Brenneripollis peroreticulatus (Brenner) Júhasz \& Góczan

Clavatipollenites spp.

Tricolporoidites sp.

Retitricolpites sp.

En cuando a las megasporas, Baldoni (1988) y Baldoni \& Batten (1991), conforman para esta unidad la siguiente lista de especies:

Arcellites santacrucensis Baldoni 1988

Praxillitriletes kachaikensis Baldoni 1988

Balmeisporites holoholodictyus Cookson \& Dettmann 1958

Bacutriletes triangularis Taylor \& Taylor 1988

Minerisporis sp. cf. M. marginatus (Dijkstra) Potonié 1956

Tenellisporites coronatus Baldoni \& Batten 1991 
Además, se han reportado los siguientes quistes de dinoflagelados (Guler \& Archanglesky, 2002;

Baldoni et al. 2001):

Kiokansium unituberculatum (Tasch) Stover \& Evitt

Oligosphaeridium complex (White) Davey \& Williams

Spiniferites spp.

Chichaouadinium boydii (Morgan) Bujak \& Davies

Muderongia sp.

Pseudoceratium turneri Gradstein \& Smelror

Florentinia sp.

Muderongia tetracantha (Gocht) Alberti

Dioxy a armata Cookson \& Eisenack

Litosphaeridium arundum (Eisenack \& Cookson) Davey

Florentinia radiculata (Davey \& Williams) Davey \& Verdier

Odontochitina operculata (Wetzel) Deflandre \& Cookson

Criboperidinium sp.

Subtilisphaera perlucida (Alberti) Jain \& Millepied

Cleistosphaeridium ancoriferum (Cookson \& Eisenack) Davey et al.

Oligosphaeridium pulcherrimum (Deflandre \& Cookson) Davey \& Williams

Hystrichodinium sp.

Cannosphaeropsis sp.

Criboperidinium edwardsii (Cookson \& Eisenack) Davey

Circulodinium distinctum (Deflandre \& Cookson) Jansonius

Psaligonyaulax deflandrei Sargeant

Pseudoceratium eisenackii (Davey) Bint

\section{IV.2.3. Rasgos característicos de la asociación de la Formación Kachaike}

La caracterización de esta asociación polínica se ha realizado en base a datos publicados y otras observaciones personales, aún inéditas.

Está definida por la presencia en algunos niveles de elementos marinos, a los que acompañan como tipos polínicos mas frecuentes: Classopollis, Cicatricosisporites y Callialasporites, además de un tipo de Cyclusphaera diferente a las especies conocidas. Por otro lado, Cyclusphaera psilata y Balmeiopsis limbatus están ausentes en esta asociación. El morfogénero Cycadopites, que representa a varios grupos botánicos y es un componente común de las unidades aptianas, aquí está muy pobremente representado.

Un aspecto relevante dentro de esta unidad es que se registran en la parte superior de la columna las primeras formas polínicas triaperturadas (Tricolporoidites sp. y Retitricolpites sp.). Así, se incrementa de manera considerable la diversidad morfológica del polen angiospérmico, dado que a esas formas nuevas se suman varios tipos del complejo Clavatipollenites y la aparición del género Brenneripollis. 
Este conjunto está caracterizado además por géneros exclusivos como Arcellites (Miner) Ellis \& Tschudy, Pilosisporites Delcourt \& Sprumont, Nodosisporites Deák, Klukisporites Couper, Crybelosporites Dettmann y Ephedripites Bolkhovitina ex Potonié. (ver lista completa en los cuadros 6 y 7).

El límite inferior de esta asociación no puede definirse con certeza. En el ámbito del Cratón del Deseado, existe un hiato que abarca el lapso entre la depositación de la Formación Punta del Barco (Aptiano inferior) y la del "Patagoniano". Por otra parte, en el sector occidental de Cuenca Austral, la sección superior de la Fm. Río Mayer que subyace a la Fm. Kachaike (?Aptiano superiorAlbiano), podría corresponder a ese intervalo de tiempo. En tal caso, el hiato estaría dado por factores tafonómicos o paleoecológicos que determinaron la ausencia de restos paleontológicos en este cuerpo de roca, lo cual impide corroborar su edad. No se descarta empero, que los niveles inferiores del perfil estudiado pertenezcan a esa sección superior.

\section{IV.2.4. Comparación con las asociaciones palinológicas del Grupo Baqueró}

En los cuadros 6 y 7 se representa la distribución de las especies reconocidas hasta el momento en las dos microfloras (biozonas) del Grupo Baqueró y, en un plano cronológico más moderno, la asociación de la Fm. Kachaike. Una diferencia muy importante con las dos asociaciones anteriores, ambas netamente continentales, es que aquí se hallaron restos de dinoflagelados que evidencian un ambiente de depositación marino (Guler \& Archanglesky, 2002; Baldoni et al. 2001).

Un rasgo distintivo de la asociación "Kachaike", es la ausencia de Cyclusphaera psilata y Balmeiopsis limbatus, que son elementos comunes en las biozonas anteriores. Este complejo polínico estaría aquí sustituido por un tipo diferente dentro del morfogénero Cyclusphaera. Por otro lado, si bien con pocos ejemplares, se registra por primera vez el género Ephedripites, al tiempo que casi desaparece Cycadopites. Dentro de las esporas triletes de este conjunto polínico es llamativa la diversidad y cantidad de esporas con fuertes esculturas, tal es el caso de los géneros: Pilosisporites, Nodosisporites, Klukisporites y Baculatisporites, entre otras.

Es de destacar también el grado de diversificación de las angiospermas, que en las unidades anteriores están representadas por el complejo Clavatipollenites / Asteropollis, en tanto aquí adquieren mayor complejidad en su pared y aperturas. Ese cambio se da entre retículos homobrocados a heterobrocados y entre aperturas o leptomas únicos y simples (monocolpados y tri-hexacotomosulcados) a tres colpos o en ocasiones colporoides.

La asociación "Kachaike” correspondería entonces, a una restitución parcial de la flora presente en la Biozona A, luego de una etapa de fuerte retracción de muchos grupos importantes (Biozona B), con la incorporación de algunos taxones nuevos, diversificación de las angiospermas, e influecias marinas. Este conjunto polínico es más moderno que los del Grupo Baqueró, pero tiene aún especies comunes con los mismos. 


\section{IV.2.5. Resultados}

El Cretácico Inferior fue un período crucial en la historia del reino vegetal, caracterizado por la aparición y diversificación incipiente de las angiospermas, seguido por un desarrollo importante que las llevó a ocupar casi todos los nichos ecológicos disponibles y convertirse así en el grupo vegetal dominante en las biotas continentales del Cretácico Superior hasta nuestros días (Lupia et al. 1999). Paralelamente al desarrollo de ese grupo vegetal se produjeron también importantes eventos evolutivos en el mundo de los insectos (Labandeira et al. 1994).

$\mathrm{Al}$ mismo tiempo, durante el Aptiano decaen y, en algunos casos parecen extinguirse, importantes taxones gimnospérmicos como las Bennettitales, Pteridospermales y Ginkgoales, que hasta ese momento habían sido componentes comunes de las floras.

Estos cambios quedaron testimoniados en la secuencia estratigráfica del Grupo Baqueró. La gran mayoría de los datos florísticos provienen de la formación inferior del Grupo -Formación Anfiteatro de Ticó- y de la superior -Formación Punta del Barco-, en tanto la Formación Bajo Tigre que se depositó entre ellas, aportó escasos registros de vegetación. El conjunto de la información brindada por los restos megascópicos permitió establecer dos biozonas: una inferior denominada Ptilopbyllum y otra superior, Gleichenites (Archangelsky, 1999 y 2001a). Esta clasificación se basó en las diferencias composicionales de las tafofloras, que reflejan un cambio drástico en la vegetación, marcado por la casi total desaparición de Bennettitales y Ginkgoales, como así también una clara disminución numérica de las coníferas, Pteridospermales y Cicadales (Archangelsky, 2001a y 2001b).

Las palinozonas aquí propuestas para el Grupo-Biozonas A y B- parecen ser equivalentes a las establecidas en base a la megaflora, y en algunos casos aportan información adicional que las sustenta.

La información palinológica aportada en este estudio confirma importantes variaciones sucedidas entre las coníferas. Este grupo se destaca como un componente principal en las asociaciones palinológicas de la Formación basal del Grupo. Dentro de estas plantas, la familia Podocarpaceae presenta una importante variedad de tipos polínicos (polen bisacado, trisacado y polisacado) con numerosas especies presentes en la asociación inferior. Este hecho demuestra que las podocarpáceas fueron componentes importantes en las comunidades boscosas que cubrían amplias extensiones y diversos nichos de la topografía aptiana patagónica (Archangelsky \& Villar de Seoane, 2005).

Este grupo vegetal cuenta con los géneros Trisaccites, Microcachryidites y Podocarpidites en ambas formaciones -Anfiteatro de Ticó y Punta del Barco-, a los que la Formación Anfiteatro de Ticó suma el género Gamerroites Arch. y Punta del Barco, Dacrydiumites. Las formas bisacadas Gamerroites y Podocarpidites son muy diversas y abundantes en la base. Sin embargo la formación superior sólo cuenta con unos pocos granos asignables a este grupo, cuya exina presenta signos de degradación (posiblemente por transporte). A esto se suma el casi ausente registro de megafósiles.

Otro hecho significativo, es el caso del tipo polínico Classopollis, que representa a la Familia Cheirolepidiaceae y es un elemento importante en la mega y microflora de la biozona Ptilophyllum 
(o Biozona A). Esto concuerda con la alta frecuencia de granos del tipo Classopollis que se observa en otras unidades coetáneas. En la Formación La Cantera (Aptiano de San Luis), por ejemplo, representa un 10-30\% del contenido polínico total (Prámparo,1989). Para el Aptiano de Cuenca Neuquina, en la sección K de la Fm. Ranquiles, representa el 73\% y para la "Arenisca Rincón" (Barremiano-Aptiano), el 75\% del contenido polínico total (Vallati, 1995 y 1996). Sin embargo, está prácticamente ausente en la zona Gleichenites (o Biozona B), donde se han registrado escasos ejemplares de este tipo. Más aun, se presentan con una exina de color muy diáfano (signo de oxidación) o bien degradada, probablemente por un retrabajo. Muy probablemente provengan de los sedimentos de la Formación Anfiteatro de Ticó.

Otro representante de las coníferas muy difundido en las microfloras eocretácicas, es Callialasporites. Este tipo polínico, común en el Jurásico y Cretácico, fue encontrado dentro de conos en conexión con ramas de Apterocladus (Archangelsky,1966c; Gamerro, 1965b) en la Formación basal. Su ausencia, una vez más, es llamativa para la unidad superior.

Existen observaciones en ambientes actuales disturbados por el vulcanismo, que muestran un cambio en el clímax de los bosques de coníferas luego de una erupción. El estudio de una asociación florística del Noroeste Pacífico revela un bosque de coníferas bien representado en ambos registros -mega y microscópico- que cambia significativamente su condición en los primeros registros posterupción y daría origen a una asociación fósil en la que las coníferas están ausentes en la megaflora, al tiempo que el registro polínico es variado (Spicer, 1980). Entonces, la merma abrupta de restos fósiles de coníferas denota una fuerte retracción de las comunidades boscosas.

Otras gimnospermas afectadas fueron las Pteridospermales, que tienen representantes de los géneros Alisporites y Vitreisporites (Archangelsky \& Gamerro, 1966a) en la zona Ptilophylum, en tanto no han sido reportadas para la zona superior. Dentro de este grupo existe también el tipo polínico monocolpado liso, con una ultraestructura alveolar de su pared idéntica a la de las Cycadales, pudiendo sólo ser diferenciadas por medio de estudios muy detallados (Archangelsky \& Villar de Seoane, 2004). Por tanto, si bien este tipo morfológico está registrado en la Formación Punta del Barco, como así también improntas de aspecto muy semejante a los ejemplares cutinizados de la zona inferior, no es posible hacer una asignación definitiva. Por lo tanto, puede decirse que el material palinológico del actual estudio no aporta información selectiva en el caso de los grupos que producen polen monosulcado y liso del tipo Cycadopites (Bennetitales, Cycadales, Pteridospermales en parte y Ginkgoales).

Por otra parte, los cambios composicionales se dieron también entre los helechos. Un caso llamativo es el de las Pteridales. Por un lado, las esporas de la Familia Lophosoriaceae son abundantes en los depósitos de la Formación Anfiteatro de Ticó, al igual que en otros depósitos eocretácicos australes (Dettmann, 1986a); así también, los de la Familia Schizaeaceae. En el primer caso se reconocieron dos formas del género Cyatheacidites; y en el segundo, las esporas cicatricosas están representadas por siete especies del género Cicatricosisporites (Archangelsky \& Gamerro, 1966b), en el que se incluyen 
también las formas con apéndices apicales del género Appendicisporites. En cambio, en la Formación Punta del Barco ambas familias están ausentes.

Otra diferencia importante está dada por un fuerte incremento en la diversidad y cantidad de esporas de la Familia Gleicheniaceae -de los géneros Gleichenïdites, Clavifera y Ornamentifera- en la Formación Punta del Barco.

El grupo de las licofitas, está representado por dos especies de microsporas del morfogénero Densoisporites en ambas unidades. Las características de su exina sugieren un hábito ligado a altas tasas de humedad o bien a hábitats acuáticos, y esto le habría conferido una ventaja en la preservación con respecto a otras formas, y por tanto una sobrerepresentación en el espectro polínico. Las megasporas son también evidencia de la participación de esos vegetales en las comunidades neoaptianas. En tal sentido, la asociación basal testimonia la presencia de ambos grupos productores de estos propágulos: Isöetales y Selaginellales. En cambio en la asociación superior sólo las últimas están presentes. Esto podría deberse a que los clados primitivos de las Isoëtales ocuparon hasta ese momento hábitats acuáticos estables -lagos, lagunas- (Taylor \& Hickey, 1992), que no habrían sido frecuentes en este nuevo escenario. Contrariamente, la Fm. Anfiteatro de Ticó presenta facies que corresponden a ese tipo de ambientes.

Un hito de relevancia en las floras eocretácicas de Patagonia ha sido la incorporación e incipiente diversificación de las angiospermas. En tal sentido, la Formación Anfiteatro de Ticó ha brindado la primer evidencia inequívoca de la presencia de plantas con flores: una antera disociada que porta granos de polen de Clavatipollenites en distintos grados de su desarrollo ontogenético (Archangelsky \& Taylor, 1993). Esto, sumado a la presencia de dos tipos de hojas angiospérmicas (Romero \& Archangelsky, 1986; Passalia et al. 2003), denota su temprana aparición en altas latitudes. La Formación Punta del Barco, por su parte, ha brindado varios tipos de polen disperso de afinidad angiospérmica, con representantes de los géneros Asteropollis, Clavatipollenites y Monocolpopollenites, además de otras formas esporádicas, probablemente con la misma afinidad (Llorens, 2003).

La diversificación de las angiospermas en este breve lapso geológico, aunque incipiente, es llamativa. El registro de tres nuevas formas en el tope del Grupo Baqueró, con la adquisición de diferentes tipos de aperturas, sugiere que en este tiempo se dio un paso evolutivo importante (Llorens, 2003; Archangesky et al. 2004). El retroceso, en el mismo lapso, de algunos grupos vegetales importantes (Bennettitales, Ginkgoales, Cheirolepidáceae, Schizaeáceae y Lophosoriaceae) habría permitido una rápida conquista de los nichos disponibles por parte de las plantas con flores.

Una consideración general sobre las dos comunidades comparadas, muestra la transición de una comunidad dominantemente arborescente-arbustiva (Podocarpaceae, Ginkgoales, Bennetittales, Araucariaceae, Cheirolepidiaceae) a otra dominada por el estrato herbáceo-arbustivo (helechos, Cycadales, angiospermas, briófitos), con algunos parches de árboles (Podocarpaceae y Araucariaceae). En esta instancia, las evidencias ecológicas sugieren que las angiospermas habrían ocupado ambientes lacustres o cercanos, siempre ligadas a cuerpos de agua dulce, y que por ello escaparon 
de los efectos de los incendios.

Este comportamiento de las floras ante las erupciones volcánicas, tiene ya algunos antecedentes. Uno es el que reportaron Falcon-Lang \& Cantrill (2002), quienes reconocieron una transición semejante a la aquí descripta, aunque con representantes de grupos vegetales diferentes, que sucedió entre las asociaciones florísticas inferior y superior de la Formación Cerro Negro del Aptiano inferior de Antártida. En esa ocasión se lo adjudicaron al incremento en la frecuencia de las erupciones a través del tiempo. Además, para el mismo período en Australia, Hill y otros autores (1999) sugieren una disminución importante de gimnospermas, criptógamas y pteridospermas, mientras que las pteridofitas mantuvieron una plasticidad ecológica que les permitió adaptarse a diferentes ambientes. Otra sucesión semejante en cuanto a la estructura de las comunidades vegetales, se dio en el Mioceno de Idaho y Oregon -Formación Succor Creek- (Taggart \& Cross, 1980).

Todos estos casos ponen en evidencia la ventaja adaptativa de las plantas con ciclos de vida más cortos en aquellos ambientes periódicamente disturbados por erupciones volcánicas.

En el Grupo Baqueró se produjo entonces un cambio en la comunidad vegetal entre las formaciones inferior y superior, como así también dentro de la Formación Punta del Barco. Este último desde un nivel basal, de un bosque con diferentes estratos y una diversidad mayor, hasta los niveles superiores donde sólo se registraron elementos planctónicos y algún grupo oportunista. En esta secuencia estratigráfica, los niveles de tobas -pulsos volcánicos- están intercalados con paleosuelos que se establecieron en los momentos de calma en esa actividad. En esos momentos la comunidad vegetal colonizaba, al menos de manera incipiente, los nichos ecológicos disponibles, hasta el advenimiento de la siguiente nube de cenizas. Estas situaciones se repitieron en un proceso cíclico que determinó un cambio vegetacional que, si bien rápido, fue gradual y más marcado con el paso del tiempo. Esto determinó un empobrecimiento paulatino en cantidad y diversidad de coníferas y demás gimnospermas, como también de algunas pteridofitas. Sin embargo, las briofitas lograron adaptarse al cambio, probablemente debido a la existencia de suficientes ambientes con bastante humedad. Los más beneficiados por este nuevo escenario ecológico en el que había mayor disponibilidad de nichos, fueron las angiospermas y los helechos oportunistas.

Un segundo cambio se registra en la flora de Patagonia austral, cuando se depositó la secuencia sedimentaria correspondiente a la Fm. Kachaike. Allí se restablece en parte la comunidad original, donde vuelven a ser conspicuos algunos grupos fuertemente afectados en la Biozona B, tales como Classopollis, Callialasporites y las schizeáceas. Estos serían taxones "Lazarus", que luego de un intervalo de tiempo en el que están ausentes en el registro estratigráfico reaparecen en las asociaciones más jóvenes (Hallam \& Wignall, 1997). Además, vuelven a registrarse ciertos grupos que, si bien no son muy abundantes, son característicos, como las esporas de Lophosoriaceae y de Isöetales. Sin embargo, otros elementos conspicuos anteriormente pierden aquí representatividad. 
Por un lado, desaparecen del registro los granos del complejo Cyclusphaera psilata-Balmeiopsis; y por el otro, el polen monocolpado liso que representa a un grupo importante de plantas (Bennettitales, Cycadales, Pteridospermales y Ginkgoales), tiene muy baja participación en el conjunto polínico albiano.

Esa asociación adquiere identidad propia también con la incorporación de elementos nuevos tales como Ephedripites, Pilosisporites y Arcellites, entre otros. Por otro lado, las gleicheniáceas pierden aquí protagonismo; al tiempo que entre las angiospermas es relevante la aparición de granos triaperturados (tricolpados o tricolporoidados).

Los cambios composicionales entre las asociaciones del Grupo Baqueró y Fm. Kachaike se han producido durante el Aptiano-Albiano (Cretácico medio). Cabe señalar que en ese lapso se produjeron cambios en las comunidades vegetales, ya sea por factores evolutivos y/o ambientales. Tal es el caso del vulcanismo en el Aptiano, y los ciclos de ingresión - regresión marina en el Albiano. De todas maneras hay dos hechos que se destacan más allá del marco ambiental de cada momento. En estas microfloras se hace evidente una dominancia de las pteridofitas y gimnospermas, por una parte, y la aparición y diversificación incipiente de las angiospermas por otra.

Los grupos polínicos que corresponden a las angiospermas basales parecen ser herramientas bioestratigráficas de gran utilidad. Sin embargo, es importante resaltar que presentan varios problemas para trabajar: la baja frecuencia en la que están representados, tamaños muy pequeños, caracteres de difícil interpretación y la dualidad de terminología y criterios de clasificación entre el material observado con microscopía óptica y electrónica. Este problema ya fue planteado por diversos autores (Traverse, 1988; Chapman, 1986; Hughes, 1994, entre otros) y genera solapamiento nomenclatural en algunos casos, mientras que en otros -tal como la especie Clavatipollenites hughesiila asignación se basa en criterios generales que impiden hacer una determinación acertada. Así, es importante contar con buen material y poder estudiarlo con ambos métodos.

Por lo expuesto, puede establecerse una sucesión florística partiendo de una flora rica y diversa en la Biozona A, seguida por un rápido empobrecimiento debido a eventos de disturbio ambiental, que mermó, y en algunos casos hizo desaparecer algunos grupos (Biozona B). Más tarde, en la asociación "Kachaike", se produjo una restitución de la flora inicial, con la aparición de algunos taxones nuevos, en medio de influecias marinas. Aunque ésta es más moderna que las asociaciones polínicas del Grupo Baqueró, tiene aún con ellas varias especies comunes. No obstante, los tipos foliares de angiospermas marcan una total divergencia entre el Grupo Baqueró y la Formación Kachaike (Cúneo \& Gandolfo, 2005).

Por último, vale señalar que el cambio florístico registrado dentro del Grupo Baqueró tendría las características de una extinción en masa: los taxones involucrados son de alto rango, brusca 
disminución en la diversidad y abundancia de organismos y simplificación de los ecosistemas (Freeman \& Herron, 1998). No obstante, mediante la comparación con la flora de Kachaike, puede determinarse que no se trató de un evento de ese tipo, dado que la flora se reestableció en gran medida.

\section{IV.3. Comparación con asociaciones eocretácicas de Argentina}

El Cretácico Inferior ha sido estudiado intensamente a nivel global y representa una de las épocas geológicas más importantes por su extensión, contenido paleontológico e importancia económica. También en nuestro país,y por extensión en el Gondwana, se realizaron importantes estudios palinológicos que permiten establecer comparaciones con la palinoflora de la Fm. Punta del Barco. En Argentina se han reconocido asociaciones polínicas eocretácicas en varias cuencas, tanto en superficie como en subsuelo y la plataforma continental.

\section{IV.3.1. Cuenca Austral}

El conocimiento de esta cuenca reviste un importante interés económico y se debe a la activa exploración realizada para tratar de encontrar reservas de hidrocarburos. En su evolución sedimentaria, se destacan tres etapas tectónicas principales: una de rift, otra de hundimiento termal y múltiples períodos de formación de cuencas de antepaís (Robbiano et al. 1996). Los sedimentos que la componen han sido hallados tanto en el continente (superficie y subsuelo) como en la plataforma continental argentina, que constituye la quinta parte de la superficie total de la cuenca, y portan información palinológica interesante.

\section{IV.3.1.1. Afloramientos en el continente}

Las unidades de esta cuenca afloran tanto en el ámbito cordillerano como en el extraandino de la provincia de Santa Cruz, y tienen edades comprendidas entre el Titoniano y el Maastrichtiano (Arbe, 1989). Este autor considera que las sedimentitas cretácicas corresponden a distintos ciclos depositacionales que pueden a su vez subdividirse, y que responden a eventos tectosedimentarios. Los ciclos deposicionales se desarrollan en períodos de ascenso relativo del nivel del mar; en tanto los regresivos, responden a eventos tectónicos.

En el sector occidental de esta cuenca aflora la Formación Springhill, cuya edad ha sido estimada por su contenido paleontológico como Berriasiano-Valanginiano (Baldoni \& Archangesky, 1983). En perfecta continuidad se apoya sobre esa unidad, la secuencia sedimentaria correspondiente a la Formación Río Mayer. Los niveles basales han sido datados por su fauna marina como barremianos. En el capítulo precedente se analizó con detalle la relación de las asociaciones polínicas del Grupo Baqueró con la Fm. Kachaike, de edad aptiana?-albiana, que sería la unidad más joven del eocretácico en esta cuenca. 


\section{IV.3.1.1.1. Formación Springhill}

Esta unidad aflora en el flanco occidental de la cuenca y está conformada por una sección basal de origen continental y una sección superior de naturaleza marina. Ambientalmente, la primera constituye depósitos fluviales de alta energía y planicie costera; mientras que la superior, representa depósitos de sistemas litorales destructivos, de naturaleza estuárica (Arbe, 1989).

Se describió una asociación palinológica sobre la base de varias perforaciones en el Sur de la provincia de Santa Cruz y en Chile, que se caracteriza por la abundancia de esporas, de granos sacados y de los tipos Callialapollenites y Classopollis. Se destaca también la ausencia de granos poliplicados y Cyclusphaera-Balmeiopsis (Baldoni \& Archangesky, 1983).

En los términos superiores de la unidad, de origen marino, aparecen algunos elementos que son comunes a la Fm. Anfiteatro de Ticó (Cornú, 1986).

\section{IV.3.1.1.2. Formación Río Mayer}

Esta unidad presenta dos secciones. Los niveles basales corresponderían a un hemiciclo transgresivo, dentro de un ciclo transgresivo de la cuenca, representados por facies marinas y litorales, con una edad de entre 121,5 y $112 \mathrm{Ma}$ (Robbiano et al. 1996).

Se recuperaron de esta unidad 2 asociaciones polínicas, denominadas " $\mathrm{A}$ " la inferior y "B" la superior. En la primera hay un amplio dominio de elementos continentales, en su mayoría ClassopollisCyclusphaera psilata, acompañados de acritarcos y quistes de dinoflagelados (Pöthe de Baldis \& Ramos, 1980). La edad estimada por la fauna y los dinoflagelados, coinciden en un Aptiano inferior (Pöthe de Baldis \& Ramos, 1983).

La sección superior tiene facies de plataforma y correspondería a un hemiciclo transgresivo, dentro de un ciclo regresivo de la cuenca, de edad entre 112 y 98 Ma (Robbiano et al. 1996). La asociación polínica "B", se caracteriza por carecer de elementos marinos y de Cyclusphaera psilata, al tiempo que hay un alto porcentaje de esporas triletes, y tendría una edad aptiana o más joven (Pöthe de Baldis \& Ramos, 1986).

\section{IV.3.1.1.3. Formación Kachaike y Grupo Baqueró}

En el ámbito de la Cuenca Austral, por encima de la Fm. Río Mayer (superior) afloran sedimentos que fueron referidos a la Fm. Kachaike, cuyo contenido polínico fue presentado y comparado con la Fm. Punta del Barco en el capítulo anterior. Estas comparaciones fueron extendidas al Grupo Baqueró que aflora en el ámbito continental del Cratón del Deseado.

\section{IV.3.1.2. Plataforma Continental Argentina}

Los sedimentos situados en el mar epicontinental incluyen dos elementos fundamentales: el Alto del Río Chico como límite oriental de la cuenca, que es un apéndice del Macizo del Deseado; y el contacto 
entre la subplaca de Scotia y la placa Sudamericana que representa su límite sur (Robbiano, 1989). En estudios recientes han comenzado a presentarse datos palinológicos sobre una serie de perforaciones realizadas en la plataforma continental. Los primeros datos fueron dados a conocer recientemente, obtenidos de secuencias tomadas frente al extremo sur de Santa Cruz y Estrecho de Magallanes (Palamarczuk et al. 2000; Archangelsky \& A. Archangelsky, 2002). El primero de esos trabajos analiza dos y el segundo seis pozos estudiados; ambos reconocieron en la columna del pozo MLD3 una sección comparable en su contenido palinológico con la Fm Anfiteatro de Ticó, y por encima de ésta un cambio en la palinoflora, con la aparición del morfogénero Asteropollis. El contenido polínico de las columnas ilustra una sección netamente continental en la base de las secuencias, que se vuelven marinas gradualmente hacia el tope. En un estudio más detallado, Archangelsky \& A. Archangelsky (2002) ilustran para el pozo ya mencionado, un comportamiento peculiar de los grupos vegetales en los niveles medios de la secuencia. Allí, entre los 1508-1511 mts, los autores señalan una sensible disminución en los porcentajes de Classopollis, podocarpáceas y araucariáceas. Esto está acompañado con un incremento en el grupo de las gleicheniáceas, al tiempo que las angiospermas adquieren una representatividad más constante.

En otro estudio de muestras provenientes de testigos laterales extraídos en seis perforaciones más al Norte que las anteriores, se reconocieron asociaciones de quistes de dinoflagelados con valor biostratigráfico. Esto permitió proponer para ellas una edad que va del Barremiano tardío al Aptiano temprano. Entre los elementos terrestres, muchos son comunes con las microfloras del Grupo Baqueró (Guler et al. 2003).

\section{IV.3.2. Cuenca del Golfo San Jorge}

Sin estar específicamente referido a esta cuenca, los sedimentos procedentes de la perforación UN OIL OS-1 del suroeste de Chubut, fueron considerados por comparación con otras microfloras, como depósitos del intervalo Hauteriviano-Aptiano inferior (Archangelsky \& Seiler, 1980).

En el centro de esa provincia, se recuperó también una palinoflora de afloramientos de edad Barremiano tardío-Aptiano temprano en la sección superior de la Formación Pozo D-129, comparable en su composición palinológica a la Formación Anfiteatro de Ticó. Sobre la base de la distribución estratigráfica de especies en seis perforaciones, Archangelsky et al. (1984) propusieron cuatro zonas para esta cuenca, que se caracterizan a continuación en edad decreciente: Zona de asociación Contignisporites-Callialasporites-Staplinisporites, definida en base a las microfloras halladas en la Cuenca Austral, Fm. Springhill (Baldoni \& Archangesky, 1983). Además de los taxones representativos mencionados, es característica la ausencia de Cyclusphaera-Balmeiopsis y la abundancia de Callialasporites. Zona de asociación Interulobites-Foraminisporis, es un conjunto polínico con muchas especies exclusivas y los primeros registros de otras significativas, tales como Cyclusphaera psilata y Balmeiopsis limbatus.

La Zona de intervalo tectifera-corrugatus, se denomina así por la aparición de Cyatheacidites tectifera, 
Trilobosporites purverulentus, Schizosporis reticulatus y Densoisporites corrugatus. Presenta cambios palinológicos graduales, de modo tal que no existe entre ella y la siguiente, un horizonte característico.

Por último, la Zona de conjunto Antulsporites-Clavatipollenites se distingue por la diversificación masiva de los tipos polínicos. El hecho relevante de este paquete sedimentario es que alberga los primeros tipos angiospermoides (o quizás verdaderas angiospermas), al tiempo que algunos tipos polínicos previos se hallan como relictos. Se cartacteriza además, por la aparición de diversos taxa como Antulsporites baculatus, Asteropollis asteroides y Clavatipollenites hughesii, entre otros. Se ha establecido una edad para esta asociación que abarca todo el Aptiano.

Por lo expuesto, se desprende que esta biozona es muy afín a la Biozona A (este trabajo), con la única divergencia dada por la presencia del género Asteropollis. La Biozona $\mathrm{B}$, correspondería entonces a aquellos niveles en los que ese taxón está presente.

Por otra parte, en la denominada Comarca del valle medio del Río Chubut, fue recuperada una serie de muestras palinológicas de sedimentitas que podrían pertenecer a esta cuenca o bien a la Cuenca los Adobes o Cuenca del General Racedo (Vallati, 2001). Del estudio de esas microfloras, se desprende la zonación propuesta por la autora, quien reconoció en esa oportunidad dos asociaciones: Asociación de Cyclusphaera morfotipo 2 que fuera datada como neocomiana, y una Asociación de Clavatipollenites bughesii. Esta última, de edad Barremiano-Aptiano, tiene como elementos característicos a los granos de angiospermas primitivas, tales como Clavatipollenites hughesii, Retimonocolpites sp. 3, y granos del "grupo" Clavatipollenites / Asteropollis. Si bien esos elementos muestran una vinculación con la Biozona B aquí propuesta, no es posible hacer una asignación sin reservas por cuanto existen diferencias importantes en los elementos "no angiospérmicos" del conjunto polínico. Esos elementos coinciden en mayor grado con la Zona Antulsporites-Clavatipollenites Archangesky et al. 1984, y con la Biozona A (este trabajo).

\section{IV.3.3.Cuenca Neuquina}

Existen diferentes esquemas estratigráficos para esta cuenca (ver Uliana et al. 1975). En este trabajo, se sigue el criterio adoptado por Vallati (2001) y se toman en cuenta también las unidades informales propuestas por esa autora, habida cuenta que en ese trabajo fueron presentados datos palinológicos útiles para realizar comparaciones entre unidades. La Formación Ranquiles es la unidad Aptiana dentro del Grupo Huitrin-Rayoso, y corresponde a una de las cinco asociaciones palinológicas reconocidas por Vallati (2001). La autora describe para ese período la Zona de Afropollis zonatus, caracterizada por la presencia de granos de polen angiospérmico de los siguientes taxones: Clavatipollenites hughesii, Retimonocolpites sp., Asteropollis asteroides y Afropollis spp.

Volkheimer \& Sepúlveda (1976) describieron para la Formación Agrio (Hauteriviano-Barremiano) de la cuenca Neuquina, la especie Cyclusphaera psilata de gran importancia bioestratigráfica. En esa oportunidad establecieron dos asociaciones características: Cyclusphaera psilata-Classopollis, que en 
esa formación están acompañadas de formas marinas además de algunas especies de Callialasporites e Inaperturopollenites (Balmeiopsis?) limbatus, entre otros; mientras la siguiente asociación HuitrinipollenitesStephanocolpites, está caracterizada por granos de polen de afinidad angiospérmica.

Más tarde, uno de los autores establece para el lapso Valanginiano-Aptiano del Sur de Sudamérica, una subprovincia (dentro de la provincia del Sur de Gondwana, descripta por Brenner, 1976) a la que denominó Subprovincia Cyclusphaera psilata, caracterizada por la asociación Cyclusphaera psilataClassopollis. Estableció su límite inferior como la primera aparición, y el superior como la extinción de esa especie guía, que coincide esta última aproximadamente con la primera aparición de los granos tri- a hexacolpados y tetra a heptacotomosulcados de polen de angiospermas (Volkheimer, 1980). Esa unidad paleobiogeográfica estaría representada a partir del Valanginiano de la Cuenca Neuquina (Formación Mulichinco), llegando a su mayor desarrollo en el Hauteriviano-Barremiano (Formación Agrio y formaciones sincrónicas), y se extiende hasta el Barremiano-Aptiano de esa cuenca (parte inferior de Formación Huitrín), de la cuenca de San Luis (Formación La Cantera) y del Deseado (Formación Anfiteatro de Ticó - ex Formación Baqueró).

La asociación Huitrinipollenites-Stephanocolpites ha sido rescatada de sedimentos depositados en un ambiente continental, en la sección superior de la Fm. Huitrín. Está caracterizada por formas polínicas tri-hexacolpadas y tetra-heptacotomosulcadas, de afinidad angiospérmica: Clavatipollenites, Huitrinipollenites, Stephanocolpites, Retitricolpites y Tricolpites (Vokheimer \& Salas, 1975 y 1976; Volkheimer et al. 1976). Otras especies características son Hyalosphaera balsensis, que es un acritarco lacustre, y una gran frecuencia de Classopollis cf. classoides. También tienen una buena representación las esporas estriadas (Cicatricosisporites/Appendicisporites), los granos monocolpados y poliplicados, y los sacados, dentro de los cuales se destacan Callialasporites, Podocarpidites, Microcachyidites y Trisaccites (Volkheimer et al. 1976). La edad estimada para ese conjunto polínico es Albiano, y se determinó en base al registro de granos tricolpados en el mundo. Sin embargo no se descarta una posible inclusión de parte del Aptiano, dentro de la sección superior de la Formación Huitrín.

\section{IV.3.4. Cuenca de San Luis}

En esta cuenca, no hay ninguna unidad coetánea con la formación en estudio. La unidad temporalmente más próxima es la Formación La Cantera (Grupo El Gigante), de edad aptianaalbiana inferior. Esta edad fue propuesta por Prámparo (1999), quien reportó una importante asociación de granos de angiospermas entre las que se encuentran: Afropollis spp., Clavatipollenites spp., Stellatopollis sp., Brenneripollis spp., Retimonocolpites spp., Liliacidites spp., Huitrinipollenites transitorius y Stephanocolpites mastrandreai.

La presencia de Brenneripollis estaría indicando que se trata de un Aptiano medio-alto.

\section{IV.3.5. Resultados}

Del análisis previo se puede inferir que la asociación polínica de la Fm. Punta del Barco no puede ser 
directamente correlacionada con otra dentro de Argentina. Sin embargo, pueden distinguirse eventos en el registro polínico que coexisten en otras asociaciones. Tal es el caso de la Zona de conjunto Antulsporites-Clavatipollenites, donde se distingue la aparición de los primeros tipos angiospermoides. Como ya se ha expuesto, sería muy afín a la Biozona A (este trabajo), con la única divergencia dada por la presencia del género Asteropollis. La Biozona $\mathrm{B}$, entonces podría corresponderse con aquellos niveles en los que ese taxón está presente.

En la cuenca del Golfo San Jorge el "conjunto Asteropollis", parece tener una distribución con valor bioestratigráfico. En el cuadro que ilustra la distribución de las especies en la columna (Archangelsky et al. 1984), puede observarse que en el pozo YPF-Ch.CRM.es - I, Clavatipollenites hughesii está presente desde los $2650 \mathrm{mts}$, en tanto Asteropollis asteroides, desde los 2290. Los autores apuntan al pozo YPF.SC.CEP.x-I, como la columna más completa, y en él, Clavatipollenites hughesii aparece en la parte superior, donde no se registra aún Asteropollis asteroides.

Esa diferencia temporal entre la aparición de Clavatipollenites hughesii y Asteropollis asteroides, está presente también en las secuencias baqueroenses y parecería ser un buen indicador biostratigráfico. Los componentes "no angiospémicos" de la microflora tienen un comportamiento único que estaría vinculado con cuestiones ecológicas y deposicionales a nivel local, por lo que no brinda herramientas útiles para una correlación.

En la Cuenca Neuquina, en cambio, la asociación Cyclusphaera psilata-Classopollis tendría su límite superior en la extinción de esa especie guía, que coincide aproximadamente con la primera aparición de los granos tri- a hexacolpados y tetra a heptacotomosulcados (Huitrinipollenites/Sephanocolpites). Esos tipos polínicos (=Asteropollis) en la presente microflora coexisten con Cyclusphaera psilata, por lo que no es posible asignarlo a aquella asociación.

Sin embargo, el creciente conocimiento de la palinología de la Cuenca Austral, está mostrando ciertas coincidencias en el comportamiento de los conjuntos polínicos, especialmente en los recuperados de perforaciones en la plataforma continental. Tal es el caso del pozo MLD3, donde se halló una sección comparable con Fm. Anfiteatro de Ticó, y por encima de ésta un cambio en la palinoflora, sumado a la aparición del morfogénero Asteropollis. Esta asociación superior podría corresponderse con Punta del Barco, aunque en ese caso hay abundante polen del tipo Classopollis. No obstante esta diferencia podría responder a factores ecológicos. La suma de cambios sucedidos en ese conjunto polínico, son comunes a la asociación recuperada en la Fm. Punta del Barco.

\section{IV.4. Comparación con asociaciones del ámbito gondwánico}

\section{IV.4.1. América del Sur}

Palinofloras aptianas y albianas han sido descriptas en varios países sudamericanos: Uruguay, Brasil, Colombia, etc.

De acuerdo a la propuesta biogeográfica de Herngreen et al. (1996), en América del Sur pueden reconocerse para el Cretácico pre-albiano, dos regiones con particularidades muy diferentes. La 
porción septentrional corresponde a la provincia Dicheiropollis etruscus/Afropollis, y está caracterizada por las especies Dicheiropollis etruscus, Complicatisaccus cearensis, Sergipea spp., Tucanopollis crisopolensis y Afropollis spp., estas dos últimas con afinidad angiospérmica. Esas plantas tuvieron un desarrollo y diversificación más tempranos, y en este perído de tiempo ya se registran las primeras formas tricolpadas. Fué importante además, la participación de los granos poliplicados y con eláteres, como así también de Eucomiidites. El clima fue cálido, y se habría vuelto más seco en el Barremiano/ Aptiano. La faja más austral, en cambio está caracterizada por los granos de gimnospermas: grupo Cyclusphaera-Balmeiopsis, polen bisacado, trisacado y Murospora florida.

Dentro de la primer región mencionada, existen múltiples citas de sedimentos aptianos para este subcontinente. Aquí serán mencionados según cuencas sedimentarias y regiones en las que se encuentran. Macizo de Quetame; Pons (1988) describió dos localidades: Villavicencio y Gachetá. Para la primera, considera una edad aptiana inferior en los niveles medio e inferior; en tanto para la segunda, propone un lapso de tiempo Barremiano-Aptiano inferior.

Cuenca de Bogotá: contiene sedimentos a los que aquella autora adjudica una edad aptiana superior, pertenecientes a la Fm. Cáqueza.

Maciso de Santander, en la región de Soganoso Yopal, la Fm. Fómeque tendría una edad BarremianoAptiano, mientras en la región de Villa de Leiva, se registró una asociación polínica aptiana.

Al Este de ese cratón, afloran tres unidades cercanas en el tiempo: Fm. Río Negro (NeocomianoAptiano); Fm. Tibú Mercedes, cuya fauna sugiere una edad aptiana;y Fm. Arguadiente, probablemente depositada en el Aptiano-Albiano (Pons, 1988).

En un estudio de integración de datos palinológicos provenientes de diversas cuencas de Brasil, Regali y colaboradores (1974) proponen una zonación para el Cretácico y Terciario. La zona denominada PC-23 (Zona de "Inaperturopollenites" crisopolensis) correspondería temporalmente con el Aptiano inferior. Más tarde, otra propuesta biostratigráfica general para ese país describe a la Asociación 7 en la base del Aptiano (Lima \& Boltenhagen, 1981), la cual está presente en las cuencas de Alagoas y Reconcavo/Tucano.

Por último, en la Cuenca de Santa Lucía (Uruguay) se emplaza la Formación Castellanos, para la que se había propuesto una edad Neoaptiano-Neoalbiano. El relevo de los palinomorfos confirma al Albiano en la cronoestratigrafía de esa unidad litológica (Campos et al. 1998).

\section{IV.4.2. Antártida}

No se han establecido hasta el momento palinozonas para el continente antártico. Sin embargo, es posible relacionar la microflora de Anfiteatro de Ticó y Punta del Barco con la Formación Cerro Negro, cuya datación absoluta es de $119 \pm 3.0 \mathrm{Ma}$ (Hathway et al. 1999). La asociación polínica presenta una mayor afinidad con la Biozona A (este trabajo), ya que tiene un alto porcentaje de granos bisacados. Dicha semajanza fue observada por Archangesky (2003), y está dada en la lista palinológica de esta unidad (Cantrill, 2000) la cual demuestra un altísimo porcentaje (90\% ?) de 
taxones comunes con esa biozona. No obstante, en la unidad antártica no se han encontrado hasta el momento granos de angiospermas y, por otra parte, allí se reportó también la ausencia de taxones característicos como son Classopollis y Callialasporites (Hathway et al. 1999).

Es interesante comentar que esos autores reportaron un cambio de la flora entre niveles que están separados por depósito piroclásticos de un espesor mayor a los 200 metros . Esto podría corresponderse con el pulso de la actividad volcánica neoaptiana, que en Patagonia austral quedó testimoniada en las formaciones Bajo Tigre y Punta del Barco.

Por otro lado, los quistes de dinoflagelados biomarcadores procedentes del Noroeste de la Isla James Ross (Fm. Punto Lagrelius), han permitido asignar una edad aptiana temprana a la secuencia; así se puede establecer la misma edad para la base del Grupo Gustavo en la Cuenca James Ross (Riding et al. 1998).

Una palinoflora recuperada de sedimentos de George V Land y asignada al Aptiano (Truswell, 1990), aportó datos que, si bien escasos, son interesantes en cuanto a los porcentajes de los tipos polínicos. Presenta características afines a la Biozonas A, como son la alta participación de podocarpaceaes (45\%) y de helechos de Cyatheaceae/Dicksoniaceae (40\%). Pero también tiene una peculiaridad que es característica de la Biozona B: una participación menor al 1\% de polen del tipo Classopollis. No se encontró hasta el momento polen de angiospermas.

\section{IV.4.3. Australia}

Dettmann (1963) describe para el SE de Australia y compara con otras regiones de ese continente, 3 asociaciones palinológicas: Stylosus (Valanginiano), Speciosus (Aptiano) y Paradoxa (AptianoCenomaniano?). La asociación Speciosus está caracterizada por la presencia de Dictyotosporites speciosus. Posteriormente Helby et al. (1987) establecen en el lapso Aptiano temprano-tardío, la Zona de Intervalo Cyclosporites hughesii, dentro de la Superzona Muderongia, que a su vez, está incluída en la Superzona Microcachyidites. La zona presenta como formas accesorias a Microcachyidites antarcticus y el grupo Cyathidites/Dictyophyllidites, y fue relacionada en esa oportunidad con otras zonaciones basadas en los dinoflagelados. Por su parte Dettmann (1986b) describió la palinoflora de una muestra de perforación equivalente a Koonwarra Fossil Bed, de la cuenca Gippsland. Efectuó en esa oportunidad correlaciones entre las distintas cuencas australianas -Gippsland, Otway, Eromanga y Surat- de las cuales las dos últimas poseen secuencias marinas que fueron datadas en base a su contenido faunístico. La flórula estudiada fue asignada al lapso de tiempo Barremiano-Aptiano, y corresponde a la Subzona Cyclosporites hughesii. La edad Barremiano?-Aptiano de esa unidad quedó confirmada con el primer registro de Clavatipollenites hughesii.

En un estudio integrado, Dettmann et al. (1992) comparan también las faunas y las macrofloras, confirmando la validez de la zonación de Helby et al. (1987), aunque con variaciones entre las diferentes regiones. Más tarde esa misma autora, en una recopilación de datos de todo el continente, menciona para la Cuenca de Perth, una Zona Balmeiopsis limbata, que en su parte superior corresponde a un Aptiano temprano (Dettmann, 1994). 


\section{IV.4.4. India}

La Formación Rajmahal en la Cuenca homónima, cuenta con una serie de estratos piroclásticos que fueron muestreados para una datación radimétrica que arrojó un resultado de 118 Ma en la base y 116 Ma en el techo (Tiwari \& Tripathi, 1995).

La aparición de las angiospermas se registró en la parte media de la secuencia (palinonivel I-B) con los géneros Retimonocolpites y aff. Clavatipollenites. La edad estimada de ese evento es 117.5 Ma. En tanto, la especie Clavatipollenites hughesii tiene su primer registro en el palinonivel IV, y el tipo Asteropollis aparece más tarde cerca del techo (palinonivel V).

En un trabajo de recopilación de los datos palinológicos de India, Tiwari (1999) menciona para el Aptiano de la Cuenca Palar, Formación Sriperumbudur, la Zona Coptospora cauveriana. En la Cuenca Krishna-Godavari, también fueron reconocidas varias palinozonas, de las cuales la zona de asociación Cyclosporites hughesii-Ceratosporites equalis, representa al lapso Barremiano-Aptiano, y está caracterizada por la primer aparición de Coptospora camveriana.

Por los datos aquí expuestos, el conjunto polínico aquí estudiado parecería estar más relacionado con aquel rescatado del palinonivel V en la Formación Rajmahal, considerando el registro de Asteropollis por encima del de Clavatipollenites hughesii. Sin embargo está presente allí también una forma tricolpada que indicaría una edad menor, coherente con la datación absoluta.

\section{IV.4.5. Africa}

No es posible comparar a nuestra unidad con los sedimentos de la Cuenca de Algoa en Sudáfrica, dado que ellos no superarían en sus términos mas jóvenes al Valanginiano (Scott, 1971).

Por otra parte, en base a muestras extraídas de perforaciones en el NO de Egipto se reconocieron 3 zonas informales que abarcan un lapso Aptiano-Maastrichtiano (Mahmoud \& Moawad, 2002). La zona definida como PS-1 corresponde al Aptiano y está caracterizada por la asociación Duplexisporites generalis-Murospora-Concavissimisporites variverrucatus- Tricolpados.

La microflora en estudio podría vincularse con la sección basal de esa unidad, aunque allí están presentes formas angiospérmicas que aparecen en Patagonia austral más tardiamente.

En las Cuencas de Congo y Gabón, también existen zonas palinológicas descriptas para el Aptiano (Doyle, et al. 1977). En ese contexto se reconoció la Asociación "f" con una edad transicional Barremiano-Aptiano.

Zavada (1987) reportó el hallazgo de Cyclusphaera psilata en una muestra de la perforación DSDP361, en la región occidental de Sud Africa, datada como de edad aptiana. Ese taxón ya había sido considerado un marcador bioestratigráfico (Volkheimer, 1980), por lo que el autor propuso el nombre de "Provincia Cyclusphaera psilata" que abarcó a Sudamérica y Sudáfrica por encima de los $30^{\circ}$ de paleolatitud para el Cretácico Inferior, con una subsecuente extensión en el Cretácico Superior que llegó a incluir Sudamérica Central, India y posiblemente Australia. 


\section{IV.4.6. Resultados}

En estudios bioestratigráficos del Mesozoico del Hemisferio Sur, se observó que el valor para correlación de los palinomorfos no marinos es muy limitado (Dettmann et al. 1992). Este es un problema que se ha hecho evidente al intentar establecer correlaciones, dado que la palinoflora de la Formación Punta del Barco es netamente continental, y por ese motivo muy susceptibles de modificaciones en sus componentes, que responden a cambios en el entorno.

Así, es dificil realizar comparaciones más allá de un nivel intracuencal, dado que las semejanzas y diferencias entre distintas asociaciones pueden ser la respuesta a factores ecológicos, sin brindar información bioestratigráfica valiosa.

De igual manera, el valor de correlación en el Aptiano de los distintos tipos angiospérmicos, está limitado por cuestiones biogeográficas como la dispersión, y por los factores ecológicos que permitieron su radiación.

En este sentido la Formación Punta del Barco ha brindado importantes novedades, con la presencia de varios tipos polínicos de esa afinidad botánica dentro de un cuerpo de roca datado por métodos radimétricos que establecen su edad absoluta. Se convierte así en un punto de referencia que permite comparar con unidades de otras cuencas e incluso otros continentes y hacer inferencias en cuanto a la radiación y vías de dispersión de las plantas con flores.

La mayor afinidad se ha encontrado sin dudas con las microfloras antárticas -en especial con la Fm. Cerro Negro-, las que evidencian cambios de composición de la vegetación ligados a la actividad volcánica. Si bien éstos involucran a grupos vegetales diferentes, podría establecerse la relación de la Biozona A y la Biozona B con los conjuntos polínicos previo y posterior, respectivamente. Por otra parte, en las muestras antárticas no se registraron hasta el momento polen de angiospermas en los yacimientos de igual edad al que aquí se estudia. Esto puede deberse muy probablemente, a los tiempos de migración de esas plantas que, tal como fuera observado en los restos foliares con esa afinidad, habrían tenido un origen cercano a la faja paleoecuatorial (Cúneo \& Gandolfo, 2005).

Se puede afirmar que las tafofloras baqueroenses, por su abundancia y grado de conocimiento, ofrecen un excelente punto de partida para realizar correlaciones y comparaciones con otras tafofloras de áreas vecinas, asignadas con dudas o con mayor grado de certeza al Cretácico temprano. En la actualidad, el Baqueroense es una referencia obligada para todos los estudios que se efectúan en Austrosudamérica y Antártida, referidos a secuencias sedimentarias continentales del Eocretácico. 
CUADRO 3
Taxones

Densoisporites velatus Densoisporites corrugatus Foraminisporis dailyi

Foraminisporis $\mathrm{sp}$ Contignisporitesglebulentus Contignisporites burgueri Contignisporites cooksoniae Biretisporites cf. B. potoniaei Biretisporites sp.A Biretisporites sp.B Biretisporites sp. C

Deltoidospora sp. A

Deltoidospora sp.B

Todisporites sp.A

Todisporites sp.B

Cyathidites sp. cf C. patagonicus Cyathidites sp. cf C. minor

Ceratosporites sp.A

Ceratosporites sp. B

Concavissimisporites penolaensis

Concavissimisporites sp. A

Staplinisporites caminus

Retitriletes sp.A

Retitriletes douglasii

Espora apiculada indet.

Auroraspora sp.

Lygodiidites sp. 1

Lygodiidites sp. 2

espora perisp. indet.

Gleicheniidites senonicus

Gleicheniidites sp.1

Gleicheniidites sp.2

Gleicheniidites sp. 3

Gleicheniidites sp. 4

Ornamentifera sp. 1

Ornamentifera sp.2

Clavifera cf. C. triplex

Laevigatosporites ovatus

Laevigatosporites sp.

Reticuloidosporites sp. 1

Reticuloidosporites sp. 2

Reticuloidosporites sp. 3

Inaperturopollenites sp

Araucariacites australis

Cyclusphaera psilata

Cyclusphaera sp.A

Balmeiopsis limbatus

Podocarpidites ellipticus

Podocarpidites marwickil

Microcachryidites antarcticus

Microcachryidites sp.A

Trisaccites microsaccatus

Dacrydiumites sp.

Cycadopites nitidus

Cycadopites sp. A

Classopollis sp

Clavatipollenites sp. A

Clavatipollenites sp. B

Retimonocolpites sp.A

Retimonocolpites sp.B

Monocolpopollenites

Retiacolpites sp.

Asteropollis sp.

Fungi

Algae $\begin{array}{llllll}\text { Nivel } 1 & \text { Nivel } 2 & \text { Nivel } 3 & \text { Nivel } 4 & \text { Nivel } 5 & \text { Nivel } 6\end{array}$
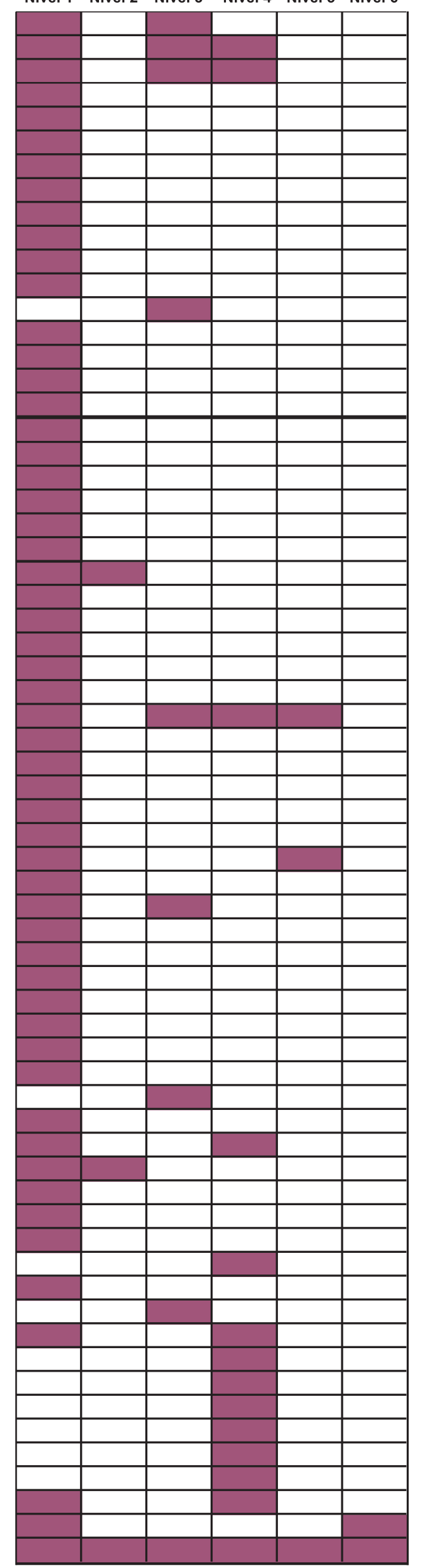


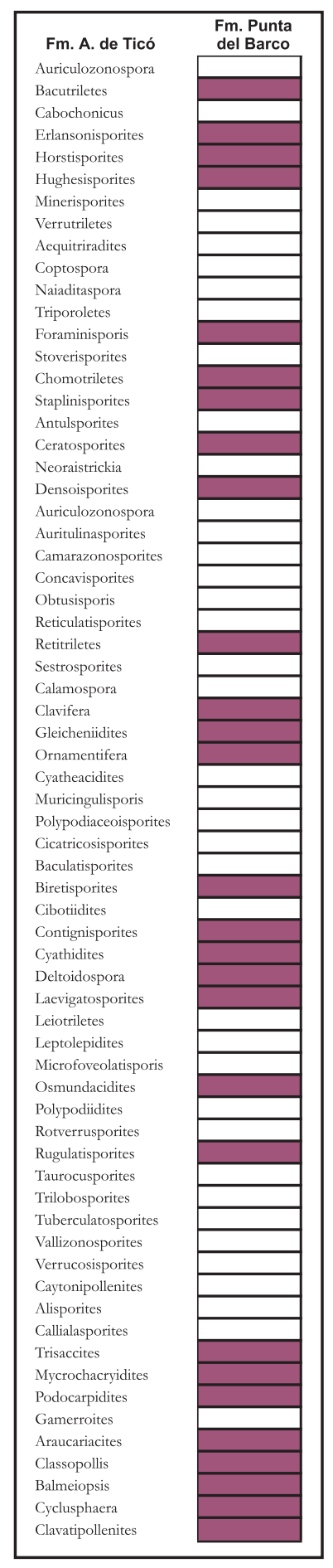

\begin{tabular}{|c|}
\hline Fm. A. de Ticó \\
\hline Auriculozonospora spongiosa \\
\hline Bacutriletes guttula \\
\hline Bacutriletes triangulatus \\
\hline $\begin{array}{l}\text { Bacutrrletes sp. A } \\
\text { Cabochonicus carbunculus }\end{array}$ \\
\hline Erlansonisporites sparassis \\
\hline Horstisporites feruglioi \\
\hline Horstisporites iridodea \\
\hline Hughesisporites patagonicus \\
\hline Hughesisporites rugulatus \\
\hline Minerisporites laceratus \\
\hline Minerisporites patagonicus \\
\hline Minerisporites elegans \\
\hline $\begin{array}{l}\text { Verrutriletes tomtaylori } \\
\text { Acquitriradites baculatus }\end{array}$ \\
\hline Aequitriradites spinulosus \\
\hline Aequittiradites verrucosus \\
\hline Coptospora foveolata \\
\hline $\begin{array}{l}\text { Naiaditaspora gemmata } \\
\text { Triporoletes reticulatus }\end{array}$ \\
\hline $\begin{array}{l}\text { Triporoletes reticulatus } \\
\text { Foraminisporis dailyi }\end{array}$ \\
\hline Foraminisporis asymmetricus \\
\hline Stoverisporites lunaris \\
\hline Chomotriletes minor \\
\hline Staplinisporites caminus \\
\hline Antulsporites baculatus \\
\hline Ceratosporites equalis \\
\hline Ceratosporites setosus \\
\hline Neoraistrickia sp. A \\
\hline Densoisporites velatus \\
\hline Densoisporites corrugatus \\
\hline Auriculozonospora spongiosa \\
\hline Camarazonosporites microalveolatus \\
\hline Concavisporites cf. laticrassus \\
\hline Concavisporites sp. A \\
\hline Obtusisporis obtusangulus \\
\hline $\begin{array}{l}\text { Reticulatisporites ornatus } \\
\text { Retitriletes austroclavatidites }\end{array}$ \\
\hline $\begin{array}{l}\text { Retitirietes austroclavatidites } \\
\text { Retitriletes baqueroense }\end{array}$ \\
\hline Retitriletes sp. A \\
\hline $\begin{array}{l}\text { Sestrosporites pseudoalveolatus } \\
\text { Calamospora aff. mesozoica }\end{array}$ \\
\hline Clavifera sp. A \\
\hline Gleicheniidites senonicus \\
\hline Gleicheniidites sp. A \\
\hline Gleicheniidites sp. B \\
\hline $\begin{array}{l}\text { Ornamentifera tuberculata } \\
\text { Ornamentifera sp. A }\end{array}$ \\
\hline $\begin{array}{l}\text { Ornamentifera sp. A } \\
\text { Cyatheacidites tectifera }\end{array}$ \\
\hline Muricingulisporis annulatus \\
\hline $\begin{array}{l}\text { Polypodiaceoisporites elegans } \\
\text { Cicatricosisporites annulatus }\end{array}$ \\
\hline Cicatricosisporites australiensis \\
\hline Cicatricosisporites baqueroensis \\
\hline Cicatricosisporites cf. ethmos \\
\hline Cicatricosisporites giganteus \\
\hline Cicatricosisporites hughesii \\
\hline Cicatricosisporites ticoensis \\
\hline Baculatisporites comaumensis \\
\hline Biretisporites sp. A \\
\hline Cibotiidites auriculatus \\
\hline Contignisporites cooksonii \\
\hline Cyathidites australis \\
\hline Cyathidites minor \\
\hline Cyathidites sp. A \\
\hline Cyathidites sp. B \\
\hline Deltoidospora minor \\
\hline Laevigatosporites belfordii \\
\hline Laevigatosporites ovatus \\
\hline Leiotriletes regularis \\
\hline $\begin{array}{l}\text { Leptolepidites major } \\
\text { Microfoveolatisporis sp. } \Lambda\end{array}$ \\
\hline $\begin{array}{l}\text { Microfoveolatisporis sp. } \Lambda \\
\text { Obtusisporis sp. A }\end{array}$ \\
\hline Osmundacidites diazii \\
\hline Osmundacidites sp. A \\
\hline Polypodiidites sp. A \\
\hline Polypodiidites sp. B \\
\hline Rotverrusporites labratus \\
\hline Rugulatisporites neuquenensis \\
\hline Rugulatisporites sp. A \\
\hline $\begin{array}{l}\text { Rugulatisporites sp. B } \\
\text { Taurocusporites segmentatus }\end{array}$ \\
\hline $\begin{array}{l}\text { Taurocusporites segmentatus } \\
\text { Trilobosporites apiverrucatus }\end{array}$ \\
\hline Trilobosporites purverulentus \\
\hline Trilobosporites trioreticulosus \\
\hline Tuberculatosporites sp. A \\
\hline Vallizonosporites spinosus \\
\hline Verrucosisporites sp. A \\
\hline $\begin{array}{l}\text { Caytonipollenites pallidus } \\
\text { Microcachrydites antarcticus }\end{array}$ \\
\hline $\begin{array}{l}\text { Microcachrydites antarcticus } \\
\text { Trisaccites microsaccatus }\end{array}$ \\
\hline Alisporites grandis \\
\hline Callialasporites sp. \\
\hline Podocarpidites marwickii \\
\hline Podocarpidites vestitus \\
\hline Podocarpidites futa \\
\hline Podocarpidites ellipticus \\
\hline Podocarpidites parviauriculatus \\
\hline Podocarpidites auriculatus \\
\hline Podocarpidites sp. A \\
\hline Gamerroites volkheimeri \\
\hline Gamerroites sp. A \\
\hline Araucariacites australis \\
\hline Classopollis sp. \\
\hline Balmeiopsis limbatus \\
\hline Cyclusphaera psilata \\
\hline Clavatipollenites hughesii \\
\hline
\end{tabular}

M. Llorens

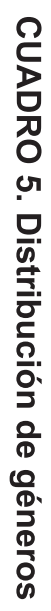




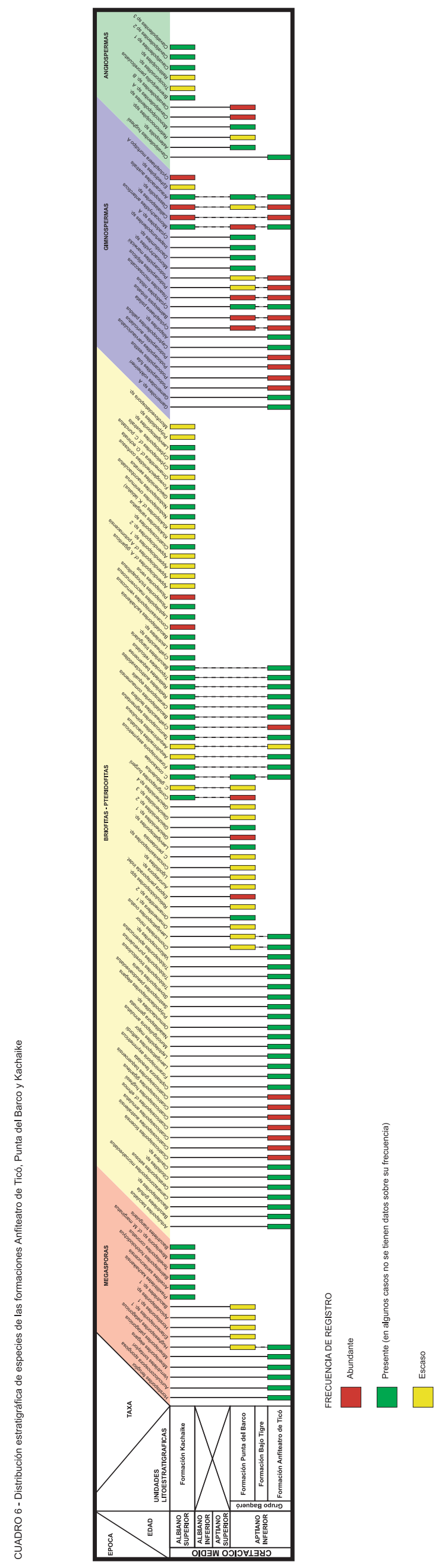

M. Llorens 


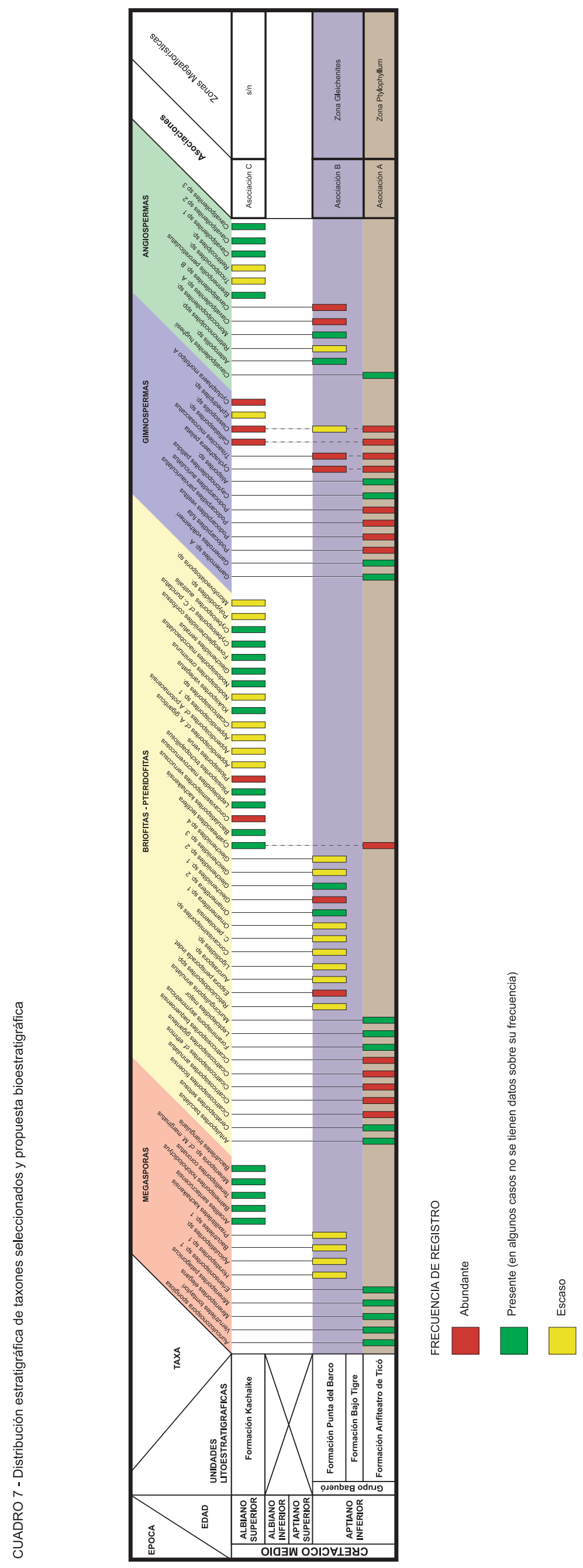

M. Llorens 


\section{CAPITULO V}

Marco Paleoflorístico 


\section{MARCO PALEOFLORÍSTICO}

\section{V.1. Marco paleobiogeográfico}

\section{V.1.1. Paleogeografía}

La mayoría de las reconstrucciones paleogeográficas para el Cretácico reconocen cinco bloques continentales mayores: Eurasia- NorteaméricaGroenlandia, Sudamérica, Africa, India-Madagascar y Australia-Antártida. Una propuesta alternativa reconoce que esta distribución existió sólo en el Cretácico tardío, en tanto durante el Cretácico temprano los bloques habrían sido tres: EurasiaNorteamérica, Sudamérica- India- Madagascar -

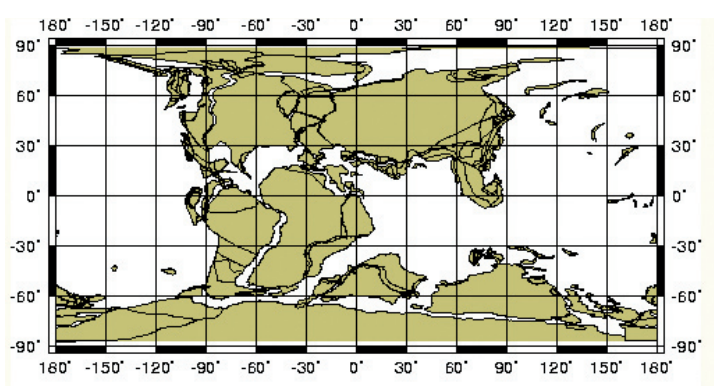

120 Ma Reconstrucción paleogeográfica - Tomado de wmw.odsn.de Australia- Antártida y Africa (Hay et al. 1999). Esta última propuesta presenta grandes diferencias en el trazado de límites en modelos paleoclimáticos.

En el presente trabajo se adopta la propuesta paleogeográfica clásica propuesta, entre otros, por Scotese (1991) (ver mapa).

En un contexto gondwánico, Patagonia fue, ya desde el Paleozoico tardío y durante todo el Mesozoico, un importante componente marginal, ubicado al oeste de la masa continental. Durante el Jurásico y Cretácico esta área limitaba, hacia el W con el Océano Protopacífico. Más específicamente, se ha establecido que a partir del Aptiano temprano, y entre los $40^{\circ}$ y $47^{\circ}$, la Patagonia fue un continente separado del Océano Pacífico por la cadena volcánica del Arco Magmático Andino (Spalletti et al. 1999).

En tanto al N, habría estado limitado por un cinturón desértico, mientras en el S y SE han existido relaciones florísticas con Antártida, y es razonable suponer que ese terreno era el límite natural de Patagonia (Archangelsky, 2003).

\section{V.1.2. Paleofitogeografía}

Han sido enunciadas varias propuestas paleofitogeográficas para el período en estudio. Aquí se presentan sucintamente y se expone el criterio escogido para este trabajo.

Para el período comprendido entre el Barremiano al Cenomaniano, Brenner (1976) reconoce cuatro provincias palinoflorísticas, que son de Norte a Sur:

Provincia de Laurasia septentrional, con clima templado-húmedo.

Provincia de Laurasia austral, con clima templado-cálido a subtropical húmedo.

Provincia de Gondwana septentrional, con clima tropical semiárido.

Provincia de Gondwana austral, con clima templado cálido a subtropical húmedo (comprende actualmente a Sudamérica austral y África austral, incluye también India, Australia y Nueva Zelanda). En un marco más regional, Volkheimer (1980) consideró a Cyclusphaera psilata como especie 
endémica de Sudamérica y propuso la existencia de una "Subprovincia de Cyclusphaera psilata" de la Provincia de Gondwana austral mencionada anteriormente. En esta subprovincia se observan altos porcentajes de Classopollis y la presencia común de polen bisacado (Alisporites, Podocarpidites, Phrixipollenites) y trisacado (Microcachryidites, Trisaccites). Entre las esporas triletes se presentan Gleicheniidites, Trilobosporites, Densoisporites y Pilosisporites.

Posteriormente Zavada (1987) reportó el hallazgo de este marcador bioestratigráfico en Sudáfrica, en una muestra de la perforación DSDP-361, datada como de edad aptiana. Propuso, entonces el nombre de "Provincia Cyclusphaera psilata" que abarcó a Sudamérica y Sudáfrica por encima de los $30^{\circ}$ de paleolatitud para el Cretácico Inferior, con una subsecuente extensión en el Cretácico tardío que llegó a incluir Sudamérica Central, India y posiblemente Australia.

Por otro lado Herngreen \& Chlonova (1981) reconocieron para el Cretácico temprano a la provincia Gondwana que comprende a Sudamérica austral, Sudáfrica, India, Australia y Nueva Zelanda; consideraron la posibilidad de incluir aquí a Antártida, que no había brindado datos palinológicos hasta el momento. Ya existían en cambio datos de estratos del Neocomiano-Aptiano y Albiano provenientes de perforaciones realizadas $700 \mathrm{~km}$. al Este de las Islas Malvinas (Kotova, 1983). Los resultados del análisis fueron reportados por Hedlund \& Beju, y Harris realizó la discusión (referencia en Herngreen \& Chlonova, 1981), a partir de la cual los autores alistaron esa área en aquella unidad biogeográfica.

Más tarde y a la luz de una gran cantidad de asociaciones estudiadas, el continente Antártico fue definitivamente incluido en la redefinida "Trisaccates Province" dentro de la Región Austral (Herngreen et al. 1996); en esa oportunidad se extendió la duración para esta unidad biogeográfica del Cretácico temprano al Cenomaniano. La particularidad de toda el área comprendida es la abundancia de gimnospermas representadas principalmente por granos sacados y del tipo Classopollis, siendo el género Trisaccites una forma característica.

En otro trabajo paleobiogeográfico global, Vakhrameev (1991) considera a los afloramientos jurásicos y cretácicos del hemisferio Sur dentro de la región Austral, compuesta por tres provincias: Patagónica, Australiana e India, basado en datos paleoflorísticos. La primer provincia fue caracterizada por la dominancia de las gimnospermas (Ordenes Bennettitales y Cycadales y Familias Cheirolepidiaceae y Araucariaceae). En cuanto a la ubicación paleobiogeográfica de Sudáfrica, considera indudable su inclusión dentro de la región Austral, aunque no la separa en una provincia en particular por no contar con datos suficientes. Incluye además dentro de esa provincia al material palinológico proveniente de la plataforma de las Islas Malvinas que fuera examinado por Kotova (1983), quien le atribuyó una edad albiana por comparación con asociaciones australianas. Sin embargo Vakhrameev, en el trabajo antes mencionado, encuentra un parecido mayor con el complejo palinológico baqueroense, característico de la provincia Patagónica.

Más tarde Archangelsky (1996) a la luz de nuevos datos florísticos refuerza el concepto de la provincia Patagónica y propone expandirla areal y temporalmente, abarcando el período Jurásico y 
parte del continente antártico.

Los sedimentos depositados durante el Cretácico Inferior en las cuencas del Golfo San Jorge, Austral, Neuquina y el Cratón del Deseado ( dentro de este último, los del actual Grupo Baqueró), están comprendidos dentro de la provincia Patagónica. Aquí se adopta este último criterio considerando a la Fm. Punta del Barco y su asociación palinológica dentro de la provincia paleobiogeográfica Patagónica. Prefiero usar una designación basada en una región geográfica amplia y reconocida internacionalmente por sus abundantes recursos paleontológicos.

Creo también, que el uso de nombres de taxones no debería caracterizar áreas geográficas por cuanto los mismos pueden cambiar por aspectos nomenclatoriales o bien, como en el presente caso, faltar debido a factores ecológicos o preservacionales. Por otra parte, cabe mencionar que Cyclusphaera es, entre otros, uno de los elementos florísticos que caracteriza a la Provincia Patagónica.

\section{V.2. Marco paleoecológico}

Un análisis paleoecológico confiable debe estar basado en la reconstrucción de comunidades individuales en una escala de 1 a 100 años (Wing \& DiMichele, 1992). Este fino nivel de resolución es alcanzado en los depósitos volcanogénicos explosivos y de lluvia de cenizas, pudiendo ser en esos casos de $10^{-2}-10^{0}$ años (Behrensmeyer \& Hook, 1992). A demás, este tipo de depósitos origina las tafofloras autóctonas mejor preservadas (Gastaldo, 1992).

Como ya se ha desarrollado en capítulos anteriores, la Formación Punta del Barco reúne esas condiciones y constituye un interesante caso para un análisis de este tipo.

Para tal fin se han considerado aquí conceptos tafonómicos que han sido largamente discutidos (ver entre otros: Behrensmeyer et al. 2000; Burnham, 1989; Ferguson, 1985; 2002), y que aportan información valiosa para la interpretación de las asociaciones paleontológicas.

La riqueza específica es el principal factor que se ha considerado en este análisis, asumiendo las limitaciones que conlleva trabajar con material fósil, que en muchos casos hace casi imposible tal estimación. Esto se debe a que existen especies raras o plantas con baja probabilidad de fosilización, y que probablemente nunca serán detectadas.

\section{V.2.1. Estudios previos}

El nivel polínico 1 de la localidad Estancia El Verano (Fig. 3) -nivel 2 en estudios de megaflora- ha sido motivo de dos trabajos tafonómicos donde se indica que la lluvia de cenizas fue lo suficientemente abundante como para sepultar in situ a la comunidad vegetal muy rápidamente. Cladera \& Cúneo (2002) realizaron el estudio tafonómico que evidenció una preservación excepcional de la comunidad, la cual mantuvo espacialmente sus tres estratos: herbáceo -principalmente gleicheniáceas-, arbustivo -Cicadales- y arbóreo -Araucariaceae- dentro del paquete de toba (lám. XIV). También existen en este nivel, asociado con los matorrales de gleicheniáceas, abundantes restos de Hausmannia (ver cap. V.3). 
La palinoflora, por su parte, coincide con esas observaciones, ya que ha brindado una asociación de esporas perisporadas, con una gradación de caracteres de la perina que reflejarían diferentes estadíos ontogenéticos. Esta situación sólo sería posible con una sedimentación suficientemente rápida como para sepultar la planta productora y sus esporas in situ (Llorens \& Cladera, 2002).

\section{V.2.2. Ambientes y vulcanismo}

\section{V.2.2.1. Marco general}

Durante toda la Era Mesozoica la actividad volcánica en Patagonia fue intensa. Al promediar el Jurásico se vigorizó esa actividad en el margen del Protopacífico originando un basamento porfírico que se extendió por Patagonia y parte de Antártida. Sobre esta platea se desarrollaron secuencias sedimentarias en el Jurásico medio y tardío (De Barrio et al. 1999; Gust et al. 1985). El vulcanismo, aunque de otra naturaleza, continuó siendo importante en el Cretácico (Ramos, 1978), cuando aquellas unidades quedaron cubiertas por los sedimentos del Grupo Baqueró, compuesto de base a techo, por las formaciones Anfiteatro de Ticó, Bajo Tigre y Punta del Barco (Cladera et al. 2002). Para el lapso Barremiano tardío - Aptiano temprano (ca. 125-120 Ma) Larson (1991) indicó un incremento del vulcanismo de intraplaca, de alcance global. Este pulso con formación de corteza, fue atribuido a una "superpluma" del manto que causó efectos mayores en la química oceánica y atmosférica. Tarduno et al. (1991) registraron un evento volcánico aún más acotado, a los 120Ma. La combinación de estos sucesos globales incidió en una susceptibilidad de los océanos que condujo a una deficiencia de oxígeno durante el Aptiano temprano, a la cual denominaron OASE ('oceanic anoxic sub event'). Estos eventos incluyeron el ascenso del nivel del mar, cambios en la circulación y química oceánicas, y en el clima.

Bralower et al. (1994) presentaron los resultados sobre disoxia/anoxia oceánica basados en varias muestras, cuyas dataciones evidencian que el pico de disoxia/anoxia se produjo entre los $121 \mathrm{y}$ $123 \mathrm{Ma}$ en el Aptiano temprano. Según estos autores, si los modelos paleoclimáticos son correctos, debe haberse producido un calentamiento global importante, asociado con el vulcanismo y el OASE, como resultado del incremente de CO2 que pudo haber producido un efecto 'invernadero'.

En suma, el Aptiano estuvo marcado por un breve intervalo de disoxia/anoxia a escala global. Eventos tectonovolcánicos que condujeron al incremento en la producción de corteza oceánica pueden haber inducido, indirectamente, el episodio disóxico/anóxico y causar así cambios considerables tanto en las biotas marinas (Mutterlose, 1992; 1998; Bralower et al. 1994; Bralower \& Lorente, 2003; Herbin 1987; Antolini et al. 2002) como en las terrestres (Archangelsky, 1999, 2001a y 2001b; Tiwari \& Tripathi, 1995; Falcon-Lang \& Cantrill, 2002; Hill et al. 1999; Cantrill \& Poole, 2002).

\section{V160.2.2.2. Tipo de vulcanismo}

Durante la depositación de la Formación Punta del Barco dominó un magmatismo silíceo. Ese 
tipo de magmatismo en la actualidad resulta en la formación de volcanes elevados y explosivos, caracterizados por erupciones efímeras de gran magnitud, que ocurren cada pocas centurias, seguidas por largos períodos de quiescencia (Cas \& Wright, 1987). Este tipo de erupciones fuertemente explosivas dan origen a aerosoles, que inyectados en la estratósfera, pueden generar cambios climáticos importantes a nivel regional y global (Kelley, 2003). Varias de estas explosiones próximas en el tiempo, podrían ocasionar "inviernos volcánicos” y provocar la expansión de las áreas áridas del planeta (Krassilov, 2003). Esto daría lugar a cambios evolutivos importantes y grandes extinciones (Axelrod, 1981). Por su parte Knoll (1984), reconoce que las plantas son altamente vulnerables a los cambios climáticos, y presenta curvas de diversidad vegetal que marcan un punto de inflexión en el lapso Aptiano-Albiano.

En tal sentido, el testimonio directo del pulso en la actividad volcánica en el momento de depositación de las formaciones Bajo Tigre y Punta del Barco, son los niveles de ceniza volcánica primaria. En ocasiones tienen espesores considerables, que pueden haber alcanzado los 8 metros en el momento de la caída, y quedaron luego reducidos por compresión a 0,8-1 metro. Esa ceniza habría provocado un estrés hídrico debido a un fuerte cambio en la composición química del sustrato, más que a una carencia de agua (Spicer, 1980; A. Archangelsky et. al. 1995). Por otra parte, los estudios tafonómicos en la zona indican que debieron ser arrastradas hasta allí por fuertes vientos provenientes del Oeste, ya que los centros volcánicos se encontraban alejados a más de $100 \mathrm{Km}$ (Cladera \& Cúneo, 2002). Además, en el primer nivel fértil estudiado se hallaron restos cuticulares sin ningún tipo de alteración térmica, y eso indica que la ceniza caída era fría (A. Archangelsky et. al. 1995).

\section{V.2.2.3. Cuerpos de agua}

El paisaje eocretácico de la actual meseta Baqueró se emplazó en una llanura con pendiente SurNorte, surcada por un sistema fluvial entrelazado (Cladera et al. 2002). En este sentido, la presencia de cuerpos de agua dulce en todos los niveles fértiles queda confirmada por el registro de restos de algas. Están presentes las clorofíceas (Botryococcus, Retirotundia y Chomotriletes), y también las Zygnemataceae, con los géneros Lecaniella, Schizosporis y Ovoidites. Estas últimas, aportan interesantes evidencias paleoecológicas, ya que poseen zigosporas muy semejantes a sus equivalentes actuales, y podría inferirse su biología por comparación directa. Las zignematáceas modernas se desarrollan en cuerpos de agua dulce, lagos, lagunas, pantanos y corrientes lentas, y sus zigosporas pueden requerir repetidas condiciones de sequía para iniciar la germinación (Zippi, 1998).

La importancia paleoecológica de estas algas fue abordada por varios autores desde diversos aspectos. Zippi (1998), por su parte, destaca el hallazgo de zigosporas como formas representativas de palinofloras empobrecidas. Sugiere además que su presencia indica un ambiente de depositación interpretado como un sistema de agua dulce con repetidas desecaciones, como es el caso de una planicie de inundación. Esto refuerza entonces las evidencias litológicas reconocidas para la Fm. Punta del Barco (ver cap. II.5.3). 
Crowley y colaboradores (1994) proponen, por otro lado, que la caída de ceniza volcánica crearía una capa semipermeable que causa el desborde y estancamiento en los cursos de agua. Uno de los aspectos en que se basan para ello es la elevada participación de algas de la Familia Zygnemataceae en muestras tomadas directamente por encima de los tonsteins -bentonitas caoliníticas derivadas de la alteración del vidrio volcánico- (Fisher \& Schmincke, 1984). Un comportamiento del sistema hídrico de este tipo, habría derivado en la formación de efímeros cuerpos laterales de agua, que según Fritz (1986), actuarían como “trampas” para el polen y esporas. Además, Rich y otros (1982) observaron que las zigosporas que corresponden a Ovoidites muestran una preferencia por cuerpos lénticos de agua dulce, ligados a depósitos de carbón de bajo rango (lignitos), en ambientes abiertos más que en los sombríos.

La predominancia de cuerpos de aguas someras estaría sustentada también por la ausencia de las Isoëtales, que son vinculadas en ese momento de su filogenia con cuerpos de agua estables (Taylor \& Hickey, 1992).

Los datos aportados por la zignematáceas, ilustran entonces el escenario del momento como una llanura con frecuentes desbordes de los canales que la surcaron, con una vegetación empobrecida que rara vez llegó a formar un dosel arbóreo.

\section{V.2.2.4. Paleoincendios}

En diversos trabajos se ha reconocido la importancia potencial de los productos de paleoincendios, dado que brindan información paleoecológica que concierne a la influencia del fuego en los antiguos ecosistemas (e.g. Scott et al. 2000; Scott et al. 2001). Esos aspectos tafonómicos, se utilizarán en este trabajo como otra herramienta para interpretar el escenario aptiano.

En varios de los niveles muestreados se hallaron fragmentos de materia orgánica carbonizada (fusinita) originada durante los paleoincendios. Esos incendios pudieron haber afectado directamente la zona de la actual Meseta Baqueró, o bien originarse en los centros de vulcanismo, que actuaron como fuente del material posteriormente allí depositado.

En el primero de los casos, la evidencia estaría dada por la presencia de palinomorfos de un mismo nivel que muestran distintos tonos en el color de la exina, correspondientes a distintos niveles de alteración térmica. Esto indicaría que la alteración se debió entonces a un proceso de catagénesis (Alpern, 1980) con distintos grados de exposición al calor del fuego, y no a uno diagenético alterativo (foto). Este fenómeno se da en las asociaciones del primer y cuarto nivel estudiados. En este último, queda evidenciado el mejor potencial en la preservación que tuvieron aquellas plantas que se desarrollaban cerca o dentro del agua, como medio de protección del fuego.

En cuanto al material alóctono producido

en áreas cercanas a los volcanes, puede suponerse que habrían sido arrastrados hasta su sedimentación por los fuertes vientos del

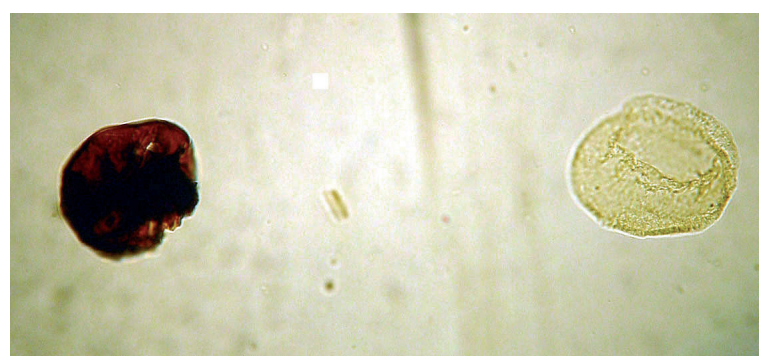


Oeste las partículas menores, y por el agua las de mayor tamaño. Esto ocurre comúnmente debido a que la materia charcolificada tiene un peso específico bajo.

Como se verá más adelante, un componente dominante de esta tafoflora son los helechos de la Familia Gleicheniaceae. Este grupo aporta un indicio interesante en cuanto a su rol en la comunidad vegetal, ya que sus representantes cenozoicos y actuales, son colonizadores en suelos devastados por incendios (Collinson, 2002; Chin, 1997).

Cabe señalar por otra parte, que la presencia de dos niveles portadores de cutículas preservadas sin alteraciones térmicas, uno en la base y otro en la sección media-superior de la columna, denota que las altas temperaturas que carbonizaron algunos restos no fueron consecuencia de una lluvia de cenizas caliente.

\section{V.2.2.5. Efectos del vulcanismo sobre la vegetación}

Los estudios de erupciones volcánicas modernas han revelado la manera en la que es alterada la vegetación. La erupción del Monte Katmai, Alaska (Griggs, 1915) y la del volcán Paricutin, México (Eggler, 1948; Segestrom, 1950; Malde, 1964) mostraron que hay plantas que son cubiertas tan profundamente por las cenizas, que no logran enviar ramas nuevas a través de esa cobertura y perecen, mientras que las que lo logran, sobreviven. De esta manera en la zona de Baqueró durante el Cretácico, solo habrían superado estos episodios los árboles de mayor envergadura, como fueron las araucarias y probablemente algunas podocarpáceas. El resto de la comunidad habría dependido de su habilidad para reproducirse y recolonizar el nuevo escenario ambiental. En este punto es dable comentar que la ausencia de un grupo muy conspicuo como fueron las cheirolepidiáceas, pueda deberse a que esas plantas no hubieran alcanzado un porte arbóreo, por lo que habrían quedado sepultadas en la ceniza sin posibilidad de repoblar el área en un corto lapso.

La alteración de la flora por el vulcanismo observada mediante estudios palinológicos, cuenta con pocos ejemplos. Uno es el del Holoceno de Montana, donde se registraron cambios inmediatamente después de la erupción de dos volcanes aledaños (Mehringer et al. 1977). En el Mioceno, el conocimiento de floras influenciadas por el vulcanismo proviene de Austria (KovarEder et al. 2001) y el resto corresponden a Oregon e Idaho, donde los cambios fueron causados por eventos volcánicos periódicos (Taggart \& Cross, 1980; Taggart et al. 1982; Cross \& Taggart, 1983). Todos estos estudios muestran que tanto en las floras modernas como en las fósiles, luego de las erupciones volcánicas existe un incremento de los elementos xéricos herbáceos, como así también una mayor diversidad de helechos oportunistas.

Por otro lado, Spicer (1980) asume que en áreas distales al volcán, sólo es posible un cambio sustancial en la composición de la comunidad vegetal si la caída de cenizas es muy grande y/o repetida con gran frecuencia (varias veces durante la temporada de crecimiento por varios años consecutivos).

Un episodio de estas características debió tener lugar en el Aptiano de Patagonia, ya que afectó fuertemente a la biota de aquel momento (Archangelsky, 1999; 2001 a y b). 


\section{V.2.3. Comunidades por niveles y preservación diferencial}

En la Meseta Baqueró, los afloramientos de la Formación Punta del Barco están representados por ciclos "paleosuelo-toba" o "canal-toba". Las tobas son primarias -que representan los picos de actividad volcánica- y alternan con momentos de calma en esa actividad que se traducen en el establecimiento de paleosuelos. Se han rescatado restos polínicos de seis de estos ciclos (ver figs.2 y 3 y cuadro 3).

\section{V.2.3.1. Nivel 1}

El primer nivel fértil -localizado en la barda Norte de la Meseta Baqueró-, es el que aportó gran parte del material estudiado en este trabajo y presenta la mayor diversidad taxonómica. Está caracterizado por la abundancia de granos de Cyclusphaera psilata y Balmeiopsis limbatus, acompañados por los de Araucariacites, Microcachryidites y Trisaccites dentro de las coníferas. El morfogénero Cycadopites está presente en baja proporción, y puede pertenecer a representantes de los órdenes Cycadales, Bennettitales, Pteridospermales o Ginkgoales. Los restos megascópicos dan cuenta inequívoca únicamente de la presencia de los primeros. Las pteridofitas de las familias Gleicheniaceae, Pteridaceae y Lycopodiaceae son las mejor representadas en el espectro polínico. Entre las angiospermas, aquí se da el primer registro de Asteropollis para el Grupo.

\section{V.2.3.2. $\underline{\text { Nivel } 2}$}

El segundo nivel fértil proviene de la Barda Sur; consta de muy pocos palinomorfos, en su mayoría elementos planctónicos. En ellos se observa el desprendimiento de la endexina muy probablemente por efecto de las altas temperaturas.

\subsubsection{Nivel 3}

En el tercer nivel el material está muy oxidado, y consta principalmente de esporas del tipo Densoisporites y Gleicheniidites, además de un nuevo tipo de grano monocolpado presumiblemente de afinidad con las Cycadales, ya que las Bennettitales y Ginkgoales están ausentes entre los megafósiles rescatados de este paquete formacional.

\section{V.2.3.4. Nivel 4}

El cuarto nivel se encuentra en la Barda Sur donde se registró un cuerpo lenticular con un espesor aproximado de $80 \mathrm{~cm}$. que representa un meandro abandonado, con bajísimos niveles de oxidación y depositación del material por decantación. Estos factores han determinado la excelente preservación de los restos vegetales micro y megascópicos. El contenido fosilífero de esta lente se compone mayormente de ramas con hojas escuamiformes del tipo Brachyphyllum y folíolos de Pseudoctenis (ambas con cutícula preservada), además de estípites carbonizados de pteridofitas; también hay leños y frondes con pínulas ‘cladophleboides’ y del tipo Gleichenites Göpp., entre otras. El carácter 
fragmentario de órganos resistentes, como ser leños y hojas, y la coexistencia de elementos con distinto tipo de preservación revelan un origen alóctono del material, que habría sido transportado y depositado por el desborde de los canales fluviales. Los restos carbonizados sugieren que parte de los fragmentos vegetales son producto de paleoincendios (Llorens et al. 2003) (ver lám. XIII).

El hallazgo de cutículas foliares conforma una novedad para esta unidad, ya que los únicos antecedente eran una cutícula carbonizada de Araucaria grandifolia (Del Fueyo \& A. Archangelsky, 2002), y una momificación de Pseudoctenis ornata (A. Archangelsky et al. 1995) con caracteres que sugieren una adaptación a condiciones desfavorables, como fueron la lluvia de cenizas y la alteración edáfica que ella produjo.

En cuanto al contenido polínico de esta lente, es evidente el amplio dominio de granos del complejo Clavatipollenites representado por dos formas diferentes. Monocolpopollenites lo acompaña en una medida mucho menor y los demás granos tienen un registro esporádico, y si bien carecen de importancia numérica en la asociación, denotan interés en cuanto a la diversidad de las plantas con flores en el Aptiano (Llorens, 2003 a y b). Otros grupos vegetales representados en esta asociación son las podocarpáceas (Dacrydiumites) y las briofitas (Foraminisporis), ambos con baja frecuencia. El medio acuático está representado por una comunidad planctónica diversa y abundante (Ovoidites spp., Botryococcus sp., entre otras) (Llorens et al. 2003).

\section{V.2.3.5. $\underline{\text { Nivel } 5}$}

Del quinto nivel se ha rescatado una asociación muy pobre que sólo contiene esporas de gleicheniáceas y Microcachryidites.

\section{V.2.3.6. Nivel 6}

El sexto y último nivel, contiene únicamente restos de algas y unos pocos granos de Podocarpaceae.

\section{V.2.3.7. $\underline{\text { Resultados }}$}

Por tanto, el grupo mejor representado a lo largo de la columna estratigráfica es el de las algas -presentes en los seis niveles relevados- y los helechos de la Familia Gleicheniaceae, presentes en cuatro de esos niveles (ver cuadro 3 ).

Las pteridofitas en general parecen haber usado estrategias de persistencia a pesar de las condiciones de estrés del momento. En el caso particular de las gleichenias, sus rizomas habrían sido los propágulos que les permitió re-poblar la planicie eocretácica. En tanto que aquellos helechos con esporas de dispersión aérea, lo habrían logrado en el caso de que la humedad fuera alta, condición que permitiría la supervivencia del gametofito, inclusive en las superficies altamente drenadas (Spicer, 1980). Los representantes cenozoicos y actuales de esta familia, son colonizadores en suelos devastados por incendios (Collinson, 2002; Chin, 1997). Este comportamiento se condice 
con el escenario que imperó en la época, signado por eventos catastróficos cíclicos, como fueron las fuertes erupciones volcánicas y los incendios que éstas provocaron, evidenciados por una gran cantidad de fragmentos vegetales carbonizados (Llorens \& Cladera, 2002; Del Fueyo \& A. Archangelsky, 2002). Durante el Aptiano temprano de Patagonia, tal tipo de situaciones ha sido muy frecuente y estos helechos parecen haber sido, en algunos de los niveles, los componentes casi exclusivos de la vegetación. Su abundancia está reflejada asimismo en los restos megascópicos (Herbst 1962, 1966) donde se observan improntas de verdaderos 'matorrales' de gleichenias (Lám. XIII, fig.e). La variedad de esporas de este grupo es por lejos mayor que la de frondes.

Actualmente esta familia ha quedado restringida en Argentina a dos especies endémicas de los bosques andino-patagónicos: Gleichenia quadripartita (Poir.) Moore que puede formar el estrato arbustivo bajo del bosque, aunque habita preferentemente en los claros (Brion et al. 1998) con un comportamiento similar a las poblaciones eocretácicas; y Gleichenia cryptocarpa Hook. con requerimientos ecológicos muy diferentes (de la Sota et al. 1998).

También persiste a lo largo de la columna el registro polínico de las Cycadales, y su contraparte en la megaflora (A. Archangelsky et al. 1995; Archangelsky, 2003). Ellas habrían adquirido un rol importante en los ambientes de estrés, ocupando el nicho que dejaran vacante las Bennettitales grupo dominante hasta ese momento.

\section{V.2.4. Efectos producidos por el estrés}

Los palinomorfos rescatados dan testimonios de una catástrofe ecológica que produjo cambios importantes en la vegetación en un corto período de tiempo (Archangelsky, 1999, 2001a).

La comparación de varios taxones presentes en esta microflora con sus equivalentes en otras asociaciones, revela el registro de esporas y granos de polen con tamaños menores (ver cap III). Tal como sucede con otros órganos vegetales -hojas, flores, etc.- (Capon, 1994), es probable que la reducción en el tamaño del polen sea también una respuesta a condiciones ambientales desfavorables; otra posibilidad es que se deba a una contracción de la exina producida por el aire caliente de los vientos provenientes de los centros de vulcanismo.

Como se expuso anteriormente, las Cycadales son, además de las gleicheniáceas, el grupo con mayor presencia a lo largo de la columna estratigráfica. Tal como lo muestra Pseudoctenis ornata con su cutícula altamente especializada, estas plantas tuvieron estrategias adaptativas que les permitieron perdurar en condiciones extremas. Los granos de Cycadopites sp. descriptos en este trabajo, también acompañan ese proceso adaptativo, con una exina muy robusta de espesores que no se habían registrado en ese morfogénero.

La ultraestructura de la exina en las megasporas de Selaginellales baqueroenses tiene una constitución esponjosa (Archangelsky \& Villar de Seoane, 1990; 1991), la cual permite una flexibilidad volumétrica, útil en la función de disecación en situaciones ambientales extremas (Tryon, 1986). Estas condiciones corresponden a muchos miembros actuales de Selaginella Beauv. Por otro 
lado, granos del tipo Balmeiopsis y Cyclusphaera, que presentan generalmente ecuador engrosado, organización granular o esponjosa de la sexina, condición mono a biaperturada con aperturas amplias, fueron todos considerados en el contexto de una estrategia particular de supervivencia y una mejor adaptación para la dispersión en ambientes de estrés (Archangelsky, 1994).

También la variedad de formas perisporadas de esta palinoflora es llamativa en relación a otras. Existe la posibilidad de que ellas pertenecieran a las polypodiáceas, que incrementaron su presencia en las floras Cretácicas (Schneider et al. 2004). El hecho de que esa capa de la exina se haya preservado puede indicar que eran de una naturaleza más resistentes que las actuales. Una estructura de ese tipo bien podría responder a la necesidad de protección hídrica y mecánica de los propágulos, que le habría conferido una ventaja adaptativa a la planta productora.

\section{V.2.5. Factores ecológicos relacionados con las angiospermas primitivas}

El grupo de las angiospermas surgió con la adquisición de características especiales como la reducción del gametofito femenino, la doble fecundación y consecuente endosperma triploide, vasos de conducción y carpelos cerrados. Según Stebbins (1974) las condiciones climáticas semiáridas fueron las que indujeron una presión selectiva que favoreció la aparición de esas novedades evolutivas, que habrían permitido un crecimiento y reproducción mas rápidos para ese nuevo grupo vegetal.

Estas observaciones concuerdan con la hipótesis del Origen Herbáceo (Taylor \& Hickey, 1996) de las angiospermas. Esos autores efectuaron un análisis a partir de datos de varias localidades portadoras de angiospemas primitivas, que brindó similares conclusiones soportadas por evidencias filogenéticas, paleoecológicas y geoquímicas. Proponen entonces para las angiospermas ancestrales un hábito herbáceo, crecimiento rápido y una estrategia oportunista que les brindó ventajas evolutivas en ambientes inestables. Un hábito herbáceo con crecimiento rápido y un ciclo de vida corto, habrían propiciado la función de elementos pioneros dentro de los ecosistemas cretácicos en los que prosperaron. En este sentido, en las floras actuales existe una clara correlación entre la cantidad de especies poliploides y las latitudes más afectadas por la última glaciación. Briggs \& Walters (1969) atribuyen este fenómeno a las ventajas que la apomixis otorga a las plantas ante un suelo devastado por algún tipo de catástrofe. Esta estrategia reproductiva se encuentra mayormente en angiospermas herbáceas y en helechos, al tiempo que no existe dentro de las gimnospermas.

Son varios los trabajos en los que se proponen ambientes inestables como escenario de la evolución y proliferación tempranas de las plantas con flor. Hickey \& Doyle (1977) ya habían sugerido una preferencia de aquellas plantas primitivas por sitios de borde de arroyos. Esa idea fue posteriormente ratificada y complementada por Taylor \& Hickey (1996), entre otros, que proponen para ellas un tamaño pequeño y el desarrollo en ambientes ricos en nutrientes y ligados a cuerpos de agua. Postulan también la hipótesis de una estrategia reproductiva de clones para una rápida y eficiente colonización de ambientes fluviales inestables. Siguiendo esa línea, recientemente Howe \& 
Francis (2004) en un estudio paleoecológico de un sistema fluvial albiano, les adjudicaron el rol de elementos pioneros en ambientes devastados por inundaciones. También en el Aptiano temprano de Australia, las evidencias indican que esas primitivas angiospermas tuvieron un hábito herbáceo rastrero, y fueron vinculadas a ambientes inestables por cambios en el nivel del mar (Dettmann, 1994). Estudios muy recientes, basados en la ecofisiología de los grupos basales de angiospermas, apoyan la idea de que su origen y radiación temprana debieron suceder en ambientes disturbados y sombríos (Feild et al. 2004).

Las estrategias ecológicas y reproductivas de las angiospermas basales halladas en nuestra asociación, habrían sido muy semejantes. Sin embargo es esta la primera vez que se menciona a la actividad volcánica como factor de disturbio ambiental en la evolución de este grupo. La inestabilidad del escenario eocretácico patagónico se debió entonces, no solo a factores hídricos, sino también vulcanológicos.

Es dable resaltar en este punto, que la relación entre actividad volcánica y diversificación vegetal ya había sido observada por Scott (1990). El autor estudió una secuencia de sedimentos volcánicos del Carbonífero Inferior, y le atribuyó al vulcanismo del momento el hecho de haber estimulado la diversificación de los helechos primitivos y de las pteridospermas en particular. Por otra parte, sin haber mencionado específicamente este factor, DiMichele et al.(1987) plantean al estrés ambiental por factores extrínsecos como los principales generadores de diversificación en el reino vegetal, propiciando la proliferación de nuevos grupos que no compiten por los recursos.

La vinculación de estas plantas con cuerpos de agua dulce, también queda confirmada por estudios palinológicos, en los que se hallaron palinomorfos acuáticos acompañando a este tipo de granos. Un dato interesante en este aspecto lo reveló el estudio de una flora paleocena de Canadá, donde las zignematáceas aparecieron vinculadas con polen de angiospermas acuáticas (Jarzen, 1979). También Schrank \& Mahmoud (2002) citaron una asociación similar en los sedimentos barremianos de Egipto. En esa oportunidad los autores vincularon a las angiospermas basales tanto con ambientes de agua dulce, como con ambientes marinos.

\section{V.2.6. Consideraciones finales}

Sin dudas el paquete sedimentario de la Formación Punta del Barco da testimonio de un evento catastrófico de gran magnitud que afectó a toda la región, aunque por su corta duración no fue registrado en otras unidades coetáneas. Es probable que en las cuencas vecinas este suceso haya sido minimizado por la influencia marina, mientras la topografía del Cratón del Deseado conformó el sitio propicio para la depositación de los sedimentos netamente continentales que han permitido registrar en detalle la escena del Aptiano temprano de Patagonia.

Cabe señalar que existió un cambio en la comunidad vegetal entre las formaciones inferior y superior del Grupo Baqueró, como así también dentro de la Formación Punta del Barco. En ella, los niveles 
de tobas - pulsos volcánicos- están intercalados con paleosuelos que denotan momentos de calma en esa actividad y donde la comunidad vegetal colonizaba, al menos de manera incipiente, los nichos ecológicos disponibles, hasta el advenimiento de la siguiente nube de cenizas. Estas situaciones se repitieron en un proceso cíclico que determinó un cambio vegetacional que, si bien rápido, fue gradual y más marcado con el paso del tiempo, determinando un empobrecimiento paulatino en cantidad y diversidad de coníferas, de las demás gimnospermas y de helechos. Sin embargo, las briofitas lograron adaptarse al cambio, mientras que las angiospermas fueron beneficiadas por este nuevo escenario ecológico en el que había mayor disponibilidad de nichos.

El estudio de las extinciones considera varios tipos de comportamiento ante los eventos de disturbio ambiental. Uno de ellos es el que tienen los llamados taxones "Lazarus", que luego de un intervalo de tiempo en el que están ausentes en el registro geológico reaparecen en las asociaciones más jóvenes (Hallam \& Wignall, 1997). Tal es el caso de algunos taxa de la palinoflora de Punta del Barco. Aquí, la ausencia en la asociación polínica de esporas de la Familia Schizaceae, polen de cheirolepidiáceas y del morfogénero Callialasporites no significan una total desaparición de estos grupos vegetales, sino un fuerte retroceso en su distribución, dado que vuelven a ser elementos importantes en floras un poco más modernas ( ver entre otros A. Archangelsky \& Llorens, 2003; Llorens \& Del Fueyo, 2003; Baldoni \& Medina, 1989; Papú, 2002).

La Familia Schizaeaceae es un grupo muy importante en las microfloras eocretácicas -especialmente aptiano-albianas- y está representada ampliamente por diversas formas estriadas de los géneros Cicatricosisporites y Appendicisporites. Estas formas, sin embargo, están ausentes en la Formación Punta del Barco. Los representantes actuales de la familia tienen requisitos ecológicos muy diversos y no aportan información valiosa a los fines de interpretación ambiental.

Los estudios comparados de las floras eocretácicas muestran una declinación en el contenido de polen del tipo Classopollis a medida que nos movemos hacia el Sur en este hemisferio, lo que indica un mejor desarrollo de las cheirolepidiáceas con temperaturas elevadas; por otra parte, este tipo de polen ha sido ampliamente aceptado como indicador de climas áridos ( ver entre otros Vakhrameev 1981, 1987; Vallati ,2001). Si la comparación se hace con Australia, puede observarse una tasa mayor en nuestro continente, muy probablemente debido al clima más seco (Vakhrameev, 1991). La ausencia de este tipo polínico en la Fm. Punta del Barco no sería consecuente con estas observaciones generales, ya que se registran valores considerables de este grupo polínico dentro de la misma faja latitudinal, y por otra parte, también existían condiciones de estrés hídrico provocado por la caída de ceniza volcánica que alteró las condiciones edáficas. Sin embargo -lejos de beneficiar su desarrollo - estos factores habrían provocado la fuerte retracción de la población de este grupo de coníferas.

Frecuentemente las cheirolepidiáceas han sido relacionadas a zonas costeras o con influencia marina, inclusive se ha deducido una fisonomía de manglar en ciertas comunidades, como la del Cretácico Inferior de la región peninsular Antártica (Herngreen et al. 1996). También habrían crecido en suelos arenosos altamente drenados (Vakhrameev, 1981). Sin embargo, nunca fueron 
descriptas para condiciones excepcionales de cobertura espesa de cenizas como en nuestro caso. La Fm. Anfiteatro de Ticó, basal del Grupo Baqueró, tuvo parámetros ambientales diferentes, con escasa participación volcánica, y en su flora la presencia de estas coníferas es masiva. Su ausencia en la unidad superior respondería entonces, meramente a cuestiones relacionadas con su incapacidad de recuperación en ambientes fuertemente alterados, y resaltaría aún más el carácter catastrófico del evento. Estas observaciones parecerían sugerir que las cheirolepidiáceas poseían una amplia plasticidad ecológica en condiciones de vida normales, y su quasi desaparición responde a un evento singular que por cierto tiempo impidió su recuperación en el área de Baqueró.

En suma, Classopollis, Callialasporites y las formas bisacadas, ilustran en la presente microflora una fuerte retracción de las coníferas. Esto se condice con las observaciones de Looy et al. (1999), quienes estudiaron la dinámica de poblaciones vegetales durante una crisis ecológica del Triásico. Allí, la etapa de "supervivencia" que sigue a la crisis, está caracterizada por la dominancia de grupos vegetales como las briofitas y licofitas, mientras que las más afectadas son las coníferas, que dominan antes y después de dicha etapa.

\section{V.3. Paleoflora de la Formación Punta del Barco}

\section{V.3.1. Evidencias macroscópicas}

\section{V.3.1.1. Tipos de fosilización}

\section{V.3.1.1.1. Improntas}

Las evidencias florísticas megascópicas de este paquete sedimentario se han preservado mayoritariamente en forma de improntas. Las lluvias de cenizas propiciaron un tipo de fosilización muy peculiar en el que es dable observar la disposición original de las ramas y hojas, como sucede en Araucaria grandifolia, que se preservó de manera tridimensional (Del Fueyo \& A. Archangelsky, 2002), como así también la disposición original de los distintos estratos dentro de la comunidad vegetal. En este sentido, Cladera \& Cúneo (2002) describen una tafocenosis autóctona en la que quedaron claramente ilustrados los tres estratos -herbáceo, arbustivo y arbóreo- que conformaron el bosque eocretácico (Lám. XIV).

Es conveniente mencionar que existen morfogéneros de frondes en esta unidad que recuerdan a algunas Pteridospermales y Cycadales presentes en la unidad basal, pero que no pueden asignarse a ellas con certeza porque han sido definidas teniendo en cuenta caracteres epidérmicos.

\section{V.3.1.1.2. Momificaciones}

A pesar de la rapidez con la que se depositaron los sedimentos, no se ha producido prácticamente la momificación de las cutículas, tal como en la Formación Anfiteatro de Ticó, donde existen numerosos taxones que conservan aún ese tejido epidérmico. Para esta unidad sólo existe la mención de Pseudoctenis ornata, que conserva una cutícula altamente adaptada al estrés producido por el fuerte vulcanismo (A. Archangelsky et al. 1995). 
Recientemente, el yacimiento de la barda Sur ha brindado un nuevo registro de este tipo fosilífero para la unidad. Se trata de un cuerpo lenticular de alrededor de $80 \mathrm{~cm}$. de espesor con una alta preservación de materia orgánica, donde coinciden restos vegetales con distintos tipos de preservación: leños asbestizados o carbonizados y momificaciones de cutículas (Lám. XIII). Estas últimas son asignables al género Brachyphyllum (Llorens et al. 2003), y representan el primer registro de este tipo para las coníferas de Punta del Barco (Lám. XII c-d). Esa heterogeneidad de materia orgánica sumada a la naturaleza fragmentaria de órganos resistentes, sugiere que se trata de material alóctono transportado muy probablemente por el agua. La suma de observaciones llevó entonces a interpretar este nivel como un meandro abandonado.

La casi total ausencia de momificaciones cuticulares podría deberse a las características litológicas de los sedimentos soterradores de las comunidades vegetales. En todos los casos se trata de lluvias de ceniza primaria derivadas de un magmatismo ácido que se caracteriza por la expulsión de fragmentos pumíceos y trizas vítreas (por fractura de los anteriores) de formas cuspidales o semilunares (Scasso \& Limarino, 1997). Las tobas que resultan de la depositación de este tipo de sedimentos, son poco consolidadas debido a la forma de las partículas, que dejan entre si intersticios que permiten un intercambio gaseoso, propiciando la oxidación y consecuente desintegración de los tejidos vegetales. La porosidad original, en suma, debe haber sido mucho mayor a la actual. También existe la posibilidad de que tal como lo indican algunos estudios geoquímicos, la caída de ceniza volcánica propiciara la acción de degradación de material vegetal por microorganismos (Crowley et al. 1994).

Una tafocenosis similar ha sido descripta en la República Checa (Libertin \& Davoka, 2004.), donde tampoco se han recuperado restos de tejido vegetal.

\section{V.3.1.1.3. Fusinita}

Otro tipo de fosilización frecuente en esta tafocenosis corresponde a los restos vegetales corbonizados o fusinita (Scott, 1989b). La importancia de esos restos radica en que brindan información sistemática valiosa, por preservar excelentemente los caracteres anatómicos de los distintos órganos vegetales (Scott, 2001). En su mayoría se trata de leño, aunque existen pínulas y cutículas charcolificadas. Tal es el caso de $A$. grandifolia Feruglio, cuyo estudio fue abordado recientemente por Del Fueyo \& A. Archangelsky (2002), quienes realizaron una detallada observación de ese material con SEM y TEM, métodos mediante los cuales se pudieron conocer caracteres anatómicos preservados por el fuego. Los fragmentos leñosos charcolificados se hallan depositados en el contacto entre los paleosuelos y las tobas. Tienen mayormente forma cúbica y el tamaño (menos de $1 \mathrm{~cm}^{3}$ ) característicos de la fractura de grandes órganos charcolificados con un transporte corto (Scott, 2001).

El material que se recuperó de los distintos niveles de esta Formación está siendo estudiado actualmente. 


\section{V.3.1.1.1. Moldes}

Por último, se han registrado moldes de troncos que fueron transportados por el sistema basal de canales y depositados dentro de conglomerados. No es posible en ese caso dar ninguna apreciación al respecto por el momento.

\section{V.3.1.2. Diversidad taxonómica}

El Grupo Baqueró ( ex Formación Baqueró Archangelsky 1967) porta una de las asociaciones vegetales eocretácicas más completas y mejor preservadas en el mundo. Los numerosos aportes realizados desde principios del siglo XX (Archangelsky, 2003), en su gran mayoría se refieren a los estratos basales (actual Formación Anfiteatro de Ticó), que afloran en varias localidades con espesores considerables. El registro fósil de la Formación Punta del Barco (Cladera et al. 2002) tiene, en cambio, escasos aportes.

La primer mención de plantas fósiles para esta formación fue hecha por Berry (1924), quien estudió muestras que provenían de la Meseta Baqueró y Cerro Cuadrado con una litología caracterizada como una "ceniza volcánica poco consolidada". Describió en esa oportunidad dos nuevas especies: Gleichenites argentinica y Nilssonia clarki, y asignó a los estratos portadores una edad cretácica temprana.

Posteriormente Feruglio visitó la zona y localizó los niveles fosilíferos originales, de donde describe una nueva especie: Hausmannia patagonica, y menciona sin describir, los siguientes taxones: Cladophlebis cf. australis (Morris) Seward, C. cf. C. browniana (Dunker) Seward, Elatocladus palissyafolia Berry, Araucaria sp., Sphenopteris cf. fittonii Seward, S. patagonica Halle, S. (Ruffordia) goepperti Dunker y Gleichenia cf. G. san-martinii Halle (Feruglio, 1937 a y b). Unos años más tarde este autor describe e ilustra nuevamente aquellos ejemplares, a los que agrega: Araucaria grandifolia Feruglio, Cladophlebis patagonica Frenguelli, Hausmannia papilio Feruglio y Pachypteris? patagonica Feruglio. En esa oportunidad, describió sin ilustrar dos nuevas especies: Taeniopteris patagonica y T. argentina (Feruglio, 1951).

Herbst (1960) revisó ejemplares fértiles de Hausmannia papilio; asimismo, hizo una descripción y revisión de frondes asignadas al género Gleichenites; representado por G. argentinica y G. san-martinii, que es el componente dominante de esta tafoflora (Herbst, 1962). En un estudio posterior reportó materiales de G. feruglioi y C. patagonica Frenguelli (Herbst, 1966).

El estudio sedimentológico y paleontológico completo de este Grupo fue abordado por Archangelsky (1967) quien toma las listas paleoflorísticas de Berry y Feruglio a las que introduce dos observaciones: la posibilidad de que el material referido como Podocarpus? palissyafolia pueda corresponder a impresiones de Trisacocladus tigrensis Archangelsky; mientras que Pachypteris? patagonica Feruglio se correspondería también con alguna especie de Mesosingeria, aunque estos taxones están definidos en base a caracteres diagnósticos que no siempre se encuentran preservados.

Entre los aportes más recientes se encuentra el reporte de Psendoctenis ornata, hallado con su cutícula preservada ( A. Archangelsky et al. 1995). Además de describir ese nuevo taxón, se evaluaron 
las adaptaciones cuticulares frente a un estrés provocado por las fuertes erupciones volcánicas imperantes en la época. Este material provino de la localidad de Ea. El Verano, en la Barda Norte de la Meseta Baqueró.

El resto de las referencias de esta flora se dieron a conocer en forma de nóminas.

\section{V.3.1.3. Abundancia relativa}

No se cuenta con buenos datos de abundancia relativa de los restos megascópicos, aunque es posible deducir que el género Gleichenites es el elemento dominante. Araucaria y Hausmannia lo acompañan en una alta proporción. Este último helecho de la Familia Dipteridaceae siempre se encuentra asociado con las gleichenias. Esta situación se repite en una flora sepultada in situ dentro de una toba de edad maastrichtiana (Wing et al. 1993); en esa oportunidad la entidad fue interpretada como de ambientes abiertos.

Otro grupo con una buena representación son la Cycadales.

Sin embargo, cabe señalar que existen improntas y momificaciones de ramas que portan hojas de tipo Brachyphyllum, lo cual sugeriría una participación más o menos importante de las coníferas en la asociación florística. Todas estas colecciones requieren de nuevos estudios para tener una idea más aproximada sobre la composición de las asociaciones.

\section{V.3.2. Evidencias microscópicas}

\section{V.3.2.1. Tipo de fosilización}

El material palinológico de esta formación se ha preservado en forma de momificaciones. Scott (1989a) encuentra que la rápida depositación del material vegetal en el agua aumenta considerablemente sus posibilidades de preservación. En tal sentido, si bien en principio el ambiente de depositación de la Formación Punta del Barco no habría sido propicio para la preservación de palinomorfos, la presencia en todos los niveles de elementos acuícolas, muestran que los cuerpos de agua sirvieron de "refugio" para los mismos. Así como en la megaflora, las particularidades deposicionales posibilitaron el enterramiento casi instantáneo documentado por los distintos estadíos ontogenéticos del desarrollo de esporas con perisporio en el mismo sitio donde crecieron las plantas productoras (Llorens \& Cladera, 2002). El perisporio es la parte más externa del esporodermo, con características estructurales diferentes a las demás capas, y que se pierde en la madurez de la espora o bien inmediatamente después de su liberación (Tryon \& Tryon, 1982; Tryon, 1990).

Como ya fue mencionado anteriormente, se han observado ejemplares con su exina térmicamente alterada coexistiendo con otros sin ningún tipo de alteración. En los niveles superiores, en cambio, puede observarse que paralelamente a un empobrecimiento de la palinoflora, existe un aumento en la oxidación de la exina. 


\section{V.3.2.2. Diversidad taxonómica}

Los grupos más conspicuos de esta palinoflora son las Briofitas y Pteridofitas, como así también las algas, representadas mayormente por colonias de chlorofíceas (Familia Botryococcaceae) y zigosporas de la Familia Zignemataceae.

Dentro de los helechos, si bien hay una gran variedad de esporas, sólo para unas pocas ha sido posible establecer una afinidad cierta. La Familia Gleicheniaceae es sin dudas la más diversa y mejor representada; y cuenta con 8 especies dentro de 3 géneros (Gleicheniidites, Ornamentifera y Clavifera). En segundo término, la presencia de las pteridáceas se manifiesta en la diversidad del género Contignisporites, que cuenta con 3 especies. Por último, Todisporites es el único representante de la Fam. Osmundaceae.

La Clase Lycopsida, por su parte, está bien ilustrada por la presencia de 5 tipos de megasporas, además de 2 especies de Ceratosporites y otras 2 de Densoisporites.

Los granos de polen de Gimnospermas están representados mayormente por coníferas de la familia Araucariaceae, con formas inaperturadas (Inaperturopollenites y Araucariacites) y mono-biaperturadas (Cyclusphaera-Balmeiopsis). Dentro de las Podocarpaceae, son dominantes las formas trisacadas (Trisaccites sp., Microcachryidites sp. y Dacrydiumites sp.) mientras que las bisacadas (Podocarpidites sp.), probablemente correspondan a ejemplares retrabajados. Otro grupo de coníferas que tiene una situación semejante, es la Familia Cheirolepidiaceae.

Por último, la Familia Chloranthaceae puede haber sido el único grupo presente dentro de las angiospermas; y si bien tuvieron una participación menor en la comunidad vegetal, la diversidad alcanzó al menos a 3 especies.

\section{V.3.2.3. Abundancia relativa}

Con el fin de visualizar la abundancia relativa de los distintos grupos polínicos se han realizado conteos en dos muestras de localidades y niveles diferentes: una del nivel 1 de la Barda Norte y la otra del nivel 4 de la Barda Sur. La elección se basó en que estos niveles son los de mayor abundancia de especímenes, y por pertenecer a la parte basal y medio-superior, respectivamente, de la columna estratigráfica.

Dadas la baja densidad y diversidad de palinomorfos, se consideraron para este estudio a los grandes grupos botánicos y, en ocasiones, los grupos morfológicos o taxonómicos mejor representados dentro de ellos. Quedan así delineados los siguientes grupos de palinomorfos:

Algas (AL): incluye esporas y cuerpos vegetativos de algas dulciacuícolas.

Bryophytas (TC): esporas cinguladas.

Lycophytas (L): esporas de Densoisporites.

Filicophyta: esporas triletes lisas (TL), monoletes (M) y Familia Gleicheniaceae (Glei).

Gimnospermophyta: granos de polen de Araucariaceae (CBA) - grupo Cyclusphaera, Balmeiopsis y Araucariacites- y granos de polen sacados (GS).

Magnoliophyta (Ang): granos de polen con afinidad angiospérmica. 
Punta del Barco Sur

Nivel $4(\mathrm{~N}=323)$

TL $\quad 0,62 \%$

TC $\quad 0,93 \%$

GS $\quad 1,54 \%$

Ang $\quad 41,05 \%$

AL $\quad 55,86 \%$

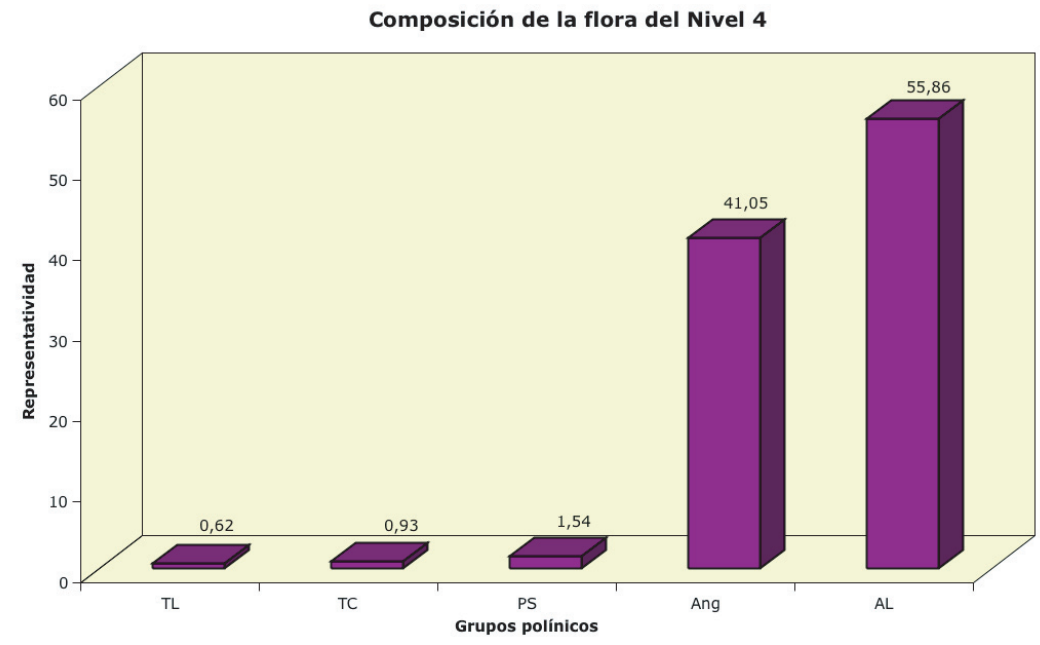

Punta del Barco Norte

Nivel $1(\mathrm{~N}=300)$

TC $\quad 1,3 \%$

L $\quad 15,7 \%$

TL $\quad 11,3 \%$

M $\quad 0,3 \%$

Glei $\quad 29,7 \%$

GS $\quad 7 \%$

CBA $19 \%$

Ang $1 \%$

AL $\quad 14,7 \%$

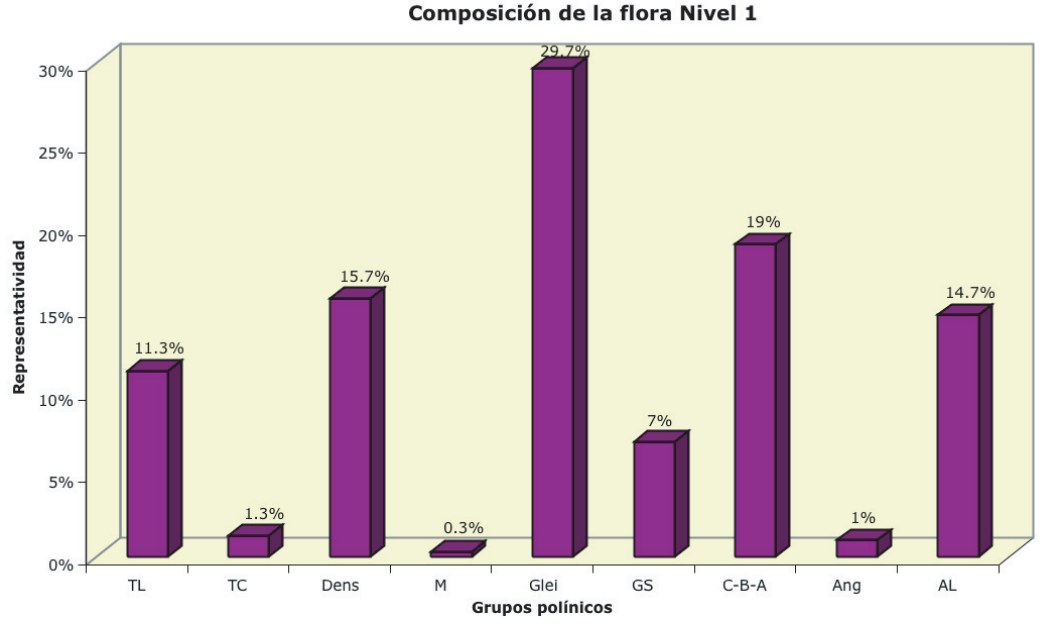

\section{V.3.3. Conjunto paleoflorístico}

En este capítulo se integran los datos aportados por la mega y microflora. No hay un correlato directo entre los taxones de ambas columnas. Una relación se ha podido establecer a nivel de grandes grupos botánicos. No se incluyeron restos planctónicos ni otros palinomorfos incertae sedis. 


\section{MEGAFÓSILES}

Bryophyta

\section{Lycophyta}

\section{Filicophyta}

\section{Filicales}

Gleichenites argentinica

G. san-martinii

G. feruglioi

G. vegagrandis

Hausmannia papilio

H. patagonica

Ruffordia goepperti

\section{Gymnospermophyta}

Pteridospermales

Pachypteris? patagonica (*)

Ruflorinia sierra (*)

\section{Cycadales}

Mesodescolea plicata (*)

Mesosingeria coriacea (*)

Pseudoctenis ornata

\section{Coniferales}

Araucariacites baqueroensis

$$
\text { A. grandifolia }
$$

Brachyphyllum sp.

Podocarpus? palissyafolia

Tomaxellia degiustoi

\section{PALINOMORFOS}

Foraminisporis dailyi

Foraminisporis sp.

Staplinisporites caminus

Densoisporites velatus

Densoisporites corrugatus

Ceratosporites spp.

Hughesisporites patagonicus

Bacutriletes sp. 1

Erlansonisporites sp.

Horstisporites sp. 1

Apiculatisporites sp.

Gleicheniidites senonicus

Gleicheniidites spp.

Ornamentifera sp.

Clavifera simplex

Todisporites spp.

Cycadopites sp. (*)

Cycadopites sp.

Aucariacites australis

Cyclusphaera psilata

Balmeiopsis limbatus

Microcachryidites spp.

Podocarpidites spp.

Trisaccites microsaccatus

Dacrydiumites sp.

Classopollis sp.

Inaperturopollenites sp. 


\section{Magnoliophyta}

Hoja indeterminada

Clavatipollenites sp. A

Clavatipollenites sp. B

Monocolpopollenites sp.

Retimonocolpites sp.

Retiacolpites sp.

Asteropollis sp.

\section{Morfogéneros de frondes}

Cladophlebis sp.

C. haiburnensis var. rectimarginata

C. patagonica

C. browniana

Sphenopteris sp.

Sphenopteris cf. fittonii

S. patagonica

\section{Morfogéneros de hojas}

Nilssonia clarkii

Taeniopteris sp.

(*)asignación incierta

\section{V.3.3.1. Consideraciones finales}

Los restos vegetales megascópicos tienen un transporte limitado, por lo que no se encuentran a lo largo de áreas muy amplias, y muestran por ello las diferencias vegetacionales de distintas comunidades contemporáneas. Por lo tanto no son suficientemente apropiados para hacer una reconstrucción regional de la vegetación (Birks \& Birks, 1980).

En este sentido, el análisis polínico permite tener una visión más aproximada de la vegetación en su conjunto.

Birks \& Mathews (1978) realizaron un estudio en sedimentos cuaternarios integrando ambos datos, y registraron varios taxa de macrofósiles no encontrados durante el análisis polínico. Esto se debe tanto a características propias de los palinomorfos, que les confieren baja probabilidad de fosilización, como así también a que usualmente los macrofósiles pueden ser identificados a niveles taxonónmicos menores que algunos tipos polínicos. En otros casos, fueron registrados taxones polínicos no presentes como macrofósiles. Por ejemplo, las pteridofitas raramente producen macrofósiles inequívocamente identificables, mientras que poseen esporas distintivas. Está en juego también la resistencia química y mecánica de las partes de la planta (Ferguson, 1985; 2002; Burnham, 1989; Gastaldo, 1992). 
Otros autores consideran que el problema es más complejo en paquetes sedimentarios más antiguos, dado que la referencia directa a taxones actuales resulta imposible de realizar.

Solo allí donde los patrones de mega y microfósiles pueden compararse directamente, es probable una mejor comprensión de la sub-representación que presentan algunos grupos (ver Wing \& DiMichele, 1992).

Resulta obvio que cada tipo de análisis es el complemento del otro, en tanto que un estudio basado en uno de ellos, aportaría resultados sesgados.

En esta ocasión ha sido posible cotejar ambos registros, y el actual estudio ha brindado un conocimiento más acabado y completo del conjunto florístico del eoaptiano de Patagonia austral. Se ha reportado la participación de dos grandes grupos vegetales que no estaban representados entre los megafósiles: Bryophyta y Lycophyta. Además, se hace evidente en la palinoflora una mayor participación de las magnoliofitas, que la que indicara el registro megascópico. Asimismo, las coníferas -podocarpáceas y las araucariaceas- se manifiestan más ampliamente en la microflora. Por el contrario, de confirmarse las asignaciones de restos de frondes de las pteridospermas, éstas resultarían sub-representadas en la palinoflora.

\section{V.3.3.2. Reconstrucción del paleoambiente}

A partir de la serie de datos presentados en este capítulo, y como corolario del mismo, se presenta en la lámina siguiente una reconstrucción del paleoambiente eoaptiano patagónico, en la que se observa la fisonomía que probablemente tuvo de la comunidad vegetal recuperada del Nivel 1. En el primer plano, se ilustran las gleichenias, pteridales y cicadales formadoras del sotobosque, acompañadas por Hausmannia en el estrato herbáceo. Ocupando ambientes palustres, los licofitos aparecen en un segundo plano, y las angiospermas basales un poco por detrás. En los planos más alejados, se vislumbra la fisonomía de "matorral" de las gleicheniaceas que, junto a las cicadales, conformaron el estrato arbustivo de aquel bosque. En tanto, el estrato arbóreo estuvo constituído principalmente por Araucaria y en menor medida por algunas podocarpaceas, que caracterizaron un bosque poco denso.

En un plano lejano, se observan columnas eruptivas características del vulcanismo pliniano. 


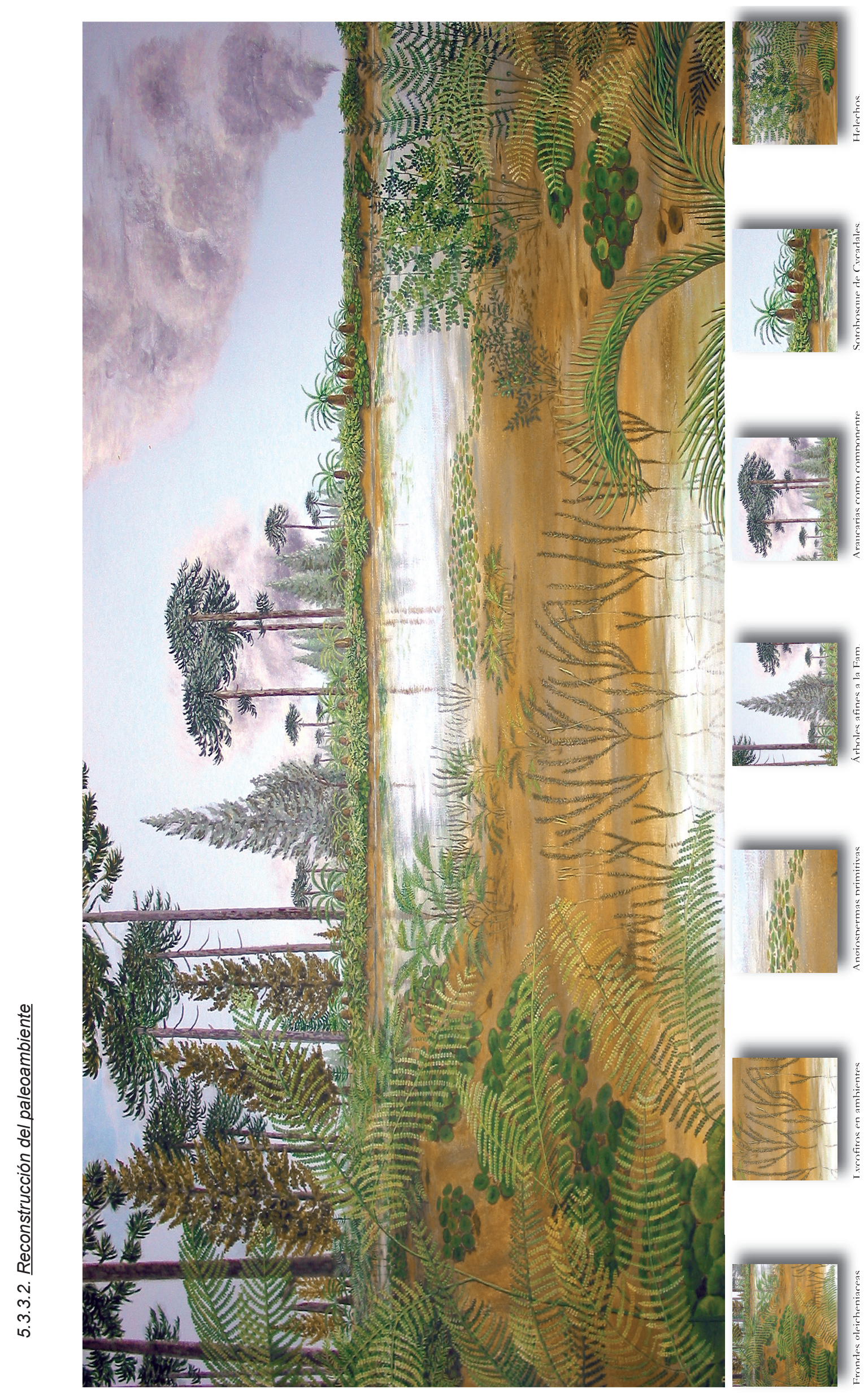



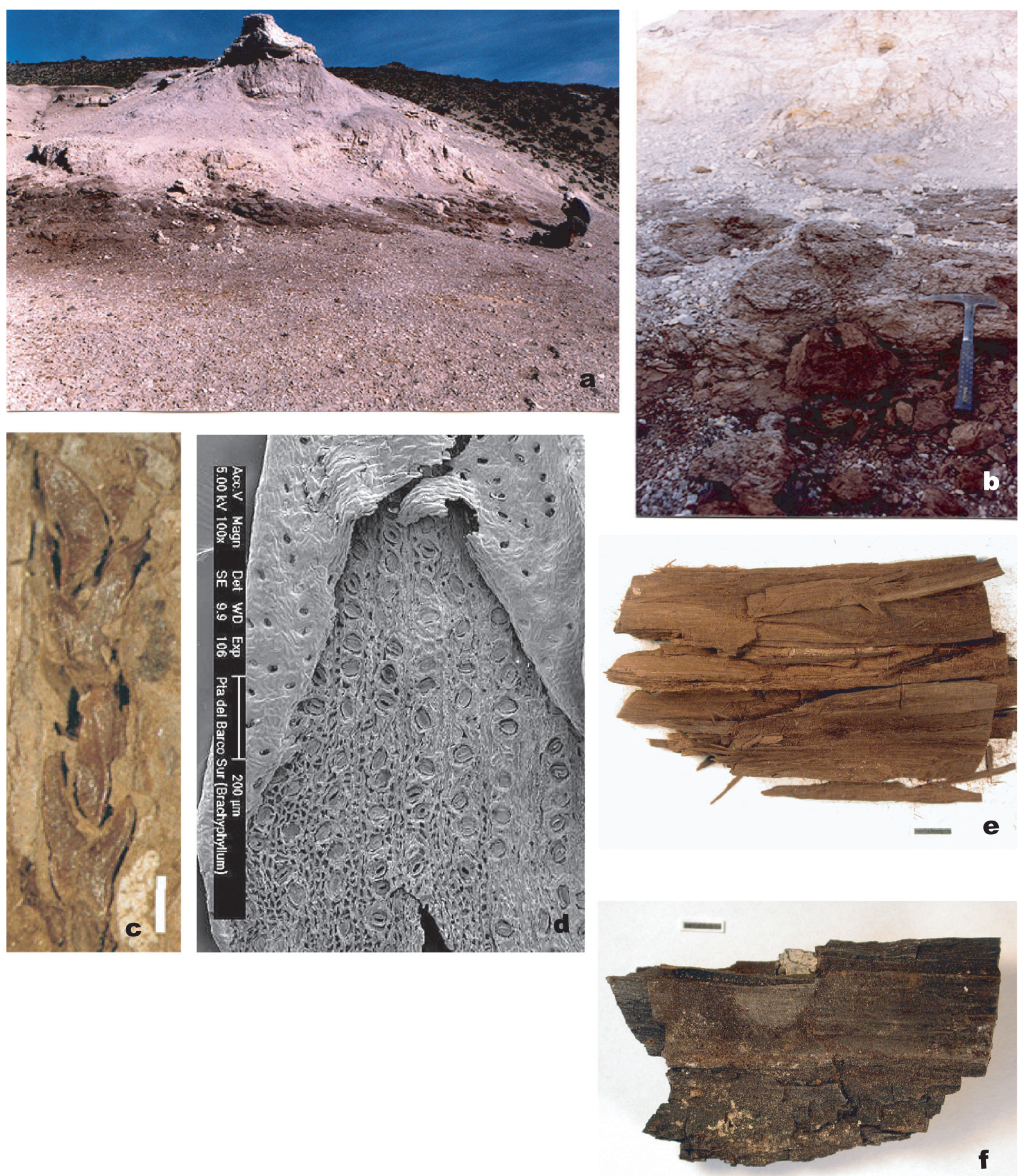

\section{LÁMINA XIII}

\section{PBS Nivel 4}

a-b: Aspecto general del nivel fosiléfero.

c-d: Brachyphyllum sp. c- Fragmento de una rama con hojas cutinizadas. d- Detalle vista interna de cara abaxial y externa de cara adaxial (foto MEB).

e: Leño 'asbestizado' (escala $=0,5 \mathrm{~cm}$ ).

f: Leño carbonizado $($ escala $=0,5 \mathrm{~cm})$ 

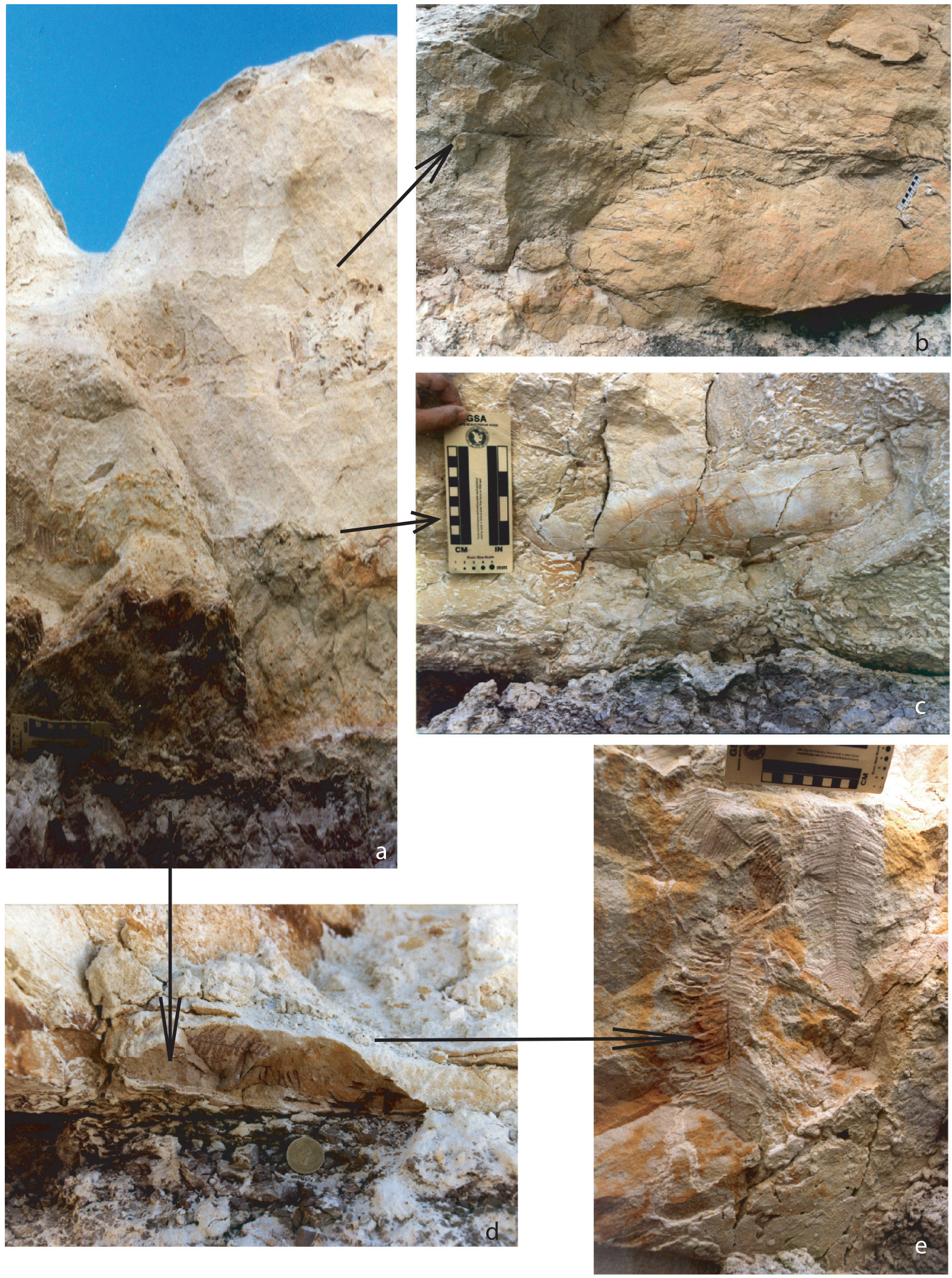

\section{LÁMINA XIV}

Tafocenosis: a- Aspecto general del nivel fosiléfero. b- Rama de Araucaria grandifolia. c- Fronde de Taeniopteris sp. d- Contacto paleosuelo-toba con impronta de Gleichenites. e- "Matorral" de gleicheniaceas. 


\section{CONCLUSIONES}

\section{Palinoflora de Formación Punta del Barco}

El análisis sistemático de la palinoflora de la Formación Punta del Barco ha establecido que ésta cuenta con 76 especies referidas a 47 morfogéneros estudiados hasta el momento. Este conjunto polínico está integrado por esporas y granos de polen dispersos, megasporas, restos de algas y formas de afinidad incierta. Los grupos mejor representados son los helechos -especialmente las gleichenias-, briofitas y algas. Ellos están acompañados en menor medida, por los granos de araucariáceas.

Es de resaltar que, aunque se trate de una flora empobrecida, se han registrado algunas formas polínicas poco comunes en las microfloras eocretácicas. Tal es el caso de las esporas perisporadas y monoletes, que generalmente tienen registros esporádicos; y sin embargo aquí, muestran una diversidad llamativa.

Por otra parte, más allá de la importancia que tiene el registro polínico en sí, estos datos han hecho posible cotejarlos con los registros de megaflora, brindando un conocimiento más acabado y completo del conjunto florístico de la Formación Punta del Barco. Se ha reportado así, la participación de dos grandes grupos vegetales que no estaban representados entre los megafósiles: Bryophyta y Lycophyta. Además, se hace evidente en la palinoflora una mayor participación de las magnoliofitas y coníferas que la indicada por el registro megascópico.

El estudio de la distribución estratigráfica de los palinomorfos ilustra un paulatino empobrecimiento de la flora en el tiempo. Este, desde un nivel basal de bosque con diferentes estratos y una diversidad mayor, hasta los niveles superiores donde sólo se registraron elementos planctónicos y algún grupo oportunista. La vinculación de esos datos con los aportados por la sedimentología, permiten proponer una dinámica de la comunidad vegetal regida por el vulcanismo. Así, los niveles de tobas -pulsos volcánicos- están intercalados con paleosuelos que se establecieron en los momentos de calma en esa actividad. En esos momentos la vegetación colonizaba, al menos de manera incipiente, los nichos ecológicos disponibles, hasta el advenimiento de la siguiente nube de cenizas. Estas situaciones se repitieron en un proceso cíclico que determinó un cambio vegetacional que, si bien rápido, fue gradual y más marcado con el paso del tiempo. Esto determinó un retroceso de las coníferas y demás gimnospermas, como también de algunas pteridofitas. Sin embargo, las briofitas lograron adaptarse al cambio, probablemente debido a la existencia de suficientes ambientes con bastante humedad. Los más beneficiados por este nuevo escenario ecológico en el que había mayor disponibilidad de nichos, fueron las angiospermas y los helechos oportunistas.

Por tanto, se concluye que la actividad volcánica se constituyó en un factor altamente disturbador de la flora aptiana, aún en zonas distales al centro eruptivo, lo cual parece confirmar la intensidad de ese evento. 


\section{Extinción / evolución}

El Cretácico Inferior fue un período crucial en la historia del reino vegetal, dado que entonces comenzó el proceso por el cual, hacia fines de ese período, la vegetación adquirió una fisonomía semejante a la que conserva hasta nuestros días.

Ese proceso refiere principalmente a la aparición y diversificación incipiente de las angiospermas, seguido por un desarrollo importante que las llevó a ocupar casi todos los nichos ecológicos disponibles, y convertirse así en el grupo vegetal dominante en las biotas continentales a partir del Cretácico Superior. Ese avance de las plantas con flor fue acompañado por el retroceso de ciertos grupos dominantes hasta ese momento. Es así que durante el Aptiano decaen, y en algunos casos parecen extinguirse, importantes taxones gimnospérmicos, tales como las Bennettitales, Pteridospermales y Ginkgoales, que hasta ese momento habían sido componentes comunes de las floras.

De esta manera puede observarse que la Formación Punta del Barco constituye un buen testimonio de estas variaciones, dado que por comparación con la flora ampliamente estudiada de la Fm. Anfiteatro de Ticó, permite establecer que existió en el Aptiano de Patagonia, un cambio brusco en la vegetación.

Ese cambio destaca dos aspectos principales: la susceptibilidad de las gimnospermas a las condiciones de estrés ambiental, involucrando a los grupos ya mencionados, y que esas condiciones habrían favorecido a los nuevos actores en la escena aptiana: las plantas con flor.

Las biozonas previamente establecidas para el Grupo en base a la megaflora - Zonas Ptilophyllum y Gleichenites- contemplan la casi total desaparición de Bennettitales y Ginkgoales, como así también una clara disminución numérica de las coníferas, Pteridospermales y Cicadales. Las palinozonas propuestas en esta tesis -Biozonas A y B- serían equivalentes a aquéllas, sustentando en algunos casos sus enunciados, mientras en otros aportan información adicional.

Tal es el caso de las Familias Schizaeaceae y Lophosoriaceae, y el Orden Isoëtales, totalmente ausentes en la unidad de estudio.

Por otra parte, si bien se había notado el decaimiento de las coníferas, este estudio palinológico ha permitido identificar cuáles fueron los grupos más perjudicados entre ellas. Dentro de la Familia Podocarpaceae, entonces, las formas más afectadas fueron las productoras de polen bisacado, en tanto que las de polen trisacado no lo fueron.

Por último, tal vez uno de los aspectos más notorios de esta palinoflora, la casi total ausencia de polen de la Familia Cheirolepidiaceae -tipo Classopollis- constituye una novedad para las floras cretácicas, y aporta información ecológica inédita para uno de los grupos vegetales más conspicuos de ese período.

La comparación de las floras del Grupo Baqueró con la secuencia sedimentaria correspondiente a la Fm. Kachaike, muestra un restablecimiento, en parte, de la comunidad que estaba presente 
en la unidad basal, donde vuelven a estar presentes de manera conspicua algunos de esos grupos fuertemente afectados en nuestra palinoflora. Además, vuelven a registrarse ciertos taxones que, si bien no son muy abundantes, son característicos. Sin embargo, otros elementos anteriormente conspicuos pierden aquí representatividad. Esa asociación adquiere también identidad propia con la incorporación de elementos nuevos; al tiempo que entre las angiospermas es relevante la aparición de granos triaperturados (tricolpados o tricolporoidados). Cabe señalar que en el lapso cronológico considerado en esta comparación (Aptiano-Albiano), los cambios en las comunidades vegetales se produjeron ya sea por factores evolutivos y/o ambientales. Tal es el caso del vulcanismo en el eoaptiano, y los ciclos de ingresión - regresión marina en el Albiano. Cualquiera sea el motivo, hay dos hechos que se destacan más allá del marco ambiental de cada momento: en estas microfloras se hace evidente una dominancia de las pteridofitas y gimnospermas, por una parte, y la aparición y diversificación incipiente de las angiospermas por otra.

En suma, si bien esa flora albiana conserva aún una semejanza con la de la Fm. Anfiteatro de Ticó, presenta ya las tendencias composicionales que se establecen definitivamente hacia fines del Cretácico.

Por lo expuesto, puede establecerse que la palinoflora de la Fm. Punta del Barco constituye una suerte de "adelanto" de las floras más modernas.

Posiblemente sea este el punto de inflexión en la tasa de extinción de algunos grupos, de la misma manera que lo sería en la tasa de evolución de las angiospermas.

\section{Angiospermas}

Los granos de polen que se estudian aquí serían, junto al único taxón reportado para la Formación Anfiteatro de Ticó, las formas más antiguas de Patagonia y probablemente del país, al menos con una edad confirmada mediante métodos directos de datación.

Además, la diversificación de las angiospermas en este breve lapso geológico, aunque incipiente, es llamativa. El registro de tres nuevas formas en el tope del Grupo Baqueró, con la adquisición de diferentes tipos de aperturas, sugiere que en este tiempo dieron un paso evolutivo importante.

El retroceso de otros grupos vegetales, produciendo vacantes en los nichos que hasta entonces ocupaban, habría favorecido el avance de aquellas plantas que detentaran estrategias oportunistas. $\mathrm{Al}$ parecer las angiospermas tuvieron ese carácter en sus albores, convirtiéndose, junto a algunos helechos, en uno de los grupos con mayor tasa de diversificación del momento.

En el marco de la dinámica de la comunidad vegetal en estudio, se arriba a la conclusión de que las angiospermas basales aquí halladas habrían tenido estrategias ecológicas y reproductivas vinculadas a un rol de elementos pioneros dentro de esa comunidad signada por la inestabilidad ambiental. Esto permite enmarcar a las primitivas plantas con flor de Patagonia dentro de las teorías evolutivas más modernas para el grupo. Sin embargo es esta la primera vez que se menciona a la actividad volcánica como factor de perturbación ambiental en la evolución de este grupo. 
La inestabilidad del escenario eocretácico patagónico se debió entonces, no solo a factores hídricos, comunes a varias asociaciones, sino también vulcanológicos.

Por lo expuesto, es de destacar que éste constituye el primer acercamiento a la comprensión del hábito y ecología de las primitivas plantas con flor de Patagonia.

\section{Aportes paleoecológicos}

Ante una flora empobrecida como la aquí estudiada, es importante indagar en busca de toda la información que pueda obtenerse a partir del material rescatado. En este trabajo se han realizado algunas contribuciones en este sentido:

\subsection{Algas}

Las algas son un grupo que generalmente no es tenido en cuenta en los análisis palinológicos. En esta tesis se ha intentado explotar su potencial como indicador ecológico, obteniendo así una fuente de datos paleoambientales de gran utilidad. El grupo que mayor información ha brindado es la Familia Zignemataceae, presente en casi todos los niveles estudiados.

\subsection{Plantas con flor}

Las evidencias ecológicas sugieren que las angiospermas aptianas ocuparon ambientes de cuerpos de agua someros o cercanos, y que por ello habrían escapado en varias ocasiones a los efectos de los incendios.

Por otra parte, aquí se expone su vinculación con los ambientes disturbados por cambios en el sistema hídrico y por el vulcanismo.

\subsection{Vulcanismo}

Esta tesis constituye un muy buen ejemplo de los efectos del vulcanismo sobre la vegetación, dando pautas en cuanto a la reacción diferencial de los diversos grupos de plantas ante estos eventos. Se introduce además la temática, pocas veces abordada, de la relación entre actividad volcánica y diversificación vegetal.

\subsection{Familia Cheirolepidiaceae}

Ante el hecho singular de la ausencia de este grupo en la palinoflora de la Fm. Punta del Barco, se ha indagado en sus posibles causas.

El análisis de los efectos de las erupciones volcánicas modernas sobre la vegetación aledaña, ha brindado un indicio, que es la recuperación de las plantas ante esos eventos según su porte. Así, se puede considerar que las mismas no alcanzaban un porte arbóreo, lo cual les habría impedido superar el nivel de cenizas caídas. 
Si bien es una observación preliminar, esto se condice con la ausencia de asociaciones orgánicas de este grupo con restos leñosos en el registro fósil.

\section{Perspectivas de nuevos estudios}

En el transcurso de este estudio han ido surgiendo interesantes temas que podrían ser desarrollados en futuras investigaciones:

- El relevamiento de nuevos afloramientos para la Formación Punta del Barco, cotejando los datos palinológicos y florísticos.

- Relevamiento de la megaflora, teniendo en cuenta su distribución estratigráfica dentro del paquete sedimentario de la Formación. De esta manera podría compararse con la distribución de los palinomorfos.

- Identificar la biozona B en otras cuencas sedimentarias para poder sustentar una propuesta formal de la misma, con una extensión areal mayor.

- Realizar conteos en materiales provenientes de las tres unidades formacionales abarcadas en este estudio -Anf. de Ticó, Pta. del Barco y Kachaike-, y así obtener una idea más acabada de la participación de los distintos grupos vegetales en sus paleofloras.

- La evolución de las angiospermas patagónicas aún no ha sido abordada en detalle, y los ejemplares que aquí se estudiaron abren la posibilidad de una nueva línea de investigación que abarque su distribución y evolución morfológica.

- El evento tectonovolcánico del eoaptiano parece haber tenido un gran alcance, por lo que existe la posibilidad de realizar correlación con otras unidades litológicas mediante los depósitos volcaniclásticos que éste produjo. 


\section{AGRADECIMIENTOS}

En primer lugar deseo expresar mi más sincero agradecimiento al Dr. Sergio Archangelsky, director del presente trabajo de Tesis Doctoral, por su constante asesoramiento, paciencia y estímulo permanentes a lo largo de estos años.

A la Dra. Marta Morbelli, por introducirme en el mundo de la palinología y brindarme su comprensión y confianza.

A mi esposo Juan Francisco, dado que sin su apoyo no hubiera sido posible realizar este trabajo de tesis.

Al Museo Paleontológico Egidio Feruglio, que me ha brindado un excelente ámbito de trabajo, y al Museo Argentino de Ciencias Naturales "Bernardino Rivadavia" donde se dieron los pasos iniciales de esta investigación.

Al Dr. Rubén Cúneo por la lectura crítica del trabajo y sus apreciadas observaciones y sugerencias.

A mis compañeros de oficina: los Lic. Silvina de Valais, Cynthia González e Ignacio Escapa, quienes me acompañaron, alentaron y compartieron conmigo buenos y malos momentos a lo largo de este proceso.

Al Lic. Gerardo Cladera, quien realizó los perfiles sedimentarios y me facilitó la información geológica y su experiencia de campo.

A la Dra. Ana Archangelsky, el apoyo brindado en los aspectos técnicos y académicos.

Al Sr. Javier García Díaz, su aporte invalorable en la edición final de este trabajo.

A la Sra. Rosario Romero, que ha puesto lo mejor de sí en la realización artística aquí presentada.

Finalmente, mi reconocimiento a todos aquellos que de una u otra manera me brindaron su apoyo. 


\section{REFERENCIAS BIBLIOGRÁFICAS}

AGUIRRE URRETA, M. B.

2002. Invertebrados del Cretácico Inferior. En: M. J. Haller (ed.) Geología y Recursos Naturales de Santa Cruæ: Relatorio del XV Congreso Geologico Argentino pp. 439-459. Calafate, Santa Cruz, Argentina

ALEMANN, A. \& R. LOPEZ RAFFO

1972. Geografía de América y Antártida. Peuser (Ed), 440 pp.

ALPERN, B.

1980. Pétrographie du kérogéne. In: Durand, B. (ed.) Kerogen: Insoluble organic matter from sedimentary rocks: 339-384.

ANTOLINI, L., R. RODRIGUES \& R. DINO

2002. O evento anóxico Aptiano-Albiano e a Palinoestratigrafia da Formaçao Codó na Regiao de Codó, Bacia do Parnaíba, Brasil. Boletim do $6^{\circ}$ Simposio sobre o Cretácio do Brasil / $2^{\circ}$ Simposio sobre el Cretácico de América del Sur. 19-23.

ARBE, H. A.

1989. Estratigrafía, discontinuidades y evolución sedimentaria del Cretácico de Cuenca Austral, provincia de Santa Cruz. Cuencas sedimentarias Argentinas: 419-442.

ARCHANGELSKY , A., R. R. ANDREIS, S. ARCHANGELSKY \& A. ARTABE

1995. Cuticular characters adapted to volcanic stress in a new Cretaceous cycad leaf from Patagonia, Argentina. Considerations on the stratigraphy and depositional history of the Baqueró Formation. Review of Palaeobotany and Palynology 89: 213-233.

ARCHANGELSKY , A. \& M. LLORENS

2003. Palinología de la Formación Kachaike, Cretácico inferior de la Cuenca Austral, provincia de Santa Cruz. I- Esporas lisas y cinguladas. Ameghiniana 40 (1): 71-80.

ARCHANGELSKY , A. \& M. LLORENS

2005. Palinología de la Formación Kachaike, Cretácico Inferior de la Cuenca Austral, provincia de Santa Cruz. II- Esporas. Ameghiniana 42 (2): 311-328.

ARCHANGELSKY, S.

1963a. Notas sobre la flora fósil de la zona de Ticó, provincia de Santa Cruz. Ameghiniana 3 (2): 57 - 63.

ARCHANGELSKY, S.

1963b. A new Mesozoic flora from Ticó, Santa Cruz Province, Argentina. Bulletin of the British Museum (Natural History) Geology 8:45-92.

ARCHANGELSKY, S.

1965. Notas sobre la flora fósil de la zona de Ticó, provincia de Santa Cruz. Dos nuevas especies 
de megasporas. Ameghiniana 4: 52-56.

ARCHANGELSKY, S.

1966a. Estudio palinológico de la Formación Baqueró(Cretácico), Provincia de Santa Cruz III. Ameghiniana IV, Nro 7.

ARCHANGELSKY, S.

1966b. Estudio palinológico de la Formación Baqueró(Cretácico), Provincia de Santa Cruz IV. Ameghiniana IV, Nro 10.

ARCHANGELSKY, S.

1966c. New gymnosperms from the Ticó Flora, Santa Cruz Province, Argentina. Bulletin of British Museum of Natural History and Geology, 13: 259-295.

ARCHANGELSKY, S.

1967. Estudio de la Formación Baqueró, Cretácico inferior de Santa Cruz, Argentina. Revista del Museo de La Plata, Tomo V. Paleontología No. 32: 63-170.

ARCHANGELSKY, S.

1972. Esporas de la Formación Río Turbio (Eoceno), provincia de Santa Cru. Revista del Museo de La Plata (Nueva Serie), Paleontología 6 (39): 65-100. La Plata.

ARCHANGELSKY, S.

1977. Balmeiopsis, nuevo nombre genérico para el palinomorfo Inaperturopollenites limbatus Balme. Ameghiniana 14: 122-126.

\section{ARCHANGELSKY, S.}

1988. Gamerroites, nuevo género de polen bisacado del Cretácico de Patagonia, Argentina. Boletín de la Asociaciación Latinoamericana de Paleobotánica y Palinología 11: 1-6.

ARCHANGELSKY, S.

1994. Comparative ultrastructure of three Early Cretaceous gymnosperm pollen grain: Araucariacites, Balmeiopsis and Callialasporites. Review of Paleobotany and Palynology 83: 185-198.

ARCHANGELSKY, S.

1996. The Jurassic and Cretaceous vegetation of the Patagonian Province. Memorial Conference dedicated to Vsevolod Andreevich Vachrameev (eds. M. A. Akhmetiev y M. P. Doludenko). Abstracts and Proceedings pgs. 8-10. Russian Acad. Sciences, Geological Institute.

ARCHANGELSKY, S.

1999. Evidences of an Early Cretaceous Floristic change in Patagonia, Argentina. VII International Symposium on Mesozoic Terrestrial Ecosystems (Buenos Aires, 1999) Abstracts: 6.

ARCHANGELSKY, S. 
2001a. Evidences of an Early Cretaceous Floristic change in Patagonia, Argentina. VII International Symposium on Mesozoic Terrestrial Ecosystems, Asociación Paleontológica Argentina, publicación Especial 7: 15-19.

ARCHANGELSKY, S.

2001b. The Ticó Flora (Patagonia) and the Aptian Extincion Event. Acta Paleobot. 41 (2): 115-122.

ARCHANGELSKY,S.

2003. (Ed.) La Flora Cretácica del Grupo Baqueró, Santa Cruz, Argentina. Monografías Museo Argentino de Ciencias Naturales 4: I-XIV + CD. Buenos Aires. ISSN 1515-7652.

ARCHANGELSKY , A. \& S. ARCHANGELSKY

2002. Palinología estadística en el Cretácico de la Cuenca Austral, Plataforma Continental Argentina. I

. Seis eis perforaciones del área Magallanes. Revista Museo Argentino de Ciencias Naturales, n. s. 4 (1) 54.

ARCHANGELSKY, S, V. BARREDA, M. G. PASSALIA, M. B. PRÁMPARO, E. J. ROMERO, A. ZAMUNER, R. CÚNEO, M. A. GANDOLFO, A. IGLESIAS, M. LLORENS, G. G. PUEBLA, M. E. QUATTROCCHIO \& W. VOLKHEIMER

2004. Early angiosperm diversification in the Cretaceous of Argentina: First approach. VII International Organization Paleobotany Conference (IOPC) Abstracts book: 4-6.

ARCHANGELSKY, S., A.M. BALDONI, J. C. GAMERRO \& J. SEILER

1983. Palinología estratigráfica del Cretácico de Argentina Austral. II. Descripciones sistemáticas. Ameghiniana 20 (3-4): 199-226.

ARCHANGELSKY, S., A.M. BALDONI, J. C. GAMERRO \& J. SEILER

1984. Palinología estratigráfica del Cretácico de Argentina austral. III Distribución de las especies y conclusiones. Amegbiniana 21 (1): 15-33.

ARCHANGELSKY, S., E.S. BELLOSI, G.A. JALFIN \& C. PERROT 1994. Palynology and alluvial facies from the mid-Cretaceous of Patagonia, subsurface of San Jorge Basin, Argentina. Cretaceous Research 15: 127-142.

ARCHANGELSKY, S. \& G. DEL FUEYO

1989. Squamastrobus gen. n. a fertile podocarp from the early Cretaceous of Patagonia, Argentina. Review of Palaeobotany and Palynology, 59 (1-4), 109-126.

ARCHANGELSKY, S. \& J. C. GAMERRO

1965. Estudio palinológico de la Formación Baqueró (Cretácico), Provincia de Santa Cruz I. Ameghiniana 4 (5): 159-170.

ARCHANGELSKY, S. \& J. C. GAMERRO

1966a. Estudio palinológico de la Formación Baqueró (Cretácico), Provincia de Santa Cruz II . Ameghiniana 4 (6): 201-209. 
ARCHANGELSKY, S. \& J. C. GAMERRO

1966b. Estudio palinológico de la Formación Baqueró (Cretácico), Provincia de Santa Cruz III . Ameghiniana 4 (7): 229-236.

ARCHANGELSKY, S. \& J. C. GAMERRO

1966c. Estudio palinológico de la Formación Baqueró (Cretácico), Provincia de Santa Cruz IV. Amegbiniana 4 (10): 363-395.

ARCHANGELSKY, S. \& J. C. GAMERRO

1967a. Spore and pollen types of the Lower Cretaceous in Patagonia (Argentina). Review of Palaeobotany and Palynology 1: 211-217.

ARCHANGELSKY, S. \& J. C. GAMERRO

1967b. Pollen grains found in coniferous cones from the Lower Cretaceous of Patagonia (Argentina). Review of Palaeobotany and Palynology 5: 179-182.

ARCHANGELSKY, S. \& J. SEILER

1980. Algunos resultados palinológicos de la perforación UN OIL OS-1, del SO de la provincia de Chubut, Argentina. Actas II Congreso Argentino de Paleontología y Bioestratigrafía I Congreso Latinoamericano de Paleontología: 215-225.

ARCHANGELSKY, S \& T. N. TAYLOR

1993. The ultrastructure of in situ Clavatipollenites pollen from the Early Cretaceous of Patagonia. American Journal of Botany 80(8): 879-885.

ARCHANGELSKY,S. \& L. VILLAR DE SEOANE

1989 (1990). Ultraestructura de dos nuevas megasporas cretácicas de Santa Cruz, Argentina. Boletin de la Asociación Latinoamericana de Paleobotánica y Palinología 12: 43-58.

ARCHANGELSKY, S. \& L. VILLAR DE SEOANE

1990. Morfología y estructura de megasporas cretácicas de Patagonia, República Argentina. Revista Española de Micropaleontología, Vol.22: 419-450.

ARCHANGELSKY, S. \& L. VILLAR DE SEOANE

1991. Notas sobre la Flora Fósil de la zona de Ticó, Provincia de Santa Cruz. XI. Morfología y estructura de tres megasporas. Ameghiniana 28: 353-364.

ARCHANGELSKY, S. \& L. VILLAR DE SEOANE

1992. Estudios palinológicos de la Formación Baqueró (Cretácico), provincia de Santa Cruz, Argentina. V. VIII Simposio Argentino de Paleobotánica y Palinología. Asociación Paleontológica Argentina, Publicación Especial No 2: 23-27. Buenos Aires.

ARCHANGELSKY S. \& L. VILLAR DE SEOANE

1994. Estudio palinológico de la Formación Baqueró(Cretácico), Provincia de Santa Cruz, Argentina. 
VI. Ameghiniana 31(1): 41-54.

ARCHANGELSKY, S. \& VILLAR DE SEOANE, L.

1996. Estudios palinológicos de la Formación Baqueró (Cretácico), provincia de Santa Cruz, Argentina. VII. Amegbiniana 33 (3): 307-313.

ARCHANGELSKY S. \& L. VILLAR DE SEOANE

1998. Estudio palinológico de la Formación Baqueró(Cretácico), Provincia de Santa Cruz, Argentina. VIII. Ameghiniana 35, (1): 7-19.

\section{ARCHANGELSKY, S. \& L. VILLAR DE SEOANE}

2004. Cycadean diversity in the Cretaceous of Patagonia, Argentina. Three new Androstrobus species from the Baqueró Group. Review of Palaeobotany and Palynology 131 (1-2): 1-28.

\section{ARCHANGELSKY, S. \& L. VILLAR DE SEOANE}

2005. Estudios palinológicos del Grupo Baqueró (Cretácico Inferior), provincia de Santa Cruz, Argentina. IX Polen bisacado de Podocarpaceae. Revista Española de Paleontología, 20 (1): 37-56.

AXELROD, D. I.

1981. Role of volcanism in climate and evolution. Geological Society of America Special Paper 185: 59pp.

\section{BALDONI A. M.}

1888. Dos nuevas especies de megasporas de la Formación Kachaike, Cretácico Inferior de Santa Cruz, Argentina. X Congr. Bras. de Paleont., An. II: 669-670. Rio de Janeiro.

\section{BALDONI A. M. \& D. J. BATTEN}

1991. Megaspores from the Lower Cretaceous Kachaike Formation, Santa Cruz Province, Argentina. N. Jb. Geol. Palaont. Abh. 182 (3): 377-393.

\section{BALDONI A. M. \& F. MEDINA}

1989. Fauna y microflora del Cretácico, en bahía Brandy, isla James Ross, Antartida. Serie Científica INACH 39: 43-58.

\section{BALDONI, A. M. \& T. N. TAYLOR}

1982. The ultrastructure of Trisaccites pollen from the Cretaceous of Southern Argentina. Review of Palaeobotany and Palynology 38 : 23-33. 
BALDONI A. M. \& T. N. TAYLOR,

1988. Ultraestructura de una nueva especie de Arcellites en el Cretácico Inferior de la provincia de Santa Cruz y sus vinculaciones con la Familia Marsileaceae. IV Cong. Arg. de Paleontología y Bioestratigrafía, Actas 3 (Mendoza 1986): 15-22.

BALDONI, A. M. \& S. ARCHANGELSKY

1983. Palinología de la Formación Springhill (Cretácico Inferior), Subsuelo de Argentina y Chile Austral. Revista Española de Micropaleontología, Vol.XV, núm. 1: 47-101.

BALDONI, A.M., R.A. ASKIN \& D. RAGONA

2001. Palynology of the Lower Cretaceous Kachaike Formation, Santa Cruz province, Argentina. In: Goodman, D.K. \& Clark, R.T. (eds.), Proceedings of the IX International Palynological Congress, Houston, Texas, U.S.A., 1996; American Association of Stratigraphic Palynologists Foundation: 191-200.

BALDONI, A.M. \& V.A. RAMOS

1981. Nuevas localidades con plantas fósiles cretácicas en la cordillera patagónica. VIII Congreso Geológico Argentino, San Luis. Actas IV: 743-759.

BALME, B. E.

1957. Spores and pollen grain from the Mesozoic of Western Australia. C.S.I.R.O., Coal Res. Sect., 25: $1-48$.

BALME, B. E.

1995. Fossil in situ Spores and Pollen grains: An annotated Catalogue. Review of Palaeobotany and Palynology, 87 (2-4): 81-322.

BARREDA, V., PALAMARCZUK, S. \& MEDINA, P.

1999. Palinología de la Formación Hidden Lake (Coniaciano-Santoniano), Isla James Ross, Antártida. Revista Española de Micropaleontología_31: 53-72.

BATTEN, D. J.

1996. Chapter 26A. Palynofacies and palaeonvironmental interpretation. In: Jansonius, J. \& Mc. Gregor, D. C. (ed.) Palynology: Principles and Applications. American Association of Stratigraphic Palynologist Foundation, Vol. 3: 1011-1064.

BEHRENSMEYER, A. K. \& R. W. HOOK

1992. Paleoenvironmental Contexts and Taphonomic Modes. In: Behrensmeyer, A. K., J. D. Damuth, W. A. DiMichele, R. Potts, H. D. Sues \& L. W. Scott (eds.). Terrestrial Ecosystems through Time- Evolutionary Paleoecology of Terrestrial Plants and Animals: 15-136.

BEHRENSMEYER, A. K., S. M. KIDWELL \& R. A. GASTALDO

2000. Taphonomy and paleobiology. In: Erwin, D. A. \& S. L. Wing (eds.) Deep Time, Paleobiology's 
perspective. Supplement to Volume 26 (4): 103-147.

BERRY, E. W.

1924. Mesozoic Plants from Patagonia. American Journal of Sciences. Fifth Series, Vol. VII No. 42: 473-482.

BIRKS, H. J. B. \& H. H. BIRKS

1980. Quaternary Palaeoecology. University Park Press: 289pp.

BIRKS, H. H. \& R. W. MATHEWES

1978. Studies in de vegetation history of Scotland, V. Late Devensian and Early Flandrian pollen and macrofossils stratigraphy at Abernethy Forest, Inverness-shire. New phytol., 80: 455-484.

BRACACCINI, O.

1968. Panorama general de la geología patagónica (Relatorio). Actas 3as Jornadas Geológicas Argentinas, 1.

BRALOWER, T. J., M. A. ARTHUR, R. M. LECKIE, D. J. ALLARD \& S. O. SCHLANGER 1994. Timing and Paleoceanography of Oceanic Dysoxia/ Anoxia in the Late Barremian to Early Aptian (Early Cretaceous). Palaios, vol. 9: 335-369.

BRALOWER, T. J. \& LORENTE, M. A.

2003. Paleogeography and Stratigraphy of the La Luna Formation and Related Cretaceous Anoxic Depositional Systems. Palaios vol. 18, No. 4-5: 301-305.

BRENNER, G.J.

1963. The spores and pollen of the Potomac Group of Maryland. Maryland Board Natural Resources, Department of Geology, Mines and Water Resources, Bulletin 27: 1- 215.

BRENNER, G. J.

1976. Middle Cretaceous floral provinces and early migrations of Angiosperms. In: Origin and Early Evolution of Angiosperms (Columbia University Press): 23-47.

BRIGGS, D. \& S. M. WALTERS

1969. Evolución y variación vegetal. Biblioteca para el hombre actual- Ediciones Guadarrama: 252 pp.

BRION, C., J. PUNTERO, D. GRIGENA \& S. CALVELO

1998. Flora de Puerto Bles y sus alrededores. C.R.U.B.- U.N.C., Bariloche: 201 pp.

BOLKHOVITINA, N.A.

1966. The fossil spores of the ferns of the family Gleicheniaceae (taxonomy and distribution). In: Neustardt , M. I. (ed.). The importance of palynological analysis for stratigraphic and palaeofloristic investigations: 65-75 (Nauka) Moscow (en ruso).

BOLKHOVITINA, N. A. 
1967. The fossil spores of the Family Gleicheniaceae (Morphology and Taxonmy). Review of Palaeobotany and Palynology 3: 59-64.

BOLKHOVITINA, , N.A.

1968. The spores of the family Gleicheniaceae ferns and their importance for the stratigraphy. Academy of Sciences of the Union of Soviet Socialist Republics, Geological Institute. Transactions 186: 116pp. (en ruso).

\section{BURGER, D.}

1984. Palynology of subsurface Lower Cretaceous strata in the Surat Basin, Queensland. Burean of Mineral Resources, Bull. 150: 1-16.

BURNHAM, R. J.

1989. Relationship between standing vegetation and leaf litter in a paratropical forest: Implications for Paleobotany. Review of Palaeobotany and Palynology: 58: 5-32.

\section{CAMPOS, C.C., M.J. GARCIA, R. DINO, G. VEROSLAVSKY, A.R. SAAD \& V.J. FULFARO}

1998. Palinomorphs from the Castellanos Formation in the Northern Section of the Santa Lucía Basin, Albien of Uruguay. Revista Universidade de Guarulhos Geociencias 3 (6): 5-21.

CANTRILL, D. J.

2000. A Cretaceous (aptian) flora from President Head, Snow Island, Antarctica. Palaeontografica Abt. B 253: 153-191.

\section{CANTRILL, D. J. \& I. POOLE}

2002. Cretaceous patterns of floristic change in the Antarctic Peninsula. In: Crame, J. A. \& A. W. Owen. Paleobiogeography and Biodiversity Change: the Ordovician and Mesozoic - Cenozoic Radiation. Geological Society, London, Special Publications, 194: 141-152.

\section{CAPON, B.}

1994. Plant survival. Adapting to a Hostile World. Timber press: $132 \mathrm{pp}$.

CARANZA, H. F.

1988. Estudio estratigráfico y paleoambiental de la Formación Baqueró (Cretácico Inferior), en el sector Norte del Anfiteatro de Ticó, Departamento de Magallanes, Provincia de Santa Cruz: Tesis Licenciatura Universidad Nacional de Buenos Aires, 64 pp. (inédito).

CAS, R. A. F. \& J. V. WRIGHT

1987. Volcanic Successions: Modern and Ancient. Unwin- Hyam, London: 528pp. 
CASAS, J. H.

1963. Informe sobre las Tobas Amarillas y el Baqueroense al sur del río deseado. Y.P.F. (informe inédito).

CHAPMAN, J. L.

1986. Practical Difficulties in the application of the species concept in Albian Angiosperm Pollen. Special Papers in Palaeontology No. 35: 41-53.

CHIN, W. Y.

1997. Fern of the Tropics. Timber Press, Portland, Oregon: 190 pp.

CLADERA, G. A

1998. Estratigrafía del Cretácico Inferior en la zona de Meseta Baqueró, Provincia de Santa Cruz, Argentina. Tesis de Licenciatura. Universidad de Buenos Aires: 99pp. (inédito).

CLADERA G. A. \& R. CÚNEO

2002. Fossil plants buried by volcanic ash in the Lower Cretaceous of Patagonia. Current Topics on Taphonomy and Fossilization. (Valencia 2002): 399-403.

CLADERA, G., R. ANDREIS, S. ARCHANGELSKY \& N. R. CÚNEO

1999. Baqueró Group: A New Stratigraphic Proposal for the Lower Cretaceous of Santa Cruz Province, Argentina. VII International Symposium on Mesozoic Terrestrial Ecosystems (Buenos Aires, 1999) Abstracts: 17.

CLADERA, G., R. ANDREIS, S. ARCHANGELSKY \& N. R. CÚNEO

2002. Estratigrafía del Grupo Baqueró, Patagonia (Provincia de Santa Cruz, Argentina). Ameghiniana 39 (1): 3-20.

COLLINSON, M. E.

2002. The ecology of Cainozoic ferns. Review of Palaeobotany and Palynology 119: 51-68.

COMITÉ ARGENTINO DE ESTRATIGRAFÍA

1992. Código Argentino de Estratigrafía. Asociación Geológica Argentina. Serie B (didáctica y complementaria) No 20: 64pp. Buenos Aires.

COOKSON, I.C.

1947. Plant microfossils from the lignites of Kerguelen Archipielago. B.A.N.Z. Antarctic Research Expedition 1929-1931, Rep. A 2:127-142.

COOKSON, I.C. \& M. E. DETTMANN

1959. On Schizosporis, a new form genus from the Australian Cretaceous deposits. Micropaleontology 5 (2): 213-216. 
CORBELLA, $\mathrm{H}$.

2001. Tuffs of the Baqueró Group and the Mid-Cretaceous frame Extraandean Patagonia, Argentina. XI Congreso Latinoamericano de Geología y III Congreso Uruguayo de Geología. Trabajo 190, 6 pag. (en CD)

\section{CORNU, P.}

1986. Etude Palynologique de la Formation Springhill (Cretace Inferieurd'A Argentine Australe). Palynostratigraphie, paleogeographie et paleocologie. Tesis doctoral de la Universidad de Bordeaux (inédito).

COUPER, R. A.

1953. Upper Mesozoic and Cainozoic Spores and Pollen Grain from New Zealand. New Zealand Geol. Survey, Paleont. Bull. 22: 1-77.

COUPER, R. A.

1958. British Mesozoic Microspores and Pollen Grain (A Systematic and Stratigraphic study). Palaeontographica Band 103 Abt. B: 79-117.

COUPER, R. A.

1960. New Zealand Mesozoic and Cainozoic plant microfossils. New Zealand Geological Survey Paleontological Bulletin 32: 1-87.

\section{CROSS, A. T. \& R. E. TAGGART}

1983. Causes of a short-term sequential changes in fossil plant assemblages: Some considerations based on a Miocene Flora of the northwestern United States. Annals of the Missouri Botanical Garden, v. 69: 676-734.

\section{CROWLEY, S. S., D. A. DUFEK, R. W. STANTON \& T. A. RYER}

1994. The Effects of Volcanic Ash Disturbances on a Peat-Forming Environment: Environmental Disruption and Taphonomic Consecuences. Palaios Vol. 9: 158-174.

\section{CÚNEO, R. \& M.A. GANDOLFO}

2003. Morfotipos de angiospermas en la Formación Kachaike, Cretácico medio de Santa Cruz, Argentina. XII Simposio Argentino de Paleobotánica y Palinología (Buenos Aires). Ameghiniana 40 (4 Suplemento):26 R.

\section{CÚNEO, R. \& M.A. GANDOLFO}

2005. Angiosperm leaves from the Kachaike Formation, Lower Cretaceous of Patagonia, Argentina. Review of Palaeobotany and Palynology 136: 29-47.

\section{DE BARRIO, R., M. PALMA \& J. L. PANZA}

1986. Deseado Masif. Correlation with the Andean Region. The Geologic Evolution of South America, Geological Society of America. 
DE BARRIO, R. E., J. L. PANZA \& F. E. NULLO

1999. Jurásico y Cretácico del Maciso del Deseado, provincia de Santa Cruz. In: Roberto Caminos (ed.) Geología Argentina. Instituto de Geología y Recursos minerales, Anales 29 (6): 511-527.

DE GIUSTO, J. M.

1954. Informe geológico preliminar. Reconocimiento de Florida Negra, Territorio de Santa Cruz, Y. P. F. (informe inédito).

DE GIUSTO, J. M.

1955. Informe geológico preliminar. Zona de San Julián, pcia. de Santa Cruz, Y. P. F. (informe inédito).

DE GIUSTO, J. M.

1956. Informe geológico preliminar. Zona Ea. Baqueró y Ea. Roca Blanca, pcia. de Santa Cruz, Y. P. F. (informe inédito).

DE GIUSTO, J. M.

1957. Informe geológico preliminar. Zona Aguada Alegre - Los Manantiales, pcia. de Santa Cruz, Y.P. F. (informe inédito).

DE GIUSTO, J. M.

1958. Informe geológico preliminar. Zona Cerro Vanguardia - Cerro $1^{\circ}$ de Abril, pcia. de Santa Cruz, Y. P. F. (informe inédito).

DE GIUSTO, J. M

1959. Informe geológico preliminar. Zona Cañadón León, pcia. de Santa Cruz, Y. P. F. (informe inédito).

DE GIUSTO, J. M.; C. A. DI PERSIA \& E. PEZZI

1980. Nesocratón del Deseado. En: Geología Regional Argentina. Academia Nacional de Ciencias, Córdoba: 1389 - 1430.

DE JERSEY, N. J.

1964. Triassic spores and pollen grains from Bundamba Group. Geol. Surv. Qld., Publ. 321: 21 pp. Brisbane.

DE LA SOTA, E., M.A. MORBELLI \& L. CASSÁ DE PAZOS

1998. Pteridophyta. In: Correa, M.N. (ed.) Flora Patagónica Parte I: 282-369. 
DELCOURT, A. F., M.E. DETTMANN \& N. F. HUGHES

1963. Revision of some Lower Cretaceous Microspores from Belgium. Palaeontology, Vol. 6, part. 2: $282-292$.

DELCOURT, A. R. \& G. SPRUMONT

1955. Les spores et grains du pollen du Wealdien du Hainaut. Mémoires de la Société belge de Geologie. Nouvelle Serie IN- 4 No 5.

DEL FUEYO, G. M. \& A. ARCHANGELSKY

2002. Araucaria grandifolia Feruglio from the Lower Cretaceous of Patagonia. Cretaceous Reserarch 23 (2): $255-267$.

DEL FUEYO, G. M. \& S. ARCHANGELSKY

2004. Coniferous pollen Cones with in situ Cyclusphaera Elsik Pollen from the Cretaceous of Patagonia. VII International Organization Paleobotany Conference (IOPC) Abstracts book: 22-23.

\section{DETTMANN, M.E.}

1961. Lower Mesozoic megaspores from Tazmania and South Australia. Micropaleontology vol. 7, no. 1: $71-86$.

DETTMANN, M.E.

1963. Upper Mesozoic microfloras from South- eastern Australia. Royal Society of Victoria, Bulletin 77, part. 1: 1-148.

DETTMANN, M.E.

1986a. Significance of the Cretaceous-Tertiary spore genus Cyatheacidites in tracing the origin and migration of Lophosoria.( Filicopsida). Special Papers in Palaeontology No 35: 63-94.

DETTMANN, M.E.

1986b. Early Cretaceous palynoflora of subsurface strata correlative with the Koonwarra Fossil Bed, Victoria. Mem. Ass. Australas. Palaeontols 3, 79-110.

\section{DETTMANN, M.E.}

1994. Cretaceous Vegetation: the microfossil record. In: Hill R. S. (ed.) History of the Australian Vegetation. Cambridge University Press: 143-170. 
DETTMANN, M.E. \& THOMSON, M.R.A.

1987. Cretaceous palynomorphs from the James Ross Island area, Antarctica -A pilot study. British Antarctic Survey Bulletin 77: 13-59.

DETTMANN, M.E., R.E. MOLNAR, J. G. DOUGLAS, D. BURGER, C. FIELDING, H. T. CLIFFORD, J. FRANCIS, P. JELL, T. RICH, M. WADE, P. V. RICH, N. PLEDGE, A. KEMP \& A. ROZEFELDS

1992. Australian Cretaceous terrestrial faunas and floras: biostratigraphic and biogeographic implications. Cretaceous Research 13: 207-262.

DIMICHELE, W. A., T. L. PHILLIPS \& R. G. OLMSTEAD

1987. Oportunistic Evolution: Abiotic environmental stress and the fossil record of plants. Review of Palaeobotany and Palynology 50: 151-178.

DI PERSIA, C. A.

1954. Informe previo al levantamiento geológico en escala 1:100.000 de la zona norte del territorio de Santa Cruz. Primera Campaña Y.P.F. (informe inédito).

DI PERSIA, C. A.

1955. Informe previo al levantamiento geológico en escala 1:100.000 de la zona norte del territorio de Santa Cruz. Segunda Campaña Y.P.F. (informe inédito).

DI PERSIA, C. A.

1956. Informe previo al levantamiento geológico en escala 1:100.000 de la zona norte del territorio de Santa Cruz. Tercera Campaña Y.P.F. (informe inédito).

DI PERSIA, C. A.

1957. Informe previo al levantamiento geológico en escala 1:100.000 de la zona norte del territorio de Santa Cruz. Cuarta Campaña Y.P.F. (informe inédito).

DI PERSIA, C. A.

1958. Informe previo al levantamiento geológico en escala 1:100.000 de la zona norte del territorio de Santa Cruz. Quinta Campaña Y.P.F. (informe inédito).

DI PERSIA, C. A. 
1959. Informe previo al levantamiento geológico en escala 1:100.000 de la zona norte del territorio de Santa Cruz. Sexta Campaña Y.P.F. (informe inédito).

DOYLE, J. A., P. BIENS, A. DOERENKAMP \& S. JARDINÉ

1977. Angiosperm pollen from the pre-Albian Lower Cretaceous of Equatorial Africa. Bulletin $d u$ Centre de Recherche Exploration-Production Elf-Aquitaine. I (2): 451-473.

DÖRING, H.

1965. Stratigraphische Verbreitung der sporengattugen Gleicheniidites und Trubasporites in Jura-Kreide Grenzbereich. Mitt. Zgi. 1: 191-209.

EGGLER, W. A.

1948. Plant communities in the vicinity of El Paricutin, Mexico, after two and a half years of eruption. Ecology v. 29: 415-436.

ERDTMAN, G.

1952. Pollen Morphology and Plant Taxonomy. Almqvist and Wiksell.

\section{FAEGRI, K. \& J. IVERSEN}

1975. Textbook of Pollen Analysis (3rd edition). Blackwell.

\section{FALCON-LANG \& CANTRILL}

2002. Terrestrial Paleoecology of the Cretaceous (Early Aptian) Cerro Negro Formation, South Shetlands Islands, Antarctica: A Record of polar Vegetation in a Volcanic Arc Environment. Palaios Vol. $17 \mathrm{~N}^{\circ}$ 5: 491-506.

FASOLA, A.

1969. Estudio palinológico de la Formación Loreto (Terciario Medio), Provincia de Magallanes, Chile. Ameghiniana 4 No 1: 3-49.

FERGUSON, D. K.

1985. The origin of Leaf-assemblages, New light on an old problem. Review of Palaeobotany and Palynology 46: 117-188.

FERGUSON, D. K.

2002. Plant Tafonomic Processes and the Fossil Record. Current Topics on Taphonomy and Fossilization. (Valencia 2002): 393-397. 
FERUGLIO, E.

1937a. Una interesante Filicínea fósil de la Patagonia. Bol. Inform. Petroleras XIV, nº 151: 5-20, Buenos Aires.

FERUGLIO, E.

1937b. Una nueva Dipteridae del Mesozoico superiore della Patagonia. Boll. Soc. Geolog. Ital., LVI: 1-16.

FERUGLIO, E.

1949-1950. Descripción geológica de la Patagonia, 3 tomos. Yacimientos Petroliferos Fiscales, Buenos Aires.

FERUGLIO, E.

1951. Piante del mesozoico della Patagonia. Pibl. Ist. Geol. Univ. Torino, fasc. 1: 35-80.

FEILD, T. S., N. C. ARENS, J. A. DOYLE, T. E. DAWSON \& M. J. DONOGHUE

2004. Dark and disturbed: a new image of early angiosperm ecology. Paleobiology 30: 82-107.

FILATOFF, J.

1975. Jurassic Palynology of the Perth Basin, Western Australia. Palaeontographica Band 154. Abt. B

FILATOFF, J. \& P. L. PRICE

1988. A Pteridacean spore lineage in the Australian Mesozoic. Mem. Ass. Australas. Palaeontolos. 5, $89-124$.

FISHER, R. V. \& H. U. SCHMINCKE

1984. Pyroclastic Rocks. Springer, Berlin, Heidelberg, New York: 472 pp.

FREEMAN, S. \& J. C. HERRON

1998. Mass Extinctions and their Consequences (Chapter 13). In: Evolutionary Analysis. Prentice Hall, New Jersey: 491-525.

FRIIS, E. M., K. R. PEDERSEN \& P.R. CRANE

1999. Early Angiosperm Diversification: the diversity of pollen associated with angiosperm reproductive structures in Early Cretaceous Floras from Portugal. Ann. Missouri Bot. Gard. 86: 259-296.

FRITZ, W.J.

1986. Plant Taphonomy in Areas of Explosive Volcanism. In: Broadhead, T. W. (ed.) Land Plants 
-notes for a short course. University of Tennessee, Dep. of Geological Sciences Studies in Geology 15: 1-9.

GAMERRO, J. C.

1965a. Morfología del polen de la conífera Trisacocladus tigrensis Archang. de la Formación Baqueró, Provincia de Santa Cruz. Ameghiniana 4:31-38.

GAMERRO, J. C.

1965b. Morfología del polen de Apterocladus lanceolatus Archangelsky (Coniferae) de la Formación Baqueró, provincia de Santa Cruz. Ameghiniana 4 (4): 134-138.

GAMERRO, J. C.

1975. Megasporas del Cretácico de Patagonia I. Ultraarquitectura de la pared megasporal en Hughesisporites patagonicus Archang. y Horstisporites feruglioi Archang. Amegbiniana 12:97-108.

GAMERRO, J. C.

1982. Informe palinológico del perfil arroyo Caballo Muerto, Santa Cruz. Y.P.F. Buenos Aires (informe inédito).

GAMERRO, J. C. \& O. CÁRDENAS

1980. Como hacer permanentes las preparaciones palinológicas en glicerina-gelatina. Boletín de la Asociación Ltinoamericana de Paleobotánica y Palinología 7: 39-42.

GASTALDO R., H.

1992. Taphonomic considerations for plant evolutionary investigations. The Palaeobotanist 41: 211-223.

GONZÁLEZ-AMICÓN, O. R. \& W. VOLKHEIMER

1982. Palinología estratigráfica del Jurásico de la Sierra Chacai Có y adyacencias (Cuenca Neuquina, República Argentina) III: Decripciones sistemáticas de los palinomorfos de la Formación Cura Niyeu (Bayociano). Ameghiniana 19 (1-2): 165-178.

GRADSTEIN, F. M., F. P. AGTERBERG, J. G. OGG, J. HARDENBOL \& S. BACKSTROM 1999. On the Cretaceous time scale. N. Jb. Geol. Palaont. Abh. 212 (1-3): 3-14.

GRIGGS, R. F.

1915. The effect of the eruption of Katmai on land vegetation. American Geographical Society Bulletin v. 47: 193-203. 


\section{GULER, M. V. \& S. ARCHANGELSKY}

2002. Quistes de dinoflagelados de la Formación Kachaike (Cretácico Inferior), provincia de Santa Cruz, Argentina. VIII Congreso Argentino de Paleontología y Biostratigrafía. Resúmenes: 71, Corrientes.

\section{GULER, M. V., G. R. GUERSTEIN \& S. ARCHANGELSKY}

2003. Quistes de dinoflagelados del Cretácico Inferior de la Plataforma Continental Argentina. Ameghiniana 40 (4) Suplemento: 26R-27R.

\section{GUST, D. A., K. T. BIDDLE, D. W. PHELPS, \& M. A. ULIANA}

1985. Associated Middle to Late Jurassic Volcanism and extension in South America. Tectonophysics 116: $223-253$.

HALLAM, A. \& P. B. WIGNALL

1997. Mass Extinctions and Their Aftermath. Oxford University Press: 311 pp.

HALLE, T.G.

1913. Some mesozoic plant-bearing deposits in Patagonia and Tierra del Fuego and their floras. K. svenska Vetensk. Akad. Handl. 51(3):1-58.

HARRINGTON, $\mathrm{H}$.

1962. Paleogeographic development of South America. Am. Assoc. Petrol. Geol., Bull., 46 (10): 1773-1814.

HATCHER, J. B.

1897. On the Geology of Southern Patagonia. American Journal Science, Series 4,4 (23) : 321-354.

HATCHER, J. B.

1900. Sedimentary rocks of Southern Patagonia. American Journal Science, Series 4,9 (50) : 85-108.

HATCHER, J. B.

1903. Narrative of the expeditions geography of Southern Patagonia. Report Princeton University Expedition to Patagonia, 1896 - 1899, Vol. I.

\section{HATHWAY, B., A. M. DUANE, D. J. CANTRILL \& S. P. KELLEY}

1999. ${ }^{40} \mathrm{Ar} /{ }^{39} \mathrm{Ar}$ geochronology and palynology of the Cerro Negro Formation, South Shetland Islands, Antarctica: A new radiometric tie for Cretaceous terrestrial biostratigraphy in the Southern Hemisphere. Australian Journal of Earth Science, Vol. 46: 593-606. 
HAY, W. W., R. M. DECONTO, C. N. WOLD, K. M. WILSON, S. VOIGT, M. SCHULZ, A. WOLDROSSBY, W. C. DULLO, A. B. RONOV, A. N. BALUKHOVSKY \& E. SÖDING 1999. Alternative global Cretaceous paleogeography. In: Barrera, E. \& C. C. Johnson (eds.) Evolution of the Cretaceous Ocean-Climate System: Boulder, Colorado. Geological Society of America Special Papers 332.

HEDBERG, H. D.

1972. Summary of an international guide to stratigraphic classification, terminology and usage. Boreas, 1: $213-239$.

HECHEM, J \& J. HAMOVC

1987. La relación entre las Formaciones Baqueró y Laguna Palacios en el Nesocratón del Deseado, provincia de Santa Cruz. Asociación Geológica Argentina, Rev. 42 (3-4) : 244 - 254.

\section{HELBY, R., R. MORGAN \& A. D. PARTRIDGE}

1987. A palynological zonation of the Australian Mesozoic. In Jell, P.A. (Ed.), Studies in Australian Mesozoic Palynology. Mem. Assoc. Australas. Palaeontol., 4:1-94.

HERBIN, J. P., C. MULLER, P. C. DE GRACIANSKY, J. JACQUIN, F. MAGNIEZ-JANNIN \& P. UNTERNEHR

1987. Cretaceous Anoxic Event in the South Atlantic. Revista Brasileira de Geociencias 17(2): 92-99.

\section{HERBST, R.}

1960. Descripción de algunos ejemplares fértiles de Hausmannia (Protorhipis) papilio Fer., procedentes de los estratos de Baqueró, Santa Cruz. Acta Geológica Lilloana 3: 227-232.

HERBST, R.

1962. Sobre especies de Gleichenites de los sedimentos baqueroenses de Santa Cruz, Patagonia. Ameghiniana 2: 141-151.

HERBST, R.

1965. Algunos esporomorfos del Triásico de Argentina. Ameghiniana 4 (5): 141-155.

HERBST, R.

1966. Nuevos elementos de la flora fósil de la Formación Baqueró, Santa Cruz, Patagonia. Acta Geológica Lilloana VIII : 75-89.

HERNGREEN, G. F. W. \& A. F. CHLONOVA

1981. Cretaceous Microfloral provinces. Pollen et spores, Vol. 23 (3-4): 441-555. 
HERNGREEN, G. F. W.; M. KEDVES, L. V. ROVNINA \& S. B. SMIRNOVA. 1996. Chapter 29C. Cretaceous palynofloral provinces: a review. In: Jansonius, J. \& McGregor, D. C. (eds.) Palynology: principles and applications. American Association of Stratigraphic Palynologist Foundation, Vol. 3, p. 1157-1188.

HILL, R. S., M. TRUSWELL E., S. MCLOUGHLIN \& M. E.DETTMANN

1999. Evolution of the Australian flora: fossil evidence: In: Orchard A. E. (ed.) Flora of Australia vol. 1 (2* ed.) ABRS/CSIRO, Australia.

HICKEY, L. J. \& J. A. DOYLE

1977. Early Cretaceous fossil evidence for Angiosperm Evolution. The Botanical Review. Vol. 9 No. 43: 1-101.

HOWE, J \& J. FRANCIS

2004. Mid Cretaceous fossil forest from Alexander Island, Antarctica. VII International Organization Paleobotany Conference (IOPC) Abstracts book: 57.

HUGHES, N. F.

1994. The enigma of angiosperm origins. Cambridge University Press, 303 pp.

JANSONIUS J. \& L. V. HILLS

1976. Genera File of Fossil Spores. Special Publication. Dept. Geol. Univ. of Calgary: 134; 550; 748; 1308; 1472; 1552; 1691; 1739; 2405; 2964; 3099-3101.

JANSONIUS J. \& L. V. HILLS

1982. Genera File of Fossil Spores. Special Publication. Dept. Geol. Univ. of Calgary: 3985.

JARZEN, D. M. 1979

Zygospores of the Zygnemataceae in the Paleocene of Southern Saskatchewan (Canadá). Review of Paleobotany and Palynology, 28: 21-25.

KELLEY, S. P.

2003. Volcanic inputs (Cap. 7). In: Skelton P. (ed.) The Cretaceous World. The Open UniversityCambridge University Press: 209-148.

KIESLING, R.

2002. Código Internacional de Nomenclatura Botánica (Código de Saint Louis). Instituto de Botánica 
Darwinion- Missouri Botanical Garden Press: 181pp.

KNOLL, A. H.

1984. Patterns of Extinction in the Fossil Record of Vascular Plants. In: Nitecki M. (Ed.) Extinctions. University Chicago Press: 21-68.

KOTOVA,I.Z.

1983. Palynological study of Upper Jurassic and Lower Cretaceous sediments site 511, Deep Sea Drilling Project, Leg. 71 (Falkland Plateau). Initial Reports of the Deep Sea Drilling Project, 71: 879906.

KOVAR-EDER, J., M. HAAS, C.-C. HOFMANN \& B. MELLER

2001. An Early Miocene Plant Assemblage Severely influenced by a Volcanic Eruption, Styria, Austria. Palaeontology Vol. 44, Part. 4: 575-600.

KRASSILOV, V. A.

2003. Terrestrial Palaeoecology and Global Change. Russian Academic Monographs No. 1. Pensoft: 464pp.

LABANDEIRA, C.C., D. L. DILCHER, D. R. DAVIES \& D. L. WAGNER

1994. Ninety-seven million years of angiosperm-insect association: Paleobiological insights into the meaning of coevolution. Proc. Natl. Acad. Sci. USA, Vol. 91, pp. 12278-12282. Evolution

\section{LARSON,R.L.}

1991. Latest pulse of the Earth: evidence for a mid-Cretaceous super plume. Geology 19: 547-550.

\section{LESTA, P. \& R. FERELLO}

1972. Región extraandina de Chubut y norte de Santa Cruz. En: Geologica Regional Argentina (Ed. Leanza). Academia Nacional de Ciencias de Córdoba: 601 - 653.

\section{LIBERTIN, M. \& J. DASKOVA}

2004. Autochthonous Plant Taphocoenosis preserved in Pyroclastic Rocks of the Bolsovian, Upper Carboniferous, Czech Republic (Central Europe). VII International Organization Paleobotany Conference (IOPC) Abstracts book: 75-76.

\section{LIMA, M. R. DE \& E. BOLTENHAGEN}

1981. Estudo comparativo da Evolução das Microfloras Afro-sul-americanas I - o Cretáceo Inferior. Anais II Congresso Latino-americano Paleontologia: 331-341, Porto Alegre. 
LOOY, V., W. A. BRUGMAN, D. L. DILCHER \& H. VISSCHER

1999. The delayed resurgence of equatorial forest after the Permian-Triassic ecologic crisis. Proc. Nat. Ac. Sci. vol. 96, no. 24: 13857-13862.

\section{LONGOBUCCO, M.I., C.L. AZCUY \& B. AGUIRRE URRETA}

1985. Plantas de la Formación Kachaike, Cretácico de la provincia de Santa Cruz. Ameghiniana 21 (2-4): 305-315.

LUPIA, R., S. LIDGARD \& P. R. CRANE

1999. Comparing palynological abundance and diversity: implications for biotic replacement during the Cretaceous angiosperm radiation. Paleobiology 25 (3): 305-340.

\section{LLORENS, M.}

2000. Estudio Palinológico de la Formación Punta del Barco (Grupo Baqueró) Cretácico Inferior, provincia de Santa Cruz. XI Simposio Argentino de Paleobotánica y Palinología. (Tucumán) Resúmenes: 56.

\section{LLORENS, M.}

2003a. Polen de angiospermas de la Formación Punta del Barco (Grupo Baqueró), Aptiano de Santa Cruz, Argentina. Ameghiniana 40 (4) Suplemento: 27R.

\section{LLORENS, M.}

2003b. Granos de polen de angiospermas de la Formación Punta del Barco (Aptiano), provincia de Santa Cruz, Argentina. Revista del Museo Argentino de Ciencias Naturales, n.s. 5 (2): 235-240.

\section{LLORENS, M. \& G. CLADERA}

2002. Esporas perisporadas como evidencia tafonómica. VIII Congreso Argentino de Paleontología y Bioestratigrafía. (Corrientes, 2002) Resúmenes: 73.

\section{LLORENS, M. \& G. M. DEL FUEYO}

2003. Coníferas fértiles de la Formación Kachaike, Cretácico medio de la provincia de Santa Cruz, Argentina. Revista del Museo Argentino de Ciencias Naturales, n.s. 5 (2): 241-244.

\section{LLORENS, M., M. G. PASSALIA \& G. CLADERA}

2003. Nuevos aportes a la flora de la Formación Punta del Barco (Grupo Baqueró) Aptiano de Santa Cruz, Argentina. Ameghiniana 40 (4) Suplemento: 28R. 
2002. Cretaceous palynology of the Sanhur-IX Borehole, Northwestern Egypt. Revista Española de Micropaleontología 34 (2): 129-143.

MALDE, H. E.

1964. The ecological significance of some unfamiliar geologic processes. In: Hester, J. J. \& Schoenwetter, J. (eds.) The Reconstruction of Past Environments, Proceedings of the Fort Burgwin Conference on Paleoecology, 1962: Fort Burgwin Research Center, Taos, New Mexico: 7-15.

MARIN, G.

1982. Descripción geológica de la Hoja 55 C Gobernador Gregores. Provincia de Santa Cruz. Informe preliminar. Servicio Geológico Nacional 17 pp. (inédito).

MARIN, G.

1984. Descripción geológica de la Hoja 55 C Gobernador Gregores. Provincia de Santa Cruz. Servicio Geológico Nacional. (inédito).

MEHRINGER, P. J. ARNOT, S. F. \& K. L. PETERSON

1977. Postglacial history of Lost Trail Pass Bog, Bitterroot Mountains, Montana. Arctic and Alpine Research v. 9: 345-368.

MENÉNDEZ, C. A.

1968.Estudio palinológico del Jurásico medio de Picún Leufú, Neuquén. Ameghiniana 5, No 10: 379-405.

MORBELLI, M. A.

1990. Austral South American Jurassic megaspores. Review of Paeobotany. and Palynology 65: 209-216.

MUTTERLOSE, J.

1992. Migration and evolution patterns of floras and faunas in marine Early Cretaceous sediments of NW Europe. Palaeogeography, Palaeoclimatology, Palaeoecology 94: 261-282.

MUT'TERLOSE, J.

1998. The Barremian-Aptian turnover of biota in northwestwrn Europe: evidence from belemnites. Palaeogeography, Palaeoclimatology, Palaeoecology 144: 161-173.

NULLO, F. E., J.L. PANZA, Y G. BLASCO

1999. Jurásico y Cretácico de la Cuenca Austral. En: R. Caminos (ed.) Geología Argentina. Subsecretaría 
de Minería de la Nación, Servicio Geológico Minero Argentino, Instituto Geología y Recursos Minerales, anales $\mathrm{N}^{\circ} 29: 528-535$.

\section{PADEN PHILIPS, P. \& CH. J. FELIX}

1971. A study of Lower and Middle Cretaceous Spores and Pollen from the Soudheastern United States. I Spores. Pollen et Spores Vol. XIII No 2: 279-348.

PALAMARCZUK, S., A. ARCHANGESKY, V. BARREDA, J.C. GAMERRO \& S. ARCHANGESKY

2000. Datos palinológicos en dos perforaciones de la plataforma continental argentina (ValanginianoCenomaniano) Cuenca Austral. XI ${ }^{\circ}$ Simposio Argentino de Paleobotánica y Palinología. (Tucumán). Ameghiniana 37 (4) Suplemento resúmenes: 58R.

PANZA, J. L

1982. Descripción geológica de las hojas 53 e «Gobernador Moyano» y 54 e «Cerro Vanguardia». Servicio Geológico Nacional, 197 pp. (inédito).

PANZA, J. L.

1984. Descripción geológica de la hoja 54 f «Bajo de la Leona» y 54 g «Bahía Laura», Provincia de Santa Cruz. Servicio Geológico Nacional, 197 pp. (inédito).

PANZA, J. L., 1986

Descripción geológica de la hoja 54 d «La Manchuria», Provincia de Santa Cruz. Servicio Geológico Nacional, 141 pp. (inédito).

PANZA, J. L.

1987. Descripción geológica de los lotes 18 - 19 y alrededores. (Departamento Magallanes, Provincia de Santa Cruz). Dirección Nacional de Minería y Geología, 87 pp. (inédito).

PANZA, J. L.

1988. Informe preliminar de la descripción geológica de la hoja 55 e «Cerro Rubio», Provincia de Santa Cruz. Servicio Geológico Nacional, 28 pp. (inédito).

PANZA, J. L. \& G. MARÍN

1998. Hoja geológica 4969 - I Gobernador Gregores escala 1: 250.000, provincia de Santa Cruz. Servicio Geológico Minero Argentino Boletín No 239. 
PAPÚ, O.H.

2002. Nueva microflora de edad maastrichtiana en la localidad de Calmu-Có, sur de Mendoza, Argentina. Amegbiniana 39 (4): 415-426.

PASSALIA, M. \& G. CLADERA

2003. Impresiones foliares angiospermoides en el Cretácico inferior (Aptiano) de Santa Cruz, Argentina. XII Simposio Argentino de Paleobotánica y Palinología (Buenos Aires) Resúmenes: 45.

PASSALIA, M., S. ARCHANGELSKY, E. ROMERO \& G. CLADERA

2003. A new early angiosperm from Anfiteatro de Ticó Formation (Aptian) Santa Cruz Province, Argentina. Revista del Museo Argentino de Ciencias Naturales: 245-252.

PIRRIE, D., J.D. MARSHALL, P. DOYLE, A.C. RICCARDI

2004. Cool early Albian climates, new data from Argentina. Cretaceous Research 25 (1): 27-34.

PLAYFORD, G.

1971. Palynology of Lower Cretaceous (Swan river) strata of Saskatchewan and Manitoba. Palaeontology 14: 535-565.

POCOCK, S. A. J.

1962. Microfloral analysis and age determination of strata at the Jurassic -Cretaceous boundary in the Western Canada plains. Palaeontographica Abt. B, 111: 1-95. Stuttgart.

POCOCK, S. A. J.

1970. Palynology of the Jurassic sediments of Western Canada. Part 1. Terrestrial species. Palaeontographica Abt. B, 130: 73-136. Stuttgart.

\section{PONS D.}

1988. Le Mésozoïque de Colombie. Macroflores et microflores. Cabiers de paléontologie. Éditions du Centre National de la Recherche Scientifique. France: 168 pp.

POTONIÉ, R.

1956. Synopsis der Gattungen der Sporae dispersae. I Teil: Beih. Geol. Jb., 23: 1-103.

POTONIÉ, R.

1958. Synopsis der Gattungen der Sporae dispersae. II Teil: Sporites (Nachträge), Saccites, Aletes, Praecolpates, Polyplicates, Monocolpates. Beih. Geol. Jb., 31: 1-114. 
POTONIÉ, R.

1960. Synopsis der Gattungen der Sporae dispersae. III Teil: Nachträge Sporites, Forsetzung Pollenites Mit General register zu Teil I-III. Beih. Geol. Jb., 39: 1-189.

POTONIÉ, R. \& G. KREMP

1954. Die Gattungen der paläozoischen Sporae dispersae und ihre Stratigraphie. Geol. Jahrb., 69: 111194.

\section{PÖTHE DE BALDIS, D. \& V. A. RAMOS}

1980. Las microfloras de la Formación Río Mayer y su significado estratigráfico, Provincia de Santa Cruz, Argentina. Actas II Congreso Argentino Paleontología y Bioestratatigrafía, I Cong. Latinoamer. Paleontol. (Bs. As., 1978) 5: 201-213.

\section{PÖTHE DE BALDIS, D. \& V. A. RAMOS}

1983. Dinoflagelados del Aptiano inferior de Río Fósiles, Lago San Martín, Provincia de Santa Cruz, Argentina. Revista Española de Micropaleontología, vol. 15, núm. 3: 427-446.

\section{PÖTHE DE BALDIS, D. \& V. A. RAMOS}

1986. Microplancton adicional del Aptiano de Río Fósiles, Lago San Martín, provincia de Santa Cruz, Argentina y su correlación con Australia. IV Congreso Argentino de Paleontología y Bioestratigrafía, acta 3: $23-40$.

\section{PRÁMPARO M. B.}

1988a. Nuevos aportes a la palinología de la Formación La Cantera, Cretácico de la Cuenca de San Luis, en su localidad tipo. IV Congreso Argentino de Paleontología y Bioestratigrafía, Actas 3: 277-290. Mendoza, 1986.

PRÁMPARO, M. B.

1988b. Esporas levigadas y apiculadas de la Formación La Cantera (Cretácico de la Cuenca de San Luis) en su localidad tipo. IV Congreso Argentino de Paleontología y Bioestratigrafía, Actas 3: 51-62. Mendoza, 1986.

PRÁMPARO, M. B.

1989. Las esporas de Schizaeaceae (Cicatricosisporites y Appendicisporites) del Cretácico Inferior, Cuenca de San Luis, Argentina. Revista Española de Micropaleontología Vol. XXI, núm. 3: 355-372.

PRÁMPARO, M. B. 
1999. Granos de polen de primitivas angiospermas en el Cretácico inferior de la Cuenca de San Luis y su distribución en otras cuencas cretácicas de Argentina. Boletim do $5^{0}$ Simpósio sobre o Cretáceo do Brasil (1999): 539-543.

PRÁMPARO, M. B., O. H. PAPÚ \& J. P. MILANA

1996. Estudio del miembro inferior de la Formación Pachaco, Terciario de la provincia de San Juan. Descripciones sistemáticas. Ameghiniana 33 (4): 397-407.

PRÁMPARO, M. B. \& W. VOLKHEIMER

1999. Palinología del Miembro Avilé (Formación Agrio) en el Cerro de la Parva, Neuquén. Ameghiniana 36: 217-227.

QUATTROCCHIO, M.

1980. Contribución al conocimiento de la palinoestratigrafía del Jurásico de Cuenca Neuquina. Opera Lilloana 31: 5-60.

RAMOS, V. A.

1978. El vulcanismo del Cretácico inferior de la Cordillera patagónica. Actas VII Congreso Geológico Argentino: 423-435.

REBASA, M.

1982. Análisis estratigráfico y paleoambiental de la Formación Kachaike, aflorante en la barranca epónima, provincia de Santa Cruz: Trabajo Final de Licenciatura. Facultad de Ciencias Exactas y Naturales, UBA (inédita): 60 pp.

\section{REGALI, M. DA S.P., N. UESUGUI \& A. DA SILVA SANTOS}

1974. Palinologia dos sedimentos meso-cenozóicos do Brasil (I). Bolm técnico Petrobrás, 17 (3): 177 191, Río de Janeiro.

RICCARDI, A.C.

1971. Estratigrafía en el oriente de la bahía de La Lancha, lago San Martín, Santa Cruz, Argentina. Revista Museo La Plata, 7 (geología) 61: 245-318.

\section{RICH, F. J., D. KUEHN \& T. D. DAVIES}

1982. The paleoecological significance of Ovoidites. Palynology v.6: 19-28.

RIDING, J. B., J. A. CRAME, M. E. DETTMMANN \& D. J. CANTRILL 
1998. The age of the base of the Gustav Group in the James Ross Basin, Antarctica. Cretaceous Research 19: 87-105.

ROBBIANO, J. A.

1989. Cuenca Austral sector costa afuera. En: Cuencas Sedimentarias Argentinas. Academia Nacional de Ciencias de Córdoba: 493-512.

\section{ROBBIANO, J. A., H. A. ARBE \& A. GANGUI}

1996. Cuenca Austral marina. In: Ramos, V. A. \& M. A.Turic (eds.) XIII ${ }^{0}$ Congreso Geológico Argentino y $\mathrm{III}^{0}$ Congreso de Exploración de Hidrocarburos, Geología y Recursos Naturales de la Plataforma Continental Argentina. Relatorio 17: 323-34. Buenos Aires.

ROMERO, E. \& ARCHANGELSKY, S.

Cretaceous Angiosperm Leaves from Southern South America. Science V. 234: 1580-1582.

ROSS, N. E.

1949. Investigations of the Senonian of the Kristianstad district, S. Sweden. I. On a Cretaceous pollen and spore bearing clay deposits of Scania. Bull. Geol. Inst. Univ. Upsala, 34:25-43; Upsala.

\section{SAJJADI, F. \& G. PLAYFORD}

2002a. Systematic and stratigraphic palynology of Late Jurassic-earliest Cretaceous strata of the Eromanga Basin, Queensland, Australia: Part One. Palaeontographica Abt. B 261: 1-98.

\section{SAJJADI, F. \& G. PLAYFORD}

2002b. Systematic and stratigraphic palynology of Late Jurassic-earliest Cretaceous strata of the Eromanga Basin, Queensland, Australia: Part Two. Palaeontographica Abt. B 261: 99-165.

SCASSO, R. A. \& C. O. LIMARINO

(1997). Petrología y Diagénesis de Rocas Clásticas. Asociación Argentina deSedimentología. Publicación Especial No 1. Buenos Aires. 257 pp.

SCHNEIDER, H., E. SCHUETTPELZ, K. M. PRYER, R. CRANFILL, S. MAGALLÓN \& R. LUPIA

2004. Fern diversified in the shadow of angiosperms. Nature Vol. 428: 553-557.

\section{SCHRANK, E. \& M. S. MAHMOUD}

2002. Barremian Angiosperm pollen and associated palynomorphs from the Dakhla Oasis area, 
Egypt. Palaeontology, Vol. 45, Part 1: 33-56.

SCOTESE, C. R.

1991. Jurassic and Cretaceous plate tectonic reconstruction. Palaeogeography, Palaeoclimatology, Palaeoecology. v. 87: 493-501.

SCOTT, A. C.

1989a. Reconstructing Ancient Plant Communities. In: Briggs, D. E. G. \& Crowther (eds.) Paleobiology, a Synthesis. Blackwell Scientific Publications: 351-354.

SCOTT, A. C.

1989b. Anatomical Preservation of Fossil Plants. In: Briggs, D. E. G. \& Crowther (eds.) Paleobiology, a Synthesis. Blackwell Scientific Publications: 351-354.

SCOT'T, A. C.

1990. Preservation, evolution, and extinction of plants in Lower Carboniferous volcanic sequences in Scotland. Geological Society of America, Special Paper 244: 25-38.

SCOTT, A. C.

2001. Preservation by fire. In: Briggs, D. E. G. \& Crowther (eds.) Paleobiology, a Synthesis II. Blackwell Scientific Publications: 277-280.

\section{SCOTT, A. C., J. A. CRIPPS, M. E. COLLINSON \& G. J. NICHOLS}

2001.The taphonomy of charcoal following a recent heathland fire and some implications for the interpretation of fossil charcoal deposits. Palaeogeography, Palaeoclimatology, Palaeoecology 164: 1-31.

SCOTT, A. C., J. MOORE \& B. BRAYSHAY

2000. Introduction to fire and the palaeoenviroment. Palaeogeography, Palaeoclimatology, Palaeoecology 164: vii-xi.

\section{SCOT'T, L.}

1971. Lower Cretaceous pollen and spores from the Algoa Basin (South Africa) Bloemfontein. Tesis MSE Univ. of the Orange Free State: 80 pp.

SEGERSTROM, K. 
1950. Erosion studies at Paricutin, State of Michoacan, Mexico. U.S. Geological Survey Bulletin 965 A: 25-38.

SINGH, C.

1964. Microflora of the Lower Cretaceous Mannville Group, East- central Alberta. Research Council of Alberta, Bull. 15: 1-239.

SINGH, C.

1971. Lower Cretaceous microfloras of the Peace River Area, northwestern Alberta. Research Council of Alberta, Bull. 28: 1-299.

SPALLETTTI, L. A., J. R. FRANZESE, D. M. DONALD \& I. G. PÉREZ

1999. Palaeogeographic evolution of Southern South America during the Cretaceous. Boletim do $5^{\circ}$ Simposio sobre o Cretaceo du Brasil (1999): 87-95.

SPICER, R. A.

1980. The importance of depositional sorting to the biostratigraphy of plant megafossils. In: Dilcher, D. L. \& T. N. Taylor (eds.) Biostratigraphy and Fossil Plants. Dowden, Hutchinson and Ross, Inc., Stroudsburg, Pennsylvania: 171-83.

STEBBINS, G. L.

1974. Flowering Plants: Evolution above the Species Level. Belknap Press of Harvard University Press: 397pp.

STIPANICIC, P.

1957. El sistema Triásico en la argentina. XX Congreso Geológico Internacional (1956). Sec. II. México.

STIPANICIC, P. \& O. REIG

1955. Breve noticia sobre el hallazgo de anuros en el denominado Complejo Porfírico de la Patagonia extraandina, con consideraciones acerca de la composición geológica del mismo. Asociación Geológica Argentina, Revista 10 (4): 215 - 233.

STIPANICIC, P. \& O. REIG

1956. El complejo Porfírico de Patagonia Extraandina y su fauna de anuros. Acta Geológica Lilloana 1: 185 - 297.

TAGGART, R. E. \& A. T. CROSS

1980. Vegetation change in the Miocene Succor Creek flora of Oregon and Idaho: A case study in paleosuccession. In: Dilcher, D. L. \& T. N. Taylor (eds.) Biostratigraphy and Fossil Plants - Successional and 
Paleosuccessional Analyses. Dowden, Hutchinson and Ross Inc., Stroudsburg, Pennsylvania: 185-210.

TAGGART, R. E., A. T. CROSS \& L. SATCHEL

1982. Effects of periodic volcanism on Miocene vegetation distribution in Eastern Oregon and Western Idaho. Third North American Paleontological Convention Proceedings, v. 2: 535-540.

TARDUNO. J. A., W.V.SLITER, L. KROENKE, R. M. LECKIE, H. MAYER, J. J. MAHONEY, R. MUSGRAVE, M. STOREY \& E.L. WINTERER

1991. Rapid formation of Ontong Java Plateau of Aptian mantle volcanism. Science 254:399-403.

TAYLOR D. W. \& L.J. HICKEY

1996. Chapter 9: Evidence for and implications of an herbaceous Origin for Angiosperms. In: Taylor D. W. \& L.J. Hickey (eds.) Flowering Plant Origin, Evolution and Phylogeny. Chapman \& Hall: 232-266.

TAYLOR, T. N., M. S. ZABADA \& S. ARCHANGELSKY

1987. The ultrastructure of Cyclusphaera psilata from the Cretaceous of Argentina. Grana 26: 74-80.

TAYLOR, W.A. \& T.N. TAYLOR

1988. Ultrastructural analysis of selected Cretaceous megaspores from Argentina. J. Micropalaentol. 7: 73-87.

TAYLOR W. C. \& L. J. HICKEY

1992. Habitat, evolution and speciation in Isöetes. Annals of the Missouri Botanical Garden 79: 613622.

THOMSON, P. W. \& H. PFLUG

1953. Pollen und Sporen des mitteleuropäischen Tertiärs: Gesamtübersicht über die stratigraphisch uns paläontologisch wichtigen Formen. Palaeontographica Abt. B, 94: 1-138; Stuttgart.

\section{TIWARI R.S.}

1999. The Palynological succession and Spatial Relationship of the Indian Gondwana Sequence. Proc. Indian Acad. Sci. 65,Sec. A, No. 3: 329-375.

TIWARI R.S. \& A. TRIPATHI

1995. Palinological assemblages and absolute age relationship of intertrappean beds in the Rajmahal Basin, India. Cretaceous Research, 16: 53-72. 
TRAVERSE, A.

1988. Paleopalynology. Unwin Hyman, London.

TRUSWELL, E. M.

1990. Cretaceous and Tertiary vegetation of Antarctica: a palynological perspective. In: Taylor, T.N.

\& E.L. Taylor (eds.) Antarctic paleobiology: its role in the reconstruction of Gondwana. Springer pp. 71-88.

TRYON, R. M.

1986. The biogeography of species, with special reference to ferns. Botanical Review 52: 117-156.

TRYON,R.M. \& TRYON,A.F.

1982. Ferns and allied plants, with special reference to tropical America. Springer-Verlag.

TRYON, A.F.

1990. Fern spores: evolutionary levels and ecological differentiation. Pl. Syst. Evol. (Suppl. 5): 71-79.

TRYON, A. F. \& B. LUGARDON

1990. Spores of the Pteridophyta. Springer- Berlag, 648 pp.

TURIC, M. A.,

1969. Perfiles estratigráficos al sur del curso medio del río Deseado, entre Punta España y Meseta Baqueró, Provincia de Santa Cruz. Y.P.F., 55pp. (inédito).

ULIANA, M. A., D. A. DELLAPÉ \& G. A. PANDO

1975. Estratigrafía de las sedimentitas rayosianas (Cretácico inferior de las provincias de Neuquén y Mendoza). Actas II Congreso Ibero-Americano de Geología Económica, 1:177-135.

VAKHRAMEEV, V.A.

1981. Pollen Classopollis as an indicator of Jurassic and Cretaceous climates. The Palaeobotanist 28: 301-307.

VAKHRAMEEV, V.A.

1987. Climates and the distribution of some gymnosperms in Asia during the Jurassic and Cretaceous. Review of Paleobotany. and Palynology 51: 205-212.

VAKHRAMEEV, V.A.

1991. Jurasic and Cretaceous floras and climates of the Earth. Transactions of the Academy of Science 
of the USSR 430: 214 pp. Cambridge University Press.

VALLATI, P.

1993. Palynology of The Albornoz Formation (Lower Cretaceous), in the San Jorge Gulf Basin (Patagonia, Argentina). N. Jb. Geol. Palaont. Abh. 187 (3): 345-373.

VALLATI, P.

1995. Una microflora con Afropollis (polen de angiosperma) en el Cretácico Inferior de la Cuenca Neuquina. VI Congreso Argentino de Paleontologia y Bioestratigrafia, Trelew. Actas: 277-290.

VALLATI, P.

1996. Palinología de la "Arenizca" Rincón (Grupo Huitrín/ Rayoso), Cretácico inferior de la Cuenca Neuquina. Actas XIII Congreso Geológico Argentino y IIICongreso de Exploración de Hidrocarburos, V: 7792. Buenos Aires, Argentina.

VALLATI, P.

2001. Bioestratigrafía (palinología) del Cretácico temprano y medio de Patagonia Septentrional y Central. Tesis Doctoral. Facultad de Ciencias Naturales UNPSJB (inédita) 278 pp.

VOLKHEIMER, W.

1972. Estudio palinológico de un Carbón Caloviano de Neuquén y consideraciones sobre los paleoclimas jurásicos de la Argentina. Revista Museo de La Plata, Paleontología No 40, Tomo VI: 101-157.

VOLKHEIMER, W.

1980. Microfloras del jurásico Superior y Cretácico Inferior de América Latina. Actas II Congr. Arg. Paleontol. Bioestrat., I Cong. Latinoamer. Paleontol., 5: 121-136; Buenos Aires.

VOLKHEIMER, W. \& D. MELENDI

1976. Palinomorfos como fósiles guías. Tercera parte: Técnicas de laboratorio palinológico. Revista Min. de Geol. y Mineral. Sociedad Argentina de Mineralogía y Geología, 34 (1/2): 19-30.

VOLKHEIMER, W. \& M.QUATTROCCHIO

1975. Palinología Estratigráfica del Titoniano (Formación Vaca Muerta) en el area de Caichigüe (Cuenca Neuquina) Ameghiniana 12 (3): 193-241.

VOLKHEIMER, W. \& M.QUATTROCCHIO 
1981. Palinología estratigráfica de la Formación Lotena, Jurásico medio de la Cuenca Neuquina. Octavo Congreso Geológico Argentino, Actas IV: 761-775

\section{VOLKHEIMER, W. \& A. SALAS}

1975. Die älteste Angiospermen-Palynoflora Argentiniens von der Typuslokalität der unterkretazischen Huitrín-Folge des Neuquén Beckens. Neues Jabrb. Geol. Paläont. Mh., Jg. H 7: 424-436.

\section{VOLKHEIMER, W. \& A. SALAS}

1976. Estudio palinológico de la Formación Huitrín, Cretácico de la Cuenca Neuquina, en su localidad tipo. IV Congreso Geológico Argentino. Actas I: 433-453.

\section{VOLKHEIMER, W. \& E. SEPULVEDA}

1976. Biostratigraphische Bedeutung und mikrofloristische Assoziation von Cyclusphaera psilata n. sp., einer Leitform aus der Unterkreide Descripción: Neuquen Beckens (Argentinien). Neues Jabrb. Geol. Paläont. Mh. 2: 97-108.

VOLKHEIMER, W., M.QUATTTROCCHIO, A. SALAS \& E. SEPULVEDA

1976. Caracterización palinológica de formaciones del Jurásico Superior y Cretácico Inferior de la Cuenca Neuquina (República Argentina). VI Cong. Geol. Arg. Actas 1: 593-606.

\section{WEYLAND, H. \& W. KRIEGER}

1953. Die Sporen und Pollen Aachener Kreide und ihre Bedeutung für die Charakterisierung des Mittleren Senons. Palaeontographica B 95: 6-29.

\section{WILSON,L.R. \& R.M. WEBSTER}

1946. Plant microfossils from a Fort Union Coal of Montana. American Journal of Botany 33:271278. Ohio.

\section{WINDHAUSEN, A.}

1919. Geología Argentina. Peuser (Ed.), Bs. As: 1 - 40.

WINDHAUSEN, A.

1931. Geología Argentina. Segunda Parte: Geologia Histórica y regional del territorio argentino. Peuser (Ed.), Buenos Aires.

WING S. L. \& W. A. DIMICHELE

1992. Ecological Characterization of Fossil Plants. In: Behrensmeyer, A. K., J. D. Damuth, W. A. 
DiMichele, R. Potts, H. D. Sues \& L. W. Scott (eds.). Terrestrial Ecosystems through Time- Evolutionary Paleoecology of Terrestrial Plants and Animals: 139-180.

WING S. L., L. J. HICKEY \& C. C. SWISHER

1993. Implications of an exceptional fossil flora for Late Cretaceous vegetation. Nature 363: 342344.

WINGATE, F. H.

1980. Plant Microfossils from the Denton Shale Member of the Bokchito Formation (Lower Cretaceous, Albian) in Southern Oklahoma. Oklahoma Geol. Survey Bull. 130: 1-93.

ZABADA, M. S.

1987. The occurrence of Cyclusphaera sp. in Southern Africa. Actas VII Simposio Argentino de Paleobotánica y Palinología: 101-105.

ZAMBRANO, J. \& C. URIEN

1970. Geological ouline of the basin in Southern Argentina and their continuation off the Atlantic shore. Journal of Geophysical Research, 75 (8) : 1363 - 1396.

ZIPPI, P. A.

1998. Freshwater algae from the Mattagami Formation (Albian), Ontario: Paleoecology, botanical affinities and systematic taxonomy. Micropaleotology Vol. 44 Supplement 1: 1-78. 
WINGATE, F. H.

1980. Plant Microfossils from the Denton Shale Member of the Bokchito Formation (Lower Cretaceous, Albian) in Southern Oklahoma. Oklahoma Geol. Survey Bull. 130: 1-93.

ZABADA, M. S.

1987. The occurrence of Cyclusphaera sp. in Southern Africa. Actas VII Simposio Argentino de Paleobotánica y Palinología: 101-105.

ZAMBRANO, J. \& C. URIEN

1970. Geological ouline of the basin in Southern Argentina and their continuation off the Atlantic shore. Journal of Geophysical Research, 75 (8) : 1363 - 1396.

ZIPPI, P. A.

1998. Freshwater algae from the Mattagami Formation (Albian), Ontario: Paleoecology, botanical affinities and systematic taxonomy. Micropaleotology Vol. 44 Supplement 1: 1-78. 